\title{
Yucca Mountain Thermal Response: An Evaluation of the Effects of Modeled Geologic Structure and Thermal Property Descriptions
}

Randy Longenbaugh, Christopher A. Rautman, Eric E. Ryder

Prepared by

Sandia National Laboratories

Albuquerque, New Mexico 87185 and Livermore, California 94550 for the United States Department of Energy

under Contract DE-AC04-94AL85000

(3)

Approved for public release; distribution is unlimited.

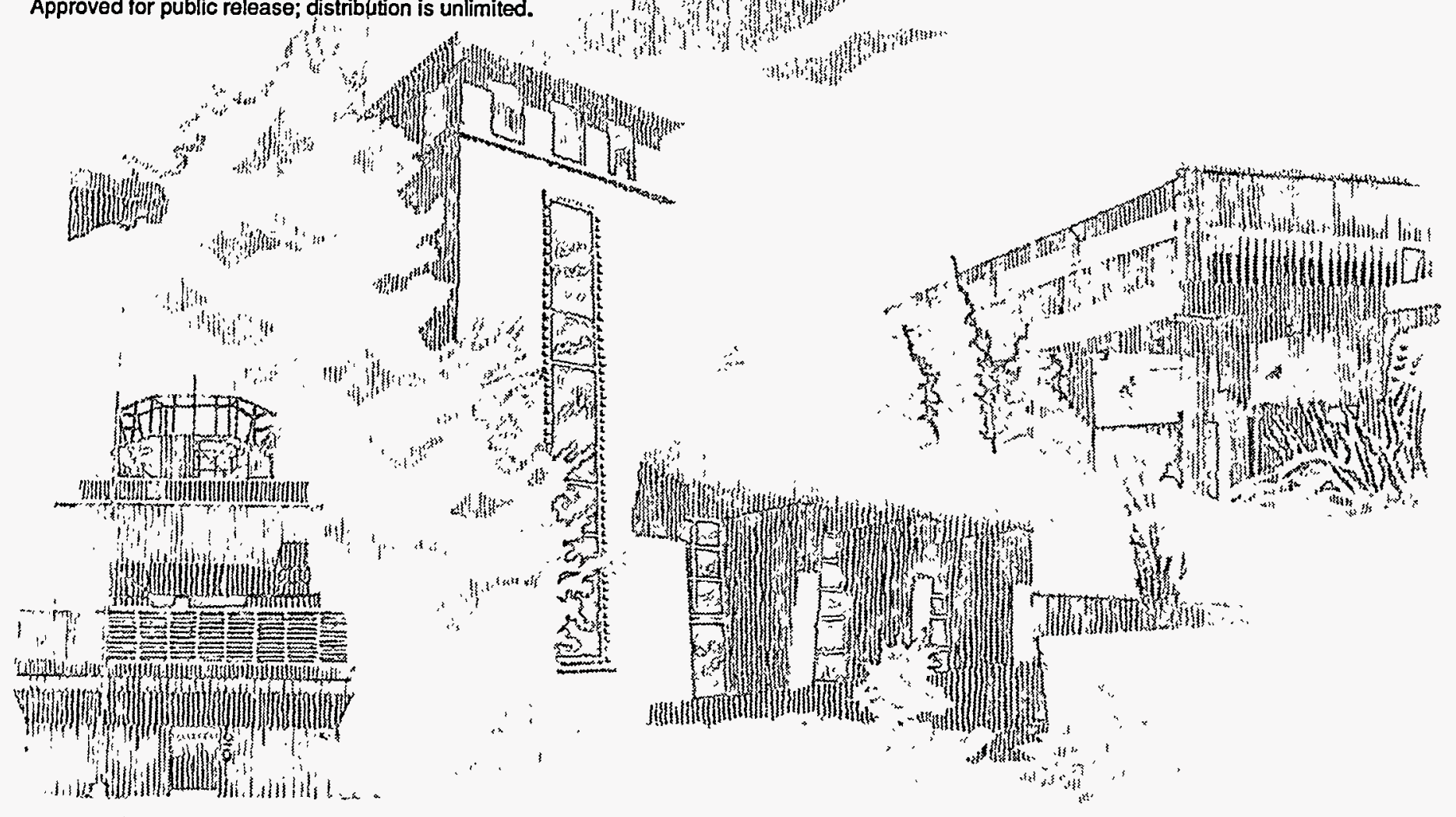


"Prepared by Yucca Mountain Site Characterization Project (YMSCP) participants as part of the Civilian Radioactive Waste Management Program (CRWM). The YMSCP is managed by the Yucca Mountain Project Office of the U.S. Department of Energy, DOE Field Office, Nevada (DOE/NV). YMSCP work is sponsored by the Office of Geologic Repositories (OGR) of the DOE Office of Civilian Radioactive Waste Management (OCRWM)."

Issued by Sandia National Laboratories, operated for the United States Department of Energy by Sandia Corporation.

NOTICE: This report was prepared as an account of work sponsored by an agency of the United States Government. Neither the United States Government nor any agency thereof, nor any of their employees, nor any of their contractors, subcontractors, or their employees, makes any warranty, express or implied, or assumes any legal liability or responsibility for the accuracy, completeness, or usefulness of any information, apparatus, product, or process disclosed, or represents that its use would not infringe privately owned rights. Reference herein to any specific commercial product, process, or service by trade name, trademark, manufacturer, or otherwise, does not necessarily constitute or imply its endorsement, recommendation, or favoring by the United States Government, any agency thereof or any of their contractors or subcontractors. The views and opinions expressed herein do not necessarily state or reflect those of the United States Government, any agency thereof or any of their contractors.

Printed in the United States of America. This report has been reproduced directly from the best available copy.

Available to DOE and DOE contractors from

Office of Scientific and Technical Information

PO Box 62

Oak Ridge, TN 37831

Prices available from (615) 576-8401, FTS 626-8401

Available to the public from

National Technical Information Service

US Department of Commerce

5285 Port Royal Rd

Springfield, VA 22161

NTIS price codes

Printed copy: A07

Microfiche copy: A01 


\section{DISCLAIMER}

Portions of this document may be illegible in electronic image products. Images are produced from the best available original document. 
SAND94-2247

Unlimited Release

Printed September, 1995

\title{
Yucca Mountain Thermal Response: An Evaluation of the Effects of Modeled Geologic Structure and Thermal Property Descriptions
}

\author{
Randy Longenbaugh \\ Christopher A. Rautman \\ Eric E. Ryder
}

Sandia National Laboratories

Albuquerque, New Mexico 87185

\begin{abstract}
To assess the influence of mountain-scale thermal property model variations on predicted hostrock thermal response, a series of heat conduction calculations were run using a representative two-dimensional cross section of Yucca Mountain. The effects of modeled geologic structure were evaluated through comparisons of results from a single-material, homogeneous model with those from a uniformly layered model, a discontinuous sloping-layered model, and a geostatistical realization of thermal properties. Comparisons indicate that assumed geologic structure can result in up to a $24^{\circ} \mathrm{C}$ difference in predicted temperature response. Further, thermal simulations of the method used to analyze geostatistical realizations of thermal properties shows promise as an efficient means of capturing geologic structure without the complexities of intricate finite element meshing.
\end{abstract}

The functional representation of two thermal property models were also investigated. The first examines the effect of using a weighting scheme to define properties for a single, homogenous material model. The second investigates the impact of thermal property temperature dependence on predicted response. As with the investigation of geologic structure, noticeable differences in predicted temperatures (up to $29^{\circ} \mathrm{C}$ ) were found to result. 


\section{Acknowledgments}

The work documented in this report was performed for the U. S. Department of Energy, Yucca Mountain Site Characterization Project Office, for contract DE-AC04-94AL85000; under work description WBS 1.2.5.4.3, QA grading report 1.2.5.4.3, Revision 00. The analyses documented in this report were performed under a fully qualified QA program. Data used are from nonqualified sources.

The authors thank their fellow coworkers who helped in the preparation of this report. Sharon Shannon and Corinne Taylor provided invaluable graphic support and Edward Boucheron and John Pott reviewed the technical content of this document and offered corrections. 


\section{Table of Contents}

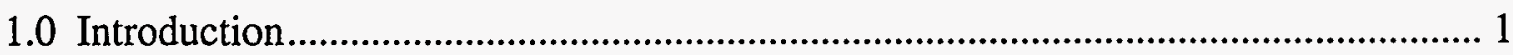

2.0 General Description of Thermal Models ..................................................................... 3

2.1 Stratigraphy Cross Section Description ..................................................................

2.2 Heat Transfer Code Description ………………......................................................

2.3 Description of Finite-Element Meshes ......................................................................

2.4 Description of Calculations and Thermal Property Data ....................................14

2.4.1 Uniform Mesh Using Homogeneous Temperature-

Independent Thermal Properties Obtained From the RIB .......................... 14

2.4.2 Layeyered Model Using Homogeneous Temperature-

Independent Thermal Properties at Each Layer Obtained

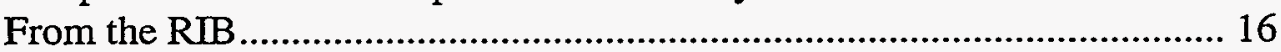

2.4.3 Layered Model Using Temperature-Dependent Thermal

Properties Obtained From The RIB ........................................................ 17

2.4.4 Heterogeneous Spatially Correlated Models ................................................. 18

2.5 Repository Heat Generation and Decay Heat ……................................................21

2.6 Boundary and Initial Conditions ...................................................................21

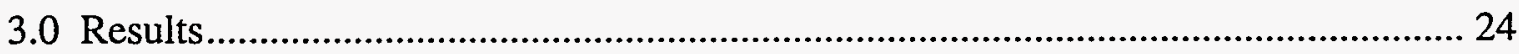

3.1 Presentation of Results ..................................................................................

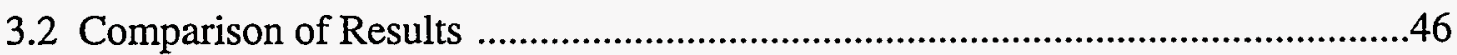

3.2.1 Geologic Structure Comparisons ................................................................. 46

3.2.2 Thermal Property Comparisons .................................................................... 49

3.2.3 Comparison of Heterogeneous, Spatially Correlated Models with Homogeneous, Sloped-Layer Models.................................... 50

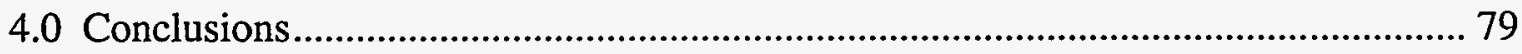

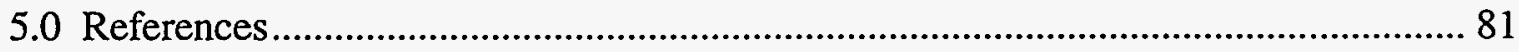

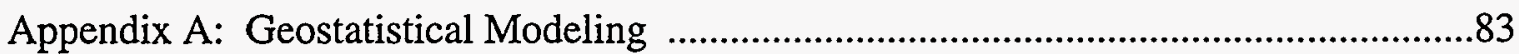

A.1 Mapping Geostatistical Thermal Property Information Onto

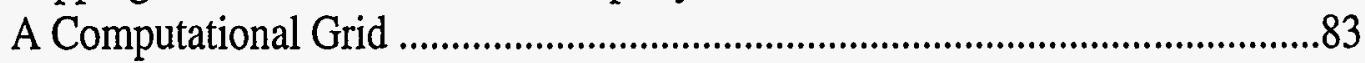

Appendix B: Pre- and Post-Processing Code Listings ….................................................85

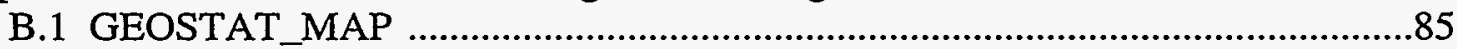

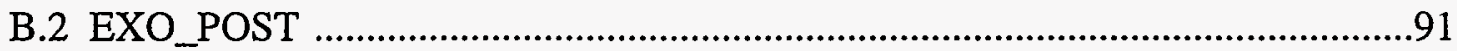

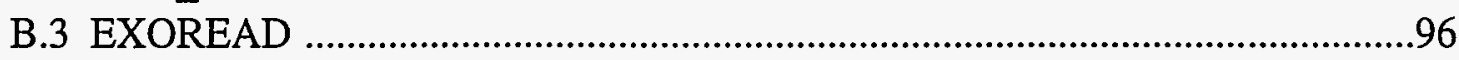

Appendix C: Listing of Code Modifications Made to COYOTE-II ..................................107

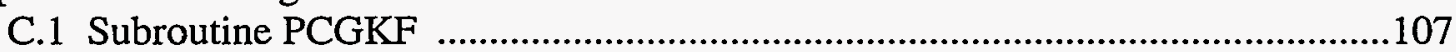

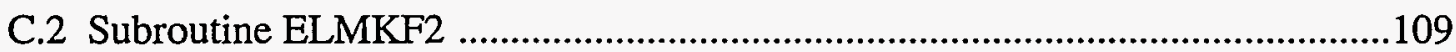




\section{Table of Contents (continued)}

Appendix D: User Subroutines Used in COYOTE ………...........................................111

D.1 Volumetric Heating, USRVHS_100 ...............................................................111

D.2 Thermal Property Subroutines Used for LVRHL and LVRSL

Calculations ..................................................................................................113

D.3 Thermal Property Subroutines Used for LVLHL and

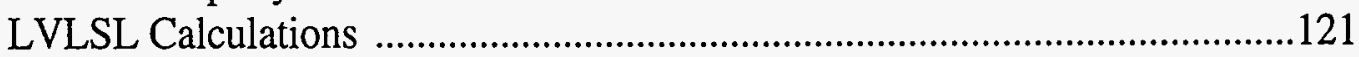

D.4 Thermal Property Subroutines Used for Geostatistical

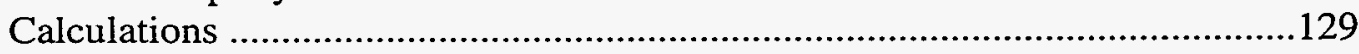

Appendix E: RIB Appendix ..................................................................................131 


\section{List of Figures}

Figure 1. Thermal Stratigraphy in Cross Section C-C at Yucca

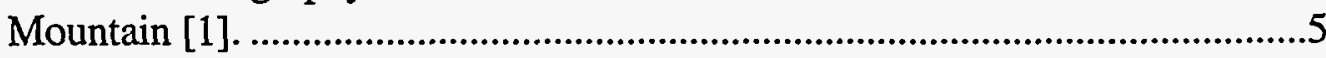

Figure 2. Map of Yucca Mountain Showing the Cross Section C-C Location [2].

Figure 3. Correlation diagram showing correspondence between thermal/mechanical nomenclature (Ortiz et al. [3]) and conventional geologic stratigraphic names.

Figure 4. Sloped-Layer Finite Element Mesh Including Both

Far- and Near-Field Regions. 8

Figure 5. Near-Field Region of the Sloped-Layer Finite Element Mesh...........................9

Figure 6. Thermal Stratigraphy for the Sloped-Layer Finite Element Mesh. ..................10

Figure 7. Horizontal-Layer Finite Element Mesh Including Both Far- and Near-Field Regions.............................................................................11

Figure 8. Near-Field Region of the Horizontal-Layer Finite Element Mesh.

Figure 9. Thermal Stratigraphy for the Horizontal-Layer Finite Element Mesh.

Figure 10. Spatially correlated heterogeneous models of (a) thermal conductivity and (b) bulk density corresponding to calculational models GC1HL. Range of spatial correlation is $5,000 \mathrm{~m}$.

Figure 11. Histograms of material properties corresponding to calculational model GC1HL. (a) thermal conductivity;

(b) bulk density.

Figure 12. Decay Heat Curve Used for All Calculations (from Equation 6) .....................22

Figure 13. Thermal Boundary Conditions Applied to Horizontal-Layer Mesh .................22

Figure 14. Temperature Contour Map of Calculation UCHL at 50 years..........................26

Figure 15. Temperature Contour Map of Calculation UCHL at 100 years.......................27

Figure 16. Temperature Contour Map of Calculation UCHL at 500 years.......................28

Figure 17. Temperature Contour Map of Calculation UCHL at 1000 years.....................29

Figure 18. Temperature Contour Map of Calculation LCRHL at 50 years. .....................30

Figure 19. Temperature Contour Map of Calculation LCRHL at 100 years. ....................31

Figure 20. Temperature Contour Map of Calculation LCRHL at 500 years. ....................32

Figure 21. Temperature Contour Map of Calculation LCRHL at 1000 years. ..................33

Figure 22. Temperature Contour Map of Calculation LCRSL at 50 years........................34

Figure 23. Temperature Contour Map of Calculation LCRSL at 100 years......................35 


\section{List of Figures (continued)}

Figure 24. Temperature Contour Map of Calculation LCRSL at 500 years. ......................36

Figure 25. Temperature Contour Map of Calculation LCRSL at 1000 years. ...................37

Figure 26. Temperature Contour Map of Calculation LVRHL at 50 years......................38

Figure 27. Temperature Contour Map of Calculation LVRHL at 100 years.....................39

Figure 28. Temperature Contour Map of Calculation LVRHL at 500 years....................40

Figure 29. Temperature Contour Map of Calculation LVRHL at 1000 years..................41

Figure 30. Temperature Contour Map of Calculation GC1HL at 50 years.......................42

Figure 31. Temperature Contour Map of Calculation GC1HL at 100 years......................43

Figure 32. Temperature Contour Map of Calculation GC1HL at 500 years.....................44

Figure 33. Temperature Contour Map of Calculation GC1HL at 1000 years...................45

Figure 34. Temperature Difference Contour Map of Calculation UCRHL-LCRHL at 50 years. ........................................................................54

Figure 35. Temperature Difference Contour Map of Calculation UCRHL-LCRHL at 100 years. .....................................................................5

Figure 36. Temperature Difference Contour Map of Calculation

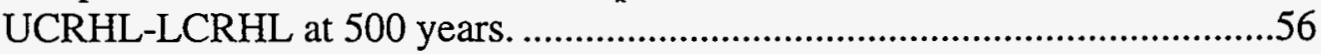

Figure 37. Temperature Difference Contour Map of Calculation

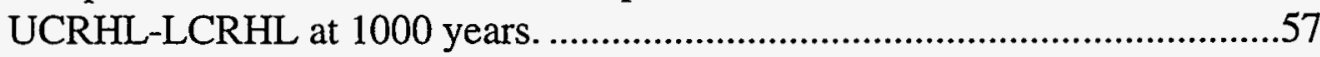

Figure 38. Temperature Difference Contour Map of Calculation

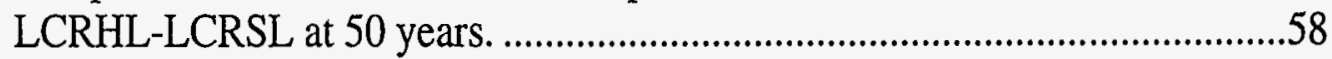

Figure 39. Temperature Difference Contour Map of Calculation

LCRHL-LCRSL at 100 years.

Figure 40. Temperature Difference Contour Map of Calculation

LCRHL-LCRSL at 500 years.

Figure 41. Temperature Difference Contour Map of Calculation

LCRHL-LCRSL at 1000 years.

Figure 42. Temperature Difference Contour Map of Calculation

UCRHL-GC1HL at 50 years.

Figure 43. Temperature Difference Contour Map of Calculation

UCRHL-GC1HL at 100 years.

Figure 44. Temperature Difference Contour Map of Calculation

UCRHL-GC1HL at 500 years.

Figure 45. Temperature Difference Contour Map of Calculation

UCRHL-GC1HL at 1000 years.

Figure 46. Temperature Difference Contour Map of Calculation

UCRHL-UCG4HL at 50 years. 


\section{List of Figures (concluded)}

Figure 47. Temperature Difference Contour Map of Calculation

UCRHL-UCG4HL at 100 years.

Figure 48. Temperature Difference Contour Map of Calculation

UCRHL-UCG4HL at 500 years.

Figure 49. Temperature Difference Contour Map of Calculation

UCRHL-UCG4HL at 1000 years.

Figure 50. Temperature Difference Contour Map of Calculation

LCRHL-LVRHL at 50 years. .70

Figure 51. Temperature Difference Contour Map of Calculation LCRHL-LVRHL at 100 years.

Figure 52. Temperature Difference Contour Map of Calculation

LCRHL-LVRHL at 500 years. .72

Figure 53. Temperature Difference Contour Map of Calculation LCRHL-LVRHL at 1000 years.

Figure 54. Spatially Correlated Heterogenous Model of Thermal Conductivity Corresponding to Calculational Model GC1HL

Mapped Onto the Sloped Layer Finite Element Mesh. .74

Figure 55. Temperature Difference Contour Map of Calculation LCRSL-GC1SL at 50 years. .75

Figure 56. Temperature Difference Contour Map of Calculation LCRSL-GC1SL at 100 years. .76

Figure 57. Temperature Difference Contour Map of Calculation LCRSL-GC1SL at 500 years.

Figure 58. Temperature Difference Contour Map of Calculation LCRSL-GC1SL at 1000 years. 
This page intentionally left blank. 


\section{List of Tables}

Table 1. Description of Calculations Used for the Heterogeneity Study ......................14

Table 2. Thermal Properties Used for Calculation UCRHL. .....................................15

Table 3. Thermal Properties and Contact Depths of Thermal/Mechanical

Units for Drill Hole USW G-4 ....................................................................16

Table 4. Thermal Properties Used for Calculations LCRHL and LCRSL. ...................16

Table 5. Thermal Properties Used for Calculation LVRHL and LVRSL. ...................17

Table 6. Coefficients from Multiple Regression Relationships Relating Thermal Conductivity and Porosity .......................................................20

Table 7. Statistical Summary of Geostatistical Model GC1HL ..................................20

Table 8. Normalized Thermal Decay Coefficients for 42,200 MWd/MTU, PWR-Type Waste.

Table 9. Maximum Temperature and Time at Which it Occurs for All

Calculations.

Table 10. Geologic Structure Comparisons, Maximum and Minimum

Temperature Difference and Times at Which They Occur.

Table 11. Thermal Property Comparisons, Maximum and Minimum

Temperature Difference and Times at Which They Occur. .49 
This page intentionally left blank. 


\subsection{INTRODUCTION}

The Yucca Mountain Site Characterization Project (YMP) is currently assessing the feasibility of locating a high-level nuclear waste repository ${ }^{1}$ at Yucca Mountain, Nevada. The radioactive waste proposed for emplacement at the Yucca Mountain site is composed of spent-fuel assemblies discharged from commercial light-water reactors and high-level waste resulting from plutonium production. As the radioactive isotopes of the waste decay, heat is produced. This thermal load will create a number of stresses on the natural system, ranging from thermally driven expansion of the rock mass to the induction of thermally driven convection cells within the hydrologic system.

No single model currently exists that can capture the complexities of both the physics of thermal process couplings and the key aspects of the engineered and natural systems. As a result, simplifying assumptions are necessary in the development of thermal and thermally coupled process models. One area in which simplifying assumptions are typically made is in the representation of physical properties at Yucca Mountain.

Thermal property representations used in design and performance assessment evaluations of Yucca Mountain typically fall into one of three categories: 1) uniform single material, 2) uniform layered material, and 3) sloping layered material. Missing from this list, is the more realistic approach of combining site-specific data with geostatistical techniques to obtain a spatially correlated distribution of material properties.

Regardless of the representation chosen, predictions of host-rock thermal response are affected by assumptions made regarding the geologic structure of the mountain. It is important therefore to understand the limitations of each category of material property representation and to begin to gain a qualitative understanding of what impacts a spatially heterogenous medium will have on our prediction of thermal and thermally coupled host-rock responses. To assist in this process, a series of heat conduction calculations were run to assess the different thermal property representations currently used by design and performance assessment analysts. Specifically, the purpose of this study was to investigate the effects of different thermal property models on the prediction of temperatures for a representative two dimensional cross section of Yucca Mountain. The thermal models used in this study were created to be as realistic as possible without distorting the original goals of the analysis which were to assess thermal property models. It is hoped that the results presented will provide guidance to design and performance assessment analysts when choosing a thermal modeling approach.

The thermal models developed are transient in nature. All calculations were made assuming a pure conduction environment. In several calculations, however, the thermal effect of boiling pore water was included.

The calculations are grouped into four categories:

1. uniform model using homogeneous, temperature-independent thermal properties,

2. layered model using homogeneous, temperature-independent thermal properties,

1. The term "repository" appears throughout this document and its appendices. The use of the term "repository" to identify the facility or some portion of the facility that may be constructed and operated at Yucca Mountain is not intended to imply that such a facility will be constructed or operated at this site. 
3. layered model using temperature-dependent thermal properties,

4. temperature-independent, heterogeneous, spatially correlated thermal properties.

Each group consists of multiple calculations in which different thermal property models and finite element meshes were used. All calculations were done at a single areal power density of $100 \mathrm{~kW} /$ acre. Results of the calculations are compared based on temperature difference throughout the entire computational domain. 


\subsection{GENERAL DESCRIPTION OF THERMAL MODELS}

\subsection{Stratigraphy Cross Section Description}

The geologic basis for the thermal models constructed and evaluated in this report is an east-west cross section of Yucca Mountain (Figure 1) developed as part of conceptual-design studies [1] and used in previous thermomechanical modeling of the site [2]. The cross section C-C [1] is located in the northern half of the potential repository block (Figure 2), and captures the east-dipping, layered sequence of welded and nonwelded tuffs that is typical of the repository setting. Major faults offset the layered sequence in the western portion of the cross section.

The cross-sectional model is based on the thermal/mechanical stratigraphy developed by Ortiz et al. [3], in which the primary basis for subdivision is the distinction between low-porosity welded tuff and high-porosity nonwelded materials. Additional distinctions are drawn based on the presence of zeolite alteration minerals within the nonwelded units. The intended repository host-unit has been subdivided into three subunits with the repository horizon identified as the middle unit, TSw2. A conceptual diagram showing the vertical sequence of units and the correlation of the thermal/mechanical units with the more conventional geologic stratigraphy is presented in Figure 3. Generally, the major units are roughly equivalent. However, significant differences in the locations of contacts occur at the top and bottom of major ash-flow sequences, where nonwelded materials with similar thermal and mechanical properties from different eruptive episodes are aggregated together and distinguished from potentially contemporaneous, but typically densely welded, tuffs with markedly different physical properties.

\subsection{Heat Transfer Code Description}

All thermal calculations presented in this report were made using the nonlinear heat conduction code COYOTE-II [4]. Developed at Sandia National Laboratories to solve multi-dimensional nonlinear heat conduction problems and other types of diffusion problems, COYOTE-II has the capability of solving both steady-state and transient conduction problems with a variety of boundary conditions. COYOTE-II, which is part of the ACCESS system [5], uses the EXODUS [6] data base for pre- and post-processing.

\subsection{Description of Finite-Element Meshes}

Two, two-dimensional planar meshes were used to perform all thermal calculations, a horizontallayer mesh and a sloped-layer mesh. Each mesh was constructed from the C-C cross section [1] shown in Figure 1 and contains both near-field and far-field information. The boundaries of the meshes were extended horizontally and vertically beyond the regions shown in Figure 1 to minimize the impact of applied boundary conditions over the modeled time frame.

The location of the repository heat source was based on a multi-level repository concept documented in Reference. 7. The repository layout consists of two emplacement regions, an upper and lower block. The upper block is situated to the west of the main drift access and contains approxi- 
mately 900 acres of waste emplacement area. The upper block slopes in two sections (one at $0.5 \%$ and the other at $2.0 \%$ ) from an elevation of $1064.6 \mathrm{~m}$ at the northern end to $1111.0 \mathrm{~m}$ at the southern end of the block. The emplacement region defined to the east of the main drift, the lower block, provides approximately 220 acres of waste emplacement area. The vertical location of the lower block is approximately $70 \mathrm{~m}$ below the upper block.

For the assumed waste characteristics and a $100 \mathrm{~kW} /$ acre loading, only the upper block is needed for waste emplacement. The upper block was modeled at an elevation of $1066.8 \mathrm{~m}$, consistent with the fact that the $\mathrm{C}-\mathrm{C}$ cross section cuts through the northern end of the repository. The repository heat source was modeled as $1124 \mathrm{~m}$ long and $1.83 \mathrm{~m}$ thick. These dimensions are consistent with the typical length of an emplacement drift in the upper block and the diameter of a large multi-purpose cask placed in an in-drift configuration [8].

The sloped-layer mesh was created from digitized points from the $\mathrm{C}-\mathrm{C}$ cross section [1]. Figure 4 shows the sloped-layer mesh including both near- and far-field regions. The mesh contains 5118 nodes and 4999 four node quadrilateral finite-elements. Figure 5 shows an enlarged view of the near-field portion of the sloped-layer mesh. In this region, element density is highest to accommodate large temperature gradients generated by the repository. The sloped-layer mesh contains several faults zones identified in Figure 1. These fault zones are modeled based on location only. The different material property regions contained within the sloped-layer mesh are shown in Figure 6. Several thermal/mechanical units identified in the C-C cross section were combined to form a single unit. Thermal/mechanical units TSw 2 and TSw 3 were combined and $\mathrm{CHn} 1 \mathrm{z}, \mathrm{CHn} 2 \mathrm{z}$, and $\mathrm{CHn} 3 \mathrm{z}$ were combined. The units were combined because either the thermal properties of the units were very similar or the units were relatively thin.

The horizontal-layer mesh shown in Figure 7 was created by using the outer boundary coordinates of the sloped-layer mesh. Vertical thicknesses of each thermal/mechanical unit of the horizontallayer mesh were determined from a vertical line projected through the center of the repository region of the sloped-layer mesh. The mesh contains 8289 nodes and 8161 four node quadrilateral finite-elements. Figure 8 shows an enlarged view of the near-field portion of the mesh. Figure 9 shows the different material property regions contained within the mesh. The thermal/mechanical units modeled are defined identically to those for the sloped-layer mesh. 


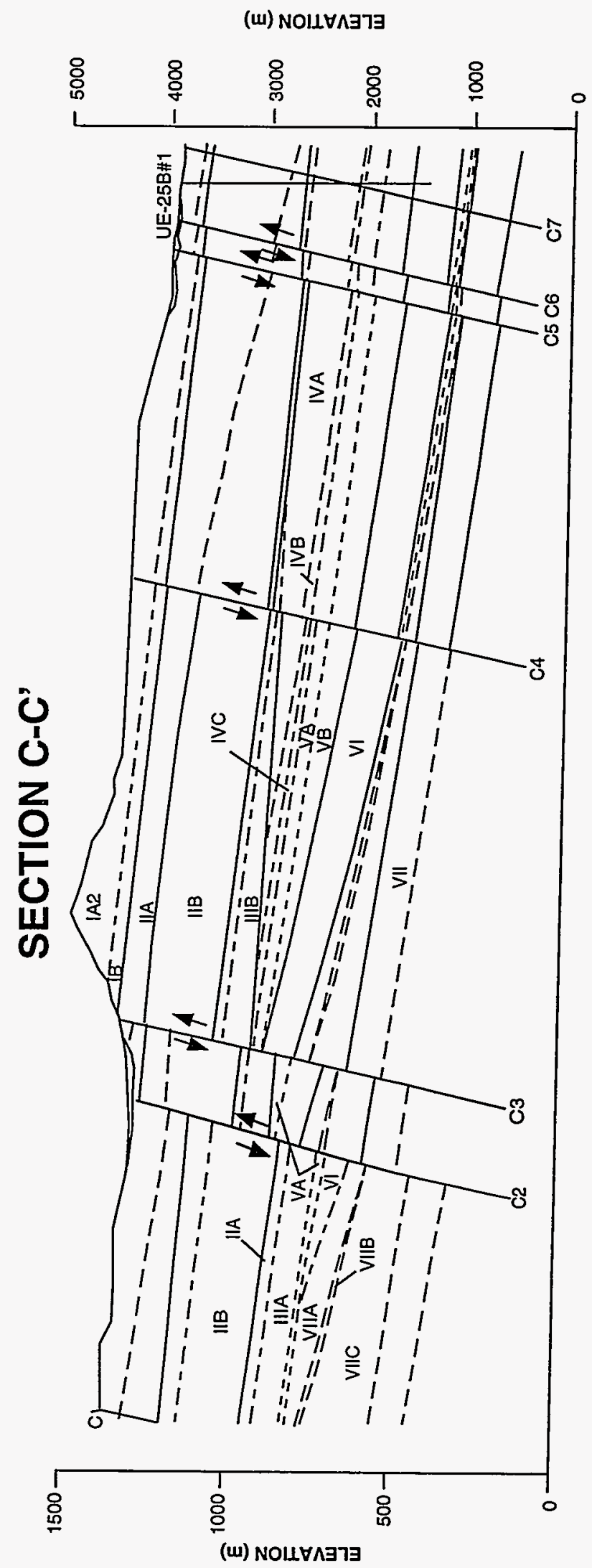

三 


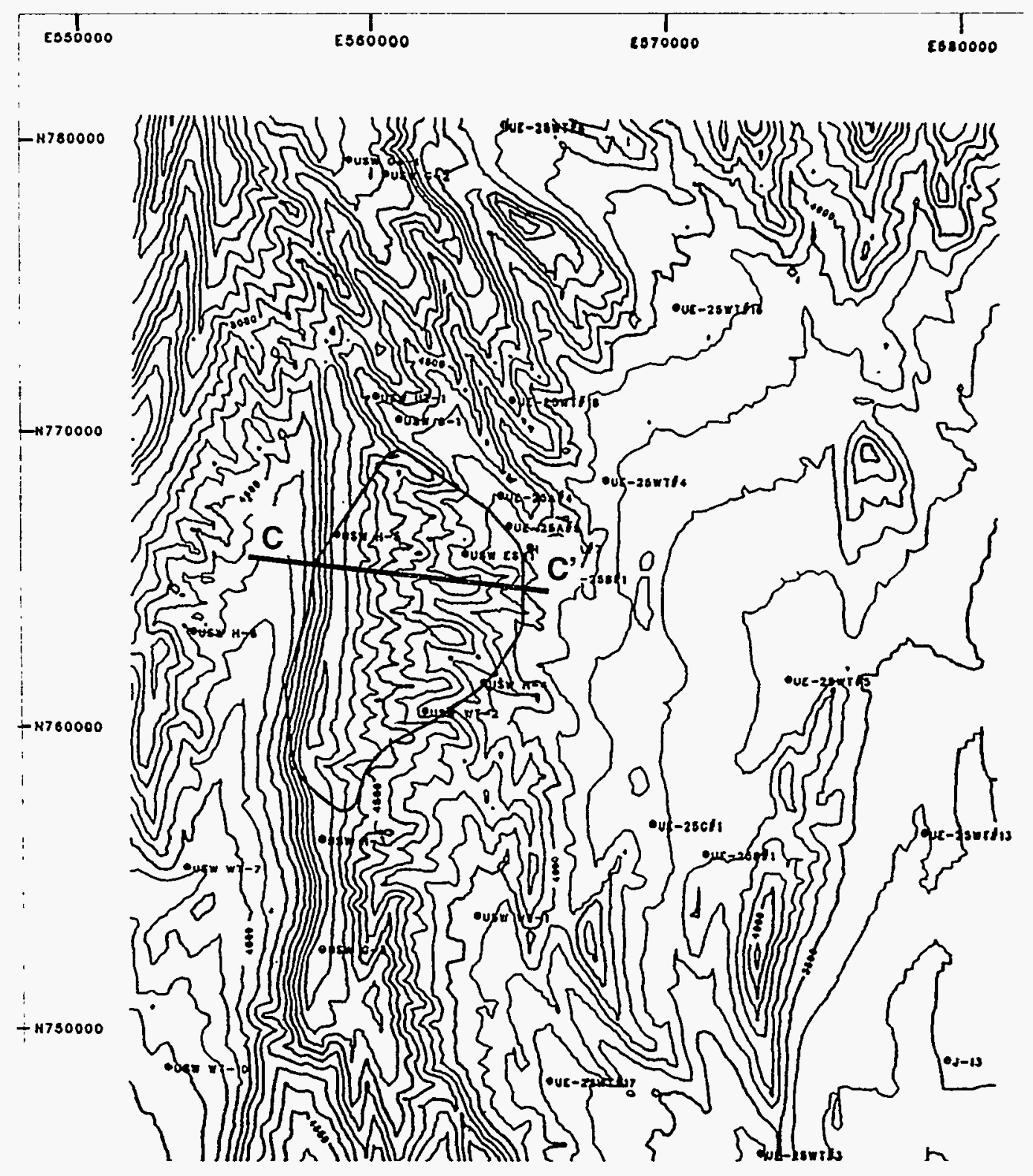

UNITS ARE IN FEET

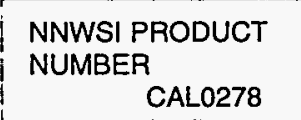

Figure 2. Map of Yucca Mountain Showing the Cross Section C-C Location [2]. 


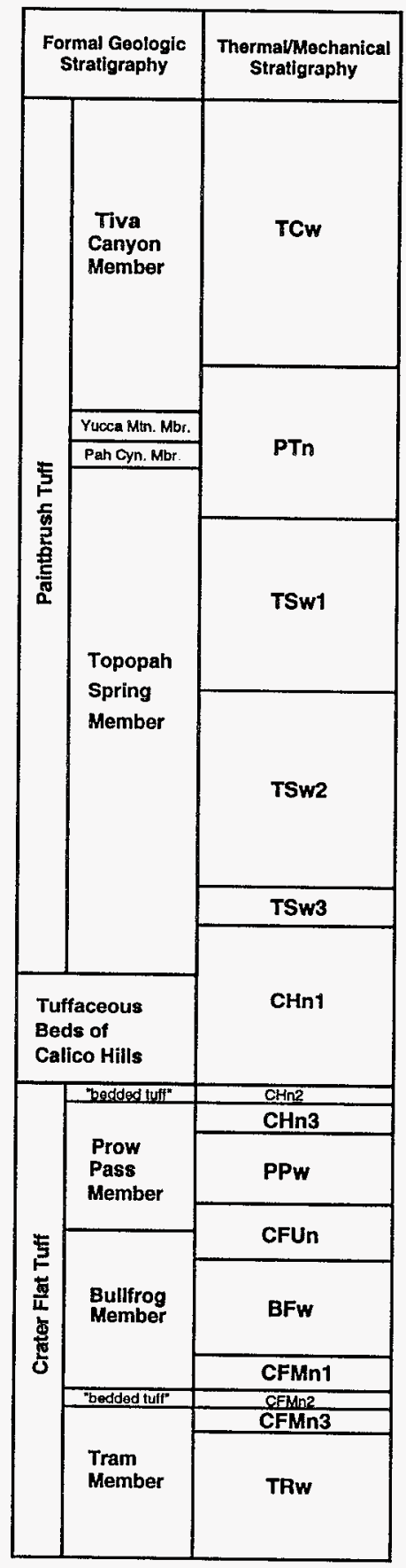

Figure 3. Correlation diagram showing correspondence between thermal/mechanical nomenclature (Ortiz et al. [3]) and conventional geologic stratigraphic names.

Mismatches of contacts arises from emphasis on similar physical properties for thermal/ mechanical subdivision. Potential repository host horizon is Topopah Spring welded unit 2 (TSw2). Not to scale. 


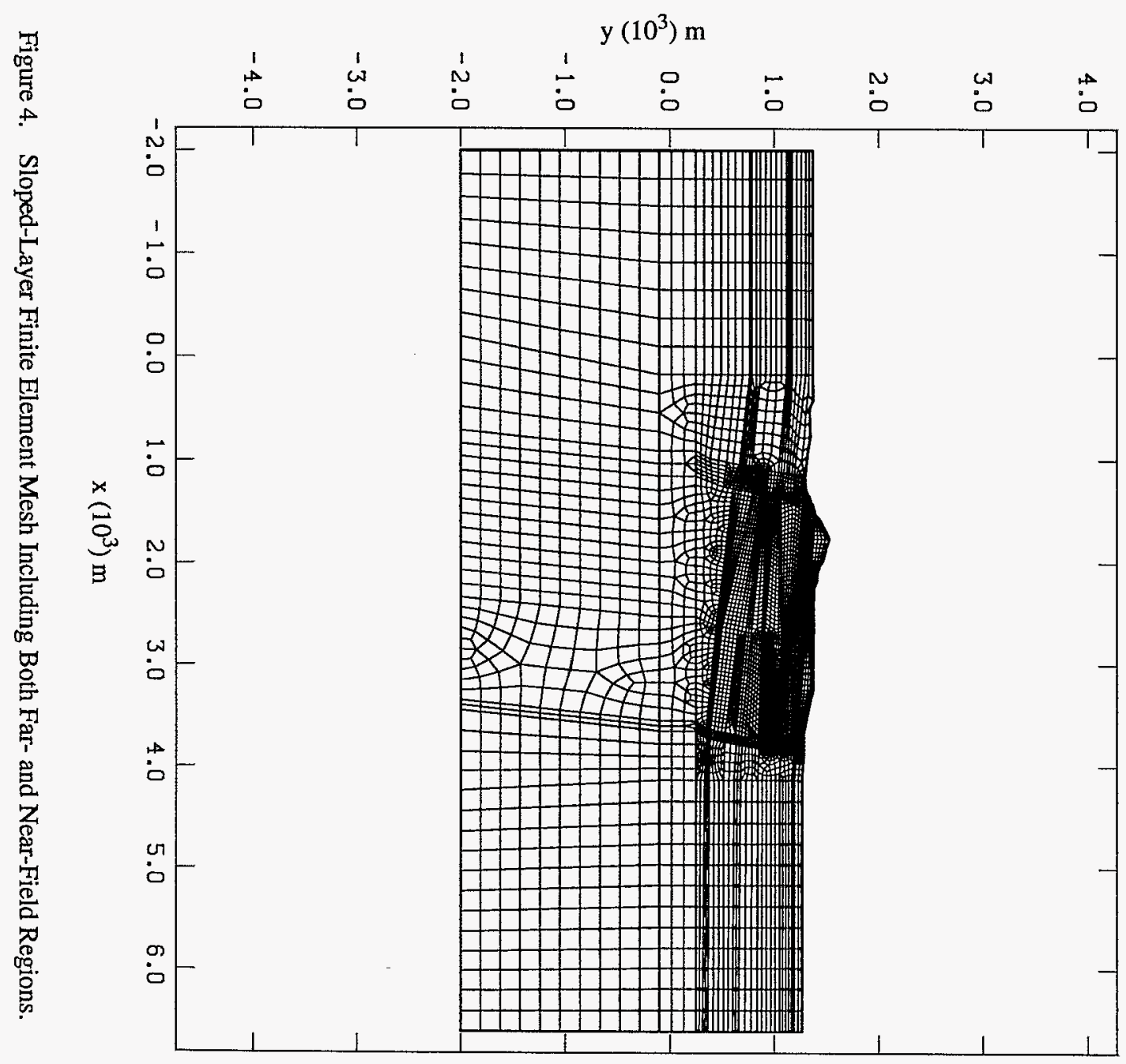




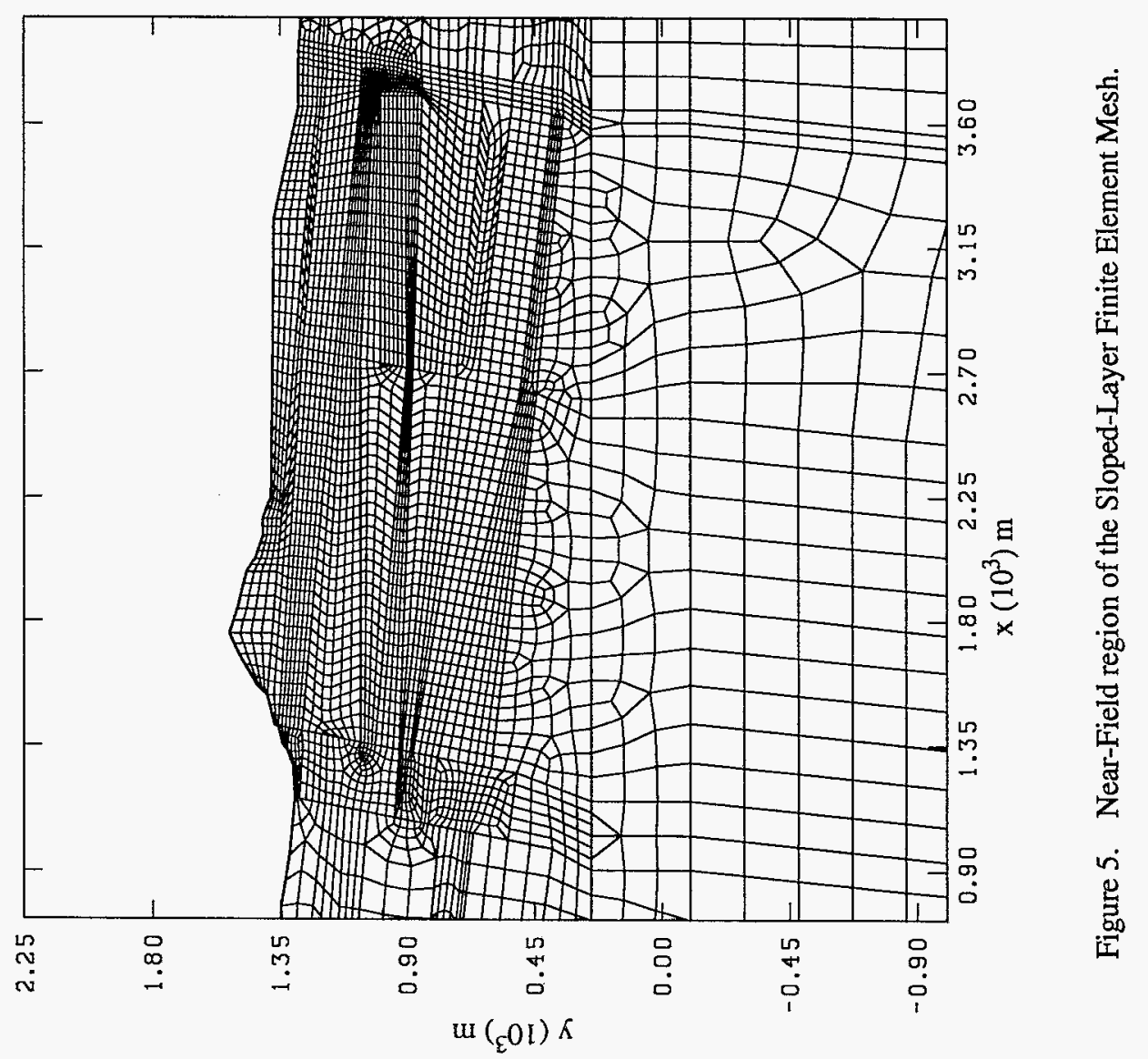




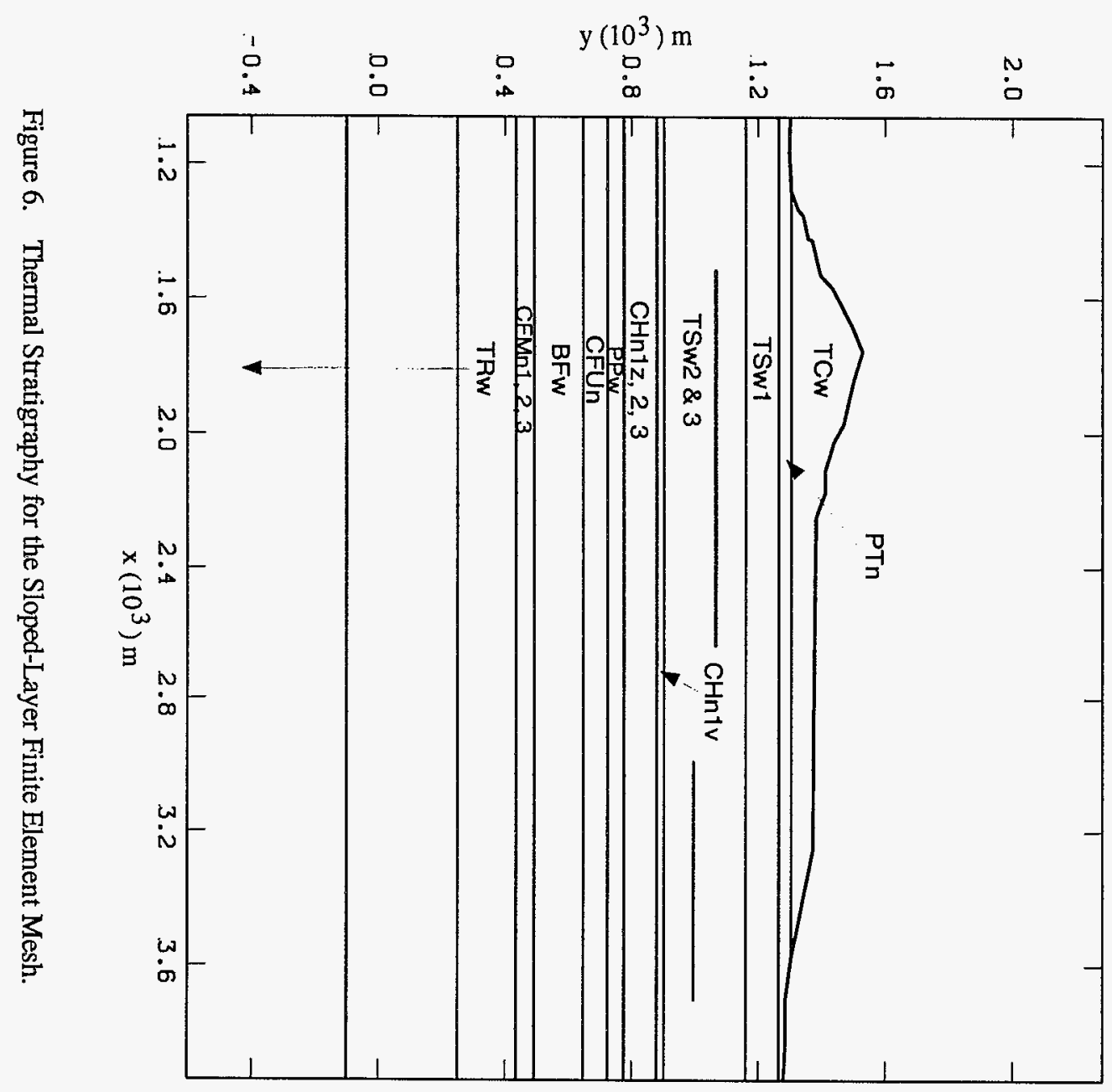




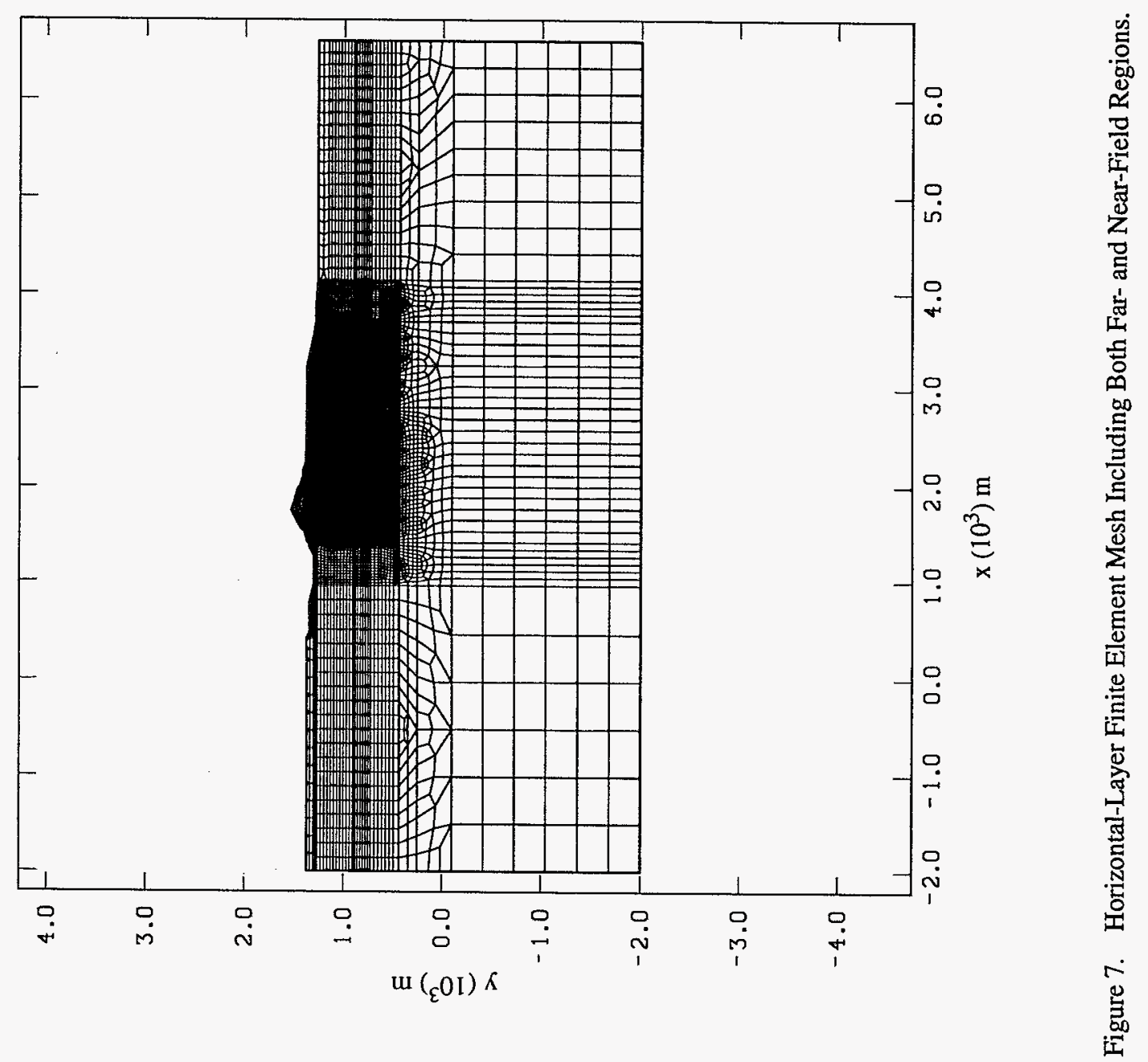




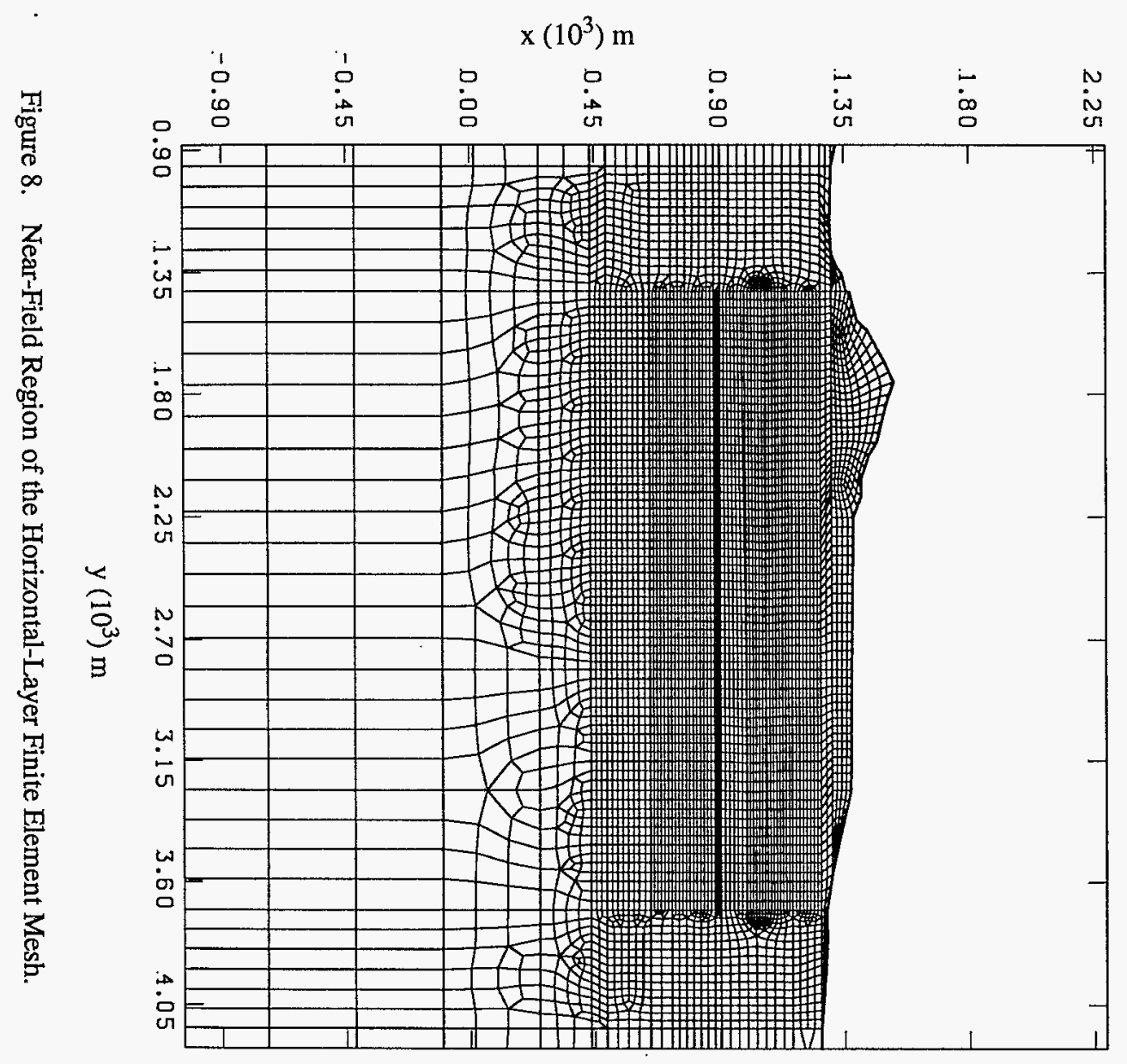




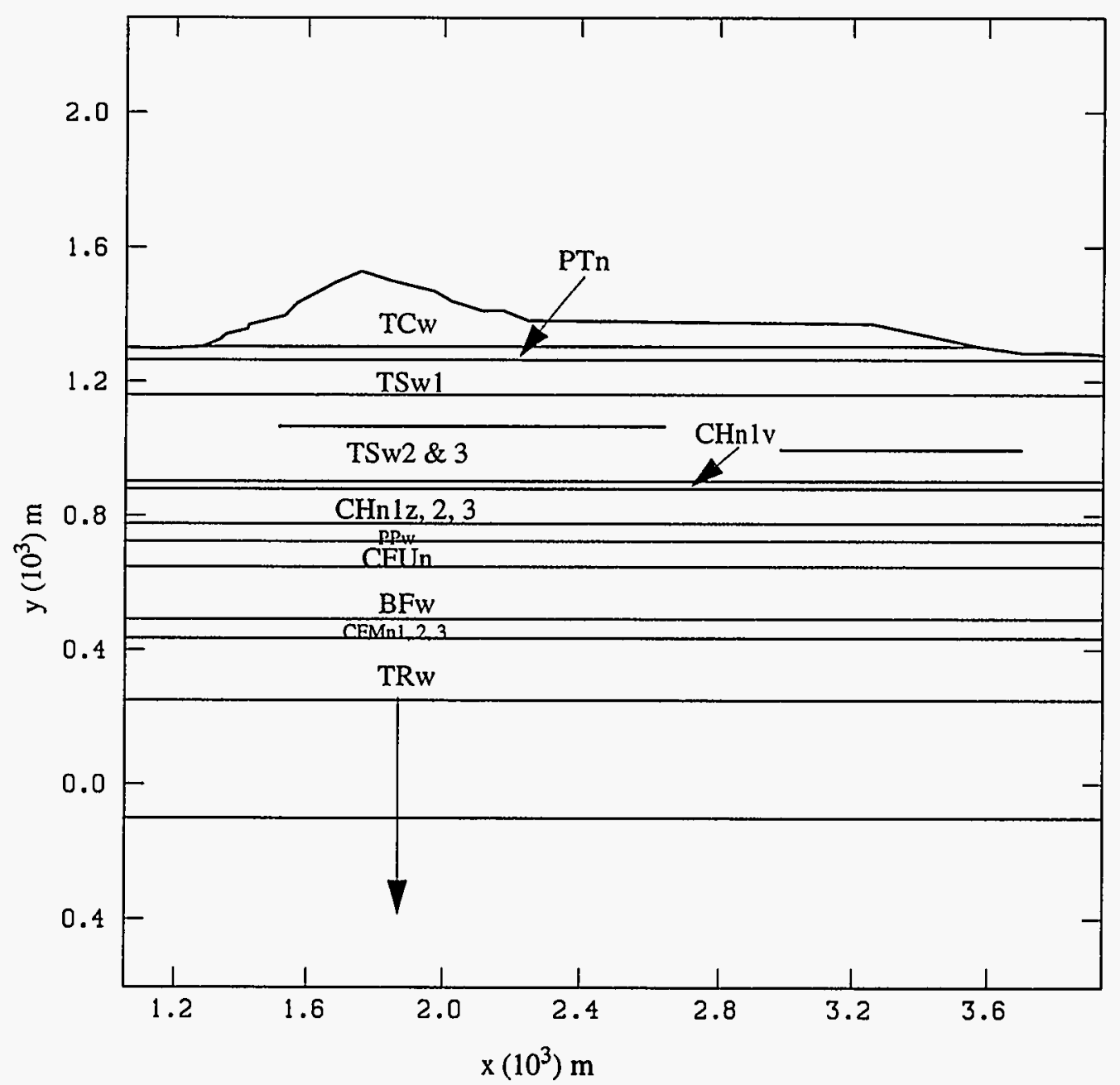

Figure 9. Thermal Stratigraphy for the Horizontal-Layer Finite Element Mesh. 


\subsection{Description of Calculations and Thermal Property Data}

The following is a brief description of the series of calculations that were made for this study. Table 1 summarizes the calculations that were performed. This section also presents the thermal property data used for each calculation. Much of the thermal property data used originated from the Yucca Mountain Reference Information Base (RIB).

The calculations are grouped into four different categories:

1. uniform model using homogeneous, temperature-independent thermal properties obtained from the RIB,

2. layered model using homogeneous, temperature-independent thermal properties at each layer obtained from the RIB,

3. layered model using temperature-dependent thermal properties obtained from the RIB, ${ }^{2}$

4. temperature-independent, heterogeneous, spatially correlated thermal properties

Table 1. Description of Calculations Used for the Heterogeneity Study.

\begin{tabular}{|c|c|l|}
\hline $\begin{array}{c}\text { Calculation } \\
\text { Number }\end{array}$ & $\begin{array}{c}\text { Calculation } \\
\text { Name }\end{array}$ & \multicolumn{1}{|c|}{ Calculation Description } \\
\hline \hline 1 & UCRHL & $\begin{array}{l}\text { Uniform Homogeneous Temperature-Independent Thermal Properties Using RIB TSw2 } \\
\text { and Horizontal-Layer Mesh. }\end{array}$ \\
\hline 2 & UCG4HL & $\begin{array}{l}\text { Uniform Homogeneous Temperature-Independent Thermal Properties Derived From } \\
\text { Thermal Resistance and Capacitance Weighting Using Drill Hole USW G-4 Stratigraphy } \\
{[5] \text { and Horizontal-Layer Mesh. }}\end{array}$ \\
\hline 3 & LCRHL & $\begin{array}{l}\text { Layered Homogeneous Temperature-Independent Thermal Properties at Each Layer } \\
\text { Using RIB Data and Horizontal-Layer Mesh. }\end{array}$ \\
\hline 4 & LCRSL & $\begin{array}{l}\text { Layered Homogeneous Temperature-independent Thermal Properties at Each Layer } \\
\text { Using RIB Data and Sloped-Layer Mesh. }\end{array}$ \\
\hline 5 & LVRHL & $\begin{array}{l}\text { Layered Temperature-Dependent Thermal Properties, Using RIB Data and the Horizon- } \\
\text { tal-Layer Mesh. }\end{array}$ \\
\hline 6 & GC1HL & $\begin{array}{l}\text { Temperature-Independent, Heterogeneous, Spatially Correlated Thermal Properties, } \\
\text { Using Horizontal-Layer Mesh. }\end{array}$ \\
\hline
\end{tabular}

\subsubsection{Uniform Mesh Using Homogeneous Temperature-Independent Thermal Properties Obtained From The RIB}

By assuming that the mountain can be represented by a single homogeneous material with constant properties, analytical solutions to the heat conduction equation are possible. This type of solution is particularly useful in performance assessment and design related calculations since it allows for the accurate representation of the repository layout through the discrete modeling of each waste package [9].

For this study, the uniform homogeneous temperature-independent thermal properties category includes the calculations described as UCRHL and UCG4HL. The thermal properties of both cal-

2. The temperature dependencies referred to in this report are derived temperature-based descriptions that allow the conduction code COYOTE-II to account for the effect of the latent heat of vaporization of water on heat capacitance $\left(\rho c_{p}\right)$ and the effect of saturation on thermal conductivity $(\mathrm{k})$. 
culations were homogenous throughout the entire mesh and were not a function of temperature. The existence of the water table was not taken into account and simulation of boiling water in the pores of the rock was not included. Both calculations use the horizontal-layer finite-element mesh with no distinction between material layers.

UCRHL used thermal properties obtained from the RIB for thermal/mechanical unit TSw2. Table 2 lists the thermal properties used for calculation UCRHL.

\section{Table 2. Thermal Properties Used for Calculation UCRHL}

\begin{tabular}{|c|c|c|}
\hline Unit & $\begin{array}{c}\text { Thermal } \\
\text { Conductivity } \\
(\mathrm{W} / \mathrm{mK})\end{array}$ & $\begin{array}{c}\text { Heat Capacity } \\
\left(\mathrm{J} / \mathrm{m}^{3} \mathrm{~K}\right)\end{array}$ \\
\hline \hline All Units & 2.1 & $2.1414 \times 10^{6}$ \\
\hline
\end{tabular}

The thermal property data used for calculation UCG4HL were determined using thermal resistance and capacitance weighting functions along with thermal property data from the RIB to determine a consistent set of properties similar to calculation UCRHL. The weighting functions also utilized stratigraphic thicknesses obtained from drill hole USW G-4.

The effective thermal conductivity was calculated using the following relationship:

$$
k_{\text {eff }}=\frac{L_{t o t}}{\sum_{i=1}^{n} \frac{L_{i}}{\bar{k}_{i}}}
$$

where

$k_{\text {eff }}$ - is the effective thermal conductivity of all units,

$L_{\text {tot }}$ - is the total length of all units,

$L_{i}$ - is the length of thermal/mechanical unit $i$,

$k_{i}$ - is the thermal conductivity of thermal/mechanical unit $i$.

The effective thermal capacitance was calculated using the following relationship:

$$
\left(\rho c_{p}\right)_{\text {eff }}=\frac{\sum_{i=1}^{n}\left(\rho c_{p}\right)_{i} \cdot L_{i}}{L_{\text {tot }}}
$$

where

$\left(\rho c_{p}\right)_{e f f}$ - effective heat capacity of all units,

$\left(\rho c_{p}\right)_{i}^{\text {eff }}$ - heat capacity of thermal/mechanical unit $i$,

$L_{\text {tot }} \quad$ - is the total length of all units,

$L_{i} \quad$ is the length of thermal/mechanical unit $i$.

Table 3 lists elevations and thermal data for each thermal/mechanical unit for which thermal data was available, and also lists the effective thermal properties used for calculation UCG4HL. The values for heat capacity shown in Table 3 represent average values from the RIB for temperatures 
less than $94^{\circ} \mathrm{C}$. For the regions below $\mathrm{CHn} 2$, property values were not available in the RIB, therefore $\mathrm{CHn} 2$ properties were assumed to exist at and below this unit.

Table 3. Thermal Properties and Contact Depths of Thermal/Mechanical Units for Drill Hole USW G-4.

\begin{tabular}{|c|c|c|c|c|c|c|}
\hline Unit & $\begin{array}{c}\text { Upper } \\
\text { Contact } \\
\text { (m) }\end{array}$ & $\begin{array}{l}\text { Lower } \\
\text { Contact } \\
\text { (m) }\end{array}$ & $\begin{array}{c}\text { Thermal } \\
\text { Conductivity } \\
(\mathrm{W} / \mathrm{mK})\end{array}$ & $\begin{array}{c}\text { Heat Capacity } \\
\left(\mathrm{J} / \mathrm{m}^{3} \mathrm{~K}\right)\end{array}$ & $\begin{array}{c}\text { Thermal } \\
\text { Resistance } \\
(\mathrm{K} / \mathrm{W})\end{array}$ & $\begin{array}{c}\text { Thermal } \\
\text { Capacitance } \\
(\mathrm{J} / \mathrm{K})\end{array}$ \\
\hline$\overline{\mathrm{TCw}}$ & $\overline{0.0}$ & 36.0 & $\overline{1.65}$ & $2.031 \times 10^{6}$ & 21.82 & $73.127 \times 10^{6}$ \\
\hline PTn & 36.0 & 74.1 & 0.85 & $2.29 \times 10^{6}$ & 44.82 & $84.910 \times 10^{6}$ \\
\hline TSw1 & 74.1 & 204.2 & 1.60 & $2.078 \times 10^{6}$ & 81.31 & $270.283 \times 10^{6}$ \\
\hline TSw2 & 204.2 & 393.5 & 2.10 & $2.141 \times 10^{6}$ & 90.14 & $405.367 \times 10^{6}$ \\
\hline TSw3 & 393.5 & 409.3 & 1.28 & $2.053 \times 10^{6}$ & 12.34 & $32.437 \times 10^{6}$ \\
\hline CHniv & 409.3 & 414.5 & 1.20 & $2.565 \times 10^{6}$ & 4.33 & $13.339 \times 10^{6}$ \\
\hline $\mathrm{CHnlz}$ & 414.5 & 518.5 & 1.28 & $2.671 \times 10^{6}$ & 81.25 & $277.774 \times 10^{6}$ \\
\hline $\mathrm{CHn} 2$ & 518.5 & 535.2 & 1.30 & $2.551 \times 106$ & 12.85 & $42.605 \times 10^{6}$ \\
\hline \multicolumn{5}{|c|}{ SUM } & 348.86 & $1199.841 \times 10^{6}$ \\
\hline \multicolumn{3}{|c|}{ Effective Values Used for All Units } & 1.534 & $2.242 \times 10^{6}$ & & \\
\hline
\end{tabular}

\subsubsection{Layered Model Using Homogeneous Temperature-Independent Thermal Properties at Each Layer Obtained From the RIB}

Although details of the engineered aspects of the repository can be captured using models that rely on homogeneous temperature-independent descriptions of Yucca Mountain, the resulting temperature predictions are affected by the lack of resolution in geologic structure. In order to evaluate the importance of this structure, two models were investigated; the first relying on a uniform horizontal layering of materials (LCRHL) and the second on a discontinuous sloped layering (LCRSL). In these calculations, thermal properties were assumed to vary as a function of thermal/ mechanical unit, but were independent of temperature. Table 4 lists the thermal properties used for each thermal/mechanical unit which were obtained from the RIB.

Table 4. Thermal Properties Used for Calculations LCRHL and LCRSL.

\begin{tabular}{|l|c|c|}
\hline \multicolumn{1}{|c|}{ Unit } & $\begin{array}{c}\text { Thermal } \\
\text { Conductivity } \\
(\mathrm{W} / \mathrm{mK})\end{array}$ & $\begin{array}{c}\text { Heat Capacity } \\
\left(\mathrm{J} / \mathrm{m}^{3} \mathrm{~K}\right)\end{array}$ \\
\hline \hline TCw & 1.65 & $2.031 \times 10^{6}$ \\
\hline PTn & 0.85 & $2.229 \times 10^{6}$ \\
\hline TSw1 & & $2.078 \times 10^{6}$ \\
\hline TSw2 \& 3 & 2.00 & $2.135 \times 10^{6}$ \\
\hline CHn1v & 1.20 & $2.565 \times 10^{6}$ \\
\hline CHn1z \& 2 & 1.28 & $2.654 \times 10^{6}$ \\
\hline
\end{tabular}

Within each unit, the thermal properties of the rock were assumed to be homogeneous with no lateral or vertical variation. The values shown in Table 4 are average values for temperatures less than $94^{\circ} \mathrm{C}$. For the regions below $\mathrm{CHn} 2$, property values were not available in the RIB, therefore $\mathrm{CHn} 2$ properties were assumed to exist at and below this unit. The existence of the water table 
was not taken into account and simulation of boiling water in the pores of the rock was not included. LCRHL uses the horizontal-layer finite-element mesh and LCRSL uses the sloped-layer finite-element mesh.

\subsubsection{Layered Model Using Temperature-Dependent Thermal Properties Obtained From The RIB}

The LCRHL and LCRSL formulations discussed in the previous section provide a basis for evaluating the importance of physical structure on predicted thermal profiles. Another aspect that was chosen for examination is the effect related to the energy required to boil pore water within a given thermal/mechanical unit. The layered, temperature-dependent thermal properties category, which includes the LVRHL and LVRSL calculations, was developed to address this issue. In these calculations, thermal properties were assumed to vary as a function of thermal/mechanical unit as well as temperature. Table 5 lists the thermal properties for each thermal/mechanical unit. Within each unit, the thermal properties of the rock were assumed to be homogeneous with no lateral or vertical variation. LVRHL uses the horizontal-layer finite-element mesh and LVRSL uses the sloped-layer finite-element mesh.

To simulate the boiling of water in the pores of the rock, properties for three different temperature ranges were defined (i.e., an apparent specific heat method for modeling the latent heat of vaporization). For thermal conductivity, the estimated values shown in Table 5 represent in situ values for temperatures at or below $94^{\circ} \mathrm{C}$. It is assumed that these values do not change until a nominal onset of boiling temperature of $94^{\circ} \mathrm{C}$ is reached. Above this temperature all the pore water is assumed to vaporize. The volumetric heat capacity is broken into three temperature ranges, below boiling, boiling, and above boiling. All values for volumetric heat capacity shown in Table 5 represent average values obtained from the RIB over each temperature range. For the regions below $\mathrm{CHn} 2$, property values were not available in the $\mathrm{RIB}$, therefore $\mathrm{CHn} 2$ properties were assumed to exist at and below this unit. The existence of the water table was not taken into account. The COYOTE-II user subroutines representing Table 5 thermal properties are presented in Appendix D.

Table 5. Thermal Properties Used for Calculation LVRHL and LVRSL.

\begin{tabular}{|l|c|c|c|c|c|}
\hline \multicolumn{1}{|c|}{ Unit } & \multicolumn{2}{|c|}{$\begin{array}{c}\text { Thermal Conductivity } \\
(\mathrm{W} / \mathrm{mK})\end{array}$} & \multicolumn{3}{c|}{$\begin{array}{c}\text { Heat Capacity } \\
\left(\mathrm{J} / \mathrm{m}^{3} \mathrm{~K}\right)\end{array}$} \\
\hline \hline Temp Range & $T \leq 94^{\circ} \mathrm{C}$ & $T>94^{\circ} \mathrm{C}$ & $T \leq 94^{\circ} \mathrm{C}$ & $94^{\circ} \mathrm{C}<T \leq 114^{\circ} \mathrm{C}$ & $114^{\circ} \mathrm{C}<T$ \\
\hline \hline TCw & 1.65 & 1.58 & $2.031 \times 10^{6}$ & $9.375 \times 10^{6}$ & $2.098 \times 10^{6}$ \\
\hline PTn & 0.85 & 0.61 & $2.229 \times 10^{6}$ & $29.311 \times 10^{6}$ & $1.524 \times 10^{6}$ \\
\hline TSw1 & 1.60 & 1.5 & $2.078 \times 10^{6}$ & $12.266 \times 10^{6}$ & $2.022 \times 10^{6}$ \\
\hline TSw2 \& 3 & 2.00 & 2.00 & $2.135 \times 10^{6}$ & $10.0180 \times 10^{6}$ & $2.212 \times 10^{6}$ \\
\hline CHn1v & 1.20 & 0.84 & $2.565 \times 10^{6}$ & $35.368 \times 10^{6}$ & $1.670 \times 10^{6}$ \\
\hline CHn1z \& 2 & 1.28 & 0.56 & $2.654 \times 10^{6}$ & $33.580 \times 10^{6}$ & $2.239 \times 10^{6}$ \\
\hline
\end{tabular}




\subsubsection{Heterogeneous Spatially Correlated Models}

As a natural geologic setting, Yucca Mountain is not ideally represented by a single material model, a horizontally layered model, or a sloping layered model. Thermal/mechanical unit designations are artificial dividers. Within any thermal/mechanical unit, variations in material properties are likely to exist. These variations could significantly impact predictions of the host rock's response to waste emplacement. In order to begin addressing the issue of heterogeneity in thermal properties, spatially correlated geostatistical simulations of thermal properties were developed and implemented within the COYOTE-II code [4] through the use of user subroutines. Details of the method used to map the spatially correlated geostatistical simulations onto the finite element meshes are given in Appendix A.

Spatially correlated fields were produced for both thermal conductivity and bulk density. Bulk density $\left(\rho_{b}\right)$ was converted to heat capacity $\left(\rho c_{p}\right)$ for input to COYOTE-II [4] using a constant value of $1184.2 \mathrm{~J} / \mathrm{kg}-\mathrm{K}$ for specific heat $\left(c_{p}\right)$ according to the relationship:

$$
\rho c_{p}=\rho_{b} c_{p} .
$$

A single model was produced to investigate the effects of varying degrees of spatial heterogeneity. The calculational model, GC1HL, was intended to capture the spatial variability implied by a well-layered conceptual model of Yucca Mountain comprised of alternating welded and nonwelded rock types. To construct this model, porosity data for a composite "drill hole" based on a vertical combination of drill holes USW G-4 and USW G-3/GU-3 were replicated at three locations across the calculational cross section of Yucca Mountain. Very sparse data from another drill hole, USW H-1, was replicated at three intervening locations in an attempt to avoid producing "perfect" spatial correlation. These data were used to condition sequential Gaussian simulations [10] of porosity [11]. A spatial correlation length of $5,000 \mathrm{~m}$ with a horizontal-to-vertical anisotropy ratio of 20:1 was assumed in order to expand the conditioning data away from the locations of the composite "drill holes." The simulated porosity cross section was generated in stratigraphic coordinates, with elevations measured relative to a well-defined contact at the base of the Tiva Canyon welded thermal/mechanical unit ( $\mathrm{TCw})$. This spatial array of porosity values was then converted to thermal conductivity values using Equation 4:

$$
k_{t}=C_{0}+C_{1} T+C_{2} S+C_{3} \phi,
$$

(EQ 4)

where $k_{t}$ is thermal conductivity, $T$ is temperature, $S$ is saturation, and $\phi$ is porosity. $C_{0}, C_{l}, C_{2}$, and $C_{3}$ are coefficients derived from multiple regression analyses and are given in Table 6 . Porosities were converted to bulk density values using Equation 5:

$$
\rho_{b}=2.3527-(2.3983 \phi) \text {, }
$$

(EQ 5)

where $\rho_{b}$ is bulk density and $\phi$ is porosity. This regression relationship has a coefficient of determination $\left(\mathrm{r}^{2}\right)$ of 0.993 [11]. The converted spatial arrays of $\rho_{b}$ and $k_{t}$ were then transformed into real-world coordinates and offset by faulting as interpreted from cross section $\mathrm{C}-\mathrm{C}$ [1]. The resulting, spatially correlated, density and thermal conductivity fields are shown in Figure 10. Statistical summaries of these fields are presented in Table 7, and the univariate distribution of values is shown in Figure 11. 
(a)

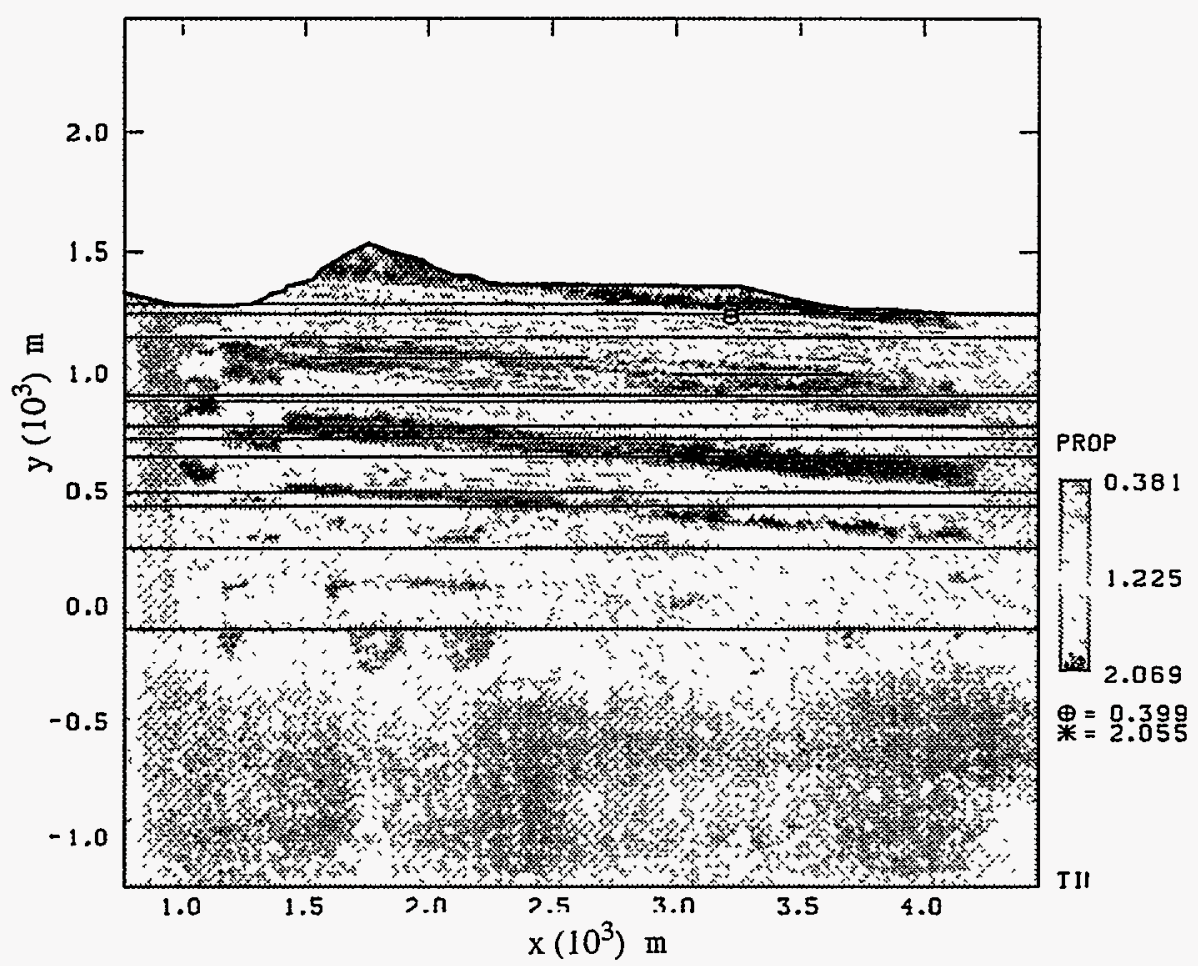

(b)

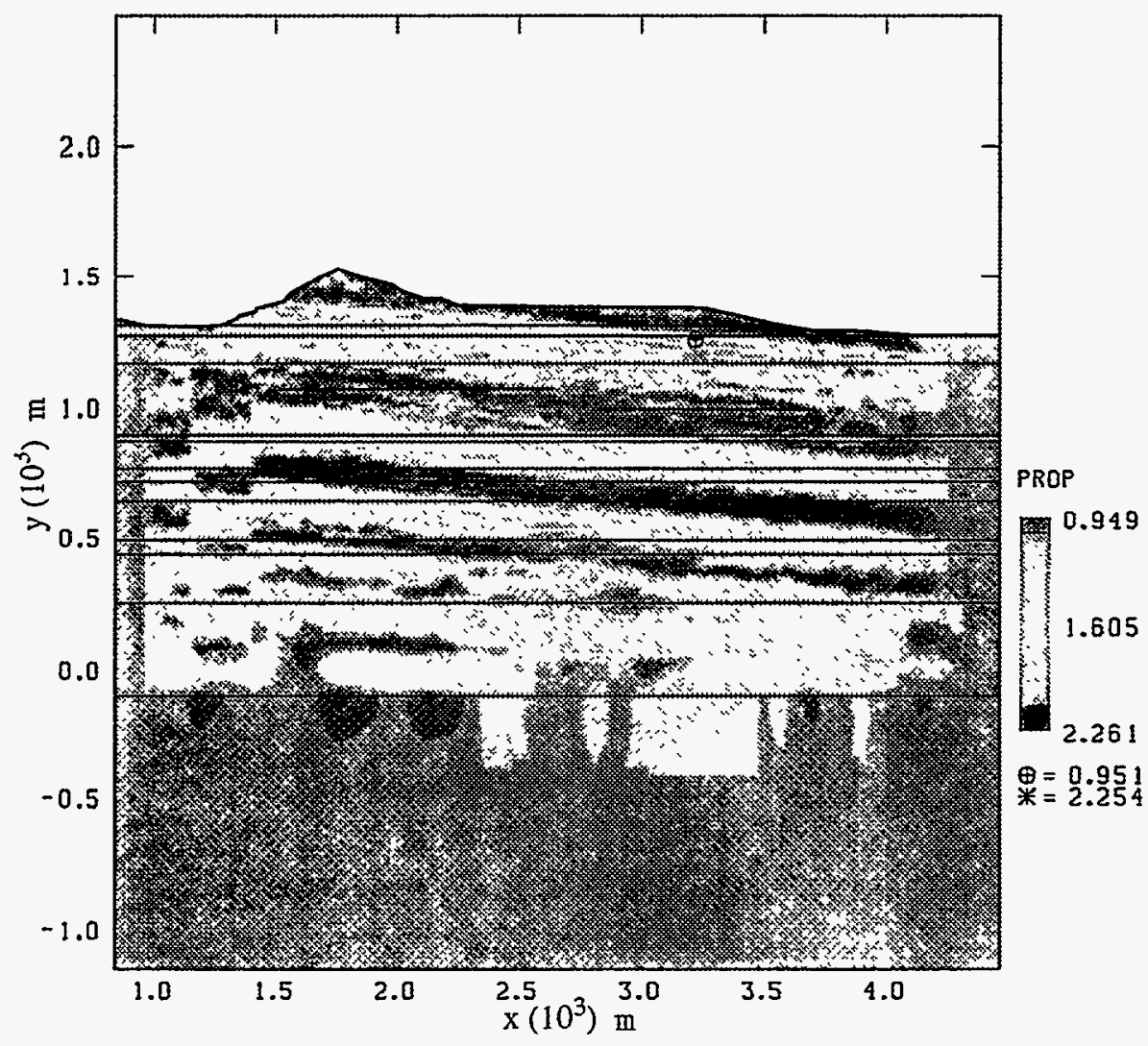

Figure 10. Spatially correlated heterogeneous models of (a) thermal conductivity and (b) bulk density corresponding to calculational models GCH1HL Range of spatial corretion is $5,000 \mathrm{~m}$. 

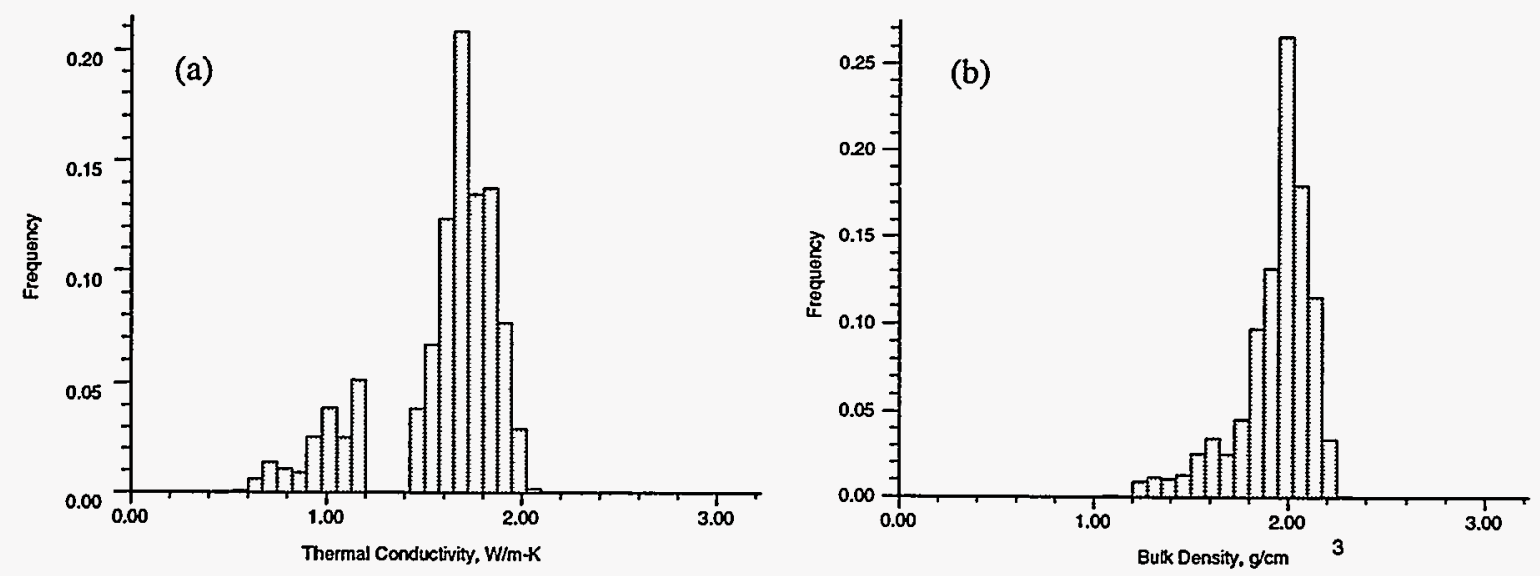

Figure 11. Histograms of material properties corresponding to calculational model GC1HL. (a) thermal conductivity; (b) bulk density.

Table 6. Coefficients from Multiple Regression Relationships Relating Thermal Conductivity and Porosity.

\begin{tabular}{|c|c|c|c|c|}
\hline \multirow{2}{*}{ Coefficient } & \multicolumn{2}{|c|}{ Low Temperature, $\mathrm{T} \leq 100^{\circ} \mathrm{C}$} & \multicolumn{2}{c|}{ High Temperature, $\mathrm{T}>100^{\circ} \mathrm{C}$} \\
\cline { 2 - 5 } & Welded & Nonwelded & Welded & Nonwelded \\
\hline \hline$C_{0}$ & 1.748256 & 1.25031 & 1.916108 & 1.039489 \\
\hline$C_{l}$ & $3.529412 \times 10^{-4}$ & $2.096154 \times 10^{-3}$ & $-1.56379 \times 10^{-4}$ & $3.37037 \times 1^{0-4}$ \\
\hline$C_{2}$ & 0.4347434 & 0.58535891 & 0 & 0 \\
\hline$C_{3}$ & -3.210442 & -2.23816 & -4.055047 & -1.529672 \\
\hline No. Analyses & 78 & 204 & 135 & 29 \\
\hline${\text { Multiple }{ }^{2}}^{2}$ & 0.58 & 0.95 & 0.47 & 0.99 \\
\hline
\end{tabular}

Table 7. Statistical Summary of Geostatistical Model GC1HL

\begin{tabular}{|r|c|c|}
\hline & $\begin{array}{c}\text { Thermal } \\
\text { Conductivity } \\
\text { W/m-K }\end{array}$ & $\begin{array}{c}\text { Bulk Density } \\
\mathrm{g} / \mathrm{cm}^{3}\end{array}$ \\
\hline mean & 1.593 & 1.933 \\
\hline std. dev. & 0.310 & 0.195 \\
\hline maximum & 2.128 & 2.231 \\
\hline median & 1.675 & 1.971 \\
\hline minimum & 0.252 & 0.794 \\
\hline correlation length & $5000 \mathrm{~m}$ & $5000 \mathrm{~m}$ \\
\hline
\end{tabular}




\subsection{Repository Heat Generation and Decay Heat}

This section describes the relationships used to calculate the decay-heat characteristics of spentfuel canisters and the repository thermal loading. The volumetric heat source that was applied to the finite-element mesh was generated using user subroutines within COYOTE-II [4]. These subroutines are presented in Appendix D.

The thermal decay characteristics of the spent nuclear fuel was represented by a six-term exponential of the following form:

$$
P(t)=\sum_{i=1}^{6} a_{i} \exp \left(-b_{i} t\right)
$$

where, $P(t)$ is the thermal power output in Watts per MTU, $a_{i}$ and $b_{i}$ are fitted constants and $t$ is time in years since discharge from the reactor. The fitted coefficients for the six-term exponential decay curve representative of the decay of $42,200 \mathrm{MWd} / \mathrm{MTU}$ were obtained using data from the Characteristics Data Base [12] and the same method presented in the RIB. These coefficients are normalized to 22.5 years out-of-reactor. Figure 12 shows the decay curve represented by Equation 6.

Table 8. Normalized Thermal Decay Coefficients for 42,200 MWd/MTU, PWR-Type Waste.

\begin{tabular}{|c|c|c|}
\hline$i$ & $a_{i}$ & $b_{i}\left(\mathrm{yr}^{-1}\right)$ \\
\hline \hline 1 & 0.02068 & $0.21903 \times 10^{-5}$ \\
\hline 2 & 0.14450 & $0.13263 \times 10^{-2}$ \\
\hline 3 & 0.13185 & $0.61814 \times 10^{-2}$ \\
\hline 4 & 0.01238 & $0.12091 \times 10^{-1}$ \\
\hline 5 & 0.67719 & $0.23888 \times 10^{-1}$ \\
\hline 6 & 0.01340 & 0.111839 \\
\hline
\end{tabular}

The 100-kW/acre areal power density was converted to volumetric power density for use in the finite-element models. The areal-power density was converted to total power using an equivalent repository foot print in acres. Then using the equivalent volume of the repository, the power density was computed. For the $100-\mathrm{kW} /$ acre case, only the upper-level repository was used. This equated to a power volumetric density of $13.5 \mathrm{~W} / \mathrm{m}^{3}$.

\subsection{Boundary and Initial Conditions}

Boundary conditions were chosen to be representative and to provide similarity among the different calculations. Figure 13 shows the boundary conditions applied to all thermal models for both steady-state and transient calculations. A constant-temperature boundary condition was applied to the bottom far-field surface, and a convective boundary condition was applied to the upper surface of the mesh. All other surfaces were assumed adiabatic. Initial conditions used for transient calculations were generated by performing a steady-state calculation using the above boundary conditions, assuming no repository is present. 


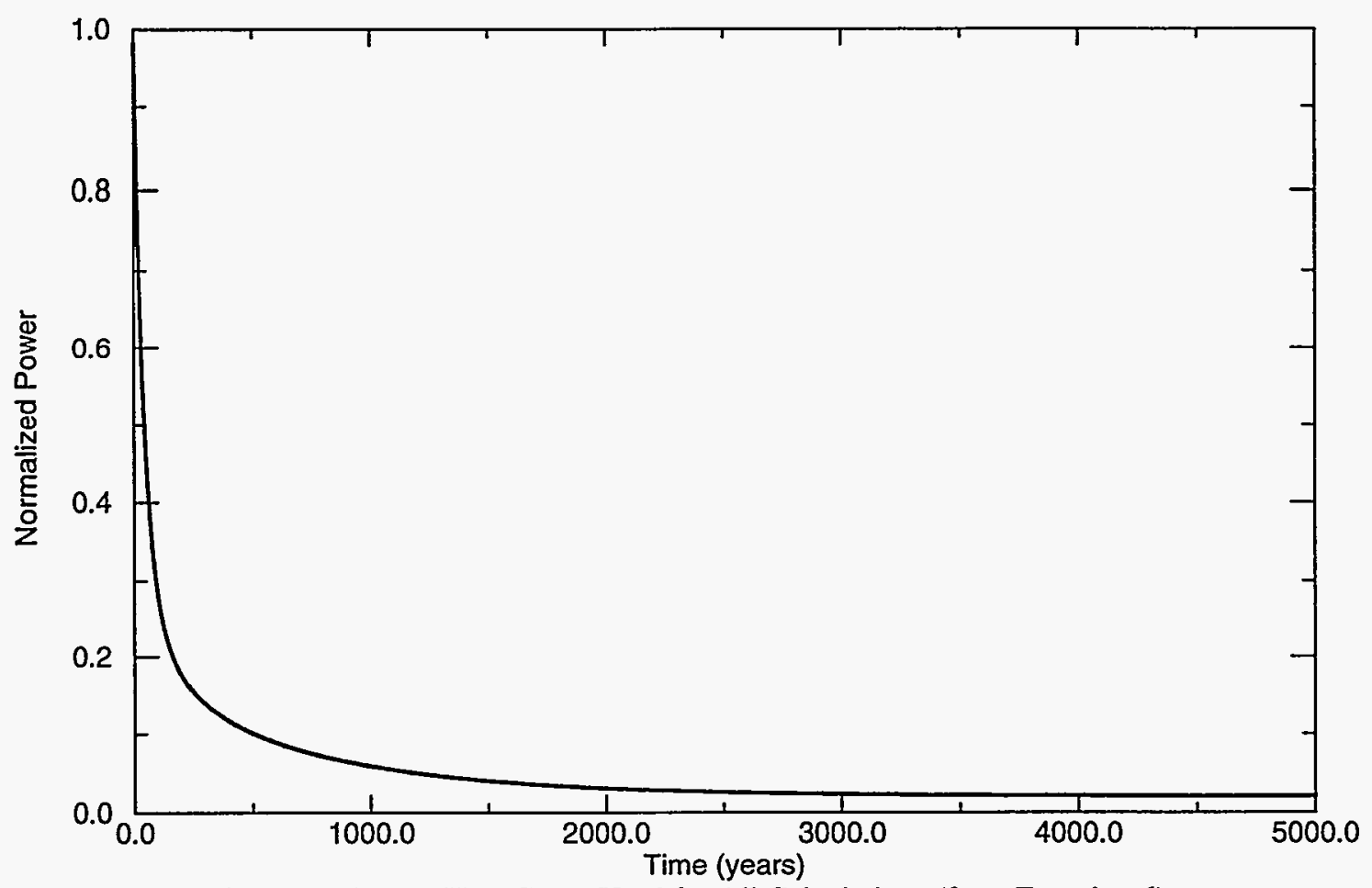

Figure 12. Decay Heat Curve Used for All Calculations (from Equation 6).

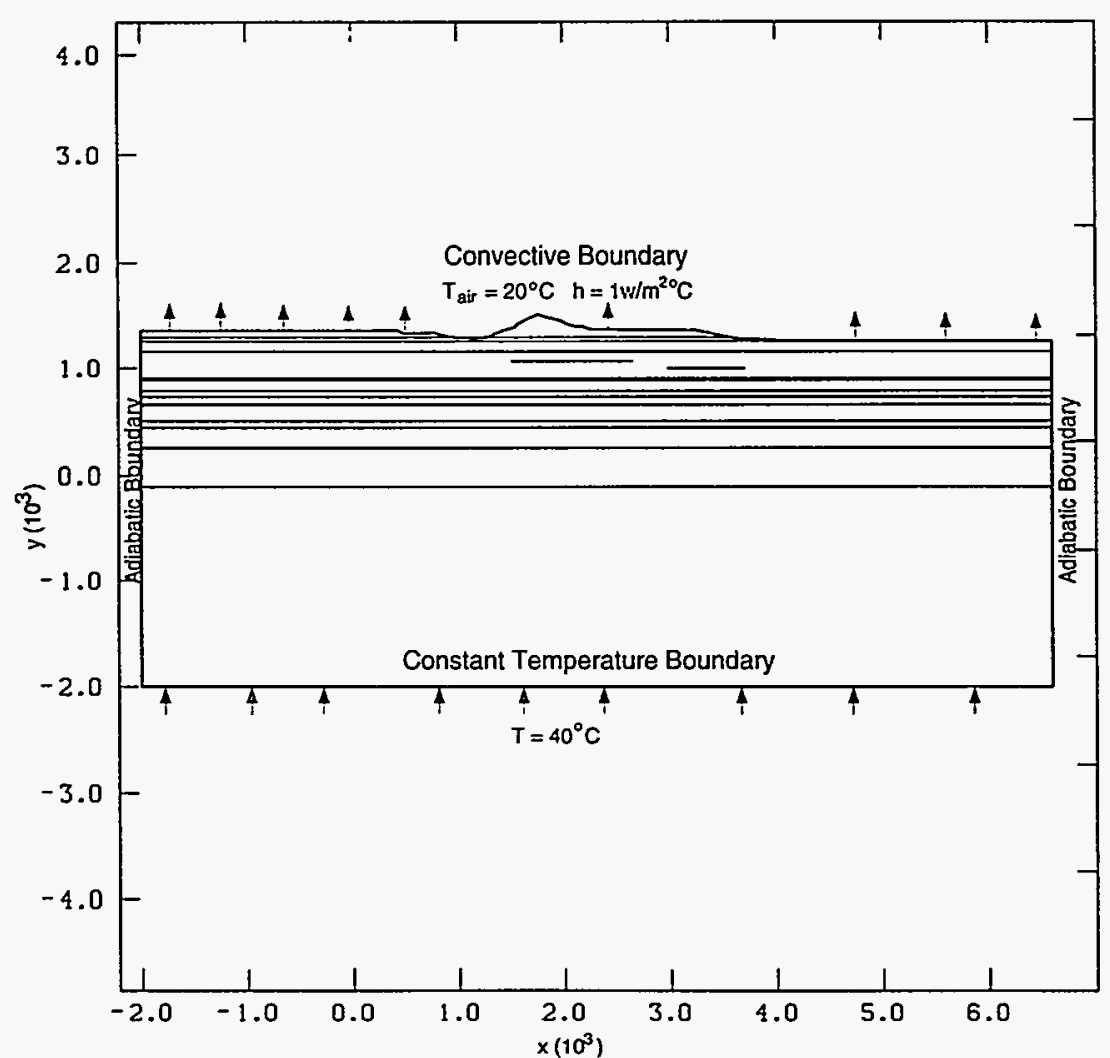

Figure 13. Thermal Boundary Conditions Applied to Horizontal-Layer Mesh. 
This page intentionally left blank. 


\subsection{Results}

\subsection{Presentation of Results}

Results from calculations defined in Table 1 are presented here in the form of color temperature contour maps. Only the near-field portion of the solutions are presented because they are adequate for resolving the heat flow that occurs for the first 1000 years of simulation time.

For the sake of brevity, only selected calculational results are presented. Each calculation employed fixed time step in conjunction with an implicit time-integration scheme. Scoping calculations using the horizontal-layer mesh took approximately 75 minutes of CPU time, and scoping calculations using the sloped-layer mesh took approximately 50 minutes of CPU time, both for a 5000-year transient simulation. All calculations were performed on a Cray-YMP8/864 using Uni$\cos 7.0 .4$.

Results of each calculation are shown at four different times: 50 years, 100 years, 500 years, and 1000 years. Table 9 summarizes each calculation with respect to maximum temperature obtained.

Table 9. Maximum Temperature and Time at Which it Occurs for All Calculations.

\begin{tabular}{|c|c|c|}
\hline Calculation Name & $\begin{array}{c}\text { Max Temperature } \\
\left({ }^{\circ} \mathrm{C}\right)\end{array}$ & $\begin{array}{c}\text { Time at which Max } \\
\text { Temp. Occurs }\end{array}$ \\
\hline \hline UCRHL & 178.9 & 81 years \\
\hline UCG4HL & 201.1 & 81 years \\
\hline LCRHL & 182.7 & 81 years \\
\hline LCRSL & 182.5 & 81 years \\
\hline LVRHL & 155.1 & 71 years \\
\hline LVRSL & 154.9 & 71 years \\
\hline GC1HL & 183.7 & 81 years \\
\hline
\end{tabular}

All maximum temperatures occurred in the finite elements representing the repository. The temperature-independent thermal property models with low maximum temperatures indicate a more efficient heat dissipating medium compared to temperature-independent thermal property models with higher maximum temperatures. The temperature-dependent thermal property models have much lower maximum temperatures (up to $30^{\circ} \mathrm{C}$ ) than temperature-independent thermal property models because large amounts of energy are being used to vaporize water in the pores of the rock.

Results from the homogeneous, temperature-independent thermal properties calculation UCRHL are presented in Figures 14 through 17. This calculation represents the base case for all calculation comparisons. It is the simplest thermal property model and corresponds to the type of model being used for repository thermal-design calculations [13]. Results indicate that the thermal pulse is contained within a 200 meter vertical distance both above and below the repository during the first 500 years.

The next set of results are from the layered, homogeneous, temperature-independent thermal property calculations LCRHL and LCRSL. Figures 18 through 21 show results from the horizontal-layer mesh (LCRHL), and Figures 22 through 25 show results from the sloped-layer mesh 
(LCRSL). Both sets of results will be compared in the next section to assess the effects of using a horizontal-layer mesh versus a sloped-layer mesh (which includes fault zones).

The next set of results were generated using a temperature-dependent thermal property model. Specifically Figures 26 through 29 show results from calculation LVRHL. Results shown in these figures are from a model that simulates the latent heat of vaporization of water in the pores of the rock. Using this type of thermal property model lowers the maximum temperature by approximately $30^{\circ} \mathrm{C}$ compared to other calculations as shown in Table 9.

Finally Figures 30 through 33 present results for the geostatistical thermal property model GC1HL. Temperature contours might be expected to be skewed when compared to simulations presented above due to the horizontal heterogeneity of the thermal properties. This was not observed because the thermal front moves perpendicular to regions of large thermal property variations. These results were found to be very similar to those for the simulation LCRSL. 

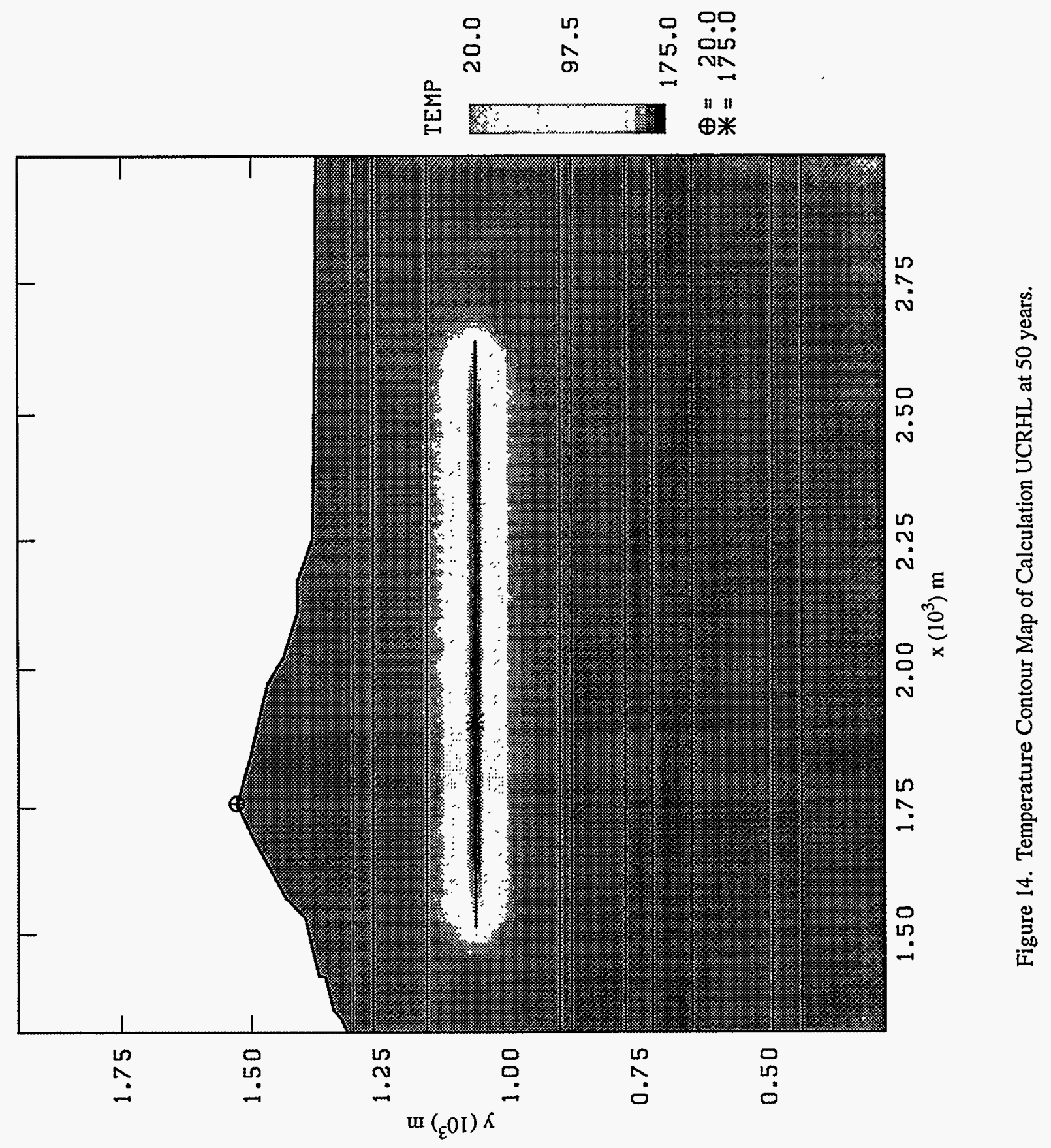


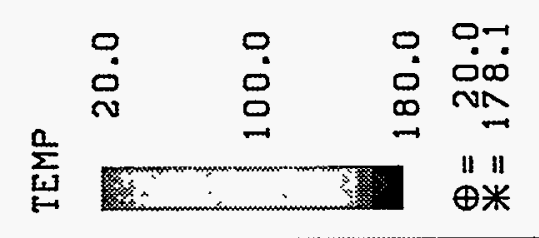

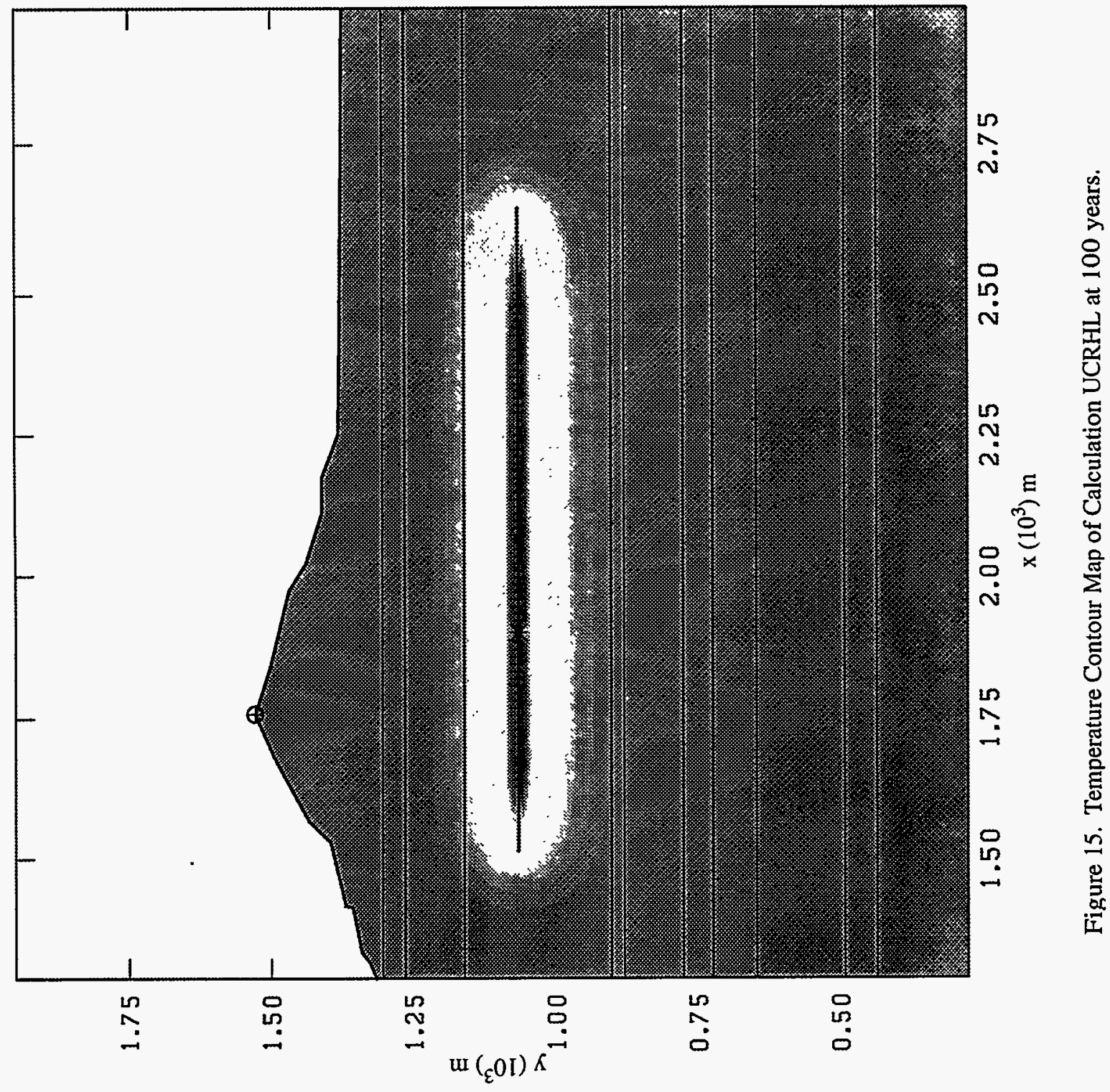



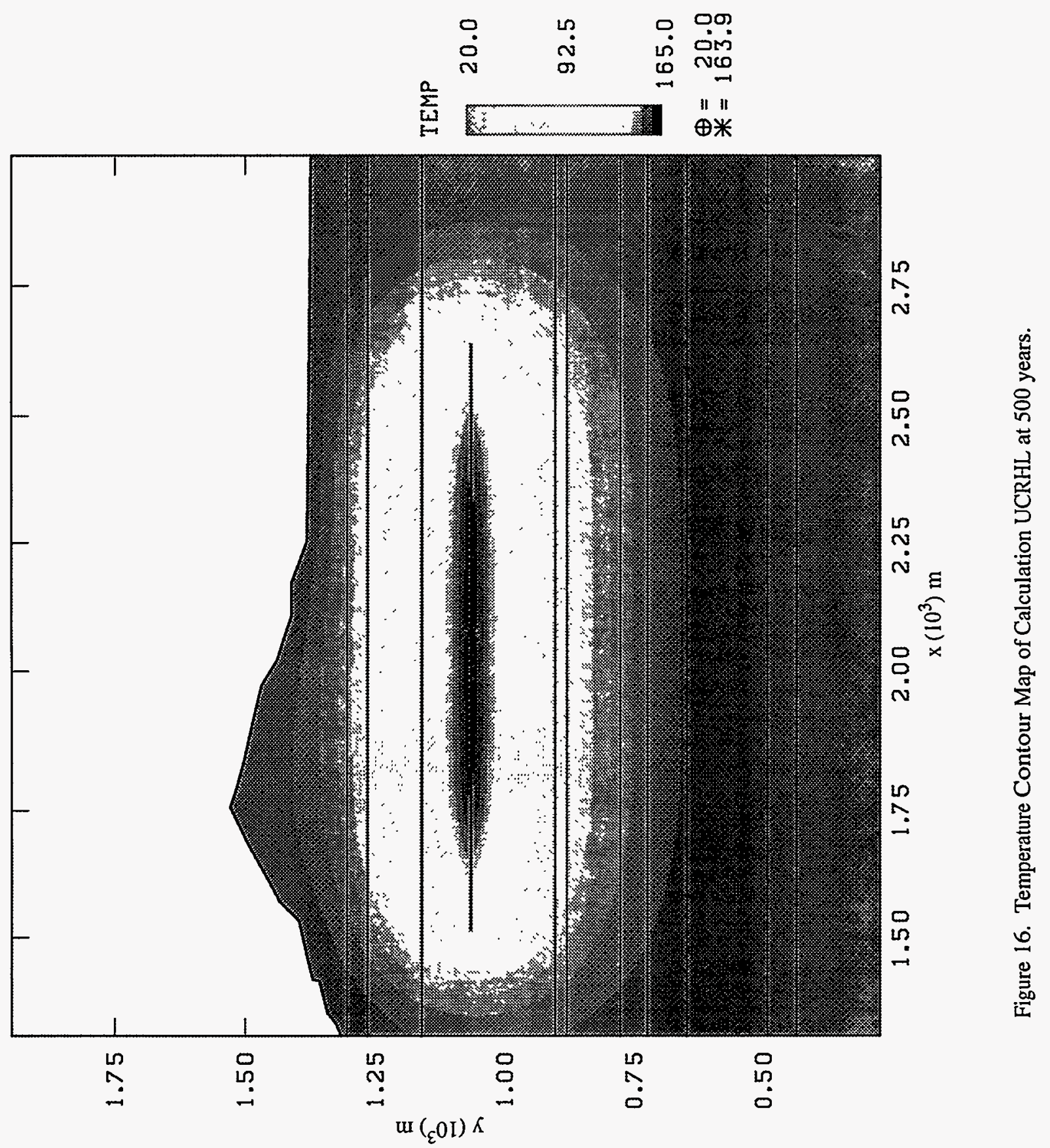


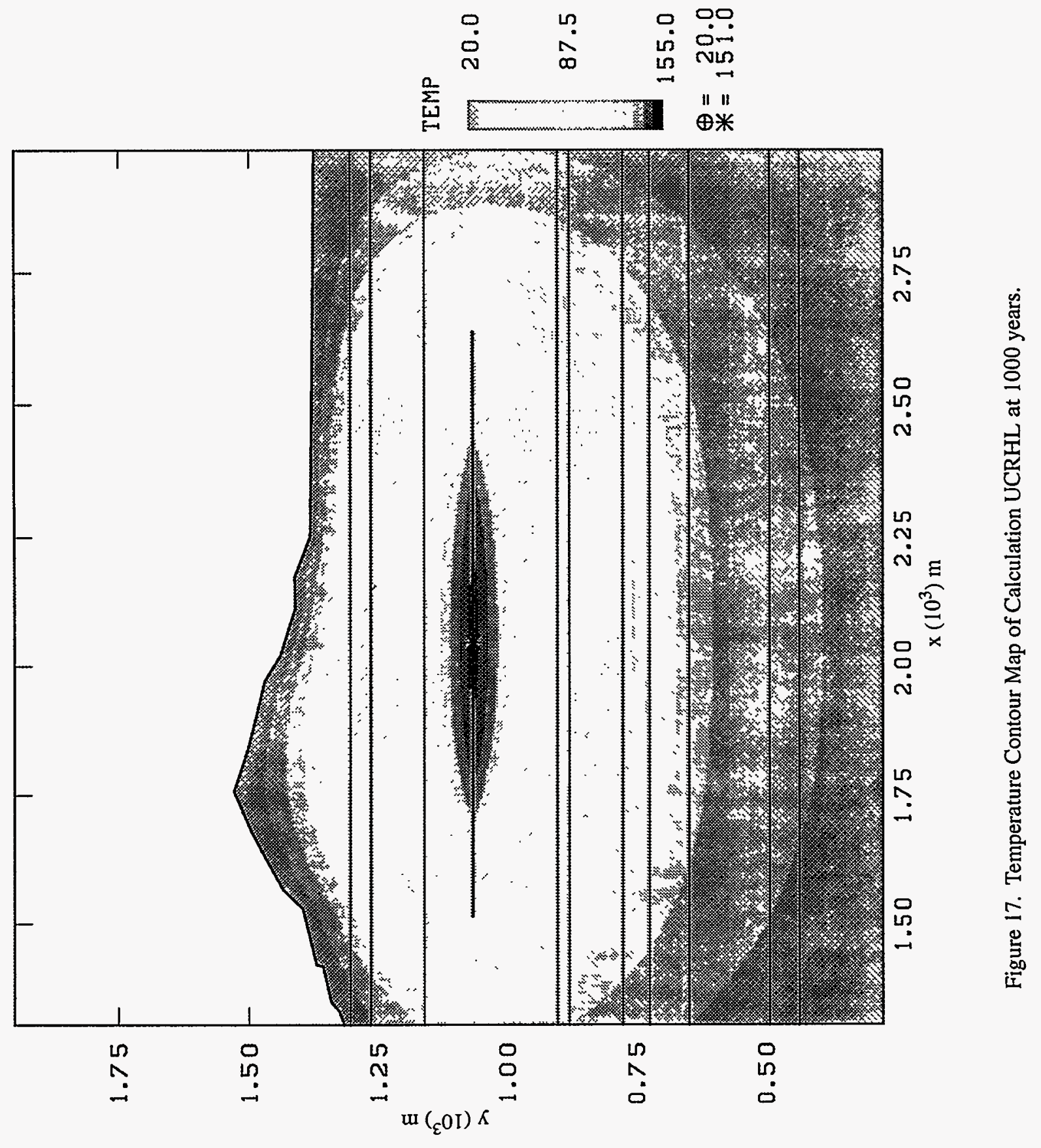



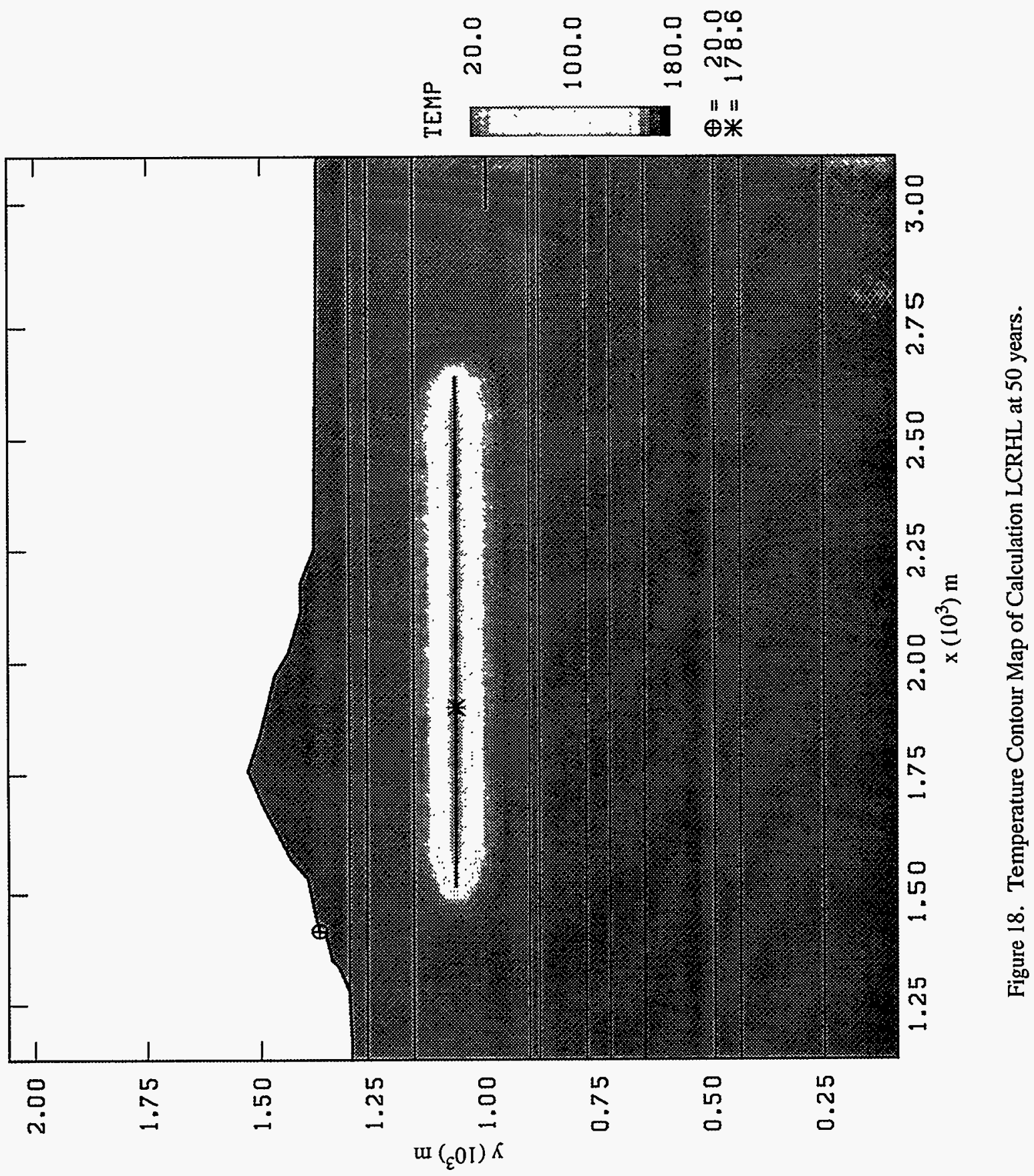

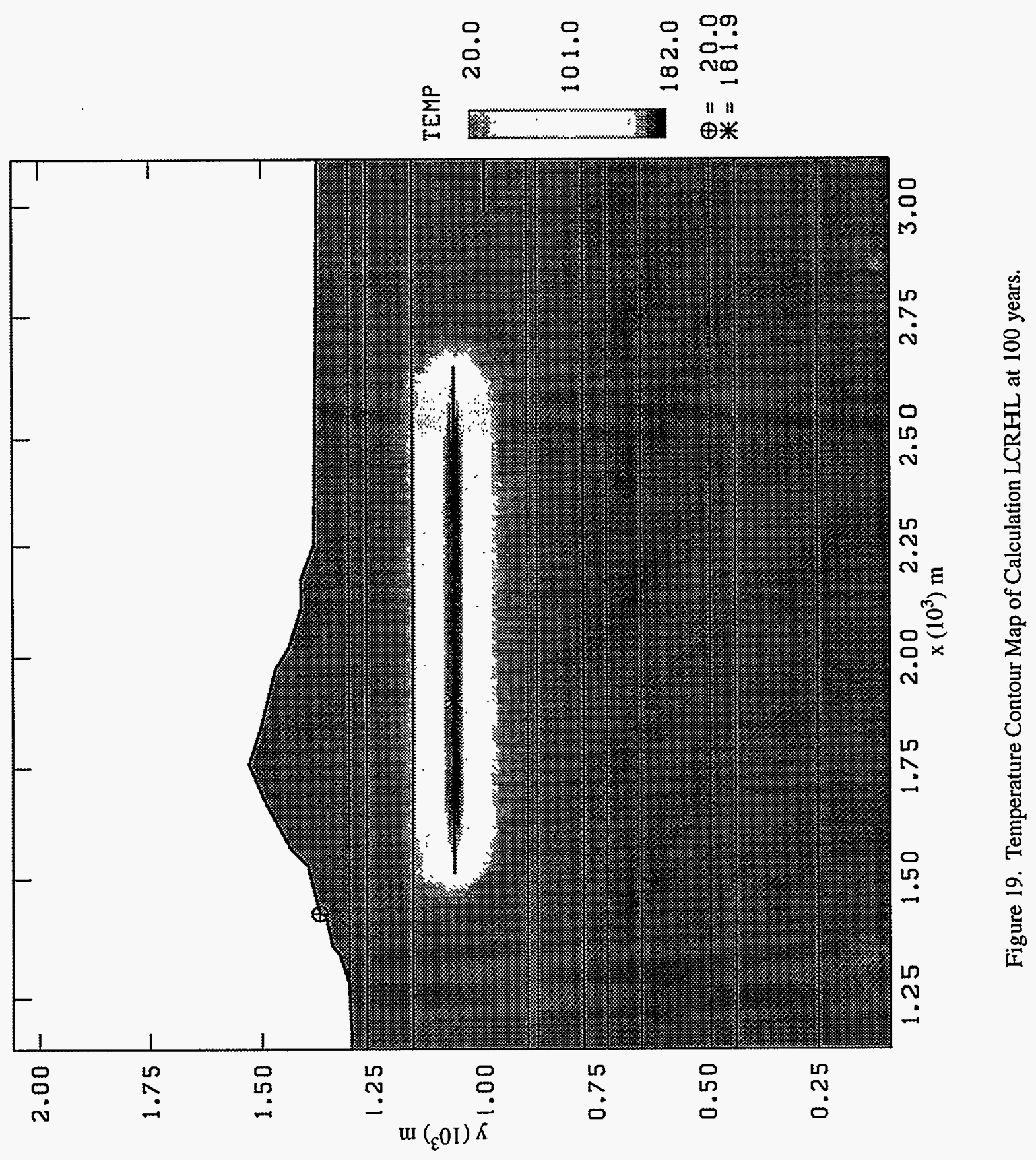

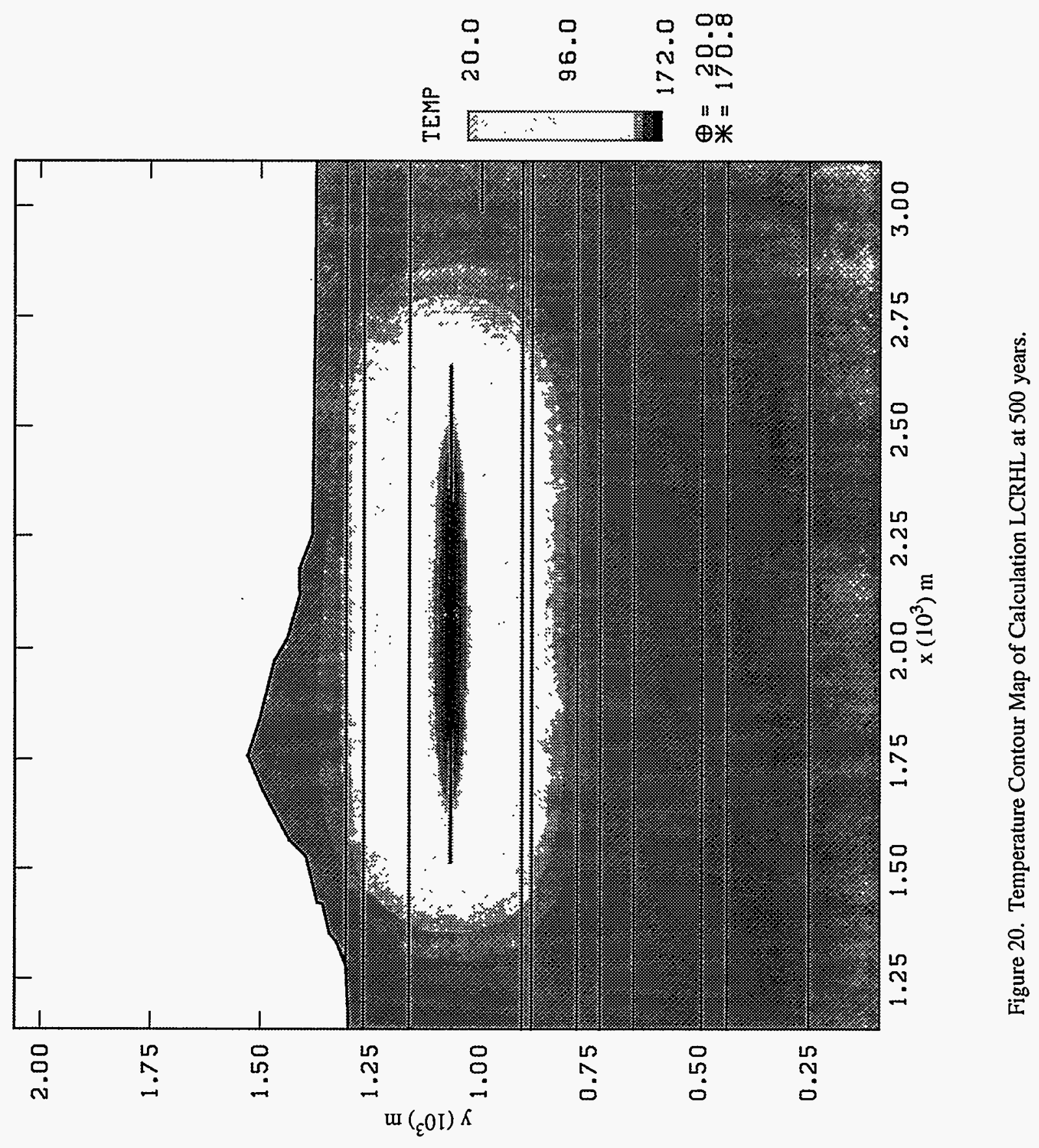


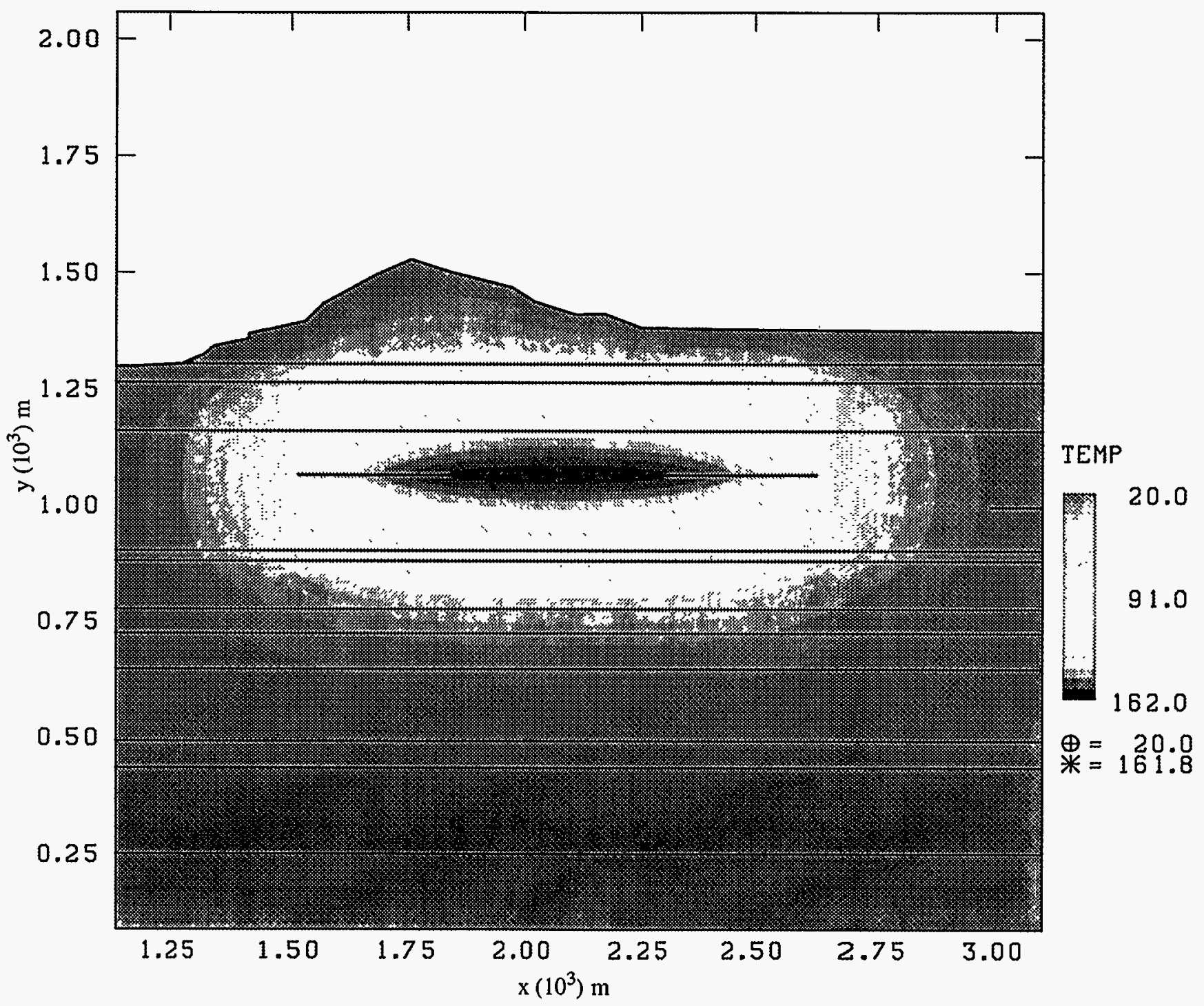

Figure 21. Temperature Contour Map of Calculation LCRHL at 1000 years. 


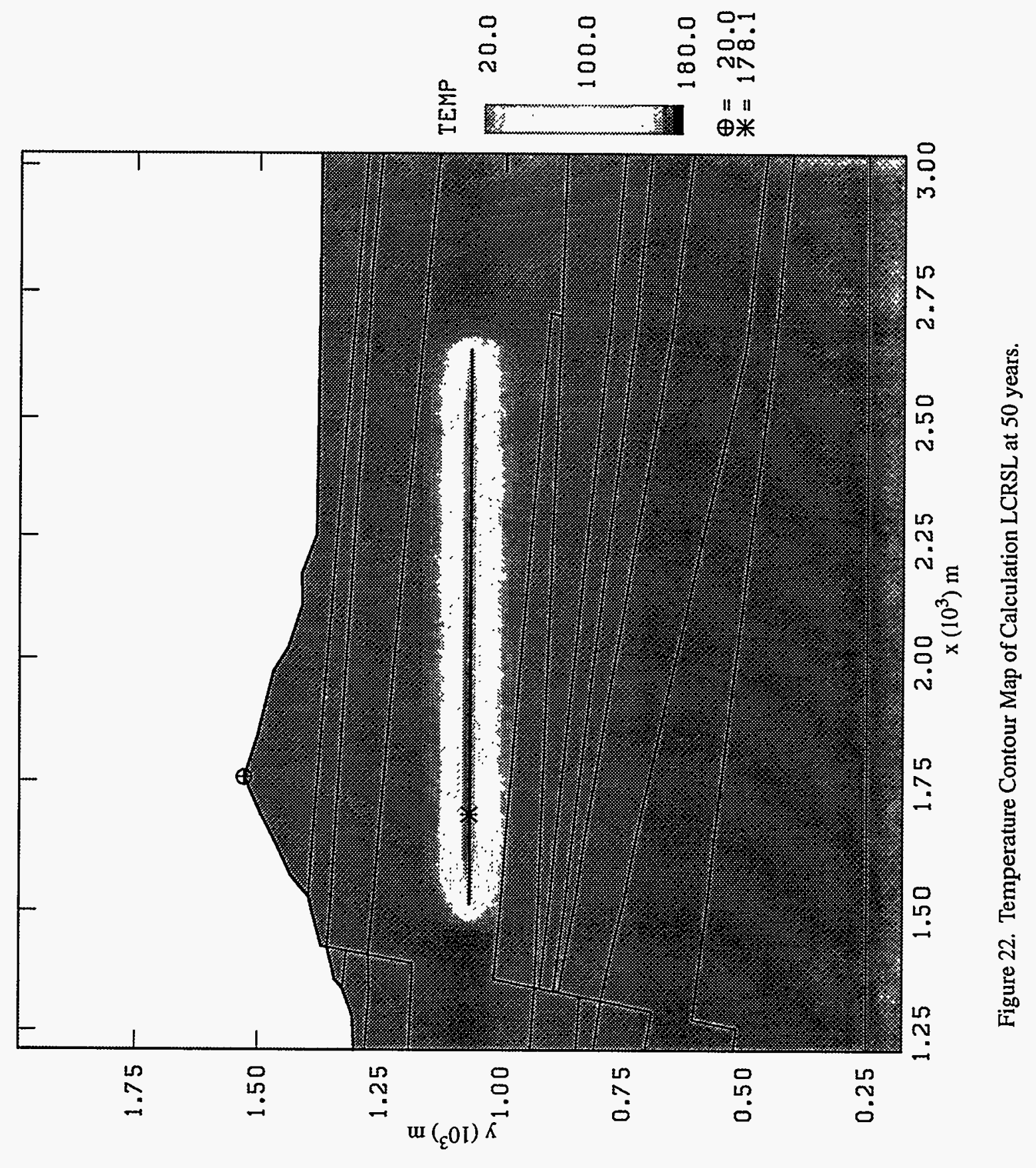




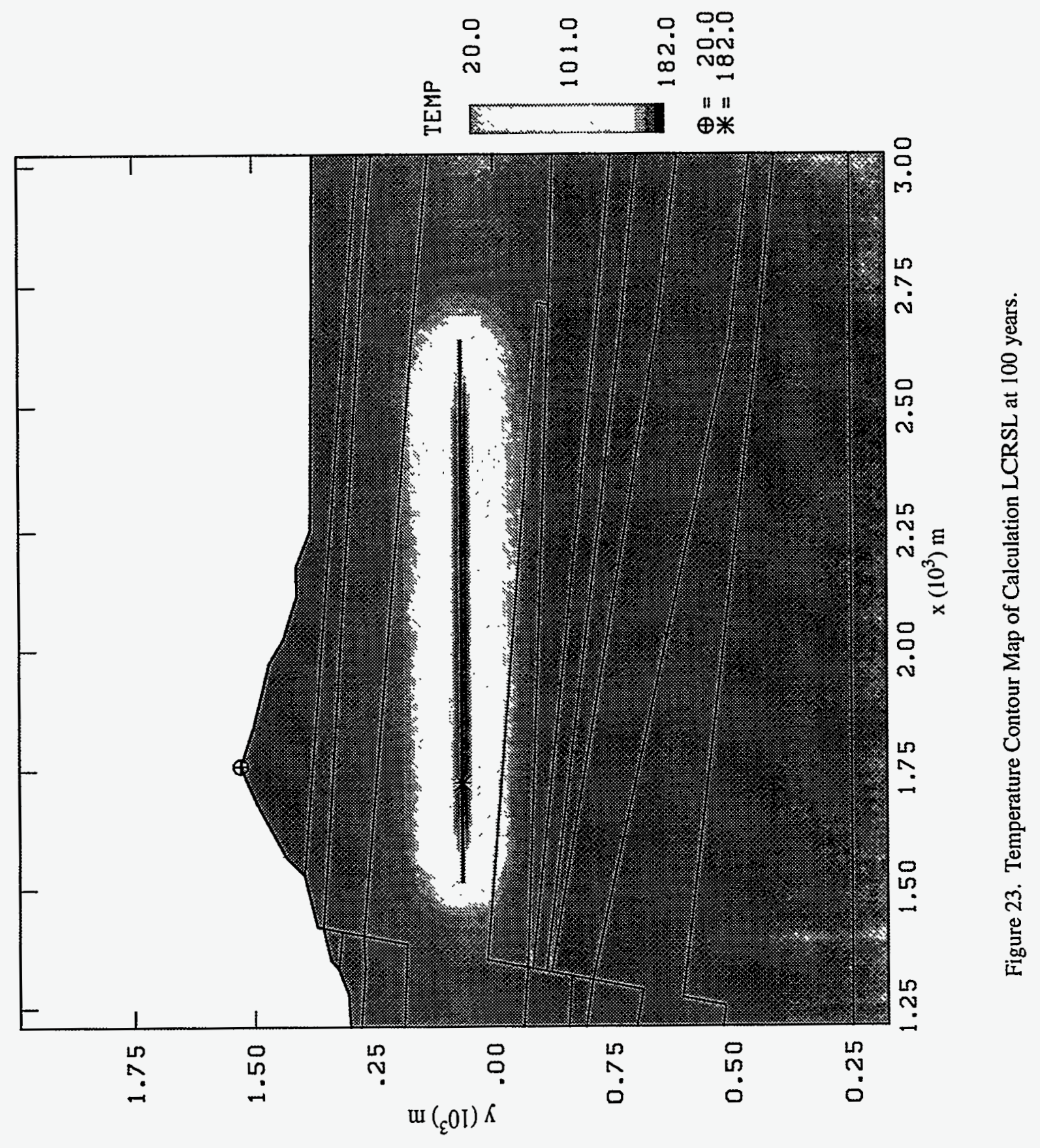




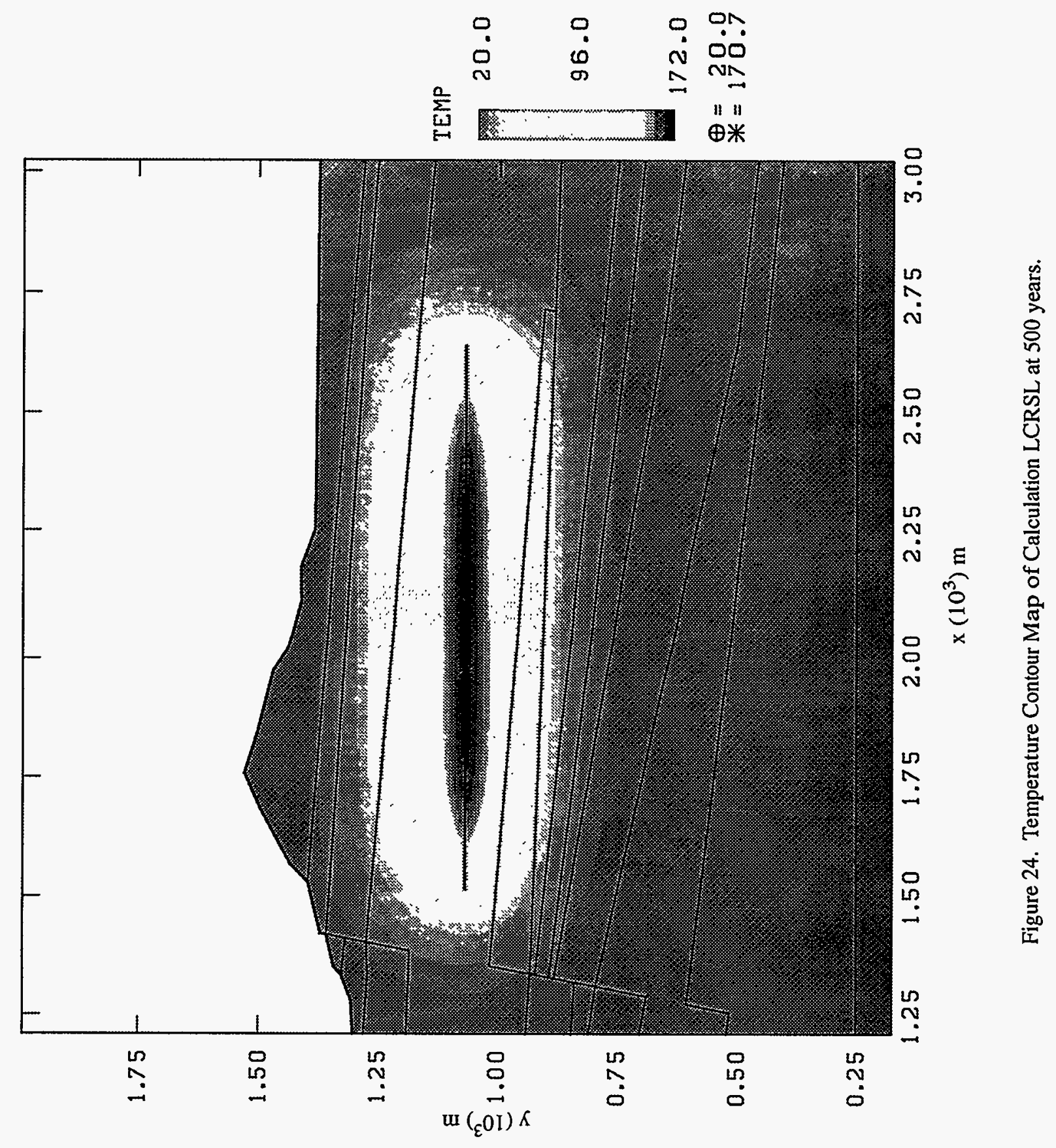



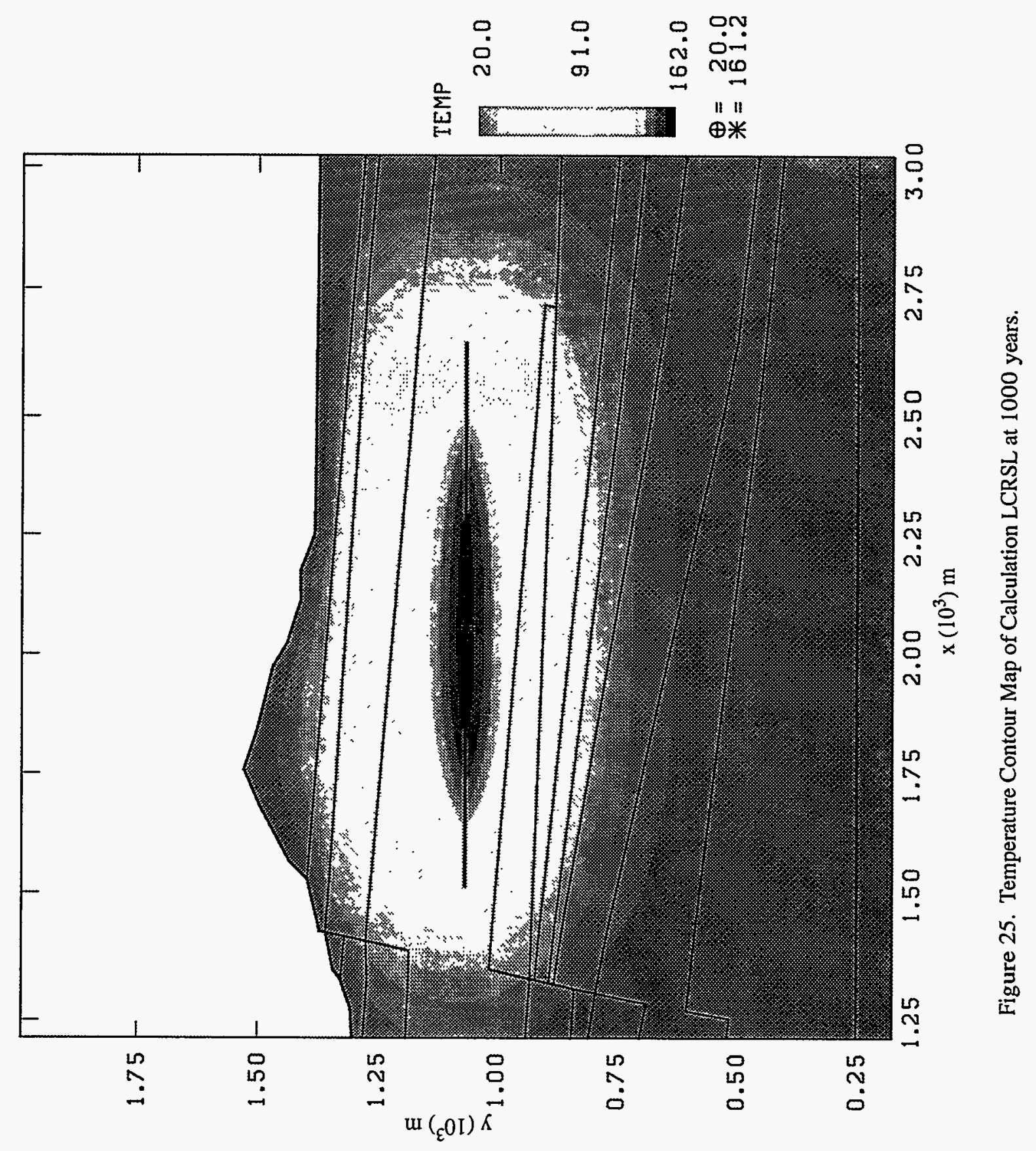


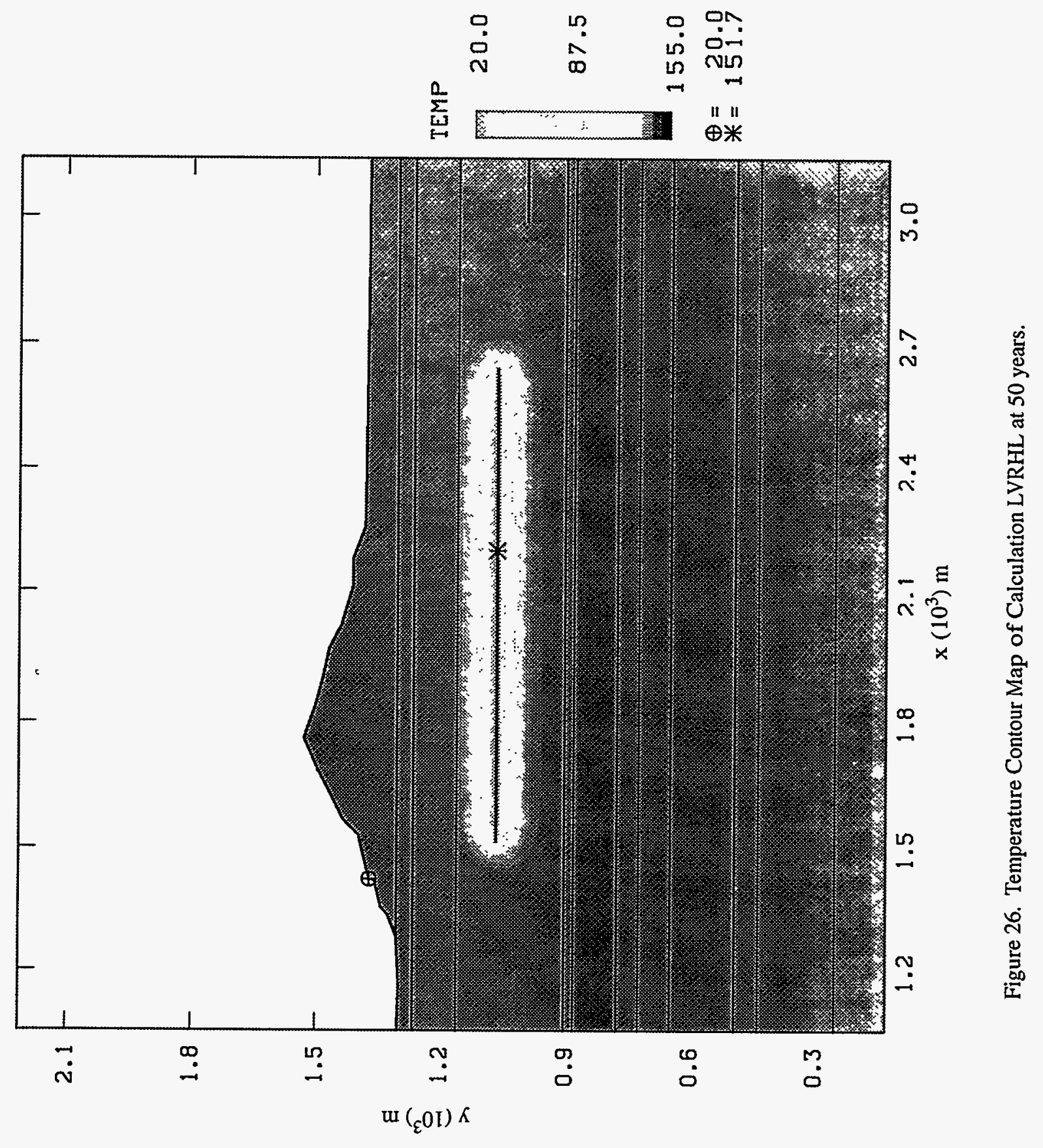



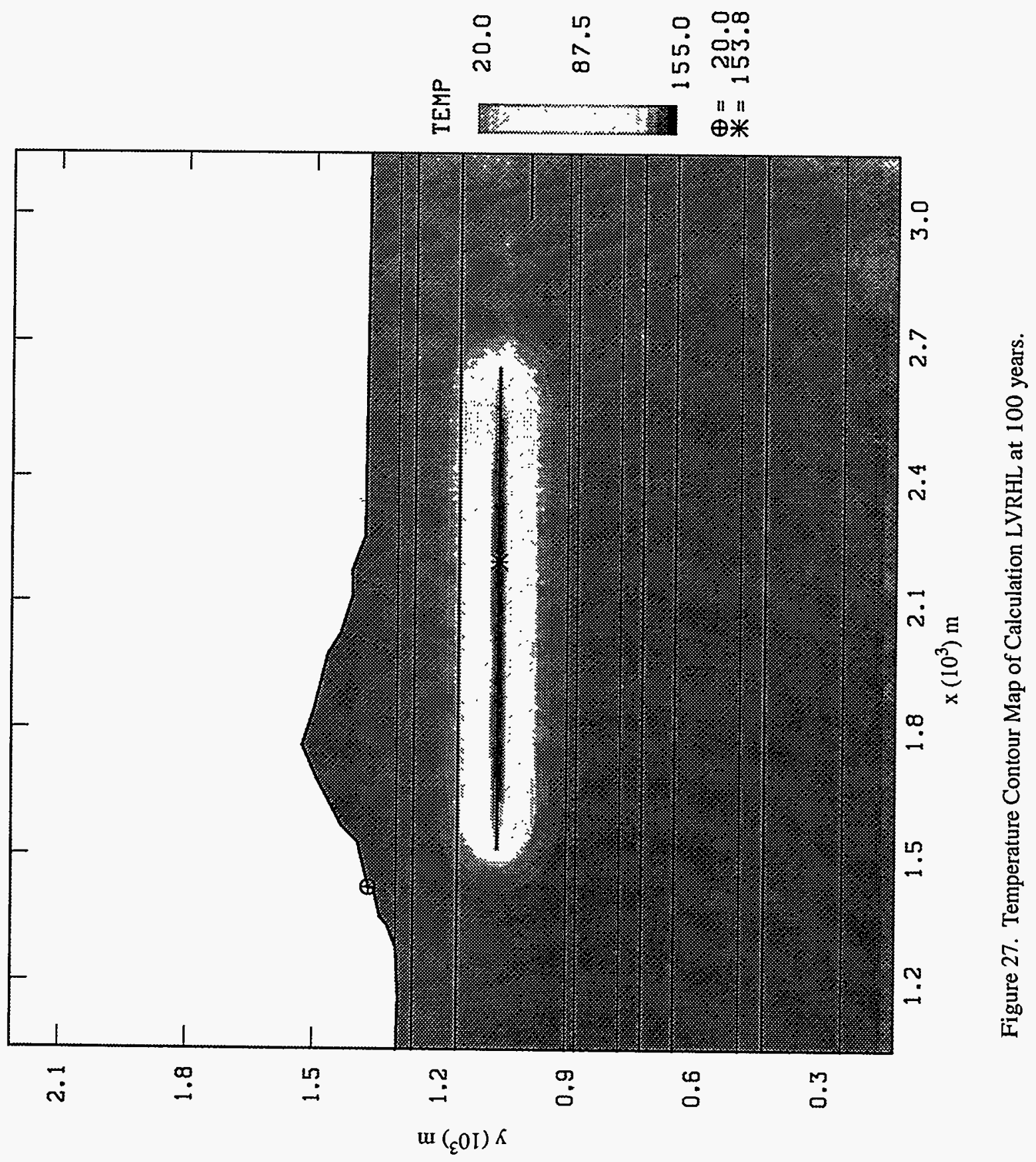

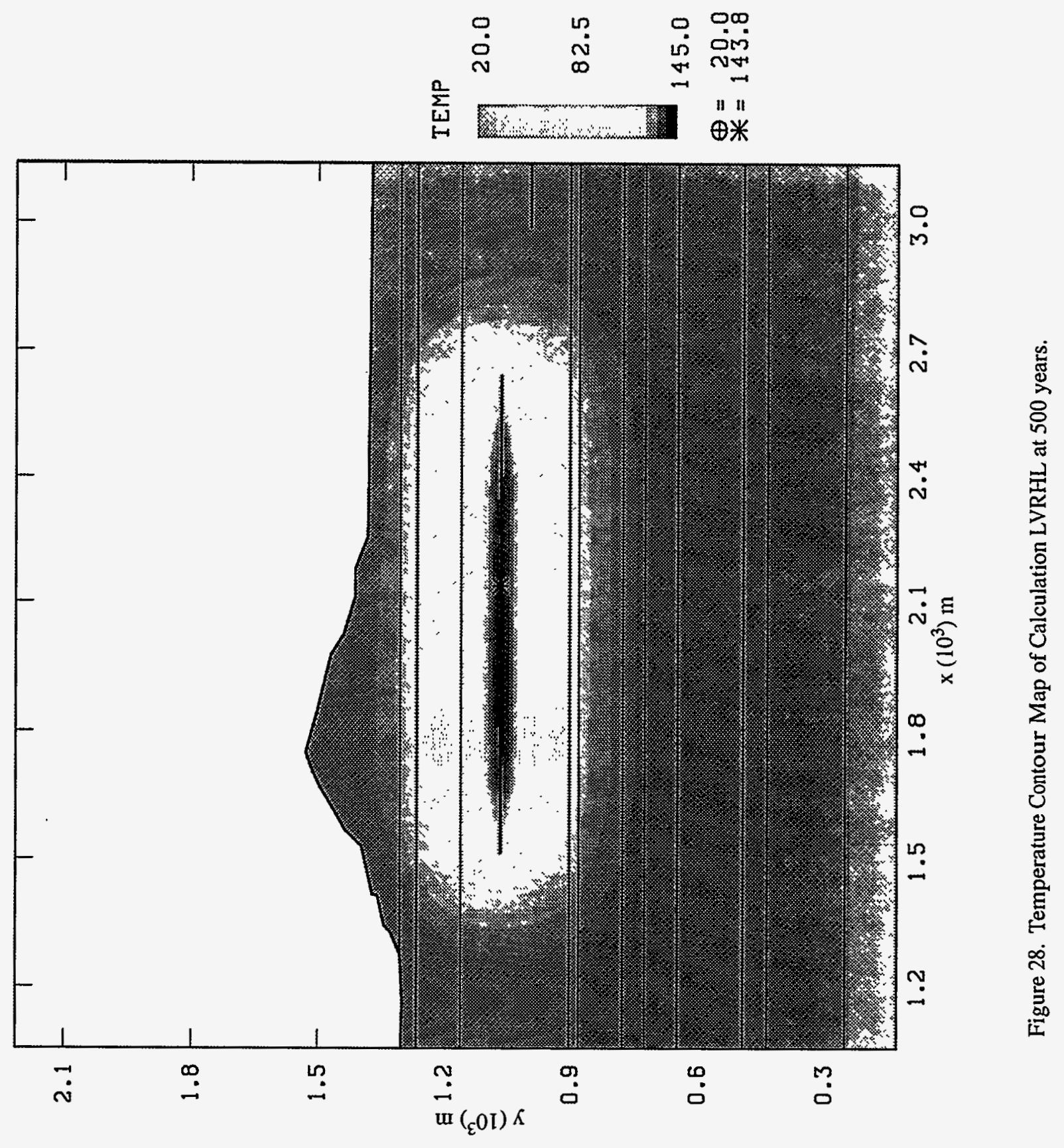

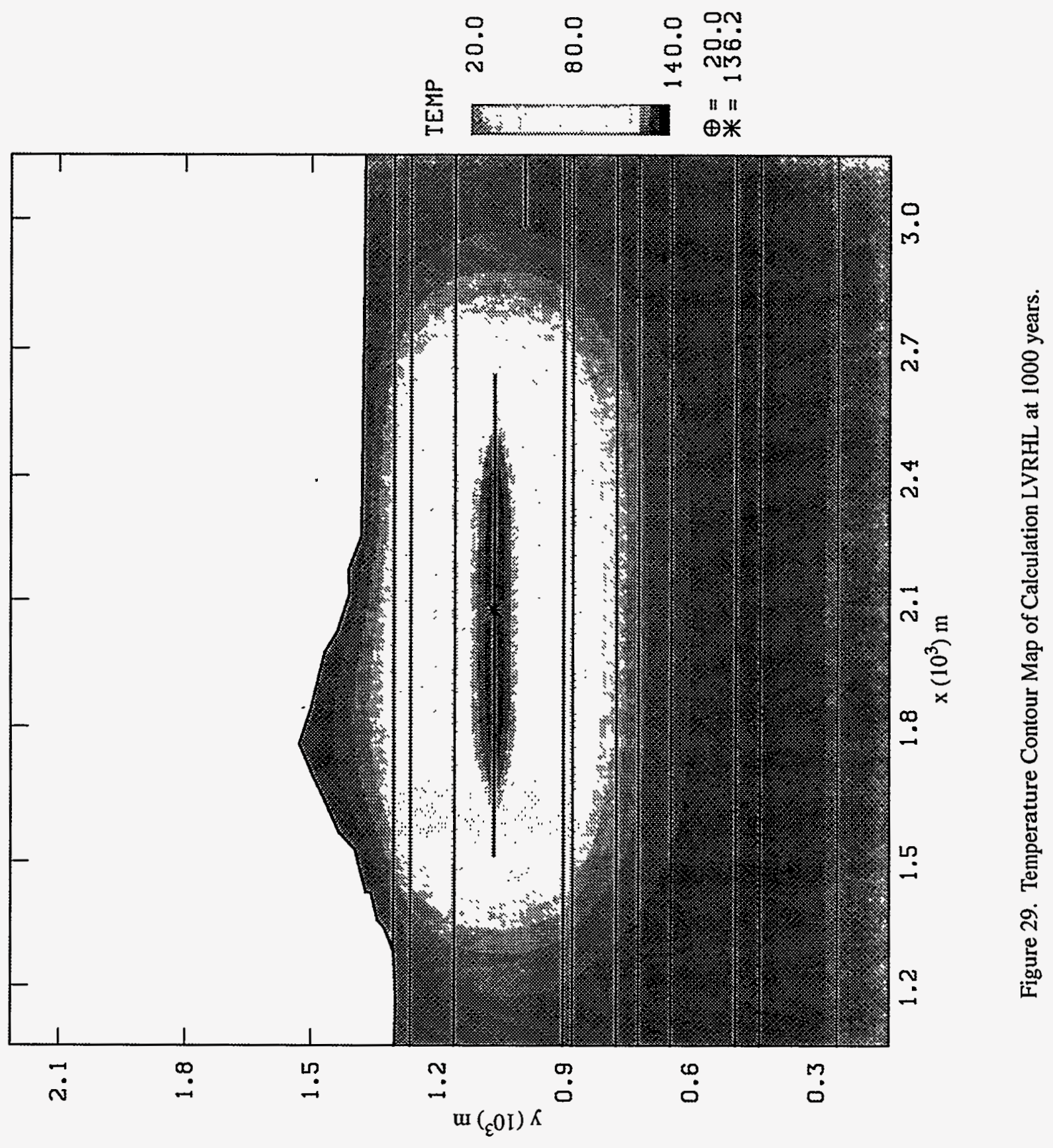


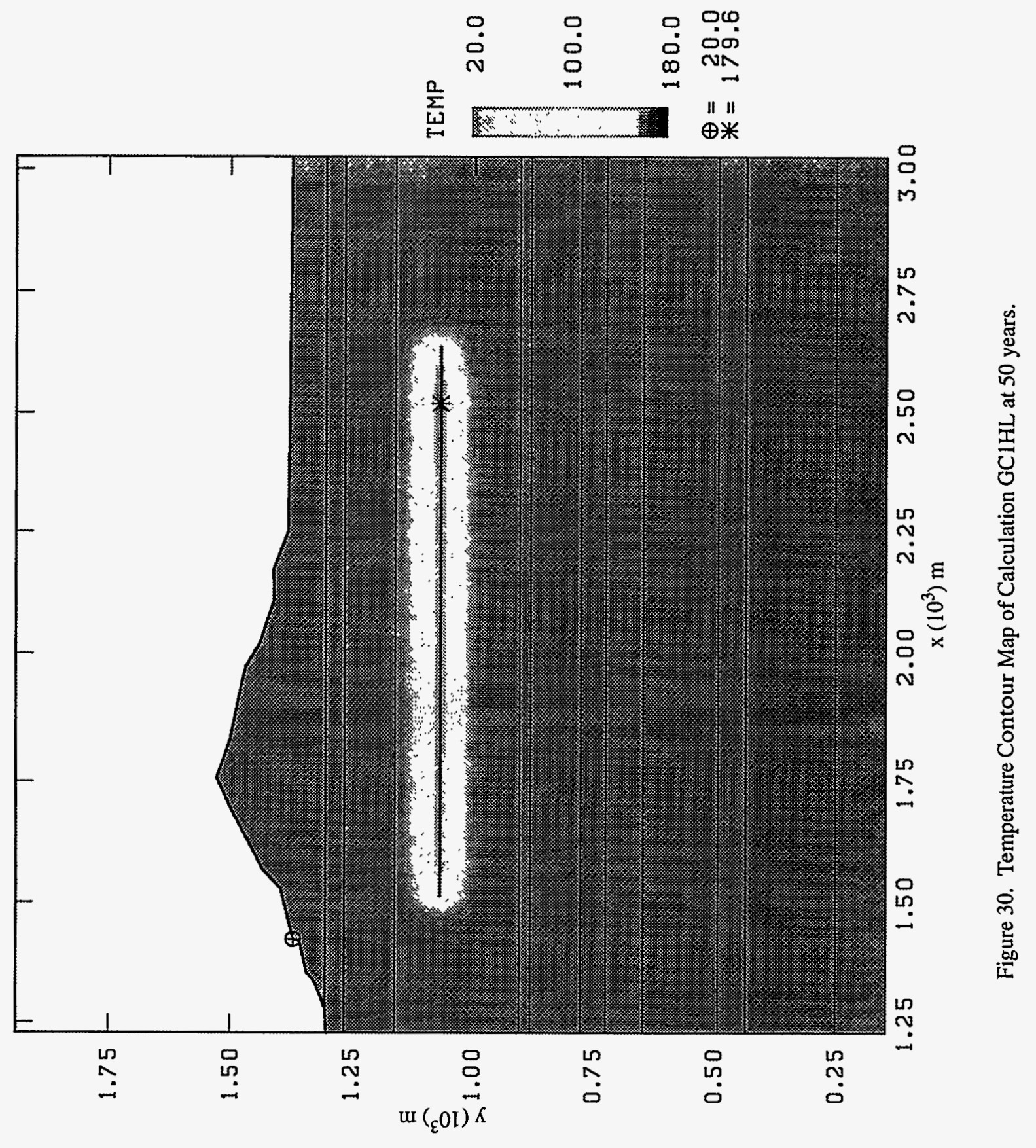




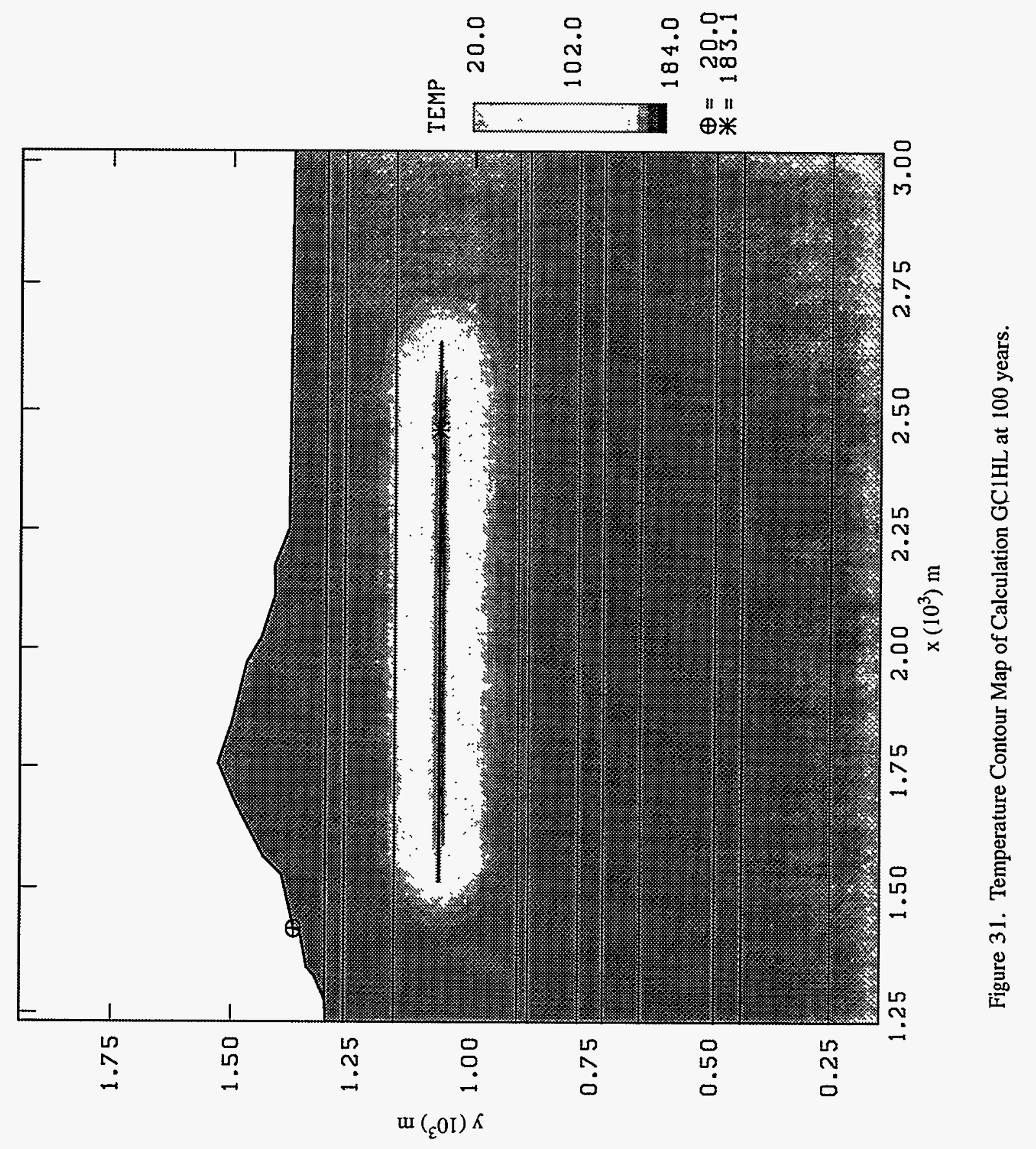




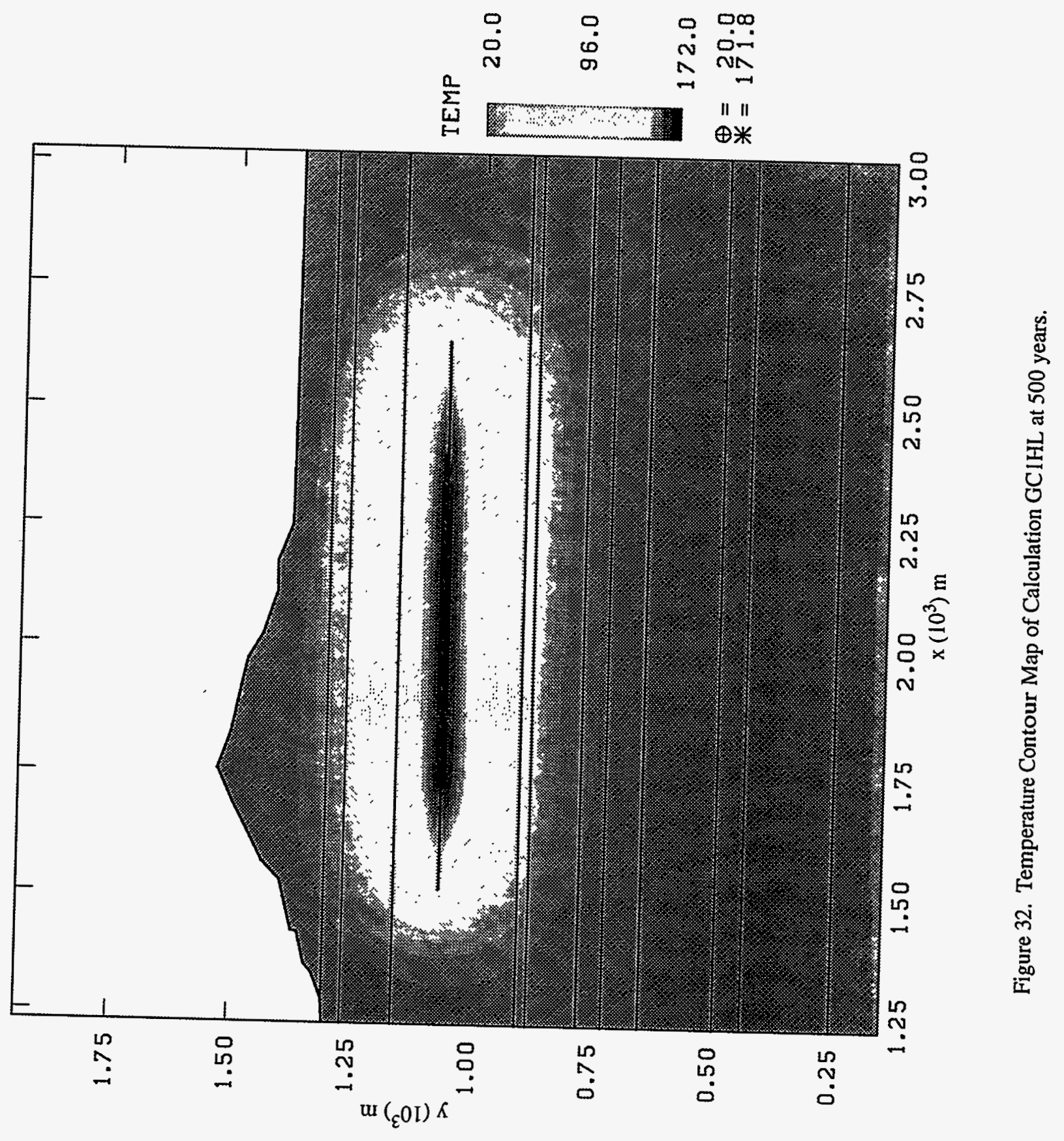




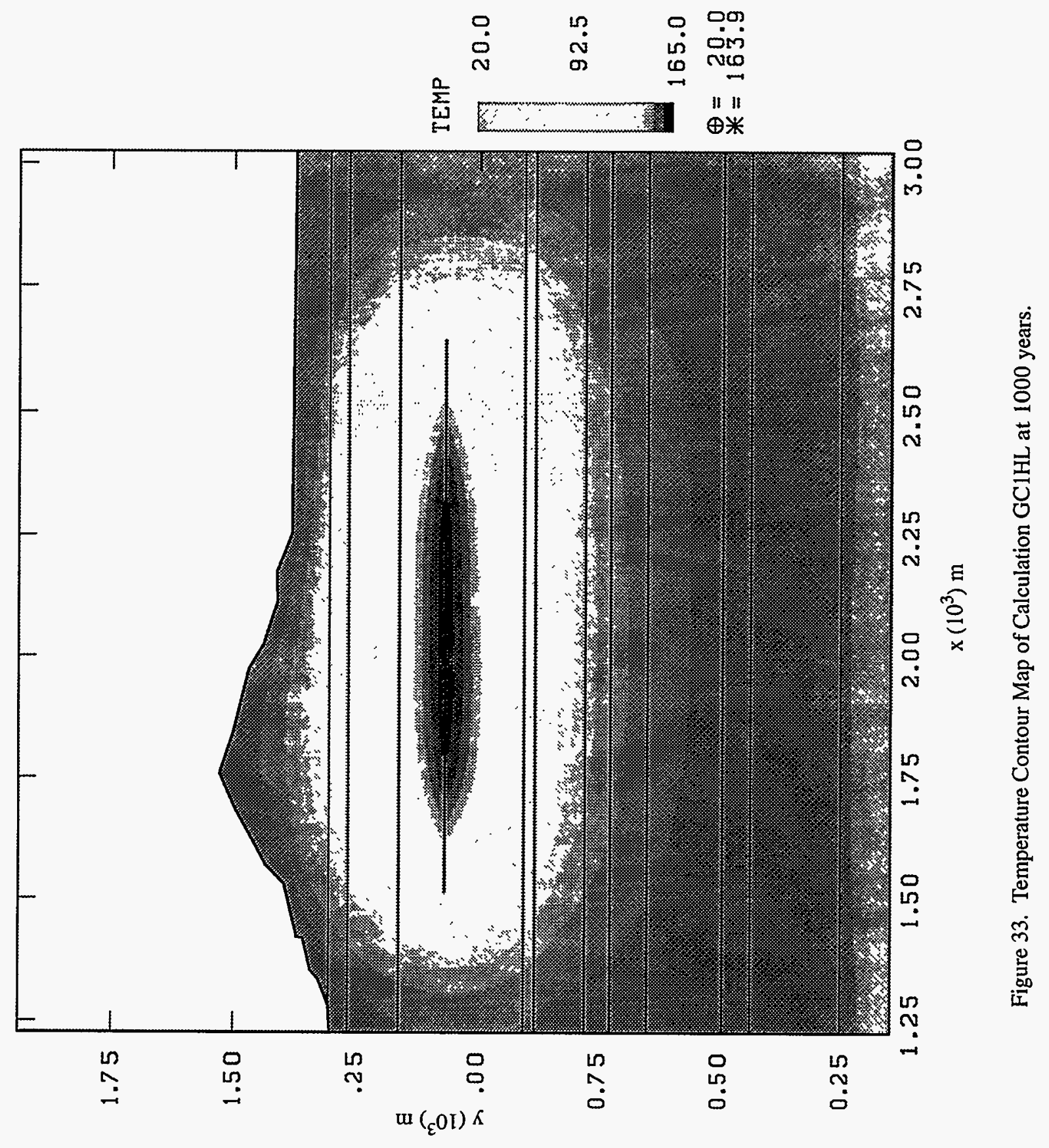




\subsection{Comparison of Results}

Results from Section 3.1 are compared to assess the differences in predicted thermal response for different thermal property models. Comparisons were grouped to provide information regarding the impact of modeled geologic structure and thermal property representations on host-rock response. Comparisons are based on calculated temperature differences at each node for the entire computational mesh, and are presented in color contour-map form. As in the results section, only the near-field portion of the temperature differences are presented. Due to the complexity of the thermal models, comparison of results are qualitative and should not be taken out of context.

Temperature differences were calculated using a post-processing code called EXOREAD (Appen$\operatorname{dix}$ B). This program reads the output EXODUS [6] binary data files from two calculations, and calculates the temperature difference at each node. This result is then written out using EXODUS binary data format for graphical display. Only two calculations required special handling, the comparison of LCRHL with LCRSL. In this case, the code MERLIN-II [14] was needed to transpose results from calculation LCRSL onto the horizontal-layer mesh so that a temperature difference calculation could be preformed directly with EXOREAD. To be consistent with the presentation of results section (Section 3.1), temperature differences are shown at four different times during the 1000 year transient: 50 years, 100 years, 500 years, and 1000 years. The expression used to calculate temperature difference is described below:

$$
\Delta \text { Temperature }=\text { Calculation } \mathrm{A}-\text { Calculation } \mathrm{B}
$$

A negative temperature difference indicates that Calculation A predicts lower temperatures compared to Calculation B. Positive temperature differences indicate the opposite.

Noticeable similarities were observed between the geostatistical thermal property models GC1HL and the sloped layer, homogeneous, temperature-independent thermal property model LCRSL. Details of the similarities are discussed Section 3.2.3.

\subsubsection{Geologic Structure Comparisons}

Comparison calculations UCRHL-LCRHL, LCRHL-LCRSL, and UCRHL- GC1HL were used to qualitatively assess the impacts of resolution in geologic structure on predicted thermal response. Table 10 summarizes the maximum and minimum temperature differences and the times at which they occur for each of these comparative calculations.

Table 10. Geologic Structure Comparisons, Maximum and Minimum Temperature Difference and Times at Which They Occur.

\begin{tabular}{|c|c|c|c|c|}
\hline Calculation Name & $\begin{array}{c}\text { Min Temp-Diff } \\
\left({ }^{\circ} \mathrm{C}\right)\end{array}$ & $\begin{array}{c}\text { Time at Which Min } \\
\text { Temp-Diff Occurs }\end{array}$ & $\begin{array}{c}\text { Max Temp-Diff } \\
\left({ }^{\circ} \mathrm{C}\right)\end{array}$ & $\begin{array}{c}\text { Time at Which Max } \\
\text { Temp-Diff Occurs }\end{array}$ \\
\hline \hline UCRHL - LCRHL & -19.19 & 2880 years & 10.81 & 1440 years \\
\hline LCRHL - LCRSL & ------- & --- & -- & - \\
\hline UCRHL - GC1HL & -23.57 & 3200 years & 14.62 & 800 years \\
\hline
\end{tabular}


Comparative calculation LCRHL-LCRSL shown in Table 10 contains no entries for maximum and minimum temperature difference due to a small signal-to-noise ratio caused by large temperature differences on the boundary of the horizontal mesh. These large temperature differences were not the result of calculation comparison but are an artifact of the MERLIN-II [14] interpolation of sloped-layer mesh results onto the horizontal-layer mesh. Since the boundary temperature differences are not due to the numerical solution of the heat conduction equation, they do not propagate into the mesh and the near-field portion of the mesh is unaffected. The temperature difference contour maps for LCRHL-LCRSL do contain useful information because only the nearfield portion of the mesh is shown.

Comparison UCRHL-LCRHL assesses differences in temperature predictions between a single homogeneous material temperature-independent thermal property model and a uniformly layered homogeneous temperature-independent thermal property model. Section 2.4.2 contains a full description of the thermal property models that were used for each simulation.

Temperature difference results for simulations UCRHL-LCRHL are presented in Figures 34 through 37 . At early simulation times (Figure 34 ), the thermal front generated by repository decay heat is contained within thermal/mechanical unit TSw2 and temperature differences are small (less than $4^{\circ} \mathrm{C}$ ). This result is expected because both simulations used TSw 2 thermal properties in this thermal/mechanical unit. As the simulation progresses, the thermal front moves beyond the TSw2 boundary (Figures 36 and 37), temperature differences become larger. As negative-temperature difference contours expand outward from the repository, they are bounded by positive-temperature difference contours. The Calico Hills non welded tuff below the repository and the Paintbrush non welded tuff above the repository are more insulating compared to other layers and heat flow is restrict for the layered thermal model causing simulation UCRHL to predict higher temperatures in these regions. These two relatively insulating layers, both above and below the repository, have a noticeable effect on temperature predictions.

Based on these results, the choice to increase the resolution of the geologic structure by changing from a homogeneous single material model to a uniformly layered model should be evaluated carefully. The strengths and weaknesses of both modeling approaches must be considered. For example, if a single material model is chosen, analytical solutions are available that allow for the assessment of such engineered aspects as repository layout and waste stream emplacement on host-rock response. If layout and waste stream are not the focus of the study, then numerical solutions afford the analyst the ability to model the geologic structure in more detail. As shown in Reference 15, the effect of eliminating resolution of the repository layout and waste stream emplacement is noticeable (on the order of $10^{\circ} \mathrm{C}$ in Reference 15). For this particular comparison, the majority of the observed temperature differences are on the order of $10^{\circ} \mathrm{C}$. The analyst must therefore determine whether resolution of the geologic or the engineered structure is most important to the questions being addressed.

Given that the analyst chooses to pursue resolution of the geologic structure, it must be recognized that a uniformly layered structure is not particularly representative of the Yucca Mountain site. A more realistic representation would involve the modeling of discontinuous, sloping layers.

Results of comparison LCRHL-LCRSL assess the difference in host-rock response between two different layered thermal/mechanical configurations, horizontal layer stratigraphy versus sloped layer stratigraphy with the inclusion of fault zones. Each simulation used identical homogeneous temperature-independent thermal properties but the thicknesses and slopes of each layer were dif- 
ferent. To better understand results of this comparison refer to Figures 6 and 9, which show the differences between the thermal/mechanical configurations for the two meshes.

Temperature-difference contour maps for LCRHL-LCRSL are shown in Figures 38 through 41. At early times, predicted temperature differences are spread out and sporadic, shifting from large negative to small positive temperature differences. At the crest of the upper surface of the mesh, large positive temperature differences occur which are an artifact of mesh interpolation. During early simulation times the thermal front has not yet moved beyond the thermal/mechanical unit TSw 2 and both meshes share the same thermal properties. One would expect to see small temperature differences as a result, but this is not the case. The early time temperature differences (Figure 38) appear to be the result of a combination of mesh interpolation error and errors due to differences in mesh density. Inaccuracies caused by mesh interpolation and differences in mesh density make interpretation of comparative results difficult at early times.

Simulation times greater than 100 years (Figure 39 and 40), produce temperature-difference contours that are less random and have defined sloped regions of both large-positive and large-negative temperature differences. The light blue contour just below the repository (Figure 39) shows large-negative temperature differences indicating that simulation LCRHL predicts higher temperatures compared to LCRSL. In this region, because of the sloped layers, simulation LCRSL uses the thermal properties of CHnlv (Figure 6) and simulation LCRHL uses thermal properties of TSw2 (Figure 9), which has a 40 percent larger thermal conductivity, thereby explaining the large negative temperature differences. The other large negative region located between thermal/ mechanical units TCw and PTn can be explained using the same logic. The large positive region below thermal/mechanical unit TSw2 (Figure 39) is caused by the insulating effects of thermal/ mechanical unit CHn1v. CHn1v is more than twice the thickness in simulation LCRSL than that used in LCRHL. Because of the larger thickness of thermal/mechanical unit CHn1v used in simulation LCRSL, simulation LCRHL predicts higher temperatures in this region.

It is clear from the above discussion that a sloped-layer model is likely to provide a better approximation of host-rock response than a homogeneous, horizontal-layered model. Unfortunately, the numerical complexities associated with generating and running a discontinuous sloped-layer model tend to limit this approach to two-dimensional simulations. An alternative that appears promising for two-dimensional simulations as well as extensions to three-dimensional thermal simulations is the method developed for this study which maps geostatistical property distributions onto finite element meshes as the basis for the material model.

As will be discussed in Section 3.2.3, the basic layered structure that is the basis of the slopedlayer model is captured by the geostatistical realization. The geostatistical realization goes one step further, however, in its ability to capture variability within a given layer. Thus, as a final evaluation of structure on predicted temperature profiles, the UCRHL and GC1HL models were compared (see Figure 42 through 45). To understand the results of this comparison, refer to thermal property maps shown in Figure10.

The blue contours at each end of the repository (Figure 42), indicate regions where simulation UCRHL predicts lower temperatures, or is more efficient at removing heat from the repository than simulation GC1HL. These results appear to be consistent with the thermal properties shown in Figure 10. The blue contour expands outward as a function of simulation time and is always bounded by red contours both above and below, representing positive temperature difference regions (Figure 43). The red contour regions are caused by the insulating effects of the Calico 
Hills non welded tuff (CHn1z) below the repository and the Paintbrush non welded tuff (PTn) above the repository (blue regions shown in Figure 10 a). The insulating layers restrict heat flow causing simulation UCRHL to predict lower temperatures in these regions.

It must be recognized that geostatistical simulations are non-unique. A number of equally valid property distributions can be obtained and should be analyzed when feasible. For this study, only one geostatistical simulation of thermal property distributions was run.

The comparisons presented in this section provide the analyst with a qualitative understanding of the impact of geologic structure on repository-temperature predictions. When compared to the simplest approach of assuming a single material representation of Yucca Mountain, calculations that use increased geologic resolution as the basis for their material models result in noticeable differences in predicted temperatures. The significance of these differences which are not discussed here should be addressed in terms of their effect on overall repository system performance in future work.

\subsubsection{Thermal Property Comparisons}

In addition to assessing the impacts of geologic structure, functional representations of thermal properties were also evaluated in this study. Comparison UCRHL-UCG4HL and LCRHLLVRHL provide qualitative insight into the effects of weighting schemes and temperature dependencies on predicted thermal response. Table 10 summarizes the maximum and minimum temperature differences and the times at which they occur for both of these comparative calculations.

UCRHL-UCG4HL assesses the difference in predicted host-rock response between two singlematerial homogeneous thermal models both using temperature-independent thermal properties. Simulation UCRHL used thermal properties for thermal/mechanical unit TSw2 and simulation UCG4HL used thermal properties that were derived from weighting functions (see Section 2.4.1) using the USW G-4 stratigraphy.

Table 11. Thermal Property Comparisons, Maximum and Minimum Temperature Difference and Times at Which They Occur.

\begin{tabular}{|c|c|c|c|c|}
\hline Calculation Name & $\begin{array}{c}\text { Min Temp-Diff } \\
\left({ }^{\circ} \mathrm{C}\right)\end{array}$ & $\begin{array}{c}\text { Time at Which Min } \\
\text { Temp-Diff Occurs }\end{array}$ & $\begin{array}{c}\text { Max Temp-Diff } \\
\left({ }^{\circ} \mathrm{C}\right)\end{array}$ & $\begin{array}{c}\text { Time at Which Max } \\
\text { Temp-Diff Occurs }\end{array}$ \\
\hline \hline UCRHL - UCG4HL & -24.07 & 106 years & 9.22 & 116 years \\
\hline LCRHL - LVRHL & -7.99 & 5000 years & 28.57 & 92 years \\
\hline
\end{tabular}

Comparative results for calculations UCRHL-UCG4HL are presented in Figures 46 through 49. At early simulation times (Figure 46), the thermal front has not traveled beyond the thermal/ mechanical unit TSw2 and large-negative temperature differences are contained within this region. This result is consistent with the thermal property models that were used. Simulation UCRHL has a much higher thermal conductivity than UCG4HL (37 percent higher) and the heat capacities are roughly the same. Temperature differences are symmetrical about the repository and remain symmetrical until the thermal front interacts with the upper boundary (Figure 48). This symmetry is expected when comparing two different homogeneous, temperature-indepen- 
dent, thermal property models. At longer times (Figure 49), the largest temperature differences are still contained within in the region of the repository.

When applying analytical models to thermal design problems, the analyst is often limited to a homogeneous single-material model with constant properties. The analyst must therefore decide which set of properties to apply. Clearly the properties applied should be developed based on the question being asked. For example, If the analyst is interested in the response of the TSw3/CHn stratigraphic interface, modeling the entire mountain with the properties of TSw2 will likely result in temperature histories at the interface that are too low. A weighting scheme for the thermal properties may be necessary to obtain representative results. Alternatively, if the area of interest is contained within the TSw 2 unit, use of a weighted property description may be overly conservative. The time frame and the location of the feature of interest should be evaluated before choosing a set of material properties.

The next set of comparative results offers the best direct comparison of temperature-independent versus temperature dependent thermal property models. Figures 50 through 53 show results from comparison calculation LCRHL-LVRHL. Secondary effects caused by layered stratigraphy are reduced in this comparison because both thermal models have identical thermal properties in each thermal/mechanical unit for temperatures below $94^{\circ} \mathrm{C}$. Therefore, the comparative results shown here principally indicate differences caused by temperature-dependent thermal properties.

The largest temperature differences occur at early simulation times in regions of high heat loading near the repository (Figures 50 and 51 ). This can be explained by realizing that calculation LVRHL reaches its maximum temperature $\left(155^{\circ} \mathrm{C}\right.$ ) which is above the boiling-of-water transition phase at 71 years. Large amounts of energy have been used to vaporize rock pore water causing LVRHL to predict lower temperatures. As in comparison calculation UCRHL-UCG4HL, temperature differences are symmetrical about the repository and remain symmetrical until the thermal pulse interacts with the upper boundary of the mesh.

As is evident from the above discussion, the effect of pore-water boiling can have a significant effect on predicted thermal response. This effect could have design and performance assessment implications and should be addressed in more detail in future work. It is important to note, however, that the effect of temperature-dependent thermal properties presented in this study is based on the somewhat arbitrary modification of heat capacitance developed in Reference 16. Clearly, more realistic approximations of the impacts of pore-water boiling will be dependent upon such aspects as the distribution of hydrologic properties, saturation levels, and fracture-matrix interactions. These effects are beyond the scope of this work and the results presented in this section are aimed at making the analysts aware that functional dependencies appear important and should be considered whenever feasible.

\subsubsection{Comparison of Heterogeneous, Spatially Correlated Models with Homogeneous, Sloped-Layer Models.}

Because the homogeneous, sloped-layer finite-element mesh was developed specifically in an attempt to represent the actual geometric distribution of thermal/mechanical units at Yucca Mountain, it is instructive to compare how the geostatistically generated, heterogeneous thermal-prop- 
erty model compares to the layered, uniform-property caricature of the geology. A color-coded image representing the mapping of the geostatistical thermal conductivity model onto the slopedlayer mesh is presented in Figure 54. Details of how this mapping is performed are given in Appendix A.

Figure 54 represents the sloped finite-element mesh representation of the geostatistical model based on the single composite drill hole data, simulated with a 5,000 m range of spatial correlation (equivalent to the material-properties data of model GC1HL). The correspondence of the material-property "units" produced by the geostatistical simulations to the meshed representation of the thermal/mechanical property units shown in the original cross section $\mathrm{C}-\mathrm{C}$ [1] is excellent in the near-surface portions of the modeled region, where adequate conditioning data are available.

The TCw and PTn thermal/mechanical units, welded and nonwelded units respectively, are reproduced almost exactly. The low porosity $\mathrm{TCw}$ thermal/mechanical unit is represented in the geostatistical model by material of high thermal conductivity, color coded as mostly red pixels. In contrast, the high porosity PTn unit is simulated as a well-correlated thin band of low thermal conductivity values, shown mostly in blue. Below the PTn, is a large interval of high-conductivity material corresponding to the TSw 1 and TSw $2 / 3$ units. The conditioning porosity data have even induced a geostatistical representation of the difference in thermal conductivity values largely matching the distinction between TSw1 (lower conductivity) and TSw2/3 (higher conductivity). Moving vertically downward, a relatively thick interval of simulated low conductivity values corresponds to the nonwelded and poorly conductive $\mathrm{CHn}$ thermal/mechanical unit. The geostatistical algorithm did not explicitly attempt to capture the difference between zeolitic and vitric materials within the Calico Hills units, except as this distinction might be indicated by changes in porosity of the conditioning data. Below the level of the Calico Hills, a highly conductive interval corresponds to the welded portion of the Prow Pass Member of the Crater Flat Tuff (PPw), and less well-defined alternating nonwelded and welded intervals can be distinguished below that. Resolution of these units becomes increasingly poor downward, because the average finite-element mesh size increases into the far-field region, and the geostatistically generated thermal conductivity values contained within a single mesh element have been averaged to represent that entire region.

The continuity of the various geostatistically generated property units is excellent, as would be suggested from the strong spatial correlation imposed on the model (a variogram range of 5,000 $\mathrm{m})$. The match of distinct material-property changes with the deterministic linear contacts obtained from the C-C [2] cross section (Figure 1) is excellent, particularly in the eastern portion of the cross section, due in no small part because the principal conditioning data was derived from drill hole USW G-4, which is located slightly east of center on the model cross section. The westward thinning represented by the sloped finite-element layers is not exactly reproduced by the geostatistical property units, because the one composite drill hole was simply replicated three times at different locations on the cross section; thus, no lateral variation in unit thickness is possible for the geostatistical model. Most of the contact mismatches in the western part of the figure can be traced to this cause.

There is a prominent difference in the representation of the down-to-the-west normal faults near the western margin of the cross section. The surface locations of the fault offsets is faithfully preserved (by construction). However, the transformation from stratigraphic coordinates to real- 
world coordinates was accomplished by assuming the offset of the geostatistical property units was vertical (for the sake of programming expediency). Thus, it is not surprising that the fault offsets differ between the color-coded property values and the finite-element line outlines. The juxtaposition of contrasting material properties near the western end of the cross section is preserved. Were the modeled temperature profiles significantly influenced by these contrasts, more sophisticated coordinate transformation algorithms can be developed to capture non-vertical fault offsets.

Comparative results for LCRSL-GC1SL are presented in Figures 55 through 58. The largest temperature differences occur at early simulation times in regions of high heat loading near the repository. The largest positive temperature difference of $11.7^{\circ} \mathrm{C}$ occurs at 255 years, and the largest negative temperature difference of $-8^{\circ} \mathrm{C}$ occurs at 1000 years. The positive temperature differences are the result of variations in thermal properties in the thermal/mechanical unit TSw2. From Figure 54 , thermal conductivities vary from approximately $1.3 \mathrm{~W} / \mathrm{mK}$ to $2.0 \mathrm{~W} / \mathrm{mK}$. The comparison in general shows high correlation indicating the two models performed similarly. 
This page intentionally left blank. 


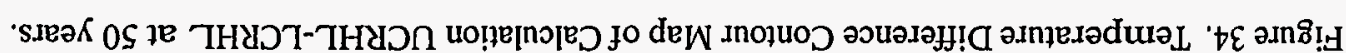

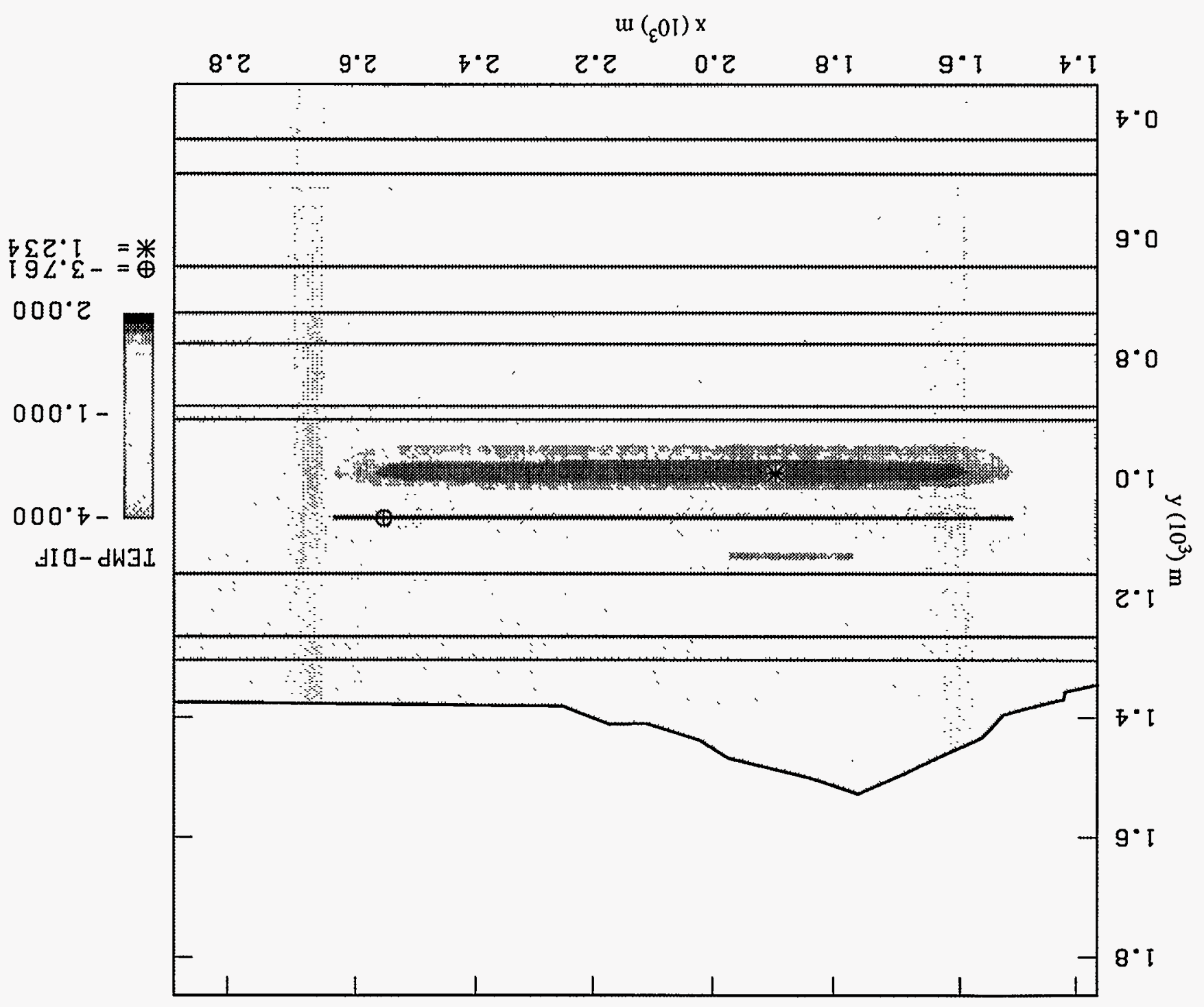




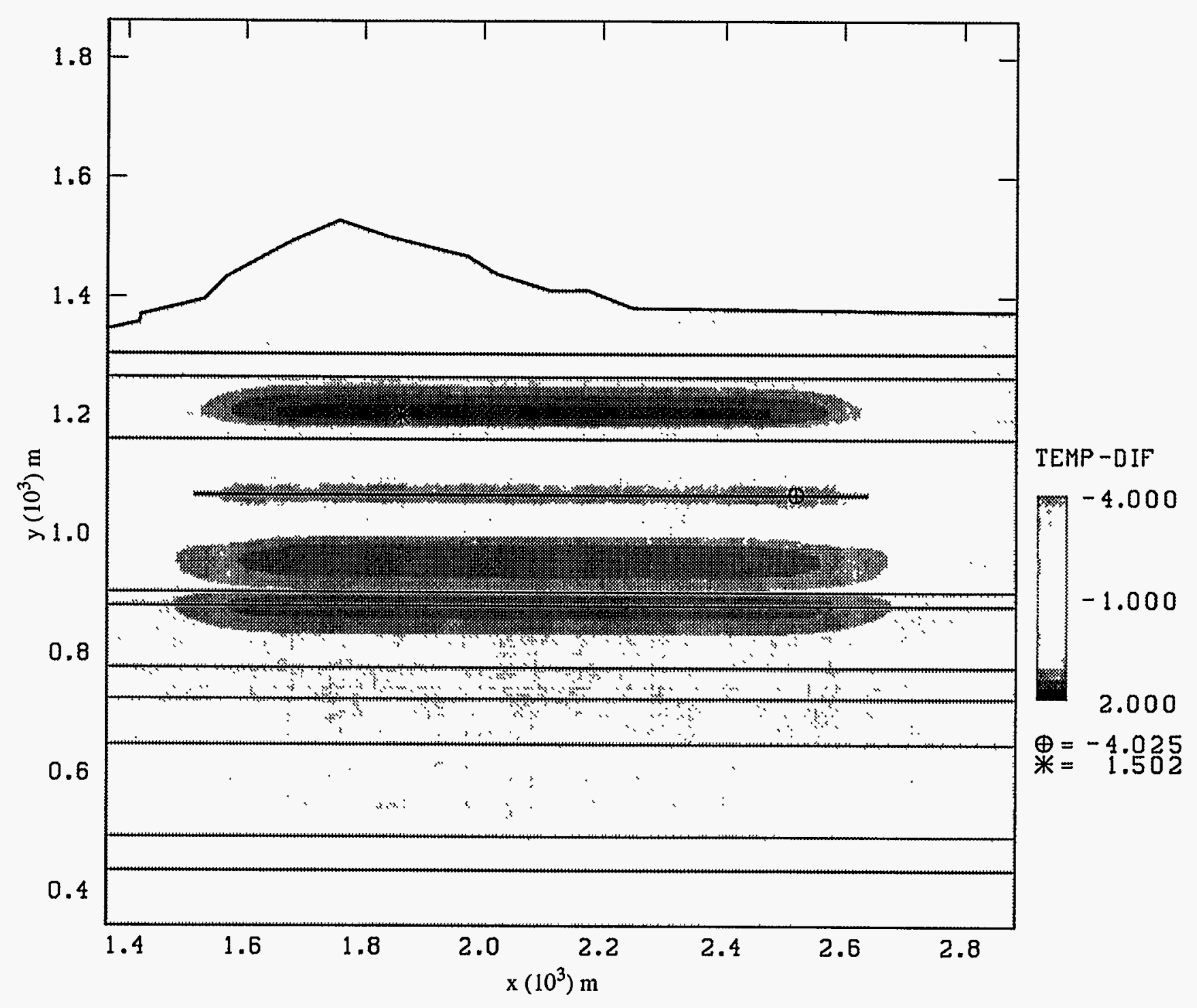

Figure 35. Temperature Difference Contour Map of Calculation UCRHL-LCRHL at 100 years. 


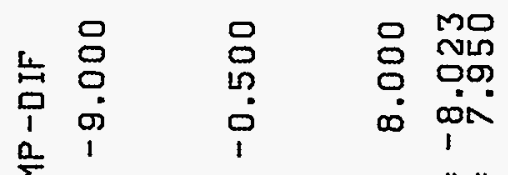

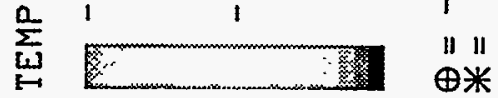

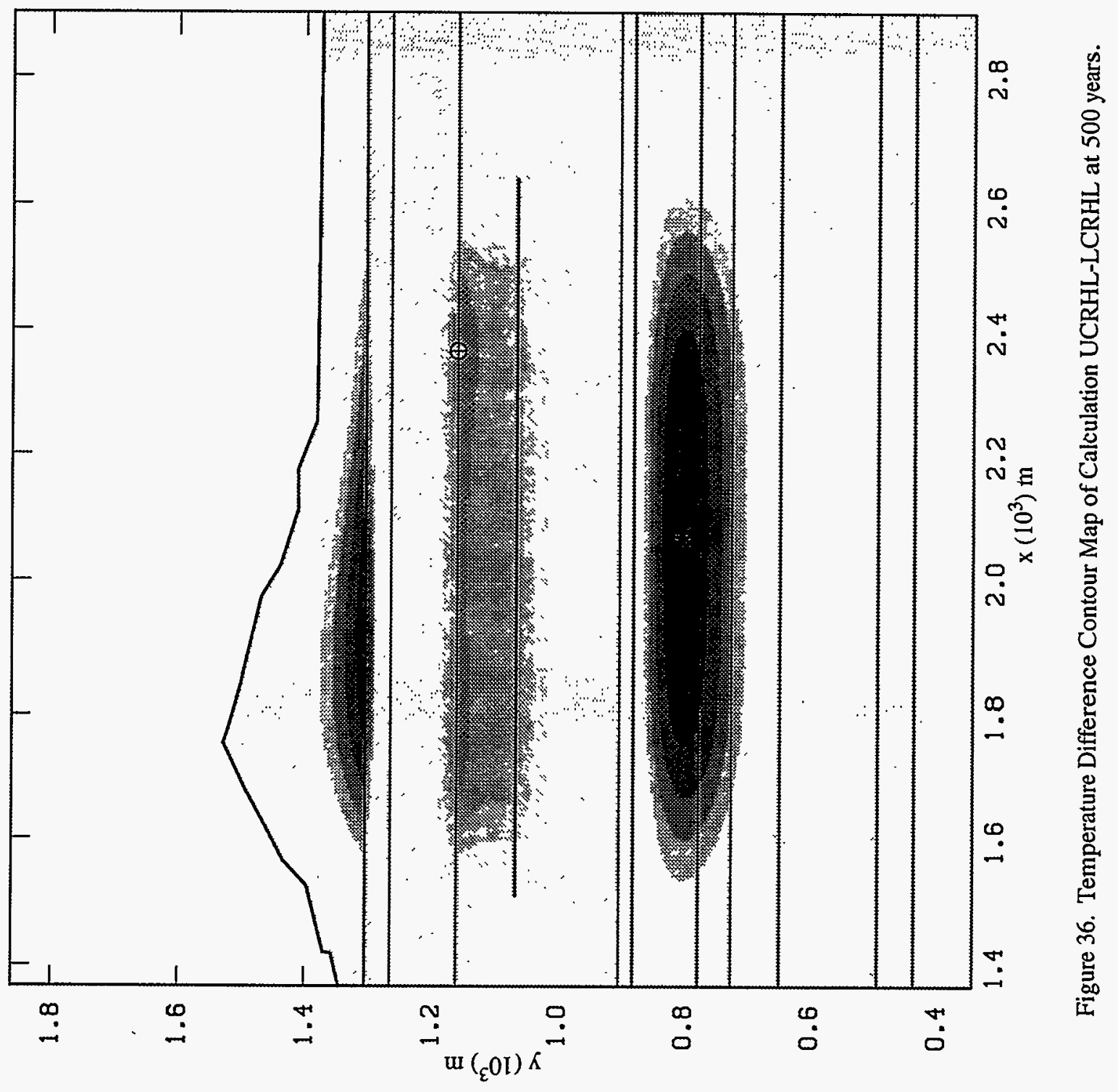




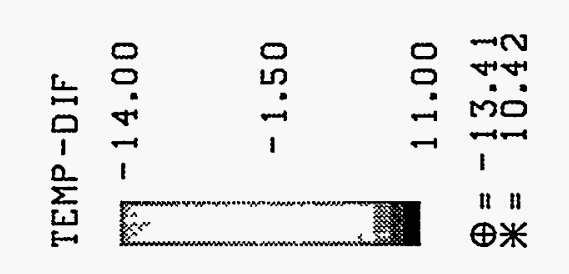

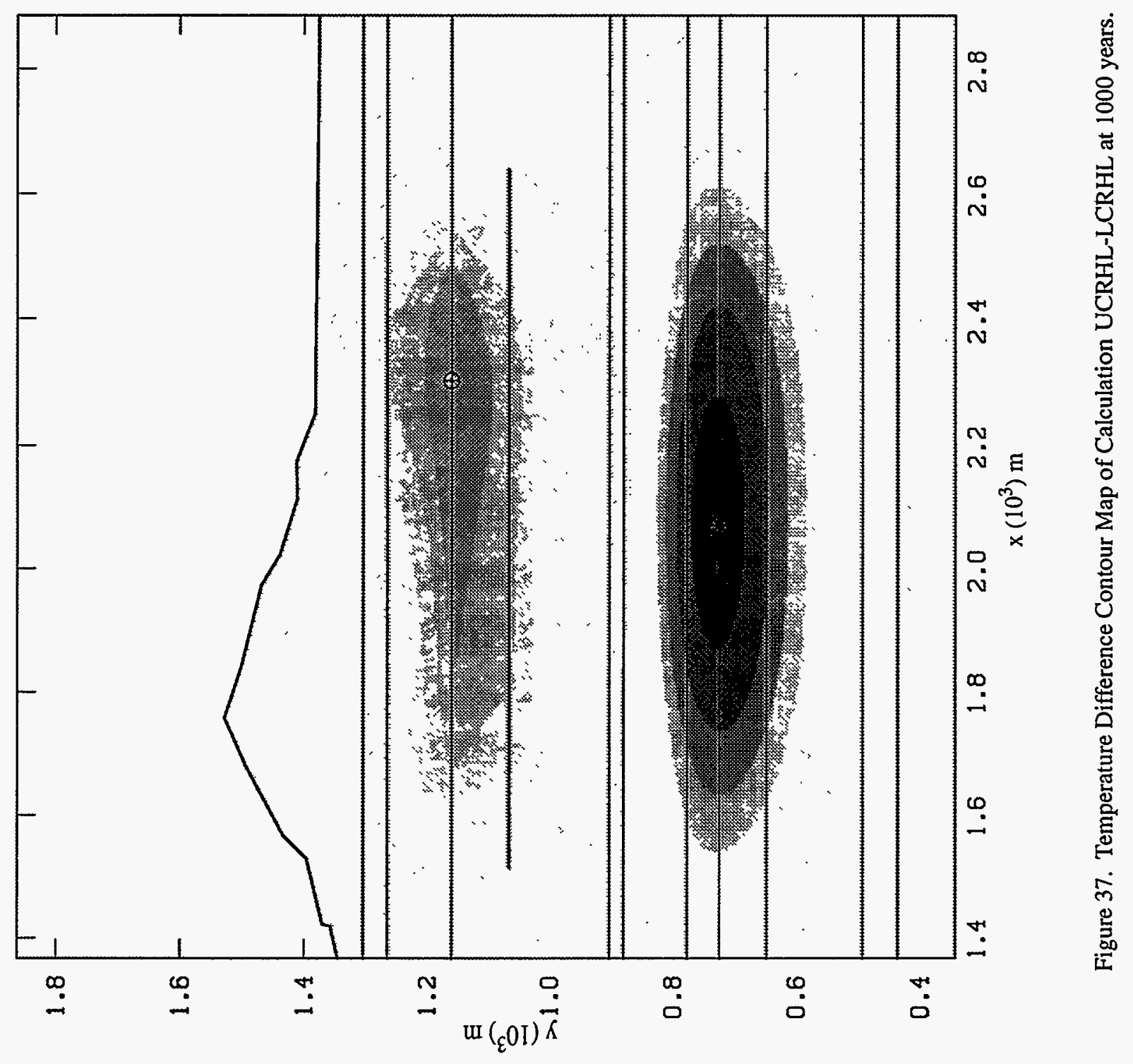




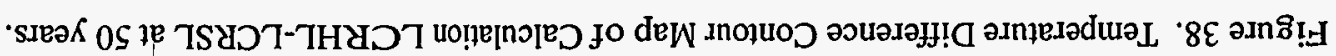

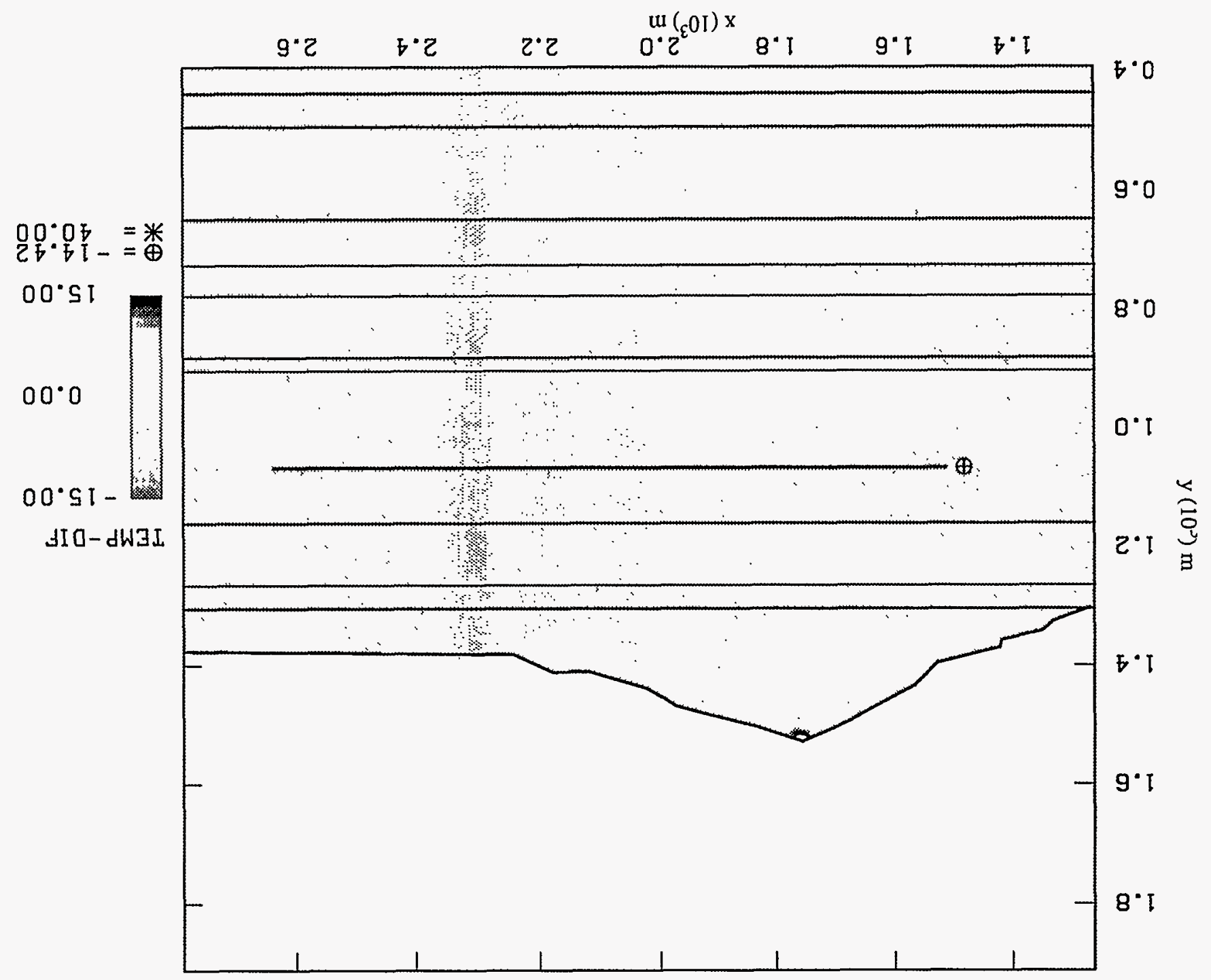




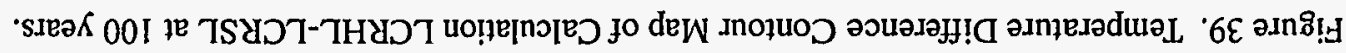

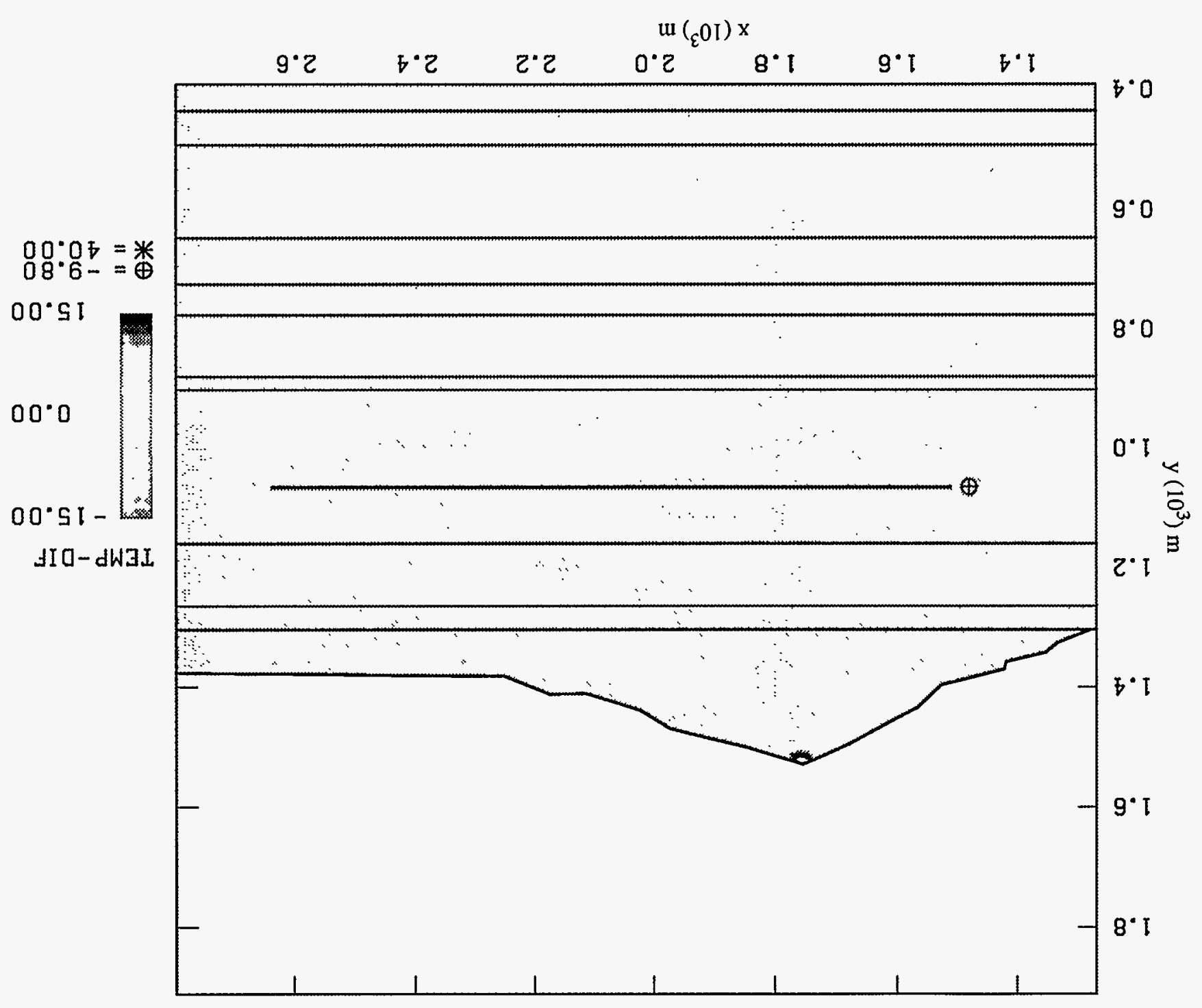




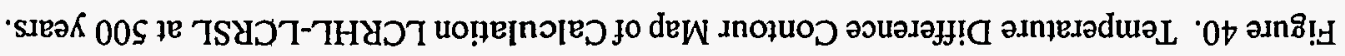

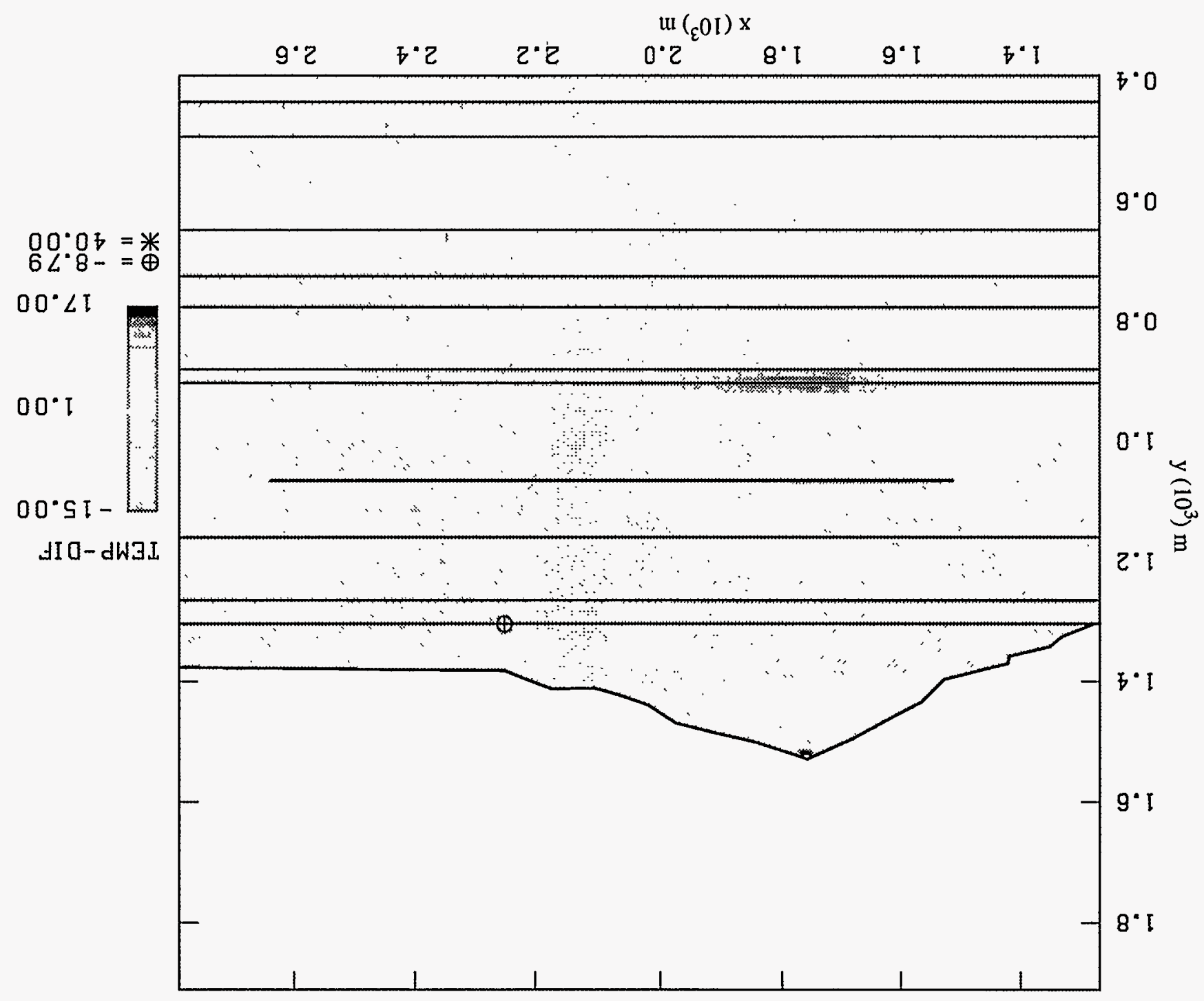




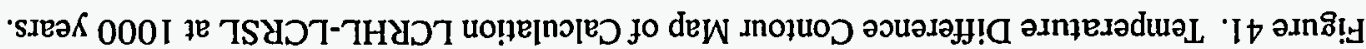

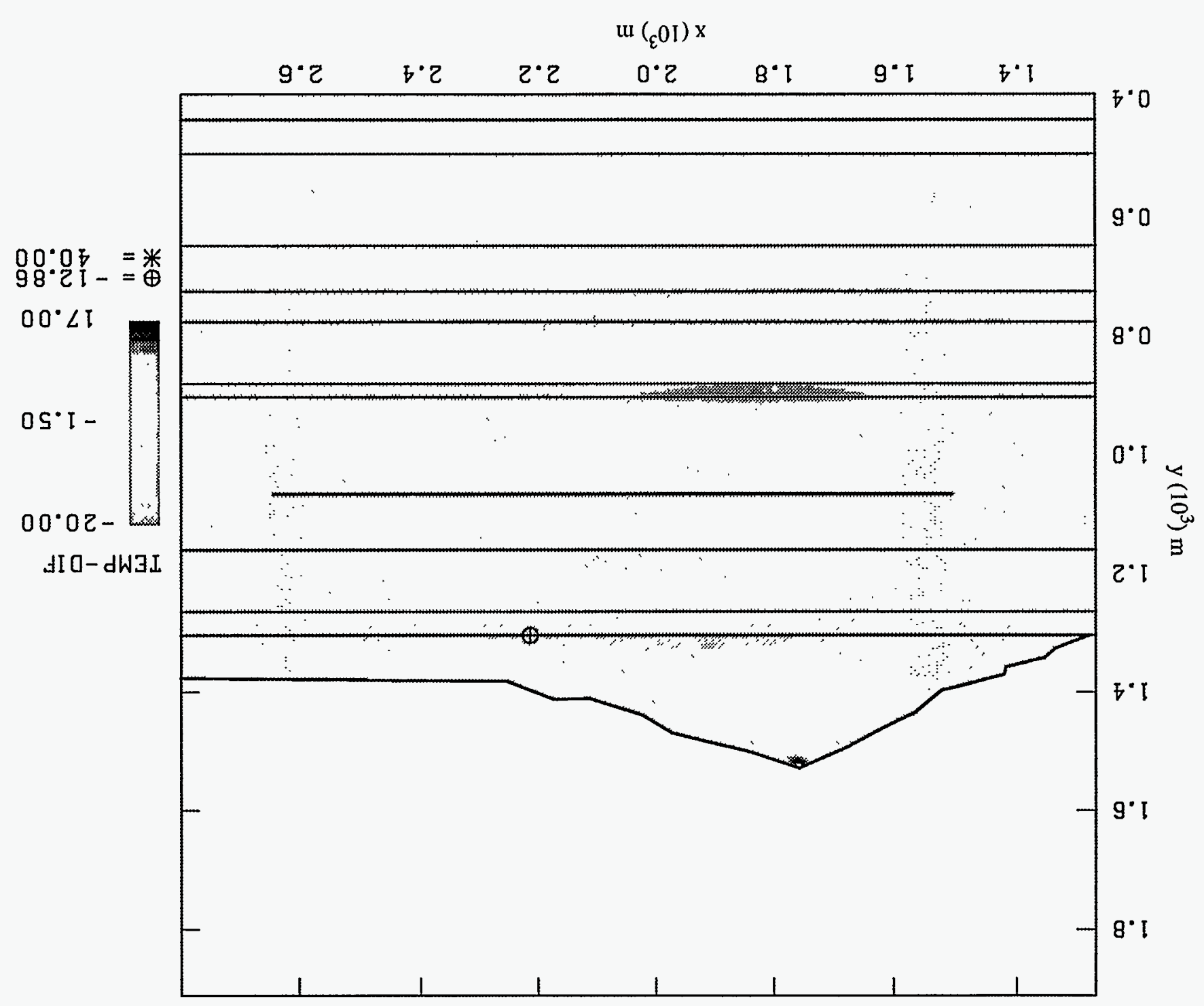



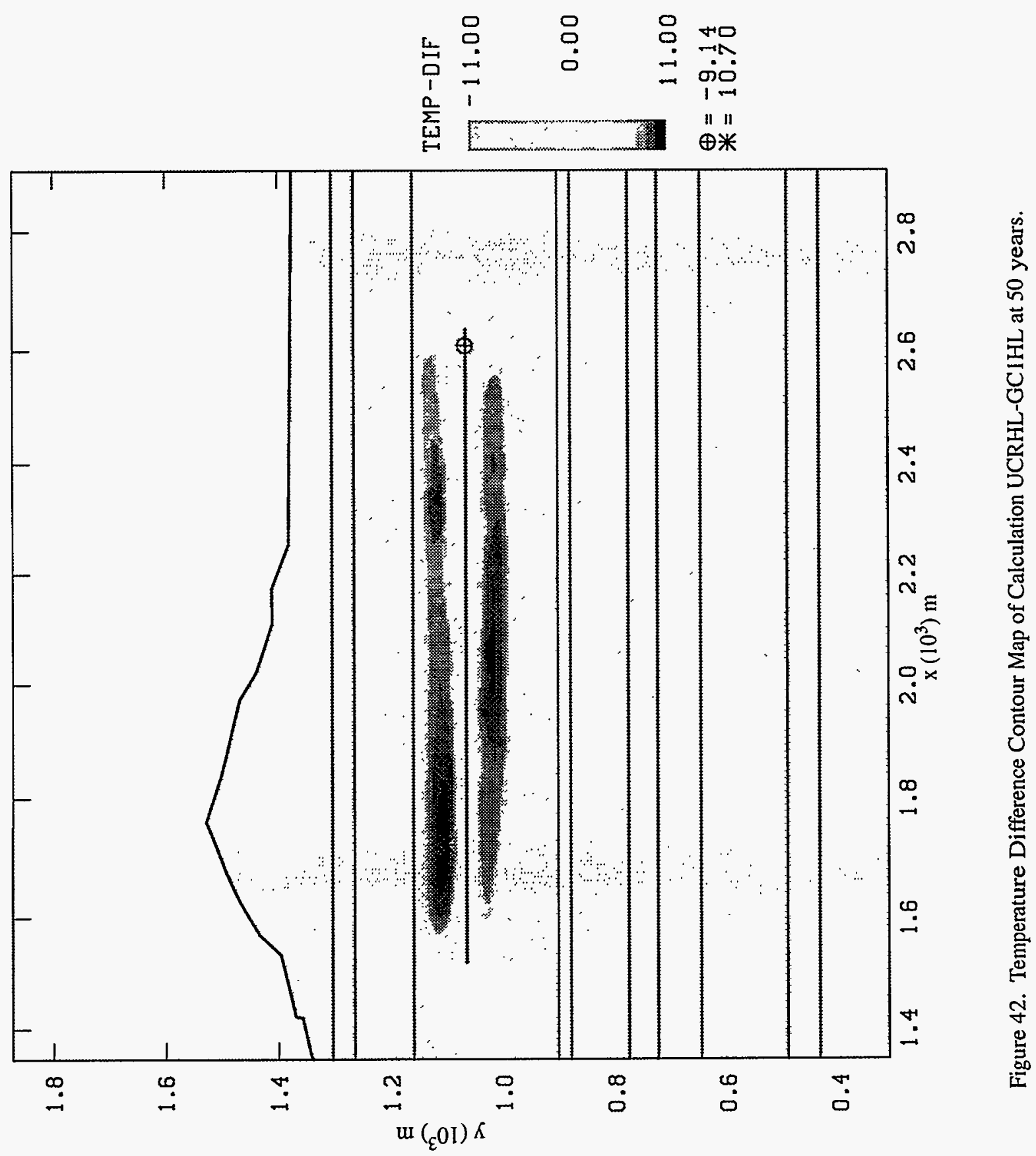


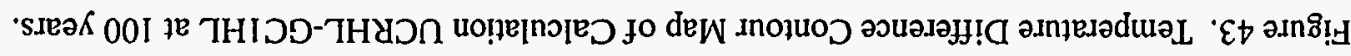

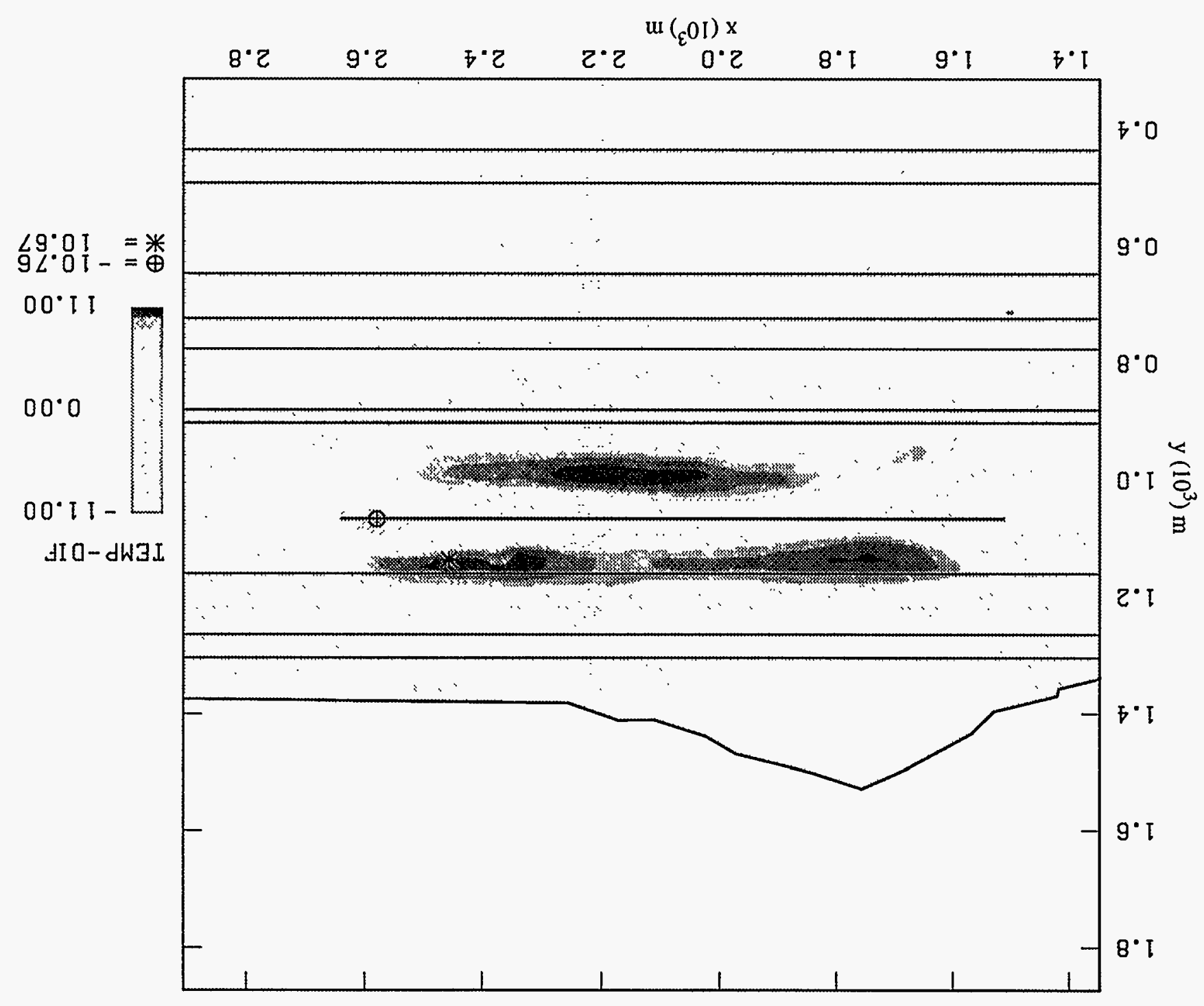




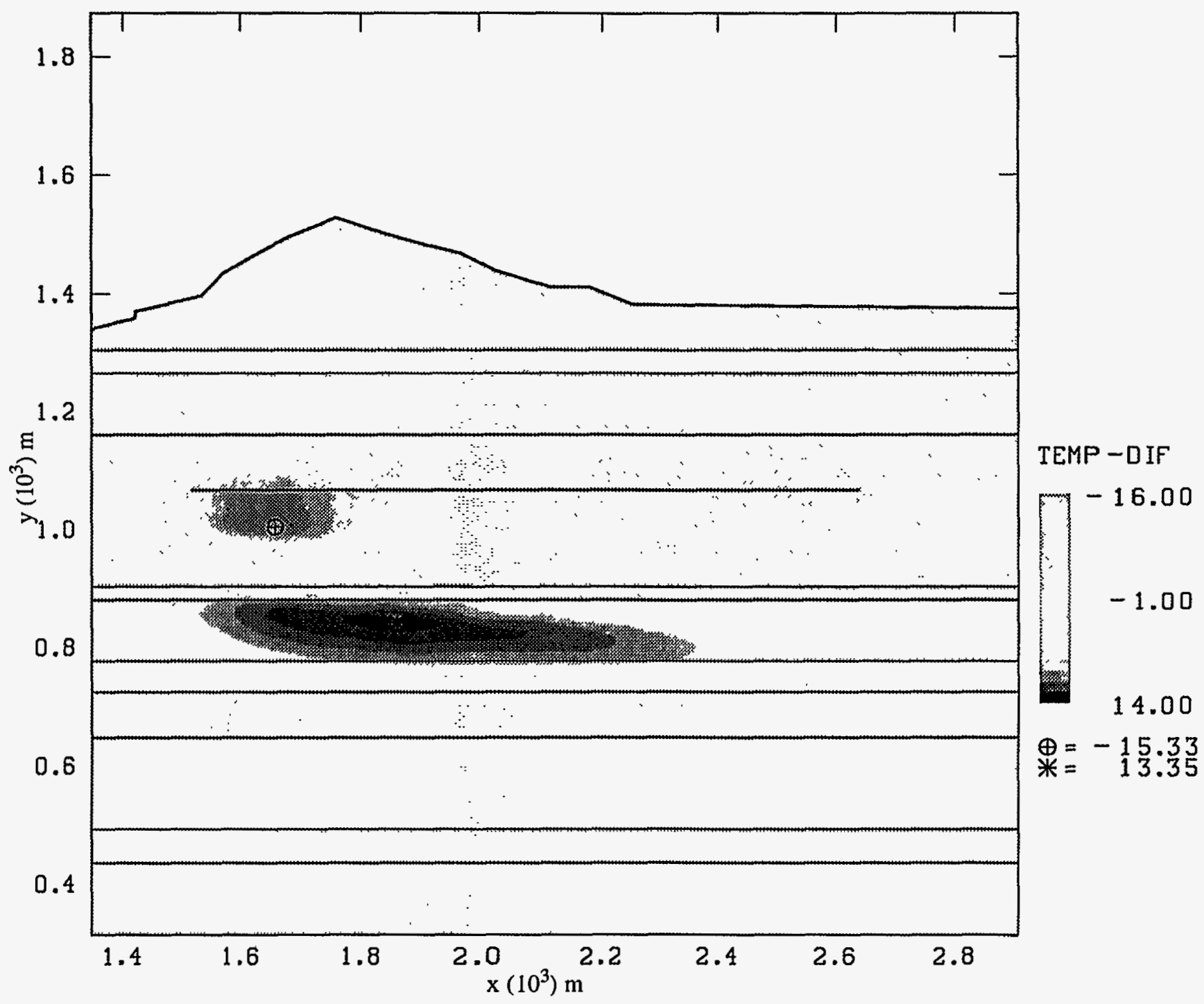

Figure 44. Temperature Difference Contour Map of Calculation UCRHL-GCIHL at 500 years. 


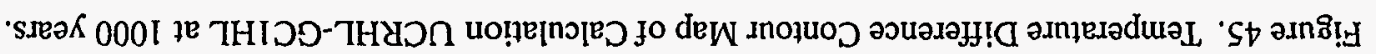

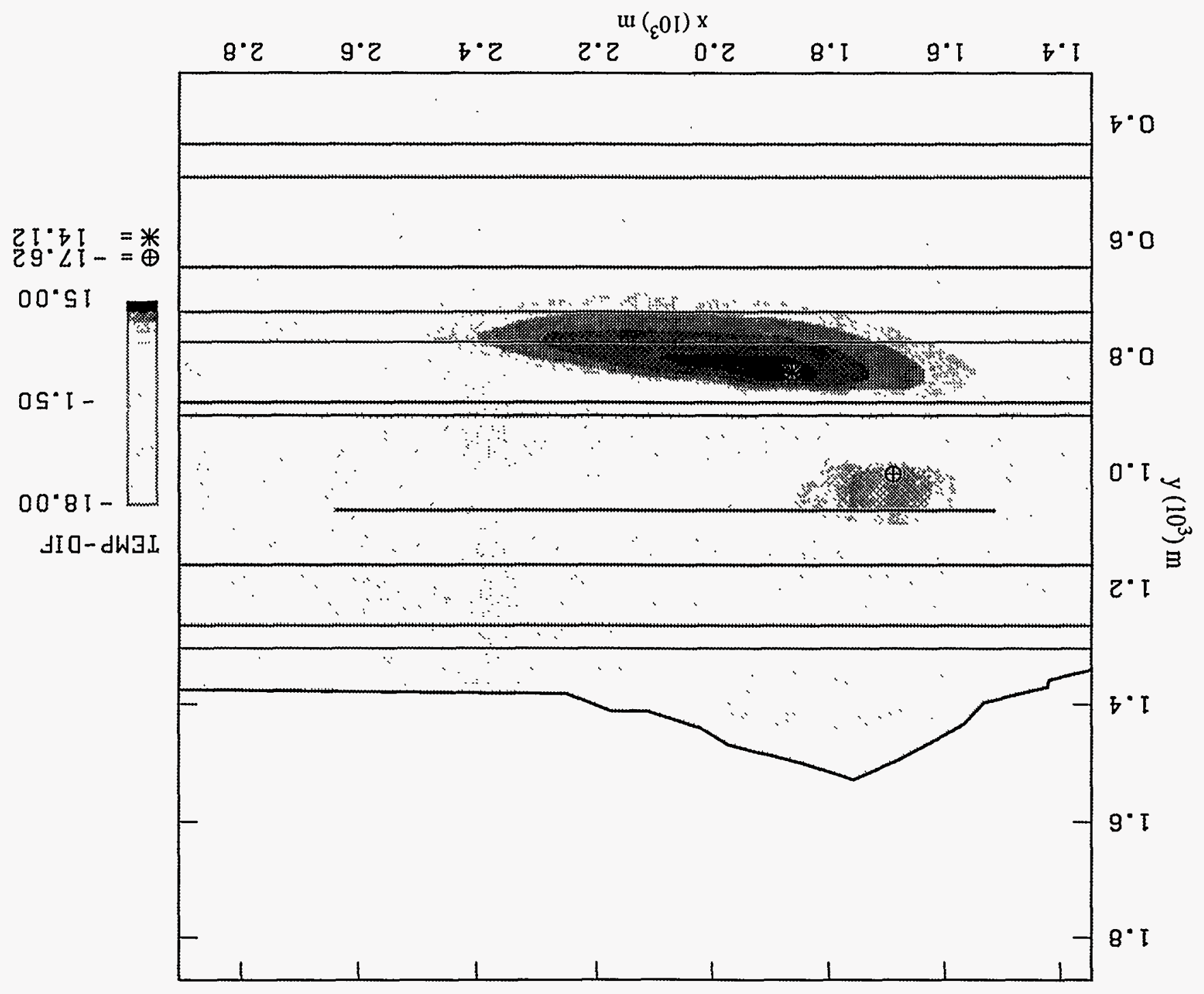




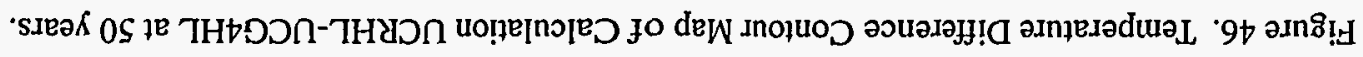

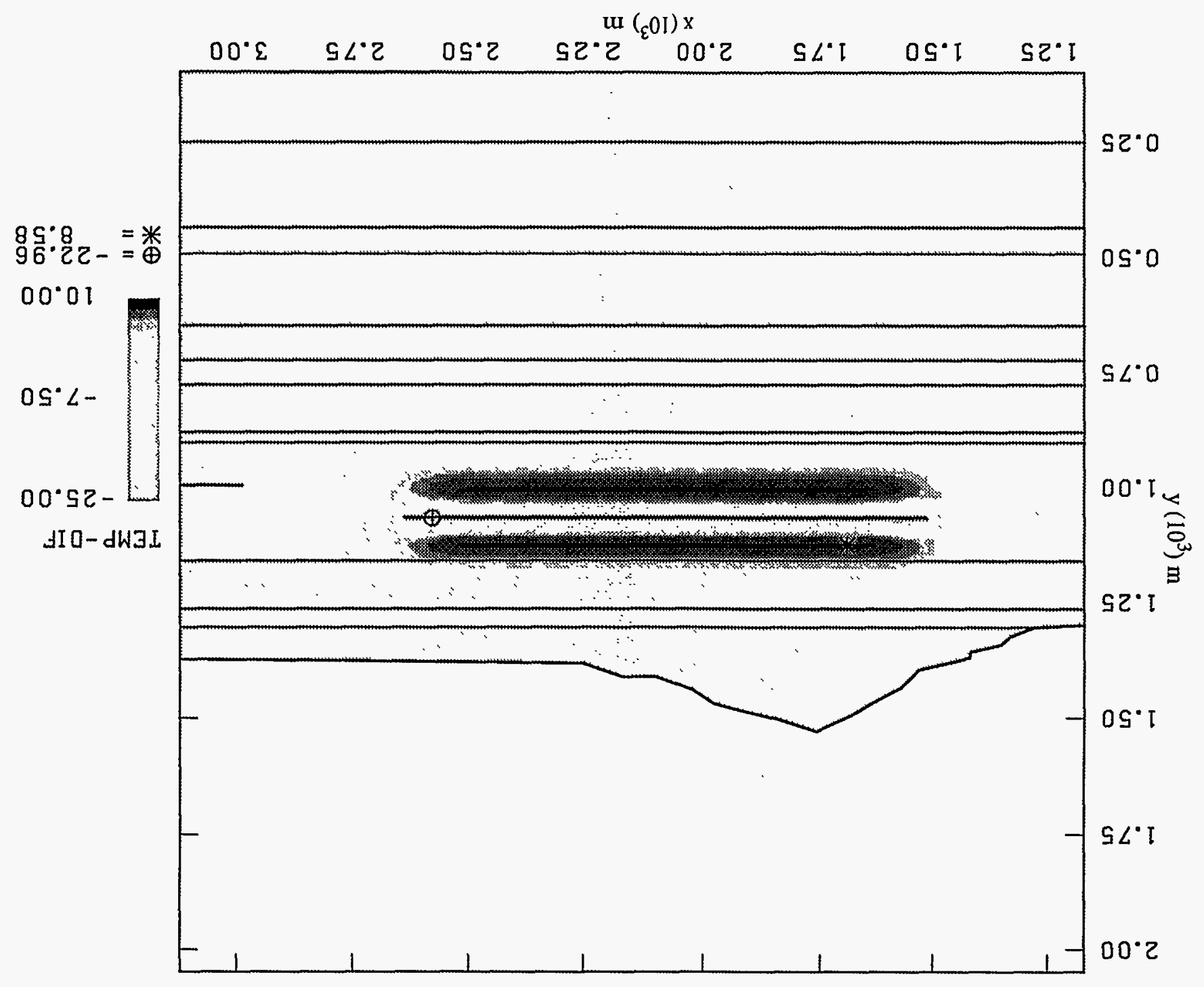




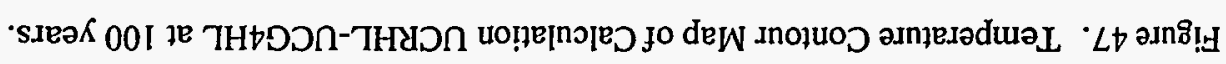

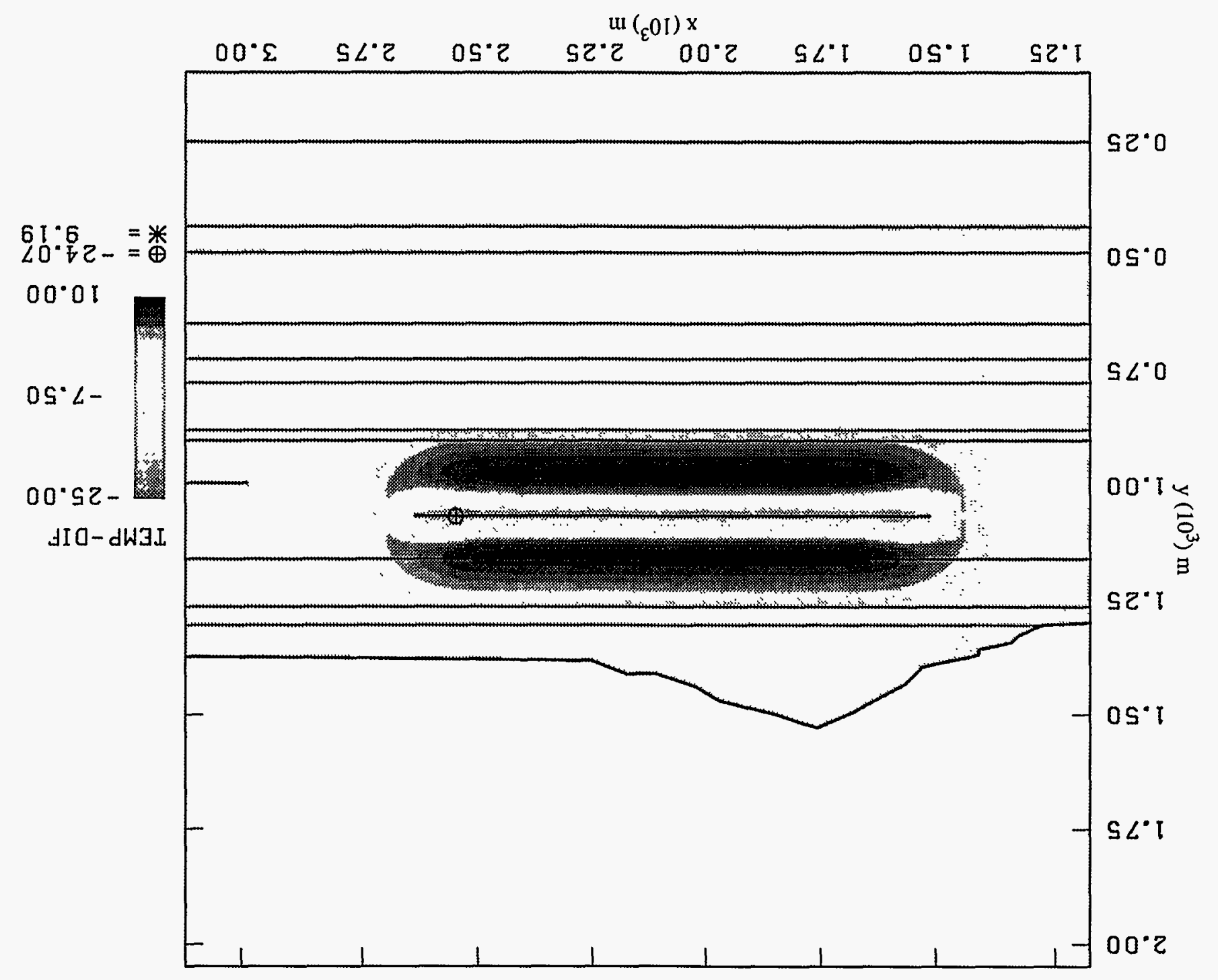




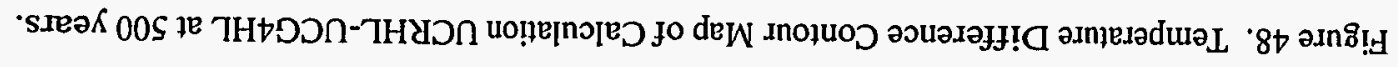

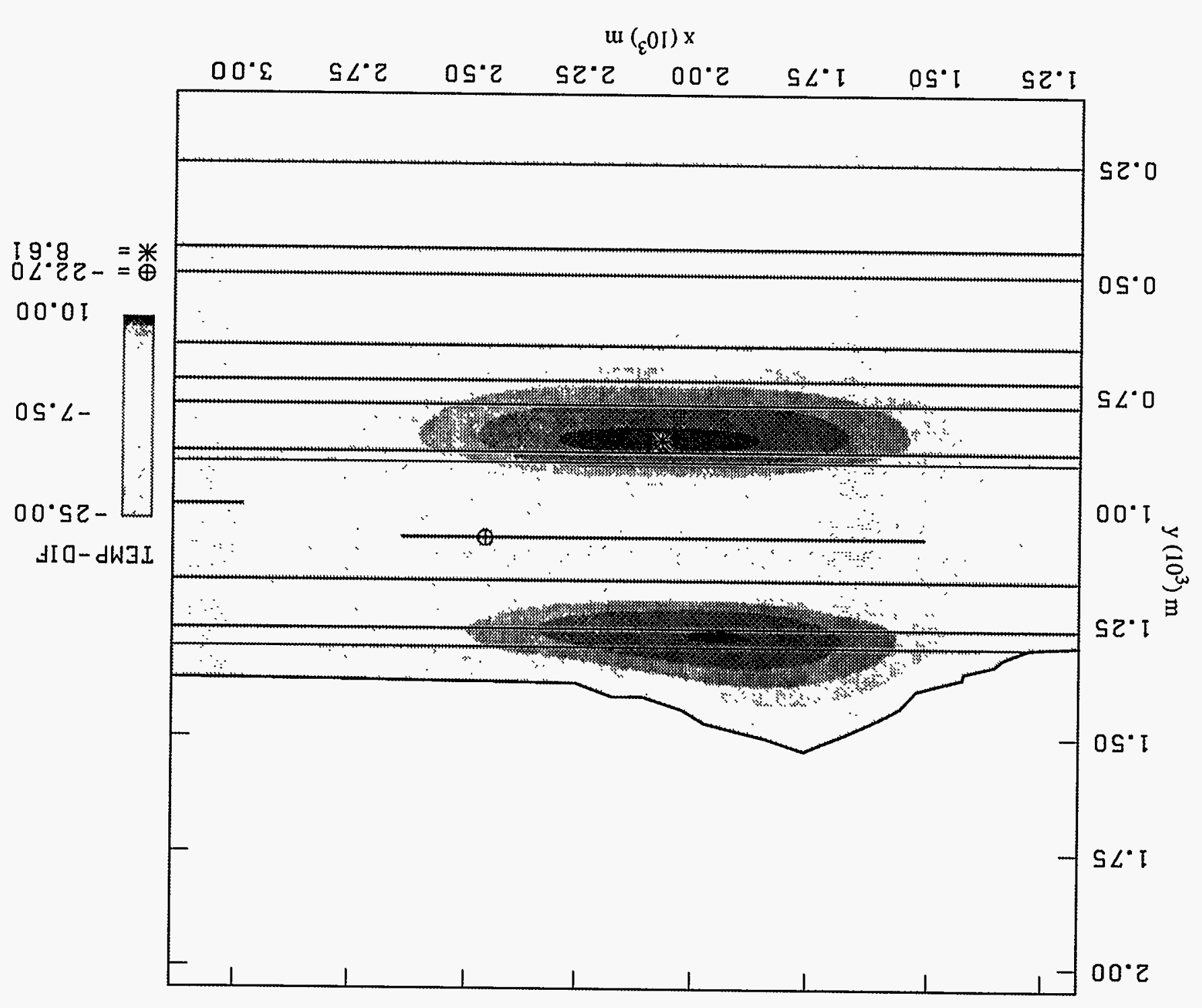




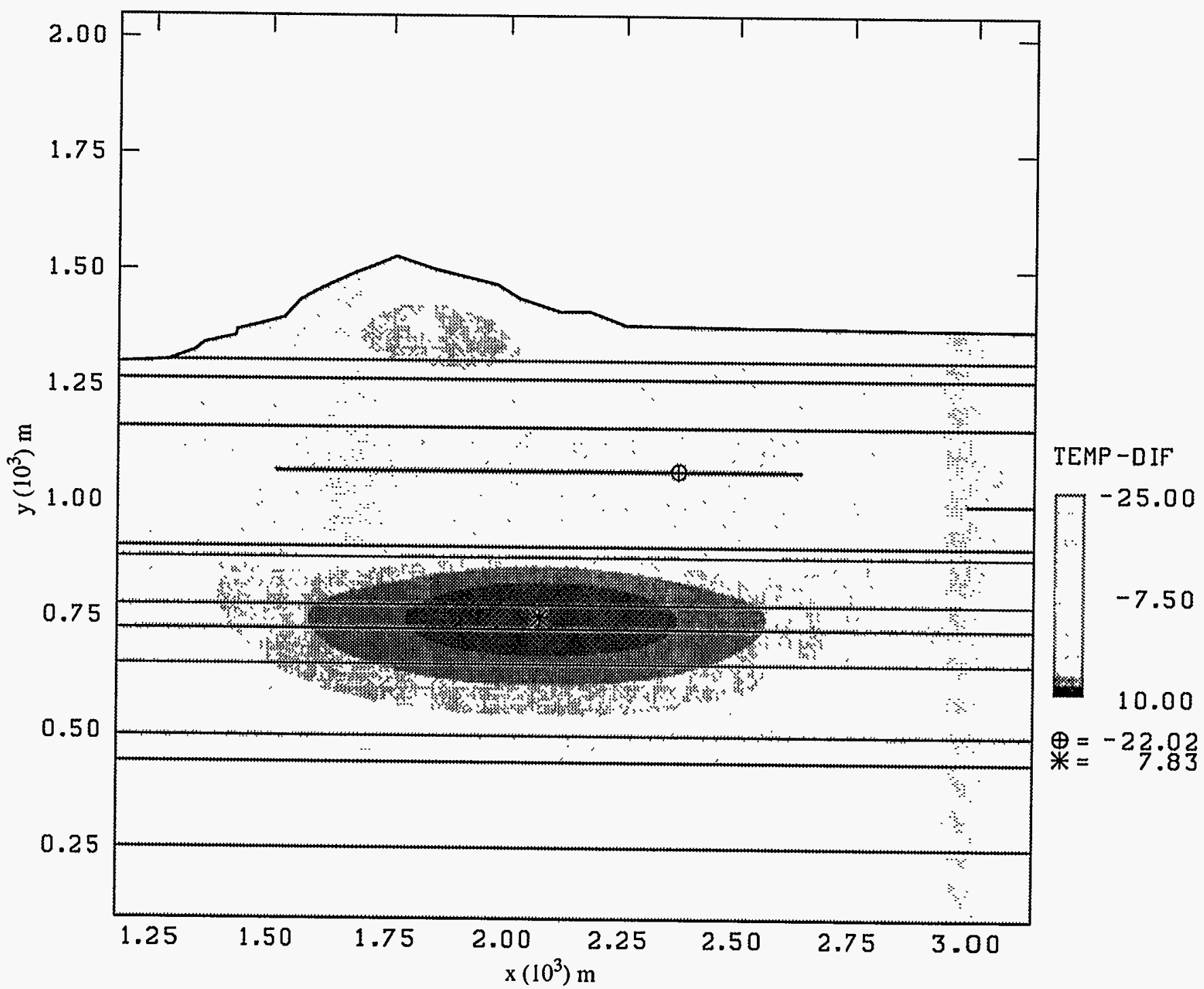

Figure 49. Temperature Difference Contour Map of Calculation UCRHL-UCG4HL at 1000 years. 


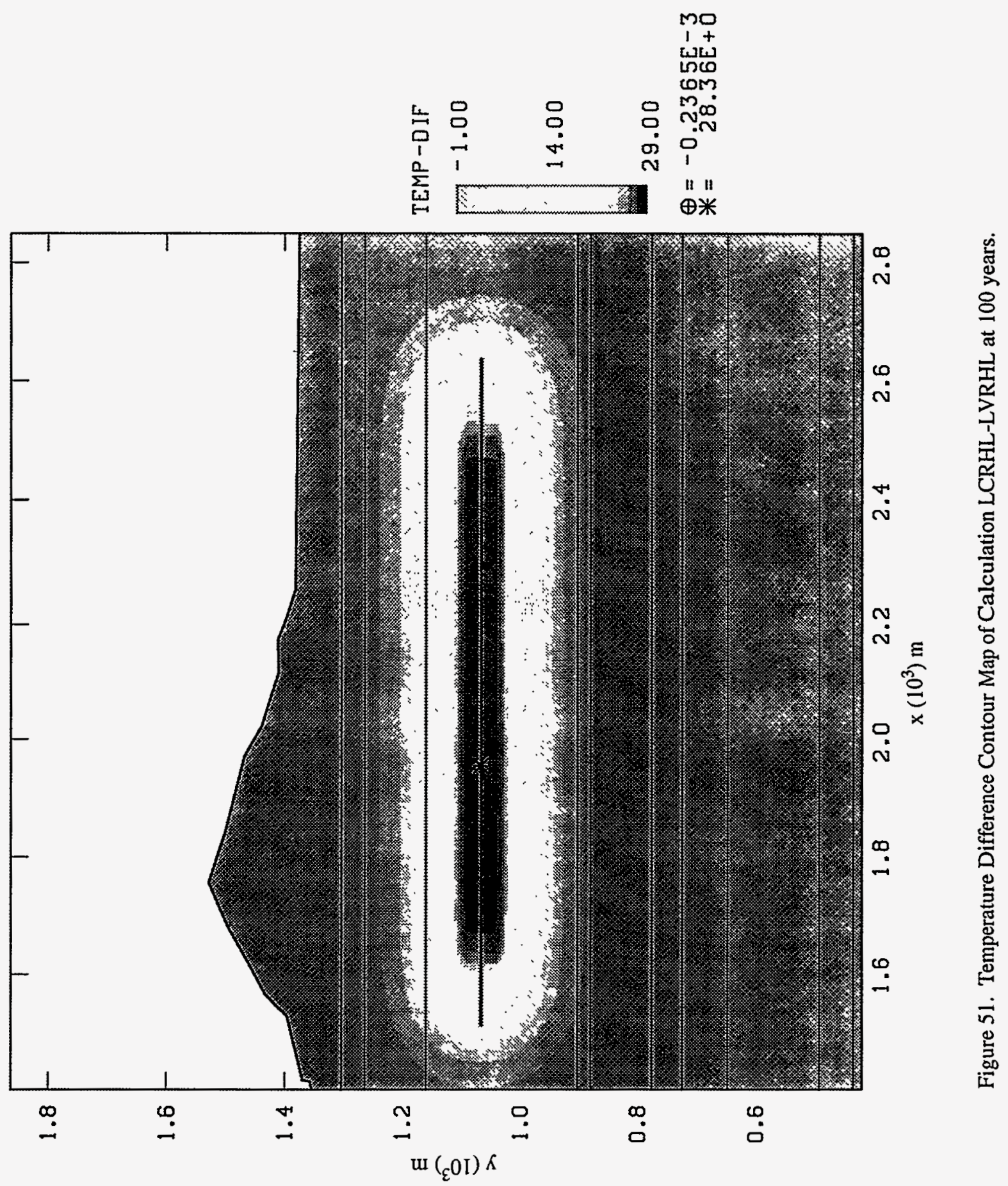


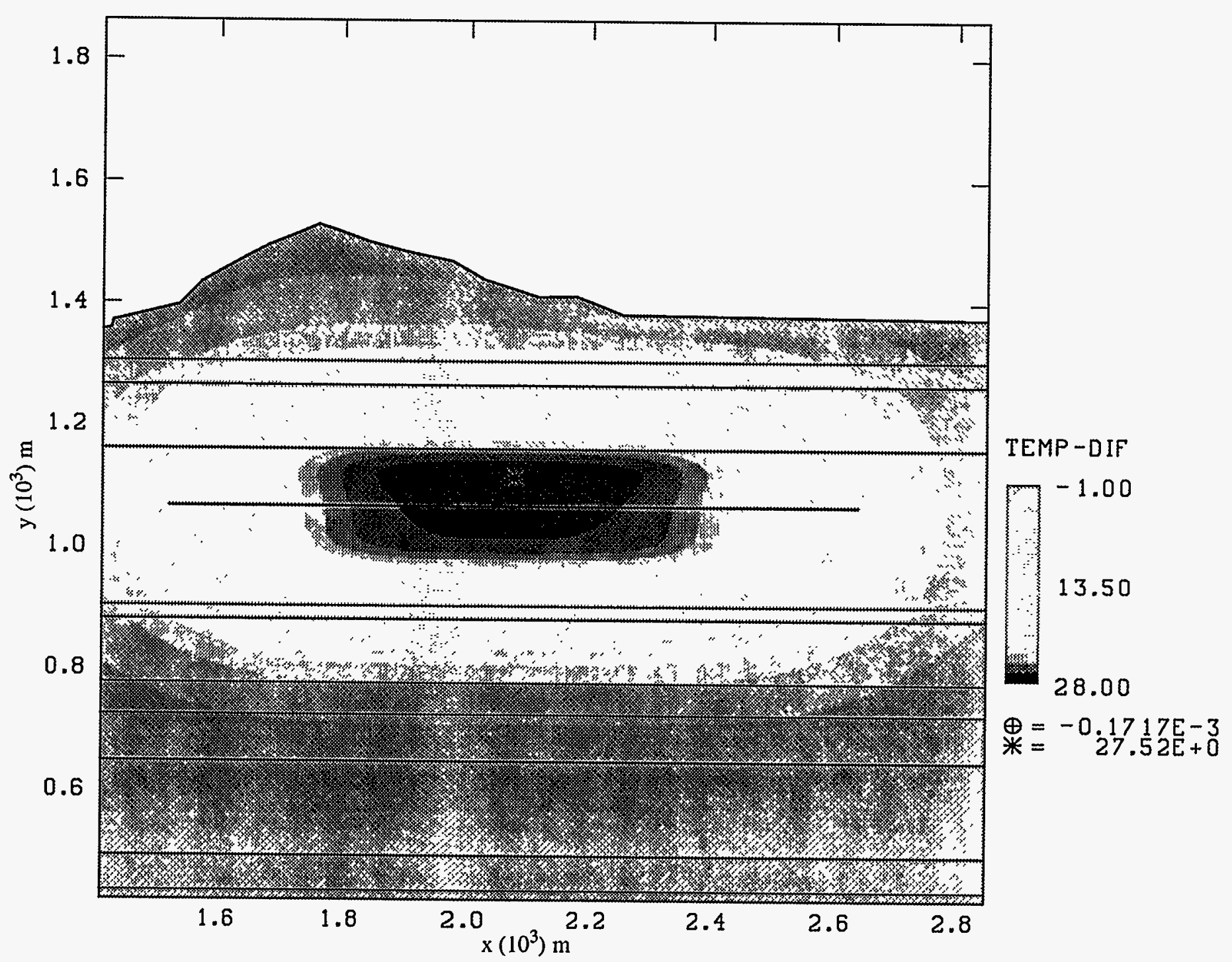

Figure 52. Temperature Difference Contour Map of Calculation LCRHL-LVRHL at 500 years. 

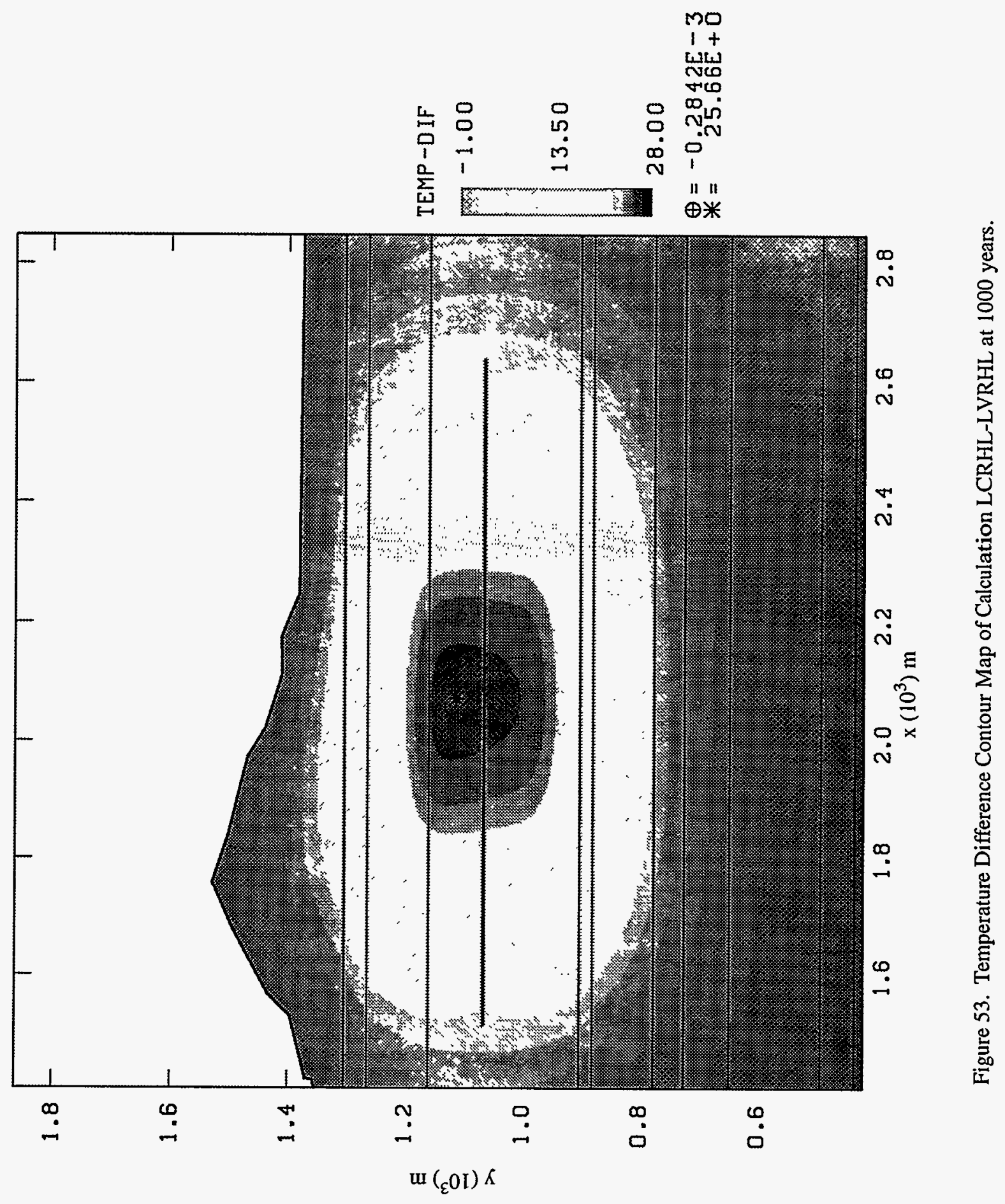


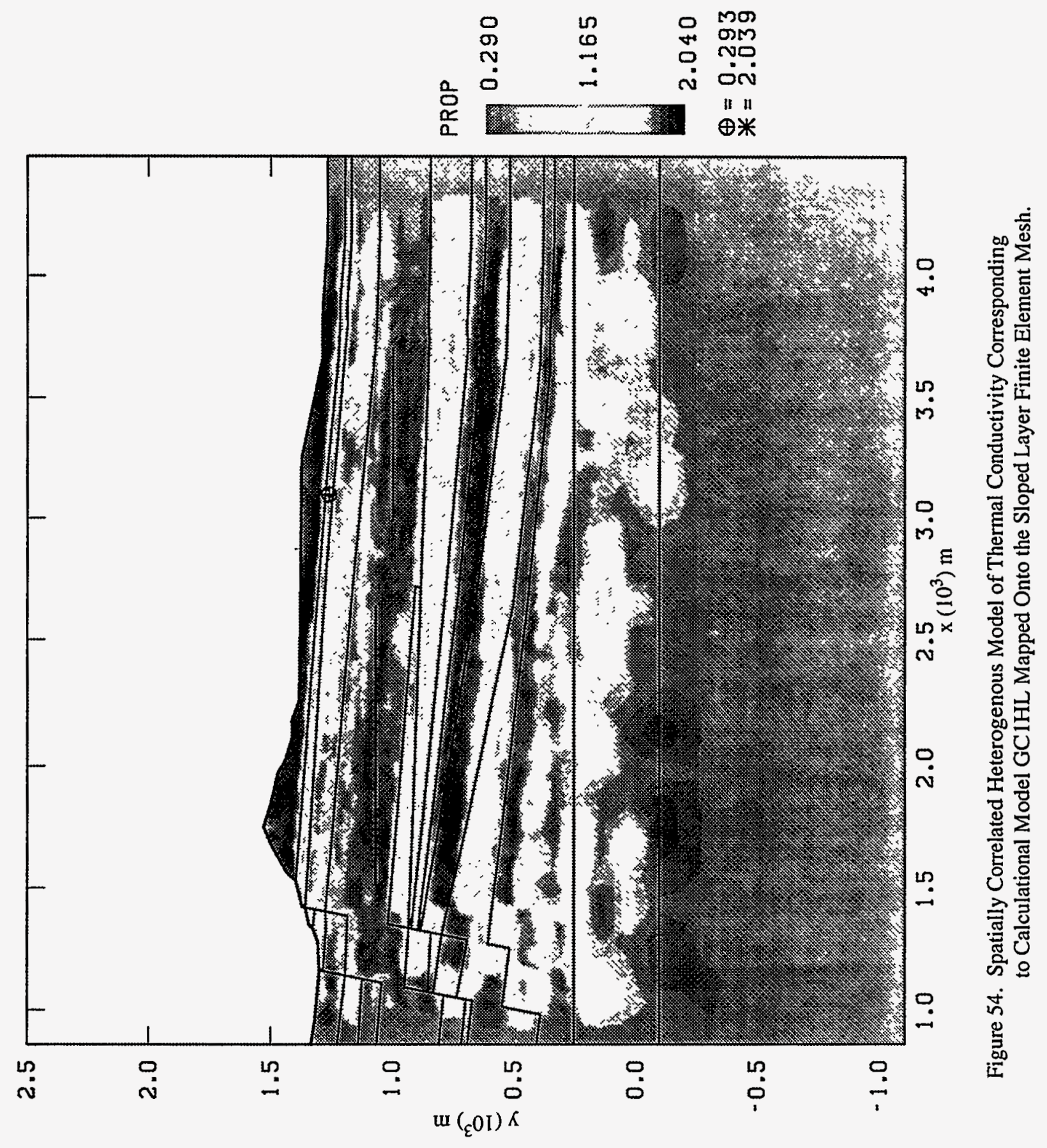




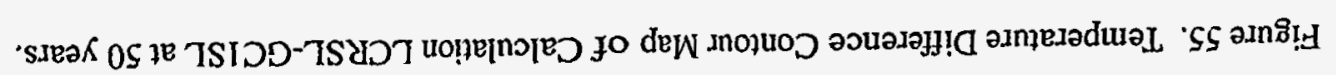

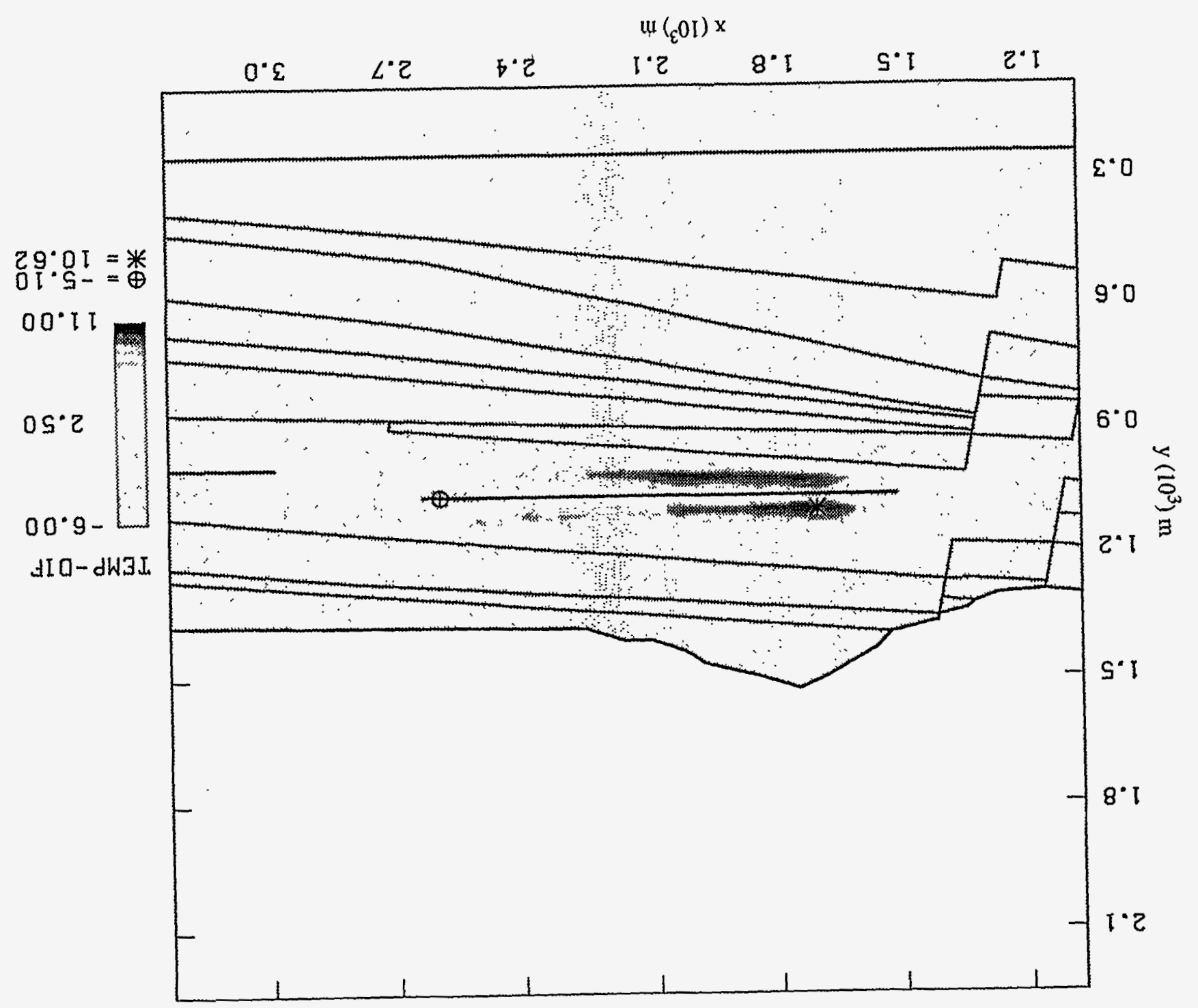




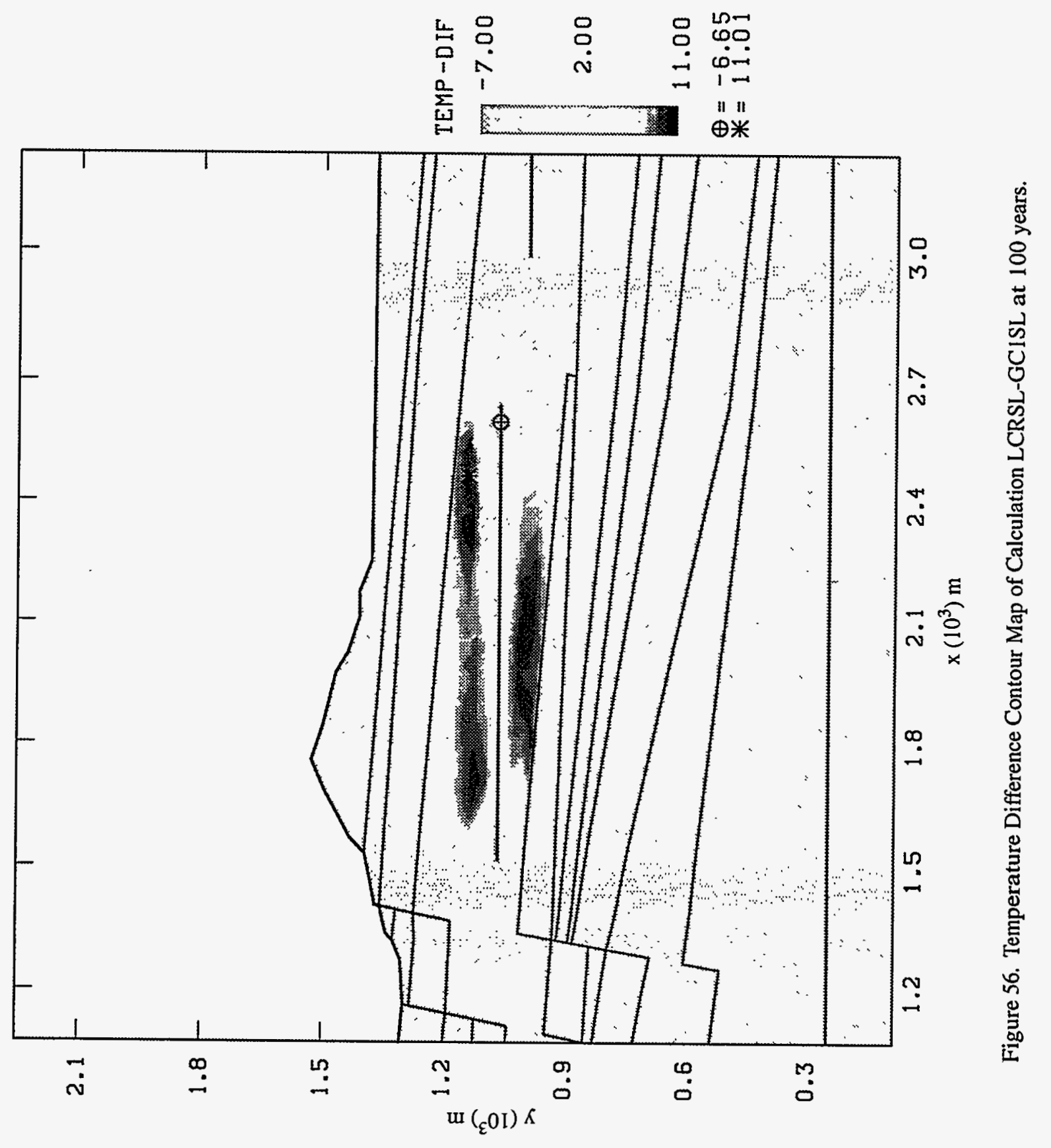




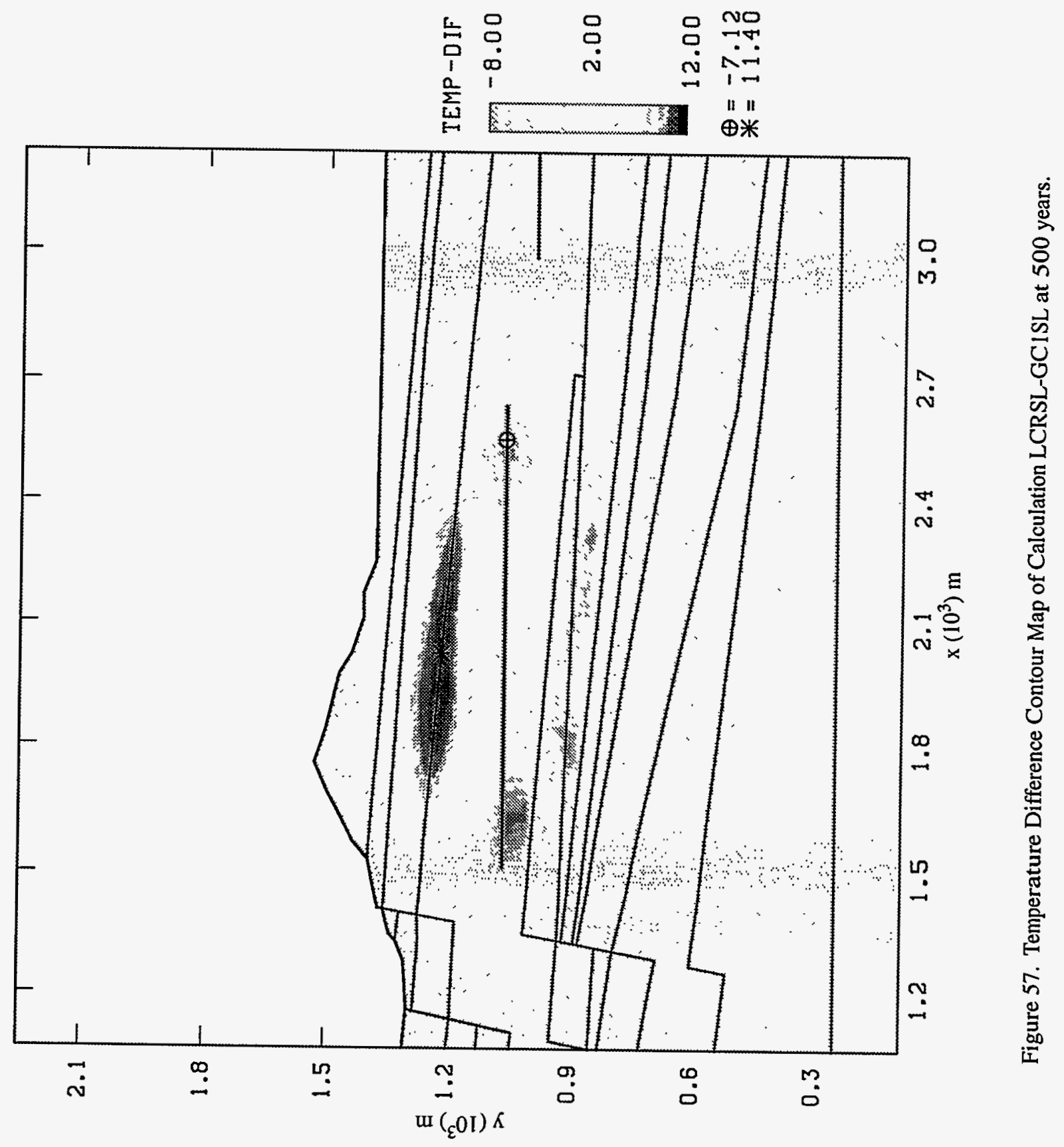




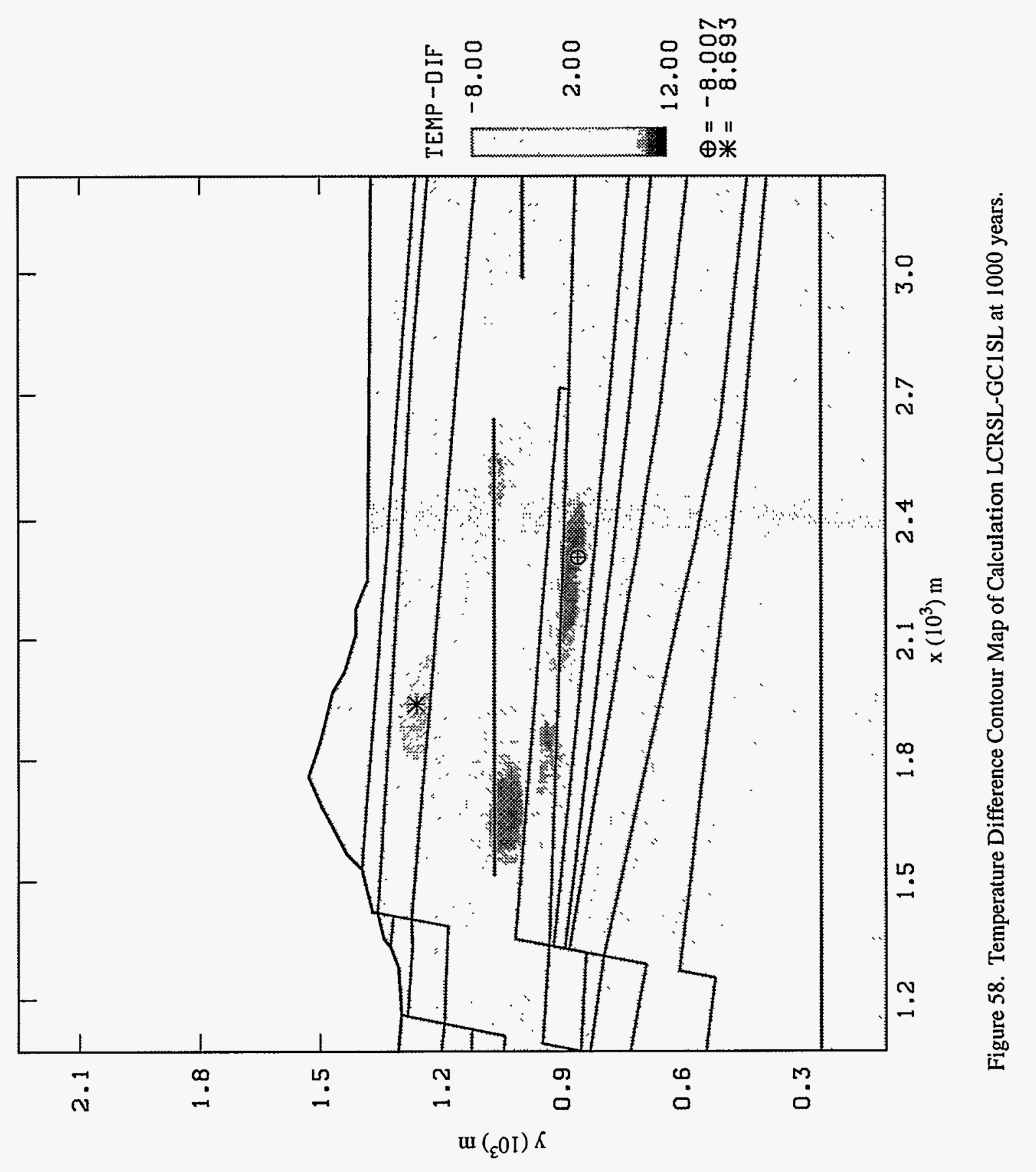




\subsection{Conclusions}

The analyses that were performed for this study were designed to qualitatively compare thermal models on the basis of predicted thermal response. The thermal property model comparisons do not answer detailed questions about differences in thermal response, but highlight trends from which general conclusions can be drawn. The most promising result of this study is the development of a method in which complex material property regions can be easily mapped onto the computational domain of a structured finite element grid.

The method that was developed for this study to map heterogeneous, spatially correlated thermal property models onto an existing finite-element mesh offers the most attractive method available for modeling complex material property regions. Building a finite element mesh, which includes sloped material layers that vary in thickness as well as complex fault zones, is extremely difficult and cumbersome. Tapered, sloped material layers changing from large thickness to small thickness are virtually impossible to mesh properly. If these layers can be meshed, it is usually at the expense of mesh density. Adding to the complexity of mesh generation is finite element connectivity. Modern meshing techniques help make finite-element mesh generation easier, but long interactive sessions with mesh generators is still required when constructing complex meshes. The sloped layer mesh is a good example of the difficulties encountered when producing a mesh of this type. Shown in Figure 5, the near-field portion of the sloped layer mesh shows intricate meshing patterns that required many interactive sessions to build. Many different types of meshing primitives were required to assure element connectivity and maintain adequate element aspect ratios. The horizontal layer mesh, on the other hand, was a relatively easy mesh to produce because it contains uniform, horizontal layers with no fault zones. Actually, the horizontal layers (based on geologic stratigraphy) are not necessary when using geostatistical mapping and can run more efficiently due to its structured gridding. Finally, as site characterization progresses, new data will be available in a continuous stream. Gridding using the approach used for the slopedlayer model is not responsive to such new understandings of the site geology.

Noticeable similarities were observed between the geostatistical thermal property model GClHL and the sloped layer, homogeneous, temperature-independent thermal property model LCRSL. Therefore a direct comparison was made by mapping the geostatistical thermal property data onto the sloped layer mesh. The comparison showed high correlation indicating the two models performed similarly. These results reinforce the need to investigate geostatistical thermal property models as an alternative to complicated and time consuming finite element meshing approaches. Geostatistical thermal property models offer both modeling simplicity as well as the most geologically realistic thermal modeling of Yucca Mountain.

In several simulation comparisons, result of this study show that non-layered (uniform), homogeneous, temperature-independent thermal property models predict higher temperatures outside of the repository host thermal/mechanical unit, TSw2. The thermal/mechanical units $\mathrm{CHn} 1 \mathrm{z}$ (Calico Hills nonwelded tuff) below the repository and PTn (Paintbrush nonwelded tuff) above the repository have relatively higher insulating effects compared to other layers which restrict heat flow from the repository. The prediction of higher temperatures occurs because heat flow is restricted by the nonwelded, insulating layers. 
The temperature-dependent thermal property model LVRHL in general predict lower temperatures in regions of heat loading when compared to temperature independent thermal property models. The prediction of lower temperatures result from energy absorption during rock porewater vaporization. Maximum temperatures for temperature-dependent thermal property models are approximately $30^{\circ} \mathrm{Cless}$ than for temperature-independent thermal property models. This magnitude of temperature difference indicates that a better understanding of thermal property dependencies is needed. 


\subsection{REFERENCES}

1. H. R. MacDougall, L. W. Scully, and J. R. Tillerson, "Site Characterization Plan Conceptual Design Report," SAND84-2641, Sandia National Laboratories, Albuquerque, NM, 1987. (NN1.880902.0014)

2. T. Brandshaug, "A Thermomechanical Far-Field Model of Yucca Mountain," SAND857101, Sandia National Laboratories, Albuquerque, NM, 1991. (NNA.891116.0083)

3. T. S. Ortiz, R. L. Williams, F. B. Nimick, B. C. Whittet, and D. L. South, "A ThreeDimensional Model of reference Thermal/Mechanical and Hydrological Stratigraphy at Yucca Mountain, Southern Nevada," SAND84-1076, Sandia National Laboratories, Albuquerque, NM, 1985. (NNA.890315.0013)

4. D. K. Gartling, R. E. Hogan, "COYOTE-II - A Finite Element Computer Program for Nonlinear Heat Conduction Problems Part 1, Theoretical Background," SAND94-1173, Sandia National Laboratories, Albuquerque, NM, 1994. (MOL.19950419.0106)

5. G. D. Sjaardema, "Overview of the Sandia National Laboratories Engineering Analysis Code Access System," SAND92-2292, Sandia National Laboratories, Albuquerque, NM, 1993. (NNA.930224.0105)

6. W. C. Mills-Curran, A. P. Gilkey, and D. P. Flanagan, "EXODUS: A Finite Element File Format for Pre- and Postprocessing," SAND87-2997, Sandia National Laboratories, Albuquerque, NM, 1992. (NNA.910813.0001)

7. TRW Environmental Safety Systems, Inc., "Repository Subsurface Layout Options and ESF Interface,” B00000000-01717-5705-00009, Rev. 00, Las Vegas, NV, December, 1993. (NNA.940124.0036)

8. TRW Environmental Safety Systems, Inc., "Waste Package Design Status Report Fiscal Year 1993," B00000000-01717-570500007-00, Las Vegas, NV, September, 1993. (HQV.931202.0005)

9. Wilson, M. L., et al., "Total-System Performance Assessment for Yucca Mountain--SNL Second Iteration (TSPA-1993)," SAND93-2675, Sandia National Laboratories, Albuquerque, NM, April, 1994. (NNA.940112.0123)

10. C. V. Deutsch, and A. G. Journel, "GSLIB - Geostatistical Software Library and User's Guide," Oxford University Press, New York, 1992. (NNA.930507.0081)

11. C. A. Rautman, L. E. Flint, A. L. Flint, and J. D. Istok, "Physical and Hydrologic Properties of Outcrop Samples from a Nonwelded to Welded Tuff Transition, Yucca Mountain, 
Nevada," Water-Resources Investigations Report 95-4061, U. S. Geological Survey, Denver, CO, 1995.

12. DOE, "Characteristics of Potential Repository Wastes," DOE/RW-0184-R1, Office of Civilian radioactive Waste Management, Washington, D. C., July, 1992. (HQO.920827.0001-HQO.920827.0004)

13. J. Jung, E. E. Ryder, E. A. Boucheron, E. Dunn, J. F. Holland, and J. D. Miller, "Design Support Analysis North Ramp Design Package 2C," TDIF-302273, Sandia National Laboratories, Albuquerque, NM, 1994. (NNA.940523.0159)

14. D. K. Gartling, "MERLIN-II - A Computer Program to Transfer Solution Data Between Finite Element Meshes," SAND89-2989, Sandia National Laboratories, Albuquerque, NM, 1991. (NNA.921223.0053)

15. Ryder, E. E., "Comparison of Predicted Far- Field Temperatures for Discrete and Smeared Heat Sources," SAND92-2838C, Proceeding of the Fourth Annual International Conference on High Level Radioactive Waste Management, Las Vegas, NV, April 26-30, 1993. (NNA.930428.0018)

16. Nimick, F.B. and J.R. Connolly, "Calculation of Heat Capacities for Tuffaceous Units from the Unsaturated Zone at Yucca Mountain, Nevada," SAND88-3050, Albuquerque, NM, May, 1991. (NNA.910308.0017) 


\section{APPEndix A: Geostatistical Modeling}

\section{A1. Mapping Geostatistical Thermal Property Information Onto A Computational Grid}

Geostatistical thermal property data was provided by the Geohydrology Department at Sandia National Laboratories using the code SGSIM from the geostatistical subroutine library, GSLIB [10]. SGSIM uses a geostatistical grid with volume-centered nodal mesh. The geostatistical grids are limited to rectangular meshes only. The thermal property input for COYOTE-II [4] follows the EXODUS [6] format which requires separate blocks of elements be defined uniquely. Within an element block, all elements must have the same material property designation. It would be virtually impossible to assign every element in the computational domain a unique material block number. A different approach was needed because theoretically every node of the finite-element mesh could have a unique set of thermal material properties.

After some investigating, it was decided to use the EXODUS data base along with MERLIN-II [14], a computer program designed to transfer solution data between finite-element meshes, to transpose the geostatistical thermal property data onto the computational mesh. With some minor coding changes within COYOTE-II (see Appendix C for difference files), and using COYOTEII's material property user subroutines (Appendix D), the material property data could be read in and used on a per node basis.

The procedure starts by defining a rectangular region of the computational mesh representing the near field region. The near field is chosen because thermal gradients will be contained in this region. The coordinates of the rectangular region are used as input to SGSIM to produce the heterogenous thermal property data. Next an equivalent finite-element mesh identical to the geostatistical grid used by SGSIM is made taking into account the volume centering of the nodes. The code GEOSTAT_MAP (Appendix B) is used to assign the nodal output from SGSIM onto the rectangular finite-element mesh on a node-by-node basis. This result is then transposed onto the computational finite-element mesh using MERLIN-II. Because of the interpolation schemes used within MERLIN-II, material properties are slightly modified particularly for the larger finite-elements at greater distances from the repository. The final step uses the code EXO_POST to read the resulting EXODUS data base file and write out node number versus thermal property for use in COYOTE-II user subroutines. 
This page intentionally left blank. 


\section{APPENDIX B: Pr- AND Post-Processing Code LISTINGS}

\section{B.1 GEOSTAT_MAP}

The following fortran code was used to map geostatistical thermal property data onto a finite-element mesh.

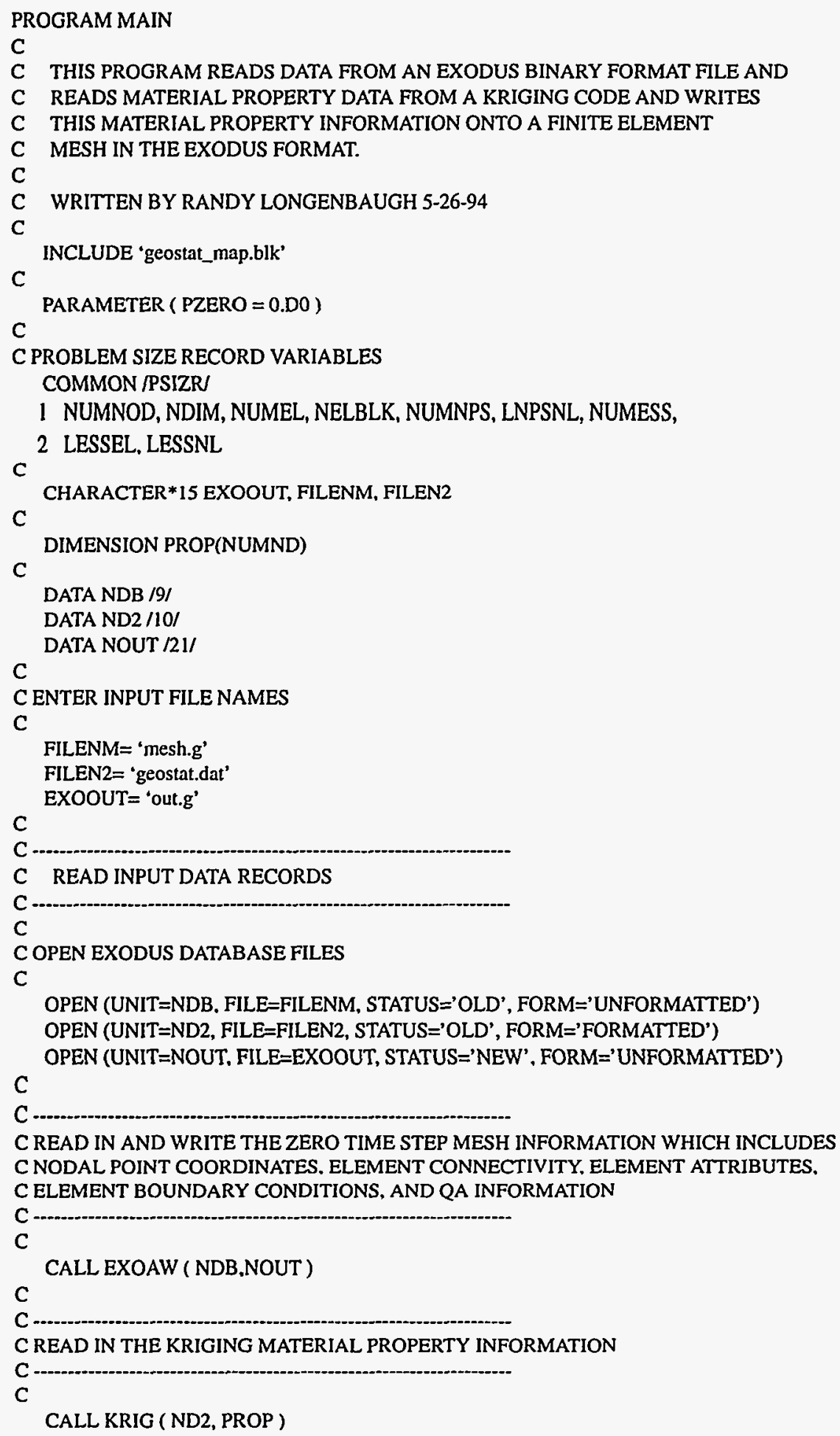




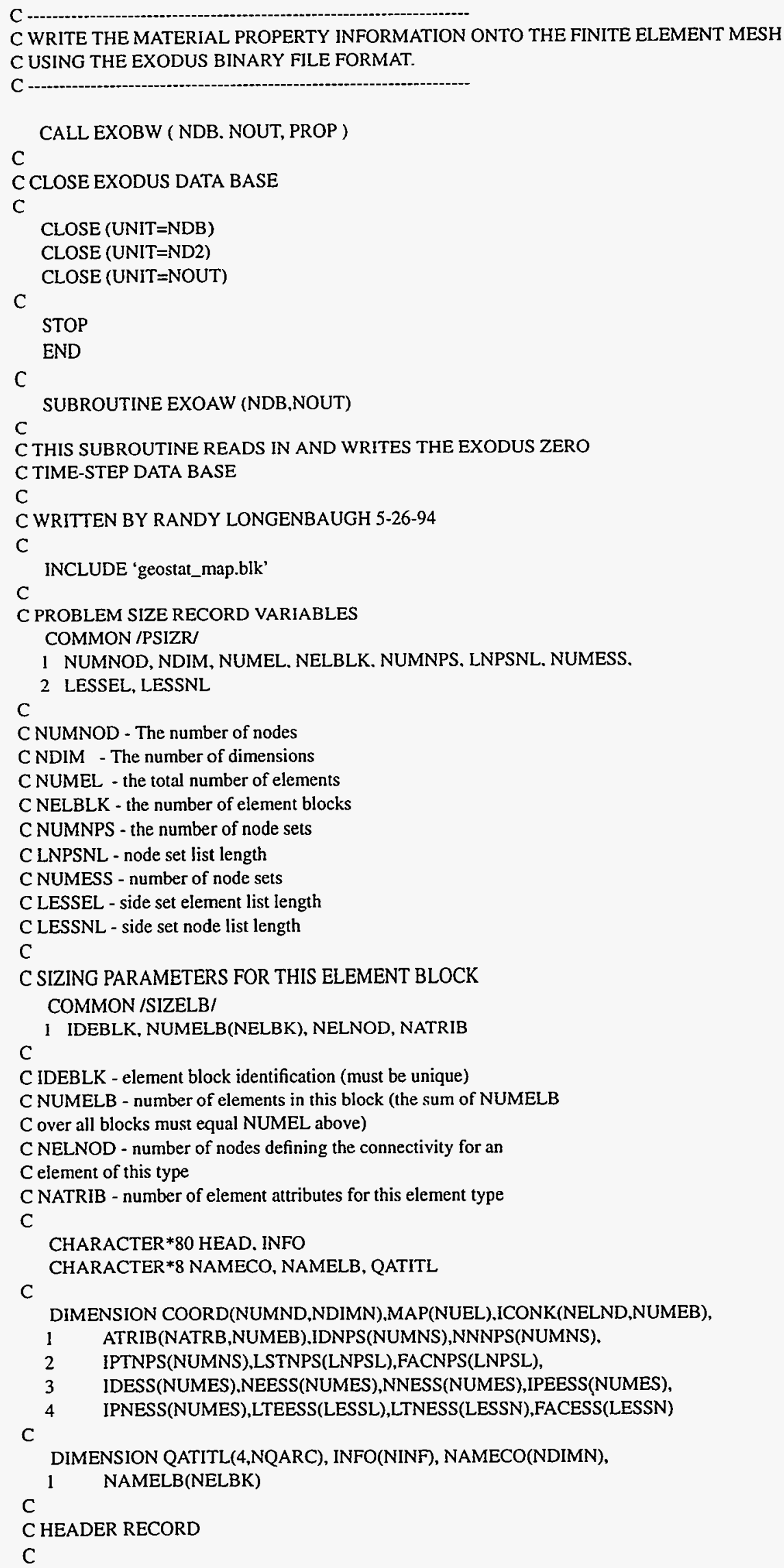




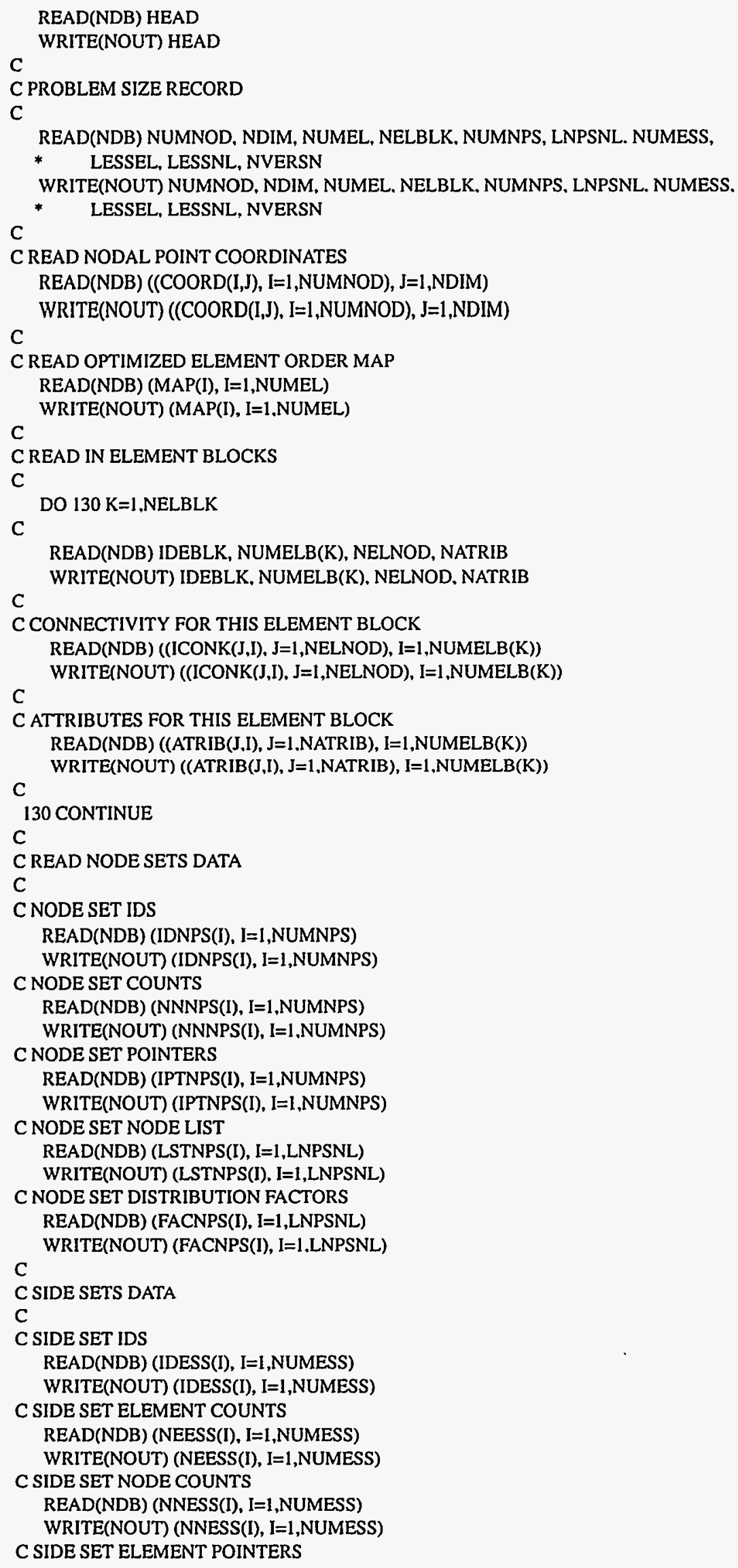




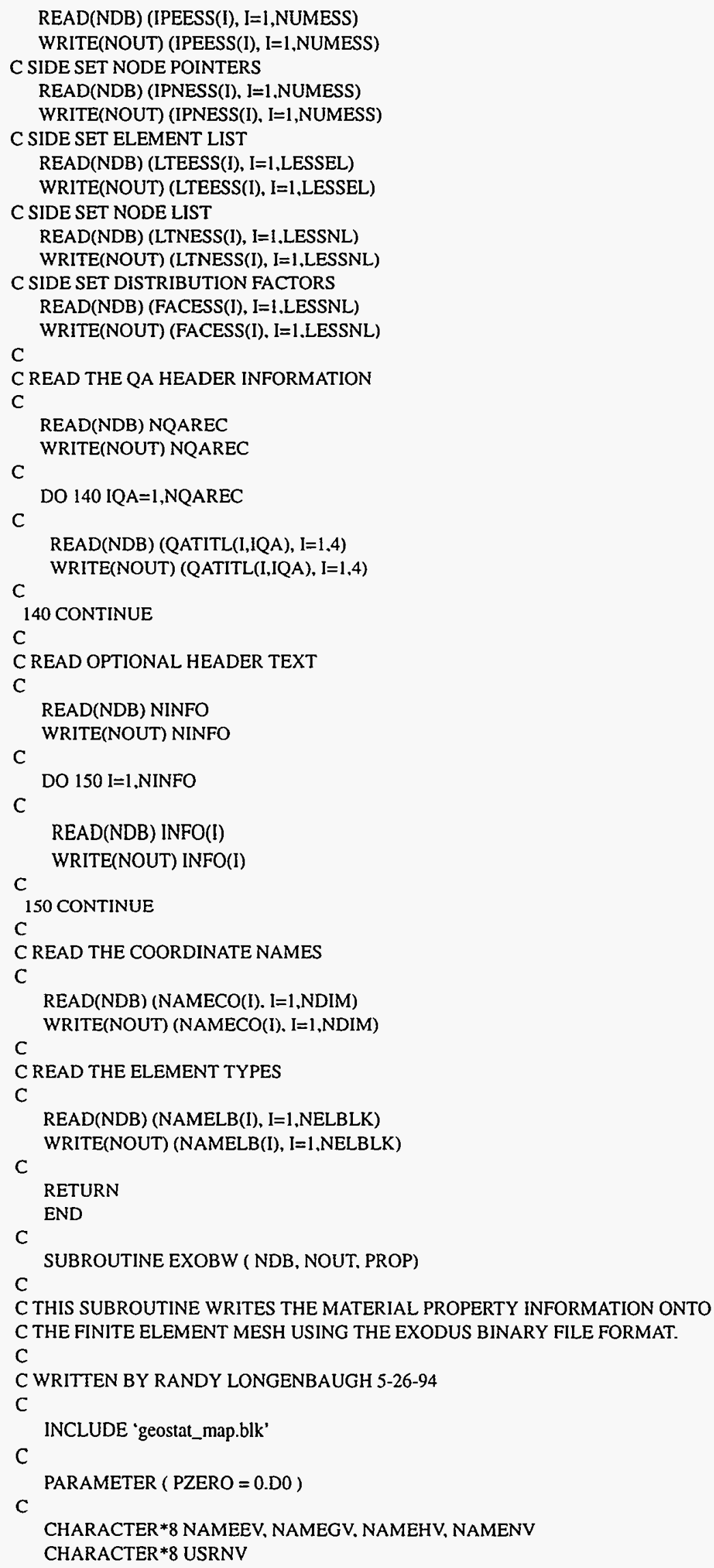




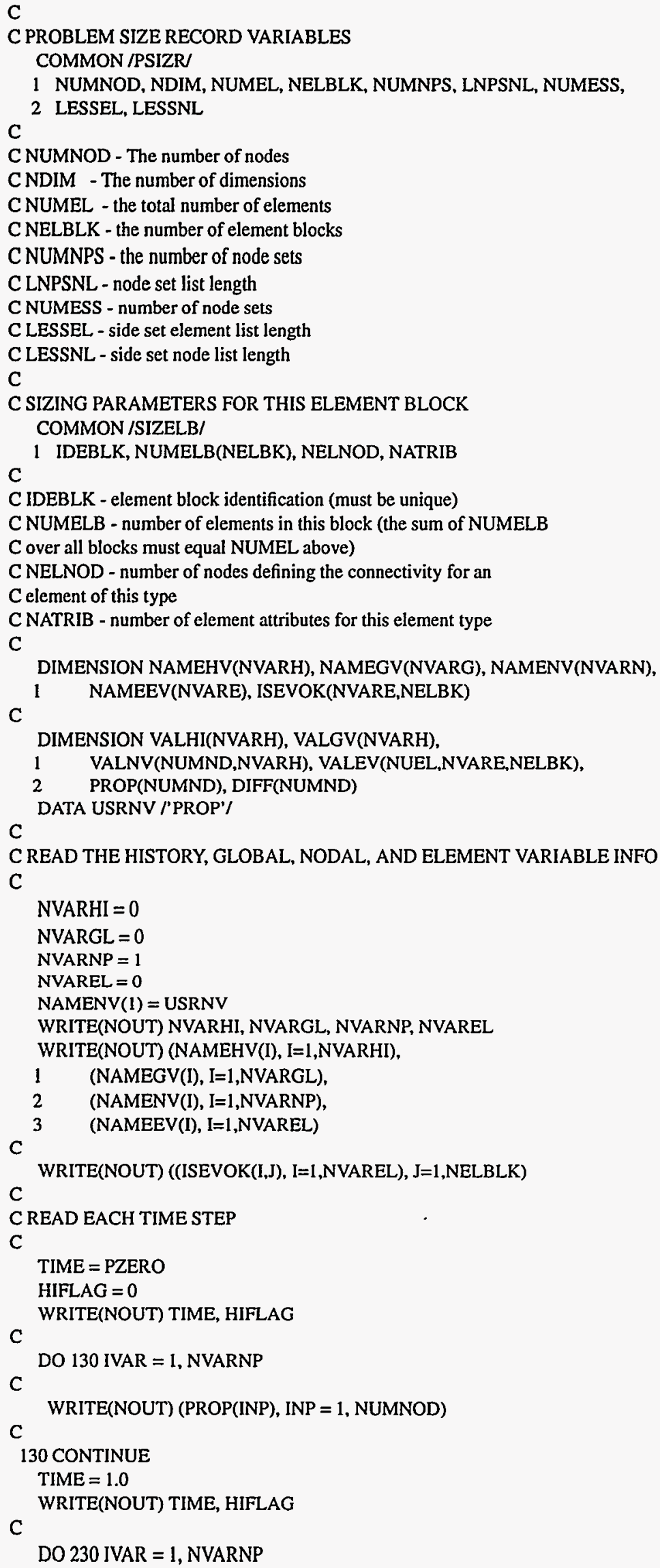




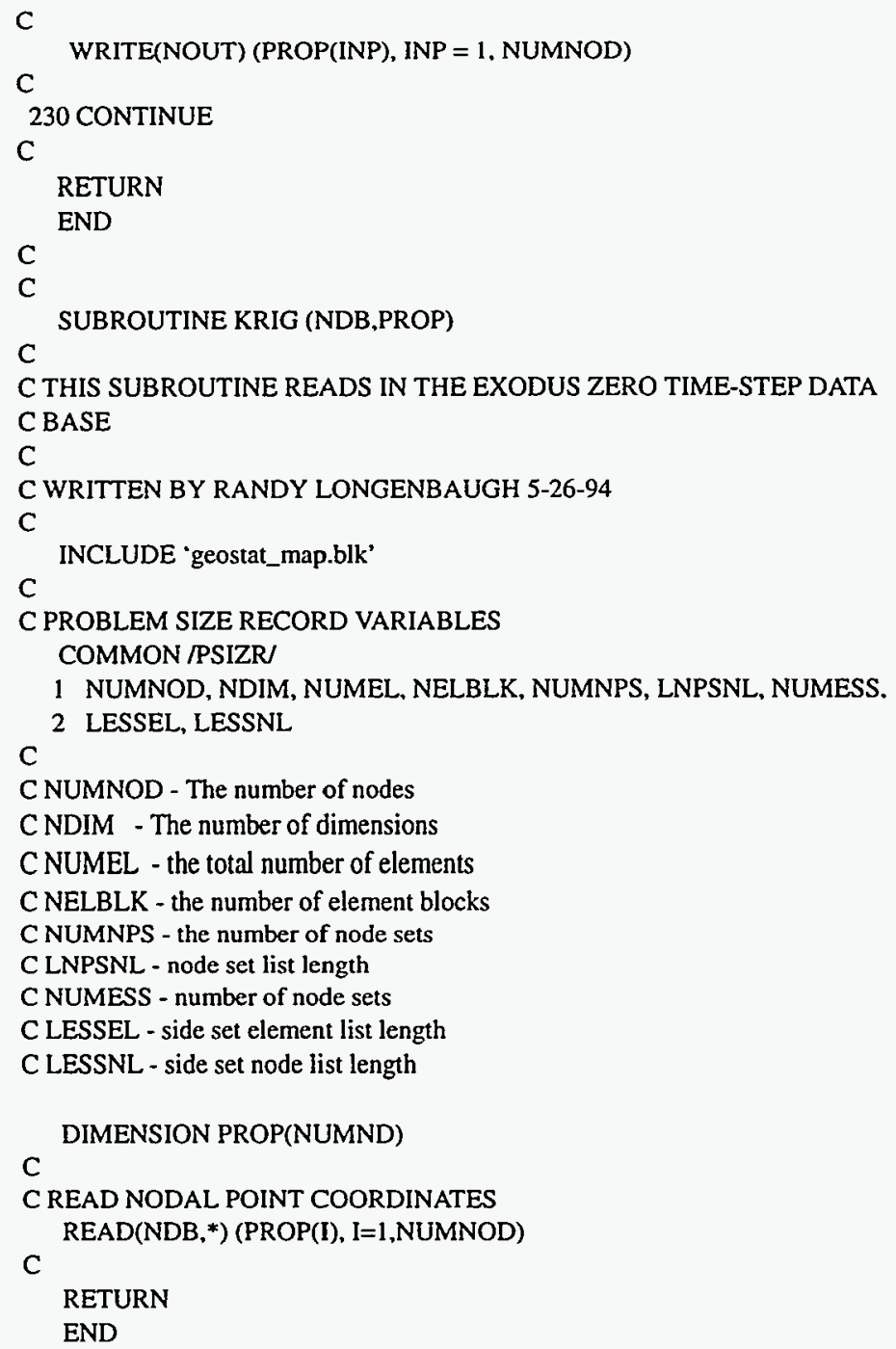




\section{B.2 EXO_POST}

Once MERLIN-II [9] was used to transfer thermal property data from rectangular finite element mesh to computional mesh, EXO_POST.F was used to read the resulting EXODUS [12] data base file and write out node number versus thermal property for use in COYOTE-II [3] user subroutines.

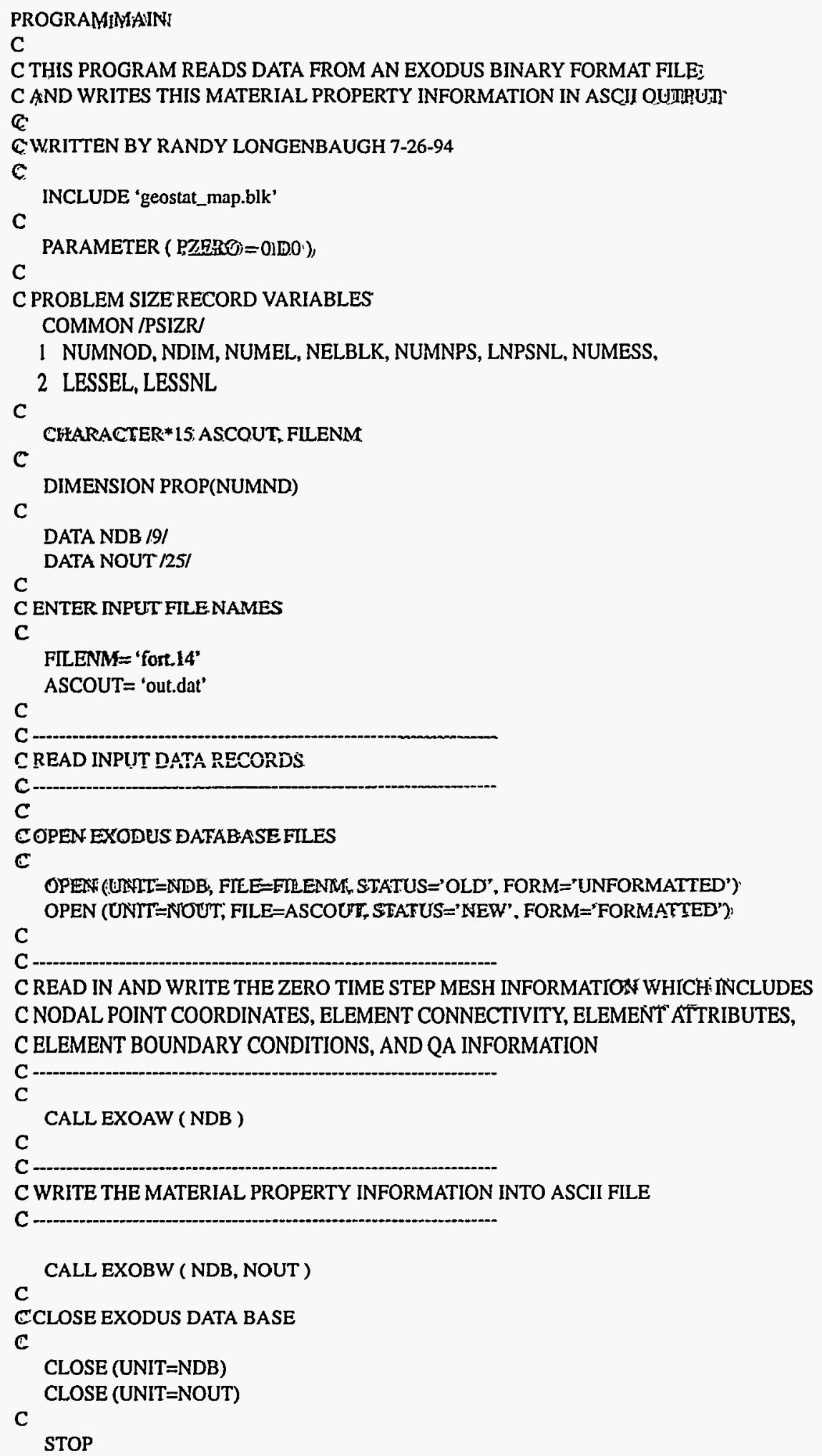




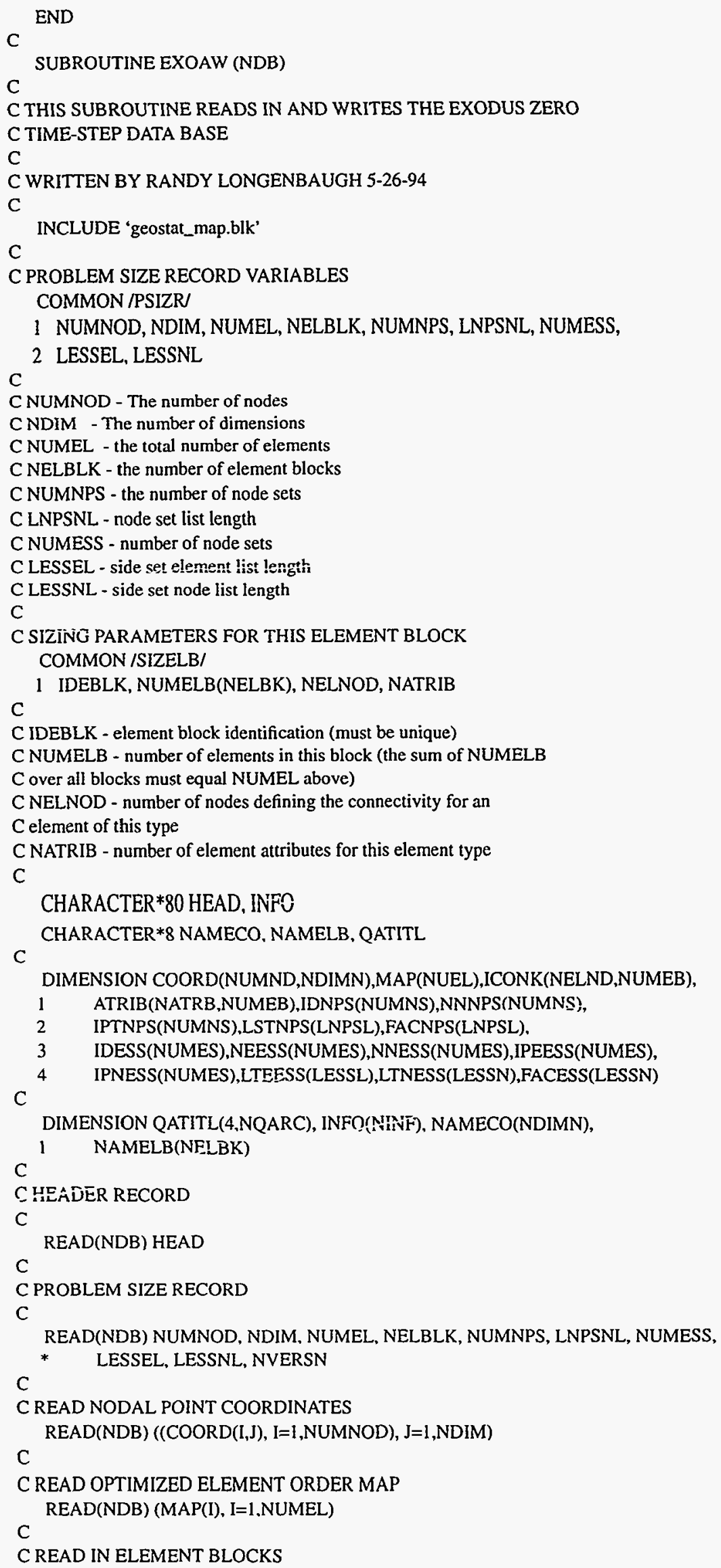


C

C

DO $130 \mathrm{~K}=1$,NELBLK

C

READ(NDB) IDEBLK, NUMELB(K), NELNOD, NATRIB

C CONNECTIVITY FOR THIS ELEMENT BLOCK

READ(NDB) ((ICONK(J,I), J=1,NELNOD), I=1,NUMELB(K))

C

C ATTRIBUTES FOR THIS ELEMENT BLOCK

READ(NDB) ((ATRIB(J,I), J=1,NATRIB), I=1,NUMELB(K))

C

130 CONTINUE

C

C READ NODE SETS DATA

C

C NODE SET IDS

READ(NDB) (IDNPS(I), I=1,NUMNPS)

C NODE SET COUNTS

READ(NDB) (NNNPS(I), I=1,NUMNPS)

C NODE SET POINTERS

READ(NDB) (IPTNPS(I), I=1,NUMNPS)

C NODE SET NODE LIST

READ(NDB) (LSTNPS(I), I=1,LNPSNL)

C NODE SET DISTRIBUTION FACTORS

$\operatorname{READ(NDB)}$ (FACNPS(I), I=1,LNPSNL)

C

C SIDE SETS DATA

C

C SIDE SET IDS

READ(NDB) (IDESS(I), I=1,NUMESS)

C SIDE SET ELEMENT COUNTS

READ(NDB) (NEESS(I), I=1,NUMESS)

C SIDE SET NODE COUNTS

READ(NDB) (NNESS(I), I=1,NUMESS)

C SIDE SET ELEMENT POINTERS

READ(NDB) (IPEESS(I), I=1,NUMESS)

C SIDE SET NODE POINTERS

READ(NDB) (IPNESS(I), I=1,NUMESS)

C SIDE SET ELEMENT LIST

READ(NDB) (LTEESS(I), I=1,LESSEL)

C SIDE SET NODE LIST

READ(NDB) (LTNESS(l), I=l,LESSNL)

C SIDE SET DISTRIBUTION FACTORS

C READ(NDB) (FACESS(I), I=1,LESSNL)

C READ THE QA HEADER INFORMATION

C

C

READ(NDB) NQAREC

C

C

DO 140 IQA=1,NQAREC

READ(NDB) (QATITL(I,IQA), I=1,4)

140 CONTINUE

C

C READ OPTIONAL HEADER TEXT

C

C

READ(NDB) NINFO

DO 150 I=1,NINFO

C

C

READ(NDB) INFO(I)

150 CONTINUE

C 


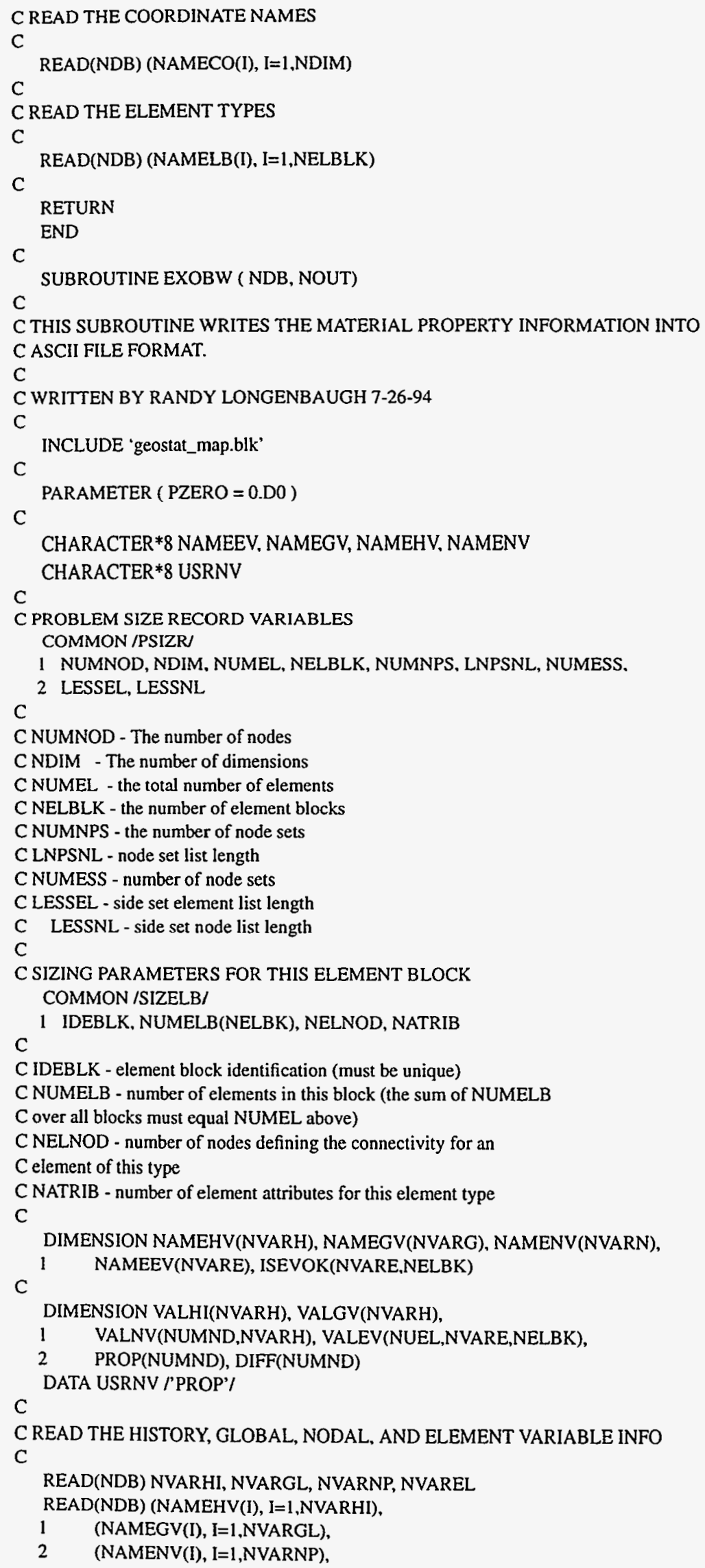




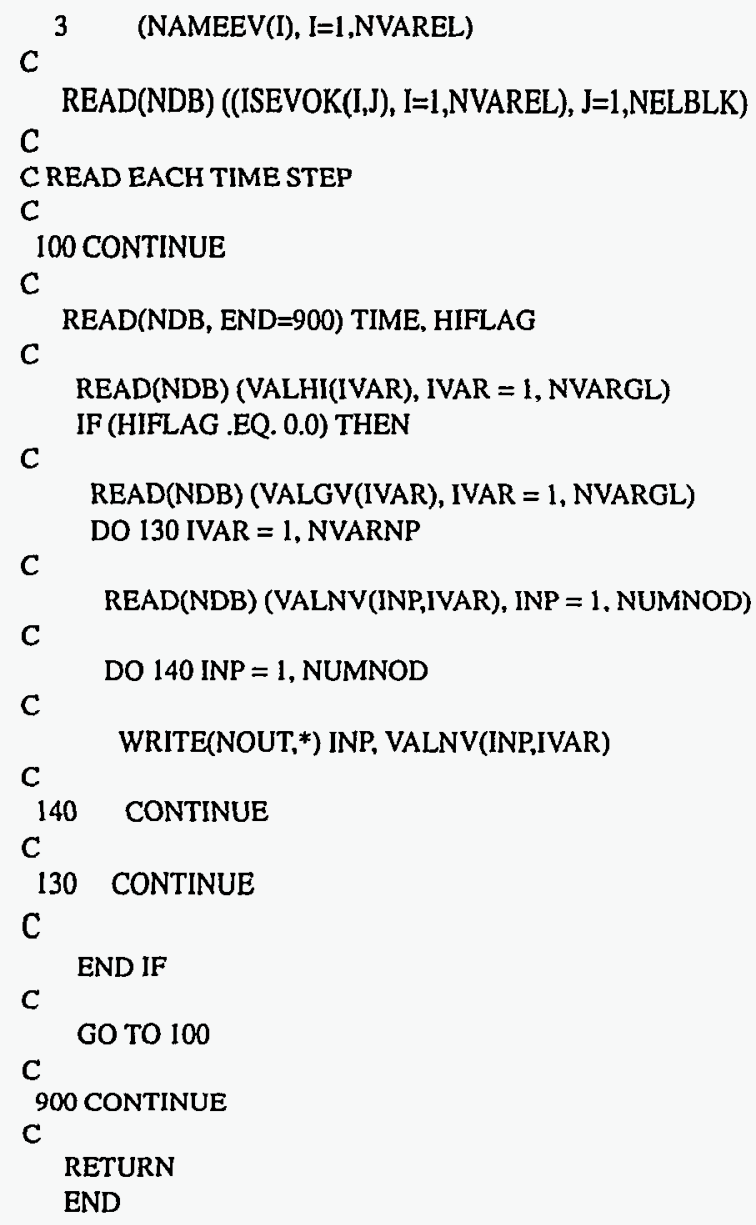




\section{B.3 EXOREAD}

This code was used to take the results from two finite element calculations and compute the difference in results at each node and then write results to an EXODUS file format for post-processing.

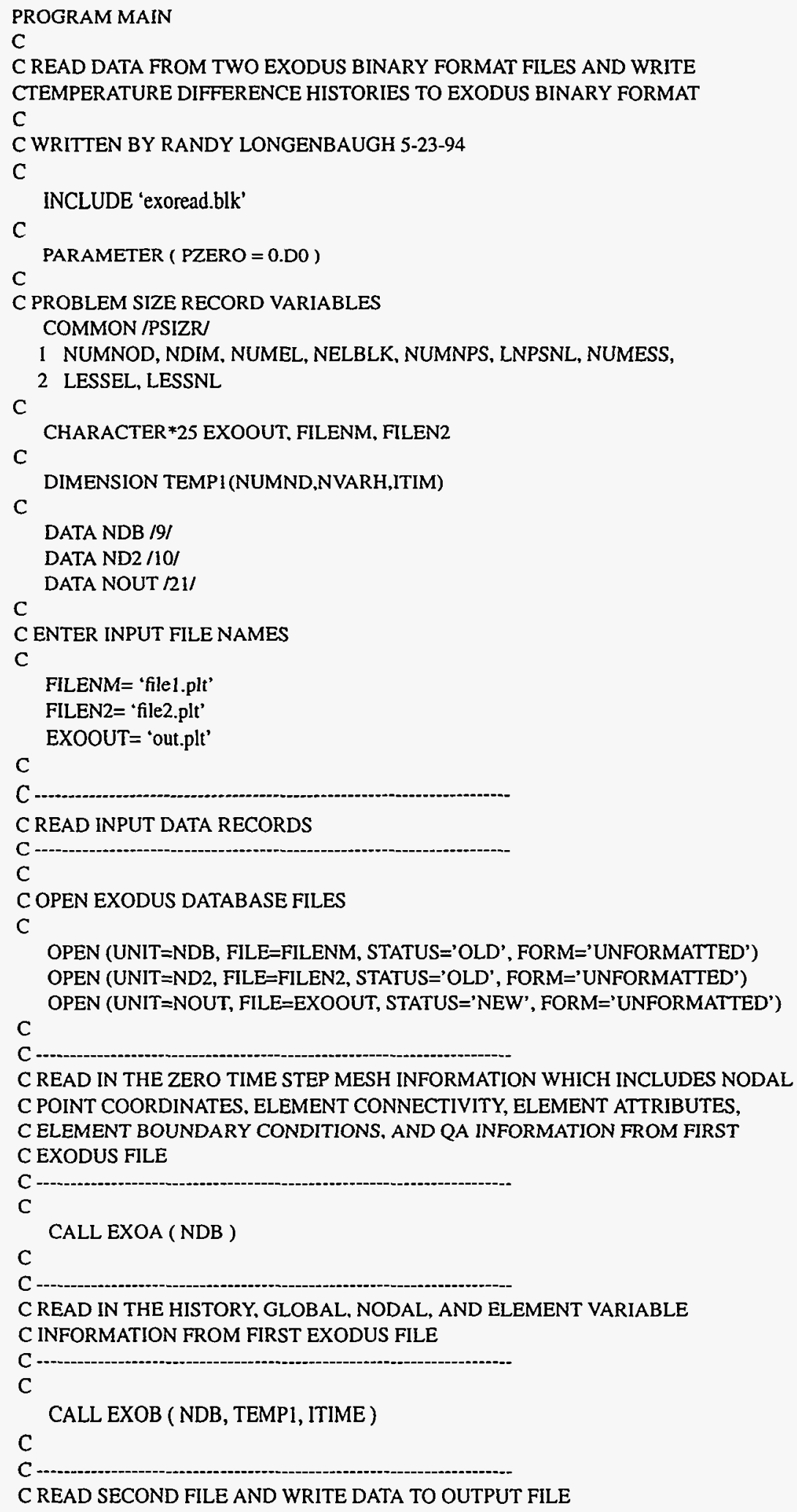




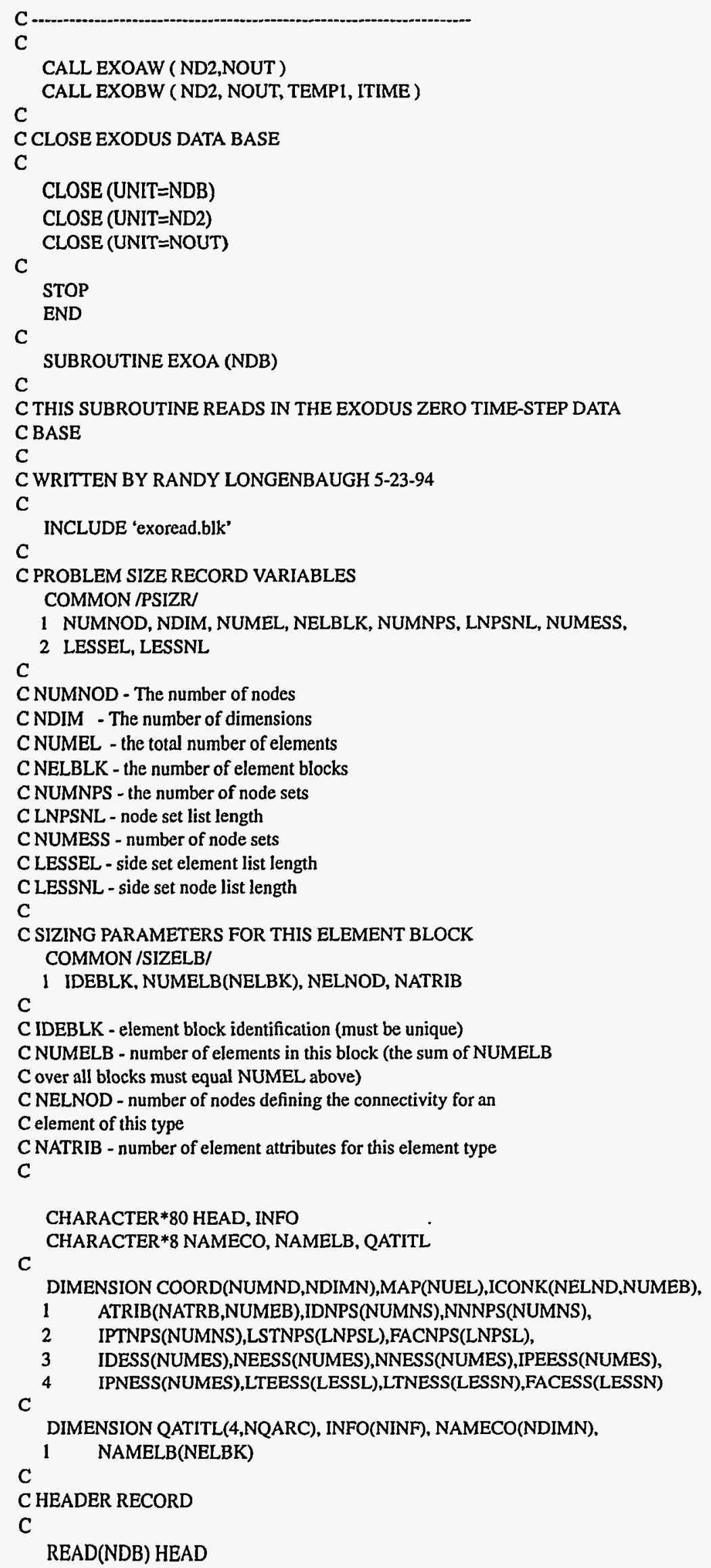




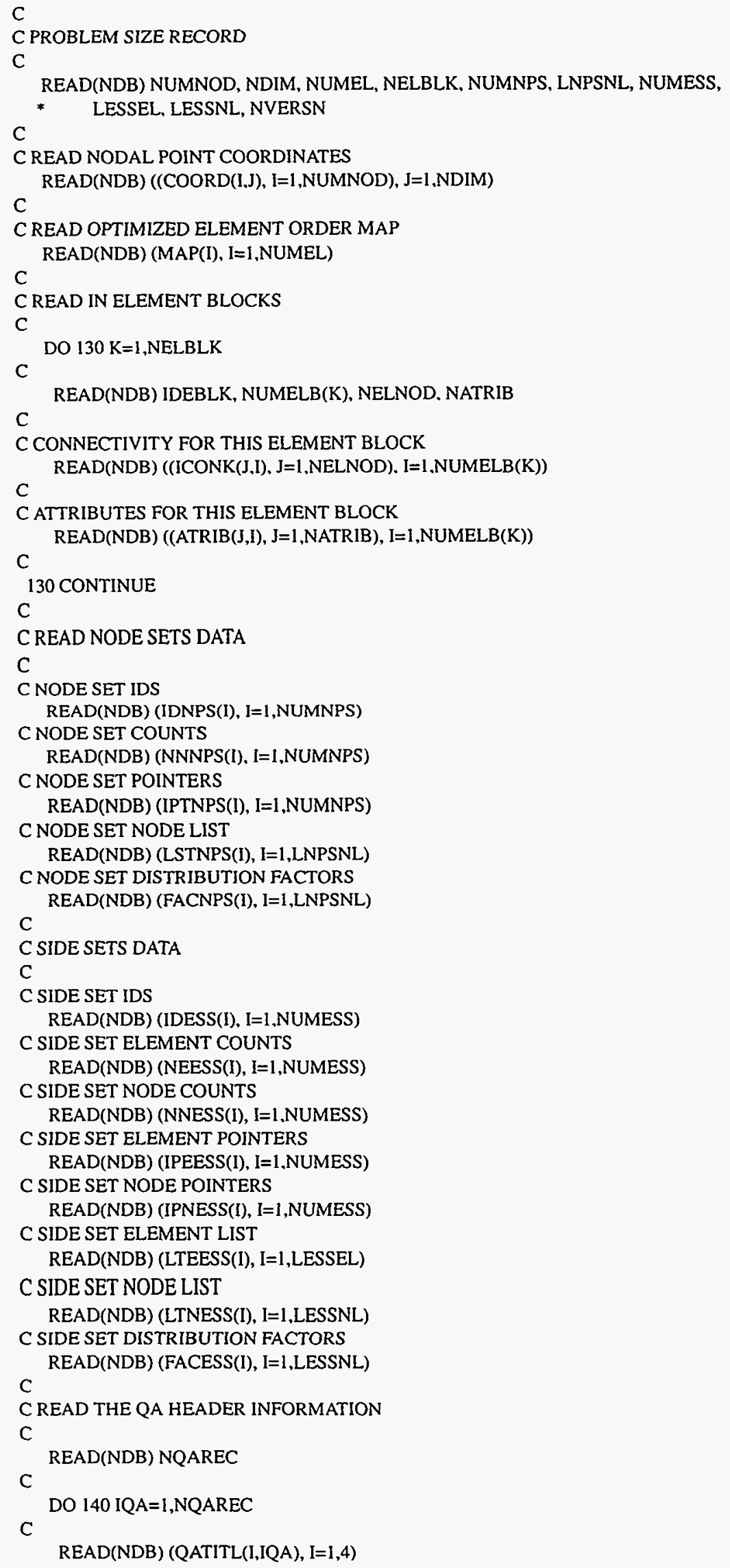




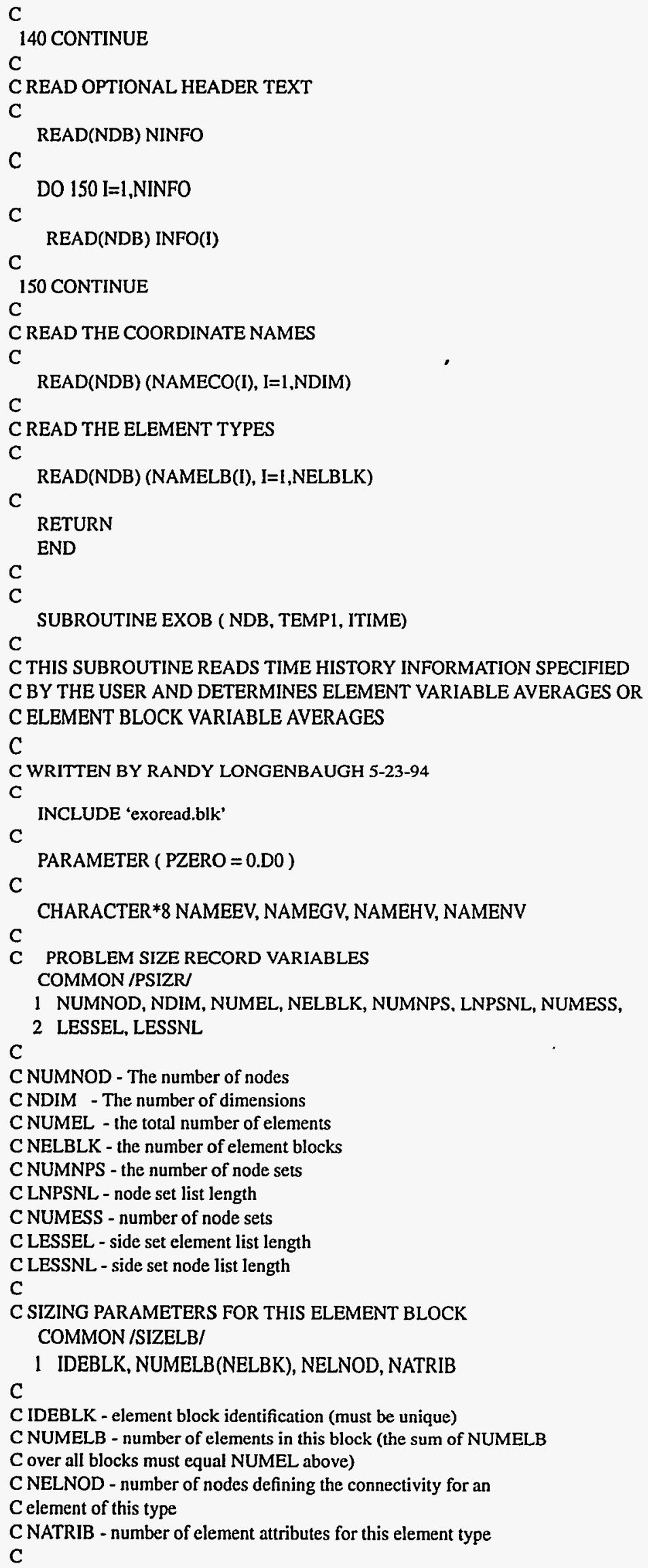


DIMENSION NAMEHV(NVARH), NAMEGV(NVARG), NAMENV(NVARN),

.

DIMENSION VALHI(NVARH), VALGV(NVARH),

1 TEMPI(NUMND,NVARH,ITIM), VALEV(NUEL,NVARE,NELBK)

C

C READ THE HISTORY, GLOBAL, NODAL, AND ELEMENT VARIABLE INFO

C

READ(NDB) NVARHI, NVARGL, NVARNP, NVAREL

READ(NDB) (NAMEHV(I), I=1,NVARHI),

1 (NAMEGV(I), I=1,NVARGL),

2 (NAMENV(I), I=l,NVARNP),

3 (NAMEEV(I), I=1,NVAREL)

C

C

READ(NDB) ((ISEVOK(I,J), I=1,NVAREL), J=1,NELBLK)

C READ EACH TIME STEP

$\mathrm{C}$

ITIME $=1$

120 CONTINUE

C

READ(NDB. END = 900) TIME, HIFLAG

C

READ(NDB) (VALHI(IVAR), IVAR $=1$. NVARHI)

IF (HIFLAG .EQ. PZERO) THEN

C

C

READ(NDB) (VALGV(IVAR), IVAR = 1, NVARGL)

C

DO 130 IVAR $=1$, NVARNP

C

READ(NDB) (TEMPI(INP,IVAR,ITIME), INP = 1, NUMNOD)

130 CONTINUE

C

C

DO 150 IBLK $=1$, NELBLK

C

DO 140 IVAR $=1$, NVAREL

C

C

IF(ISEVOK(IVAR,IBLK) .NE. PZERO) THEN

READ(NDB) (VALEV(IEL,IVAR,IBLK), IEL=1,NUMELB(IBLK))

C

END IF

140 CONTINUE

C

150 CONTINUE

C

END IF

C

ITIME = ITIME + 1

C

C

GO TO 120

900 CONTINUE

C

ITIME $=$ ITIME -1

C

RETURN

END

C

C

C

SUBROUTINE EXOAW (NDB,NOUT) 
C

C PROBLEM SIZE RECORD VARIABLES

COMMON /PSIZR

1 NUMNOD, NDIM, NUMEL, NELBLK, NUMNPS, LNPSNL, NUMESS,

2 LESSEL, LESSNL

$\mathrm{C}$

C NUMNOD - The number of nodes

CNDIM - The number of dimensions

CNUMEL - the total number of elements

CNELBLK - the number of element blocks

CNUMNPS - the number of node sets

C LNPSNL - node set list length

C NUMESS - number of node sets

C LESSEL - side set element list length

C LESSNL - side set node list length

C

C SIZING PARAMETERS FOR THIS ELEMENT BLOCK

COMMON /SIZELB/

1 IDEBLK, NUMELB(NELBK), NELNOD, NATRIB

C

C IDEBLK - element block identification (must be unique)

C NUMELB - number of elements in this block (the sum of NUMELB

C over all blocks must equal NUMEL above)

C NELNOD - number of nodes defining the connectivity for an

C element of this type

C NATRIB - number of element attributes for this element type

C

CHARACTER $* 80$ HEAD, INFO

CHARACTER $* 8$ NAMECO, NAMELB, QATITL

DIMENSION COORD(NUMND,NDIMN),MAP(NUEL),ICONK(NELND,NUMEB),

I ATRIB(NATRB,NUMEB),IDNPS(NUMNS),NNNPS(NUMNS),

2 IPTNPS(NUMNS),LSTNPS(LNPSL),FACNPS(LNPSL),

3 IDESS(NUMES),NEESS(NUMES),NNESS(NUMES),IPEESS(NUMES),

4 IPNESS(NUMES),LTEESS(LESSL),LTNESS(LESSN),FACESS(LESSN)

C

DIMENSION QATITL(4,NQARC), INFO(NINF), NAMECO(NDIMN),

C

1 NAMELB(NELBK)

C HEADER RECORD

C

READ(NDB) HEAD

WRITE(NOUT) HEAD

C

C PROBLEM SIZE RECORD

C

READ(NDB) NUMNOD, NDIM, NUMEL, NELBLK, NUMNPS, LNPSNL, NUMESS,

* LESSEL, LESSNL, NVERSN

WRITE(NOUT) NUMNOD. NDIM. NUMEL, NELBLK, NUMNPS, LNPSNL, NUMESS,

C

* LESSEL, LESSNL, NVERSN

C READ NODAL POINT COORDINATES

READ(NDB) ((COORD(I,J), I=1,NUMNOD), J=I,NDIM)

C WRITE(NOUT) ((COORD(I,J), I=1,NUMNOD), J=1,NDIM)

C READ OPTIMIZED ELEMENT ORDER MAP

READ(NDB) (MAP(I), I=1,NUMEL)

WRITE(NOUT) (MAP(I), I=1,NUMEL) 


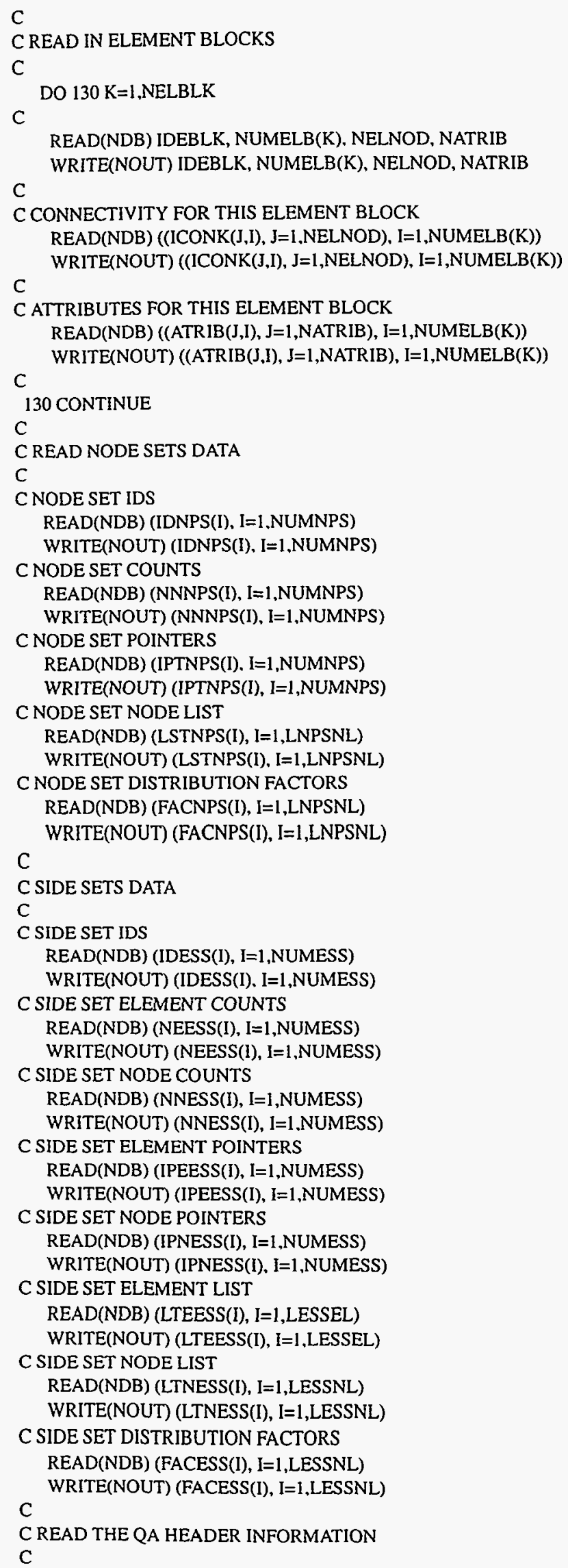


READ(NDB) NQAREC

$C$

C

DO 140 IQA=1,NQAREC

READ(NDB) (QATITL(I,IQA), I=1,4)

WRITE(NOUT) (QATITL(I.IQA), I=1,4)

C

140 CONTINUE

C

C READ OPTIONAL HEADER TEXT

$\mathrm{C}$

READ(NDB) NINFO

WRITE(NOUT) NINFO

$\mathrm{C}$

DO $150 \mathrm{I}=\mathrm{I}, \mathrm{NINFO}$

C

READ(NDB) INFO(I)

WRITE(NOUT) INFO(I)

$\mathrm{C}$

150 CONTINUE

C

C READ THE COORDINATE NAMES

C

READ(NDB) (NAMECO(I), I=1.NDIM)

WRITE(NOUT) (NAMECO(I), I=1,NDIM)

C READ THE ELEMENT TYPES

$\mathrm{C}$

READ(NDB) (NAMELB(I), I=1,NELBLK)

WRITE(NOUT) (NAMELB(I), I=1,NELBLK)

C

RETURN

END

C

C

SUBROUTINE EXOBW (NDB, NOUT, TEMP1, ITIME)

C

C THIS SUBROUTINE READS AND WRITES TIME HISTORY INFORMATION

C

C WRITTEN BY RANDY LONGENBAUGH 5-23-94

INCLUDE 'exoread.blk"

PARAMETER $($ PZERO $=0 . D 0)$

C

CHARACTER $* 8$ NAMEEV, NAMEGV, NAMEHV, NAMENV

C

CHARACTER *8 USRNV

C PROBLEM SIZE RECORD VARIABLES

COMMON /PSIZR/

1 NUMNOD, NDIM, NUMEL, NELBLK, NUMNPS, LNPSNL, NUMESS,

2 LESSEL, LESSNL

C

C NUMNOD - The number of nodes

C NDIM - The number of dimensions

C NUMEL - the total number of elements

C NELBLK - the number of element blocks

CNUMNPS - the number of node sets

C LNPSNL - node set list length

C NUMESS - number of node sets

$C$ LESSEL - side set element list length

C LESSNL - side set node list length

$\mathrm{C}$

C SIZING PARAMETERS FOR THIS ELEMENT BLOCK 


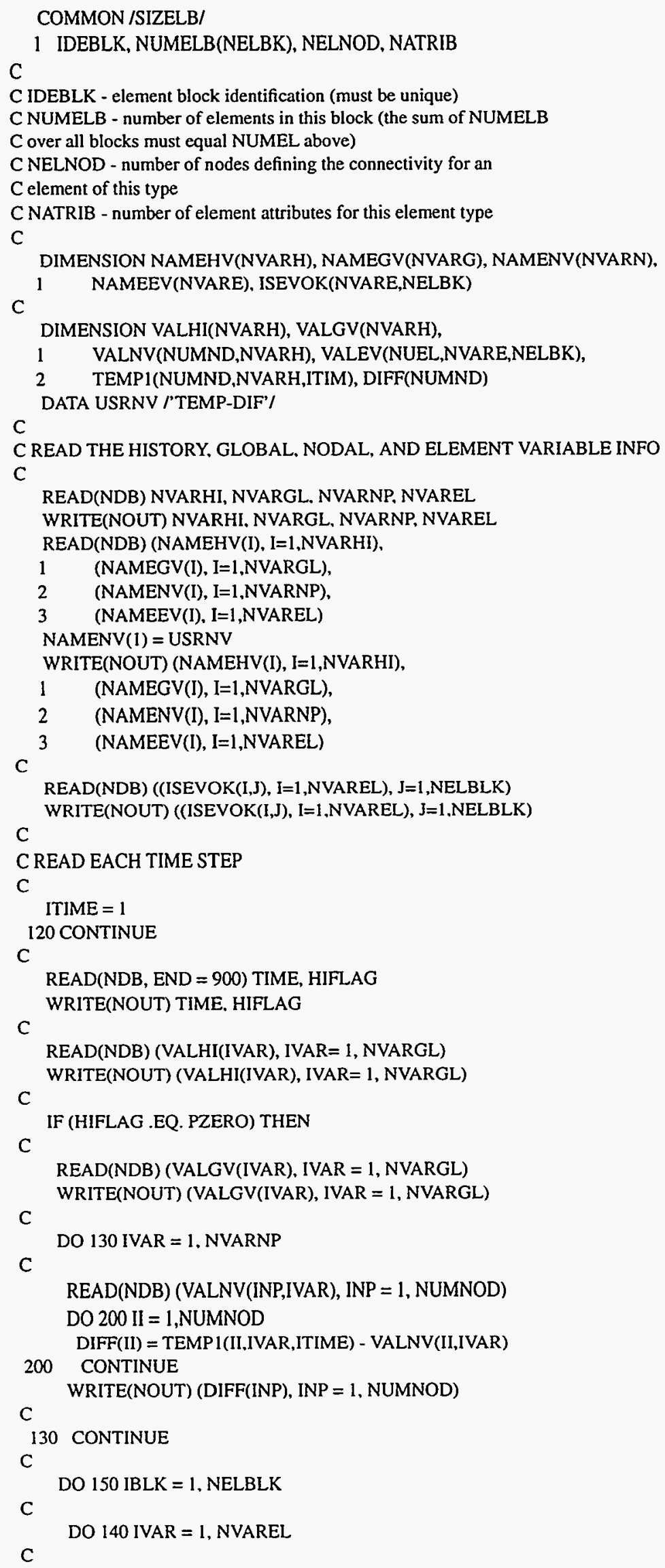


IF(ISEVOK(IVAR,IBLK) .NE. PZERO) THEN

C

READ(NDB) (VALEV(IEL,IVAR,IBLK), IEL=1,NUMELB(IBLK))

C

WRITE(NOUT) (VALEV(IEL,IVAR,IBLK), IEL=1,NUMELB(IBLK))

C

END IF

140 CONTINUE

C

150 CONTINUE

END IF

C

ITIME $=$ ITIME +1

C GO TO 120

C

900 CONTINUE

C

C

ITIME = ITIME - 1

RETURN

END 
This page intentionally left blank. 


\section{APPENDIX C: LISTING OF CODE MODIFICATIONS MADE TO COYOTE-II}

COYOTE was modified so that geostatistical thermal property data could be used. Modifications were made so that finite element connectivity could be utilized in COYOTE's user subroutines USRCON and USRDEN. The following is a listing of code differences between original and modified code.

\section{C.1 Subroutine PCGKF}

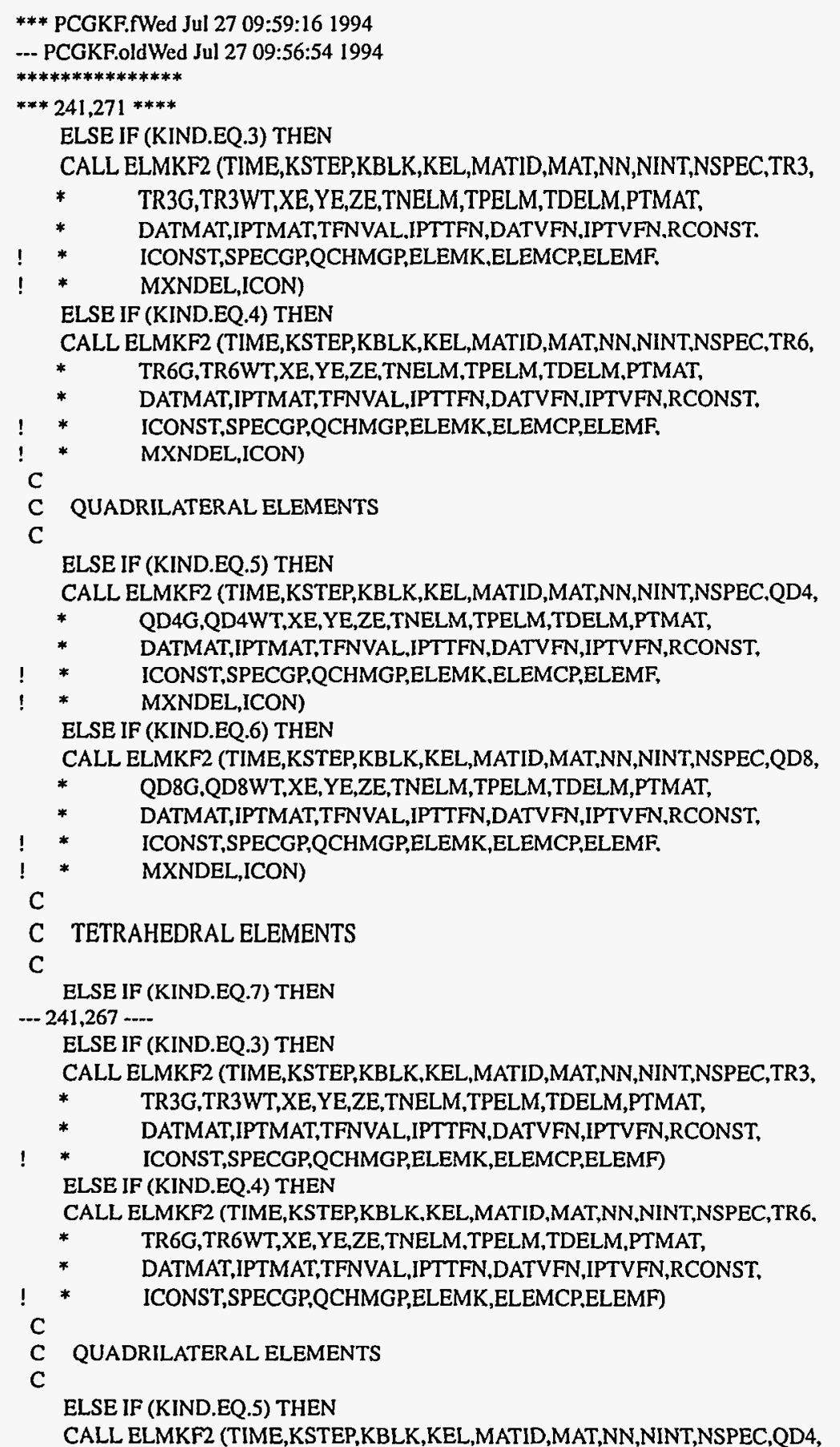


* QD4G,QD4WT,XE,YE,ZE,TNELM,TPELM,TDELM,PTMAT,

* DATMAT,IPTMAT,TFNVAL,IPTTFN,DATVFN,IPTVFN,RCONST,

! * ICONST,SPECGP,QCHMGP,ELEMK.ELEMCP,ELEMF)

ELSE IF (KIND.EQ.6) THEN

CALL ELMKF2 (TIME,KSTEP,KBLK,KEL,MATID.MAT,NN,NINT,NSPEC,QD8,

* QD8G,QD8WT,XE,YE,ZE,TNELM,TPELM,TDELM,PTMAT,

* DATMAT,IPTMAT.TFNVAL,IPTTFN,DATVFN,IPTVFN,RCONST,

! * ICONST,SPECGP,QCHMGP,ELEMK,ELEMCP,ELEMF)

C

C TETRAHEDRAL ELEMENTS

C

ELSE IF (KIND.EQ.7) THEN 


\section{C.2 Subroutine ELMKF2}

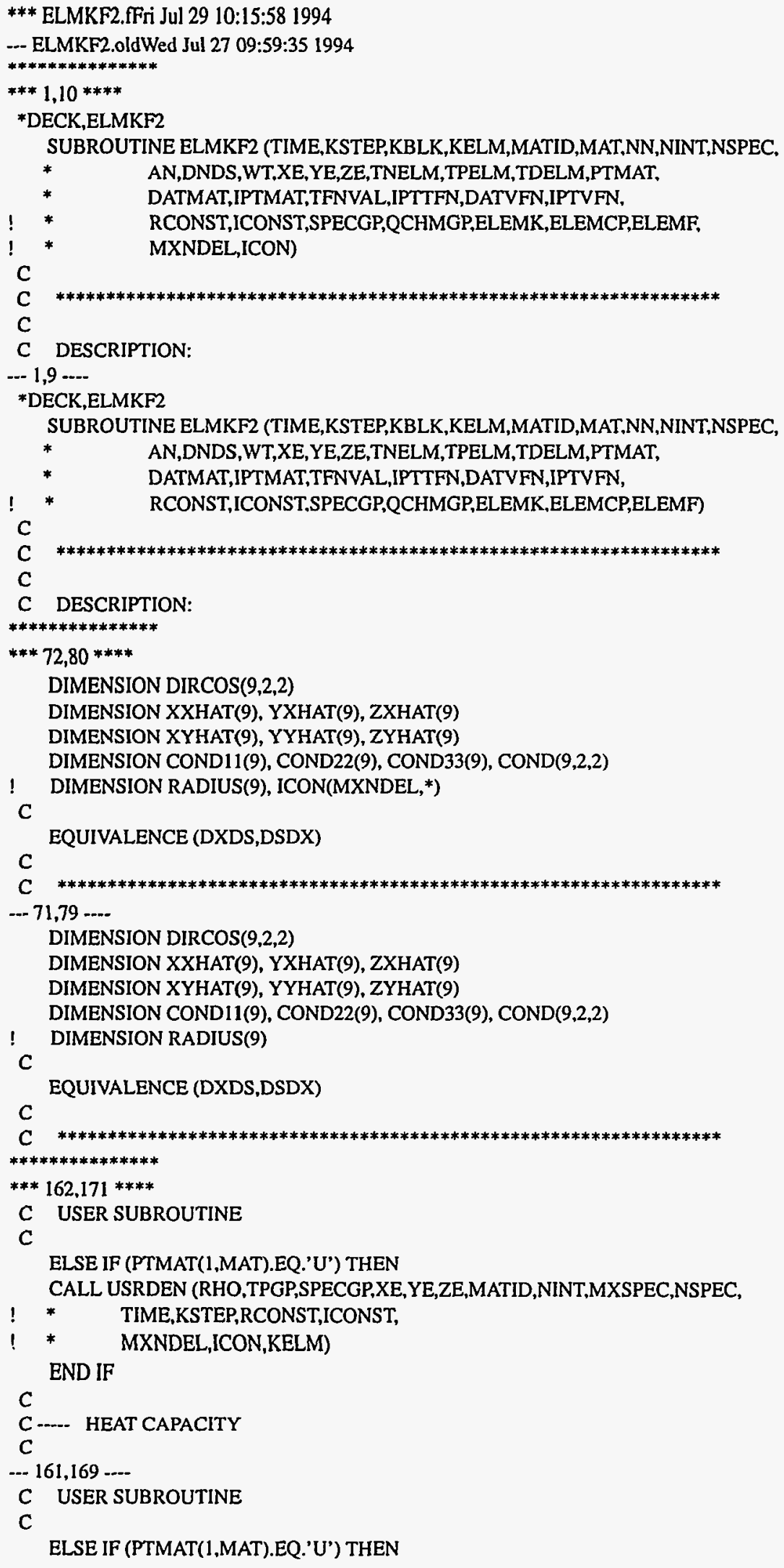


CALL USRDEN (RHO,TPGP,SPECGP,XE, YE,ZE,MATID,NINT,MXSPEC,NSPEC,

! * TIME,KSTEP,RCONST,ICONST)

C

END IF

C -.... HEAT CAPACITY

C

$* * * * * * * * * * * * * * *$

*** $224,233 * * * *$

C USER SUBROUTINE

C

ELSE IF (PTMAT(3,MAT).EQ.'U') THEN

CALL USRCON (COND11.COND22.COND33.TPGP.SPECGP.XE.YE,ZE,MATID,

$! \quad * \quad$ NINT,MXSPEC,NSPEC.TIME,KSTEP,RCONST,ICONST,

! * MXNDEL,ICON,KELM)

END IF

C

C -..- CONDUCTIVITY TENSOR (GLOBAL VALUES)

C

-.- 222,230 -...

C USER SUBROUTINE

C

ELSE IF (PTMAT(3,MAT).EQ.'U') THEN

CALL USRCON (COND11,COND22.COND33.TPGP.SPECGP.XE,YE.ZE.MATID.

! * NINT,MXSPEC,NSPEC,TIME,KSTEP.RCONST,ICONST)

C

END IF

C ..... CONDUCTIVITY TENSOR (GLOBAL VALUES)

C 


\section{APPENDIX D: USER SUBROUTINES USED IN COYOTE}

This appendix contains all user subroutines used with COYOTE. Heat generation subroutines were common to all calculations and are presented first. The material property user subroutines are specific to each calculation made.

\section{D.1 Volumetric Heating, USRVHS_100}

Subroutine USRVHS_100 was used to calculate the decay heat characteristics of spent fuel canisters using the repository thermal loading of $100 \mathrm{~kW} /$ acre aerial power density.

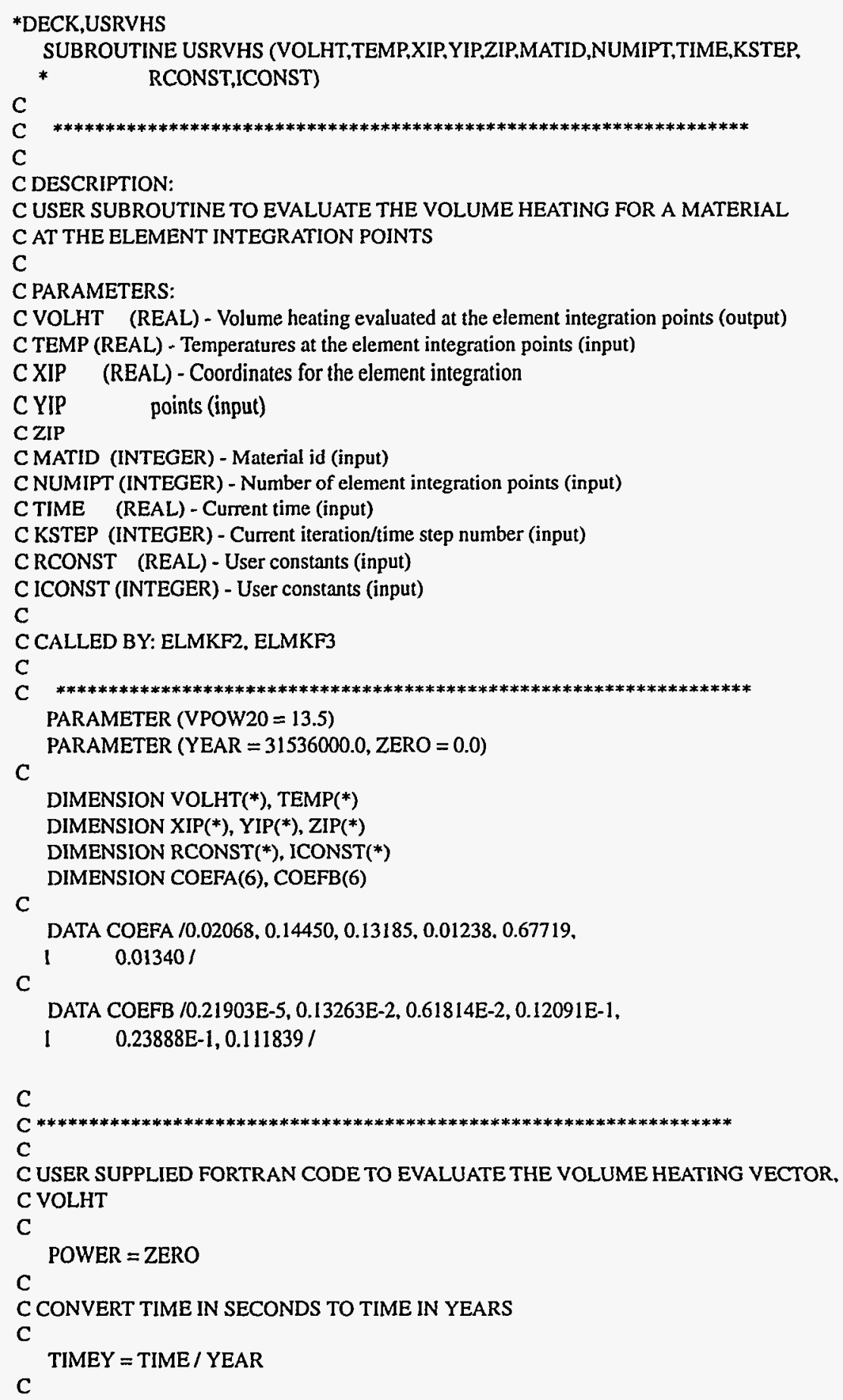




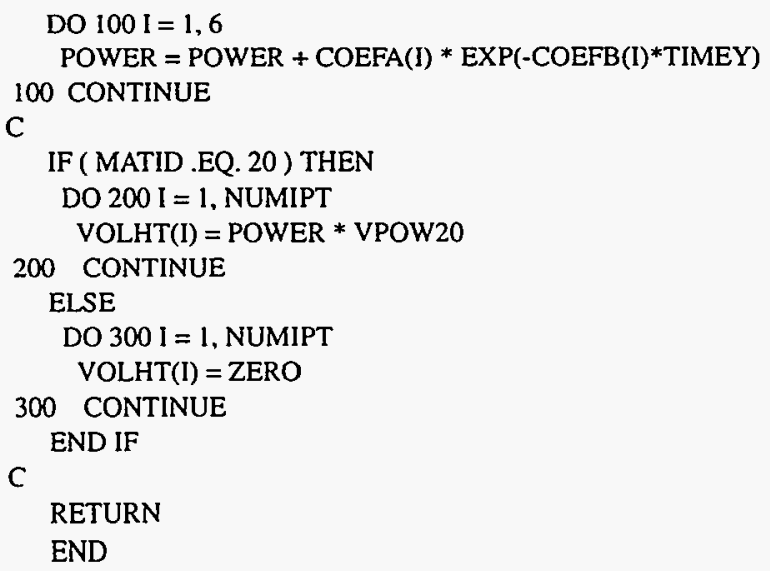




\section{D.2 Thermal Property Subroutines Used for LVRHL and LVRSL Calculations}

Subroutine USRCON is used to provide thermal conductivity as a function of temperature. Subroutine USRCP was used to provide heat capacitiy as a function of temperature. Both subroutine are presented below.

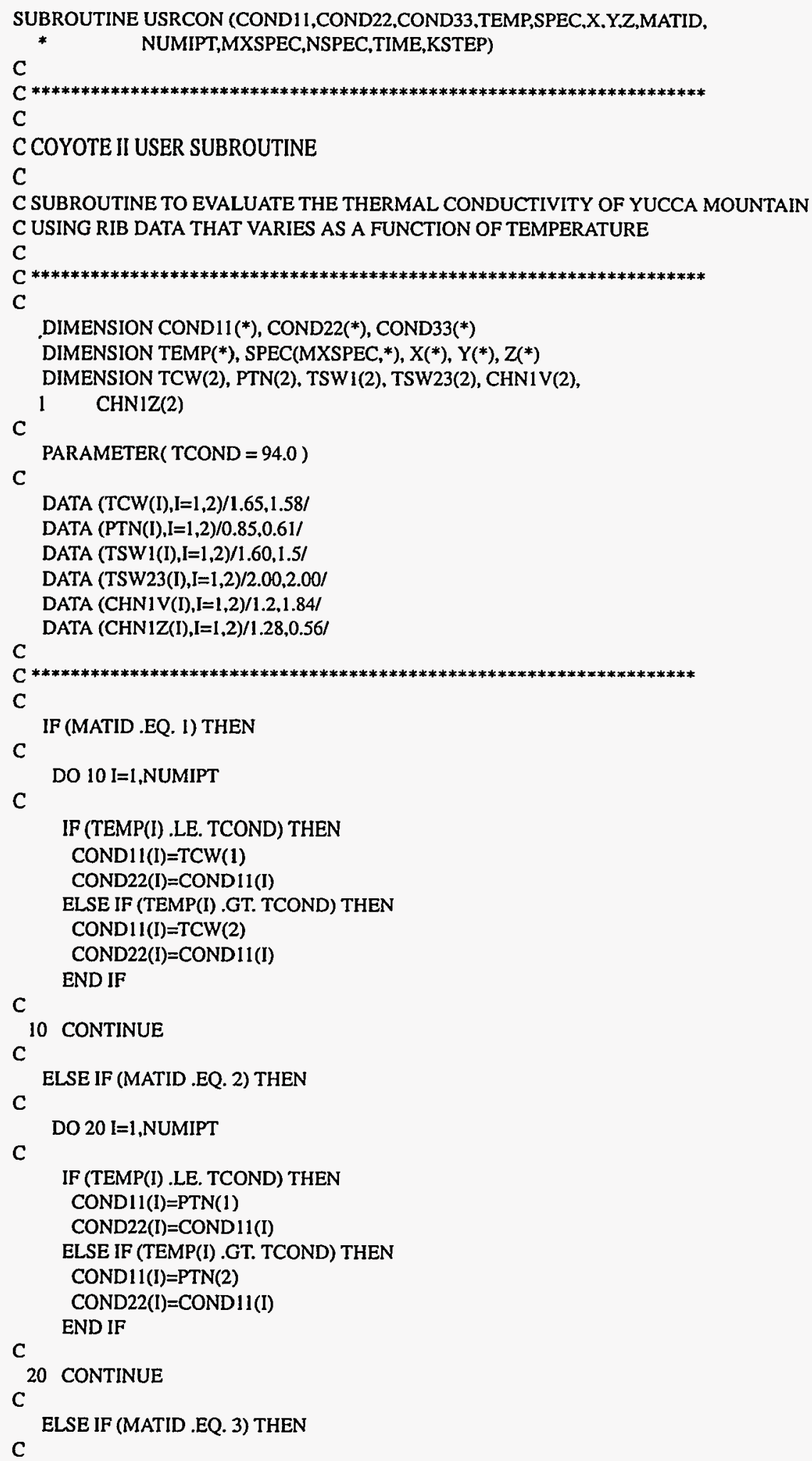




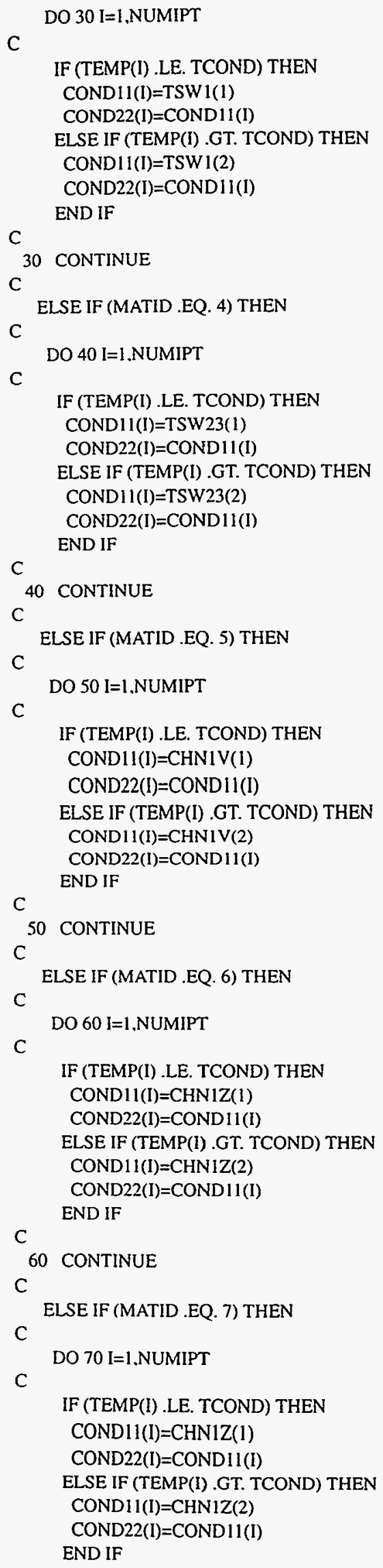


C

C

ELSE IF (MATID .EQ. 8) THEN

C

DO $80 \mathrm{I}=1$,NUMIPT

IF (TEMP(I) .LE. TCOND) THEN

COND11(I) $=$ CHN1Z(1)

COND22(I) $=$ COND11 (I)

ELSE IF (TEMP(I) .GT. TCOND) THEN

CONDII $(I)=C H N I Z(2)$

COND22(l)=COND11(I)

C

END IF

80 CONTINUE

C

ELSE IF (MATID .EQ. 9) THEN

C

DO $90 \mathrm{I}=1$, NUMIPT

IF (TEMP(I) .LE. TCOND) THEN

CONDII $(\mathrm{I})=\mathrm{CHN} 1 \mathrm{Z}(1)$

COND22(I) $=$ COND11 $(\mathrm{I})$

ELSE IF (TEMP(I) .GT. TCOND) THEN

COND $11(\mathrm{I})=\mathrm{CHN} 1 \mathrm{Z}(2)$

$\operatorname{COND22}(\mathrm{I})=\mathrm{COND} 11(\mathrm{I})$

C

END IF

90 CONTINUE

C

C

ELSE IF (MATID .EQ. 10) THEN

c

DO $100 \mathrm{I}=1$, NUMIPT

IF (TEMP(I) .LE. TCOND) THEN

COND11(I) $=\mathrm{CHN} 1 \mathrm{C}(1)$

COND22(I) $=$ COND 1 (I)

ELSE IF (TEMP(I) .GT. TCOND) THEN

$\operatorname{COND11}(\mathrm{I})=\mathrm{CHN} 1 \mathrm{Z}(2)$

COND22 $(\mathrm{l})=$ COND11 $(\mathrm{I})$

C

END IF

100 CONTINUE

C

ELSE IF (MATID .EQ. 11) THEN

C

C

DO $110 \mathrm{I}=1$, NUMIPT

IF (TEMP(I) .LE. TCOND) THEN

CONDI $1(\mathrm{I})=\mathrm{CHN} 1 \mathrm{Z}(1)$

COND22(I) $=$ COND1 $1(\mathrm{I})$

ELSE IF (TEMP(I) .GT. TCOND) THEN

COND11 $(\mathrm{I})=\mathrm{CHN} 1 \mathrm{Z}(2)$

COND22(I) $=$ COND 1 I (I)

C

END IF

110 CONTINUE

C

C

ELSE IF (MATID .EQ. 12) THEN

C

DO 120 I=1,NUMIPT

IF (TEMP(I) .LE. TCOND) THEN

COND11(I) $=$ CHN1Z(1) 


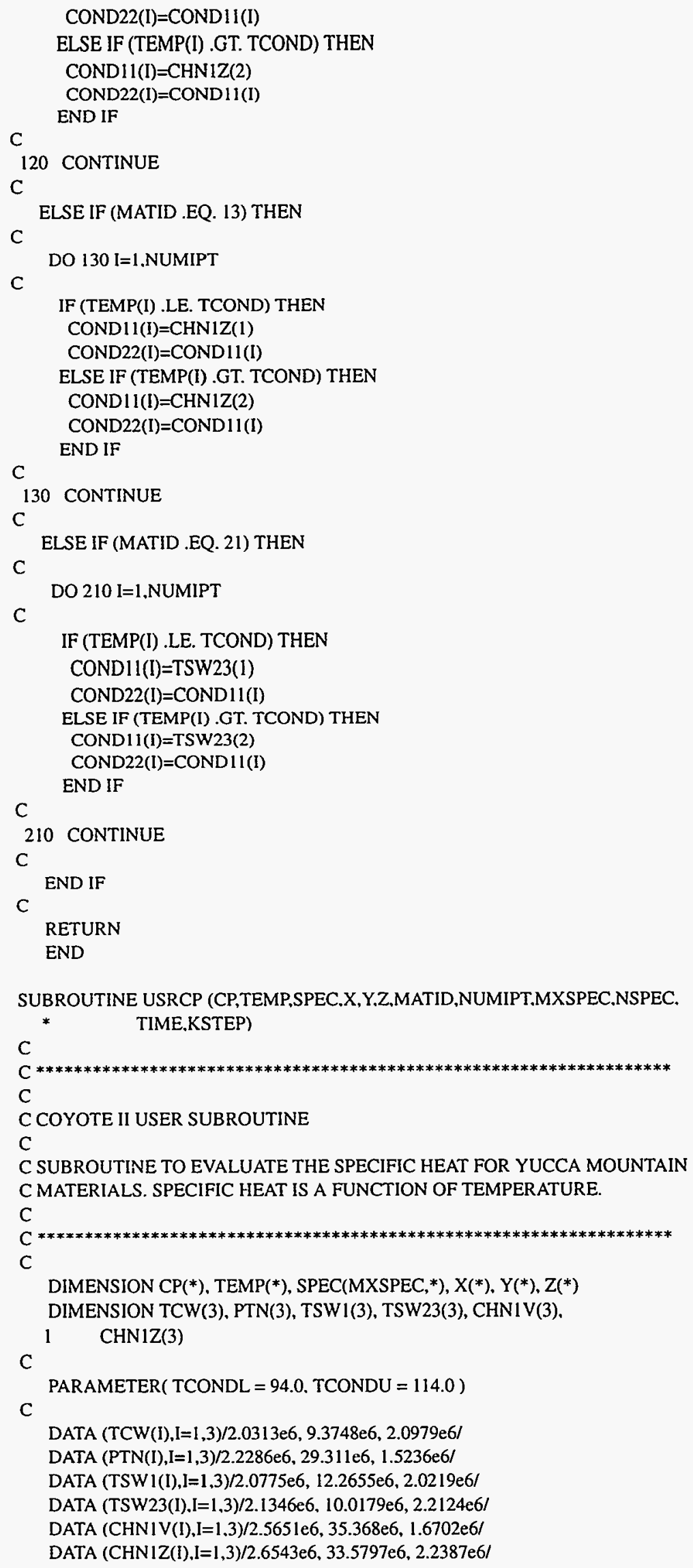




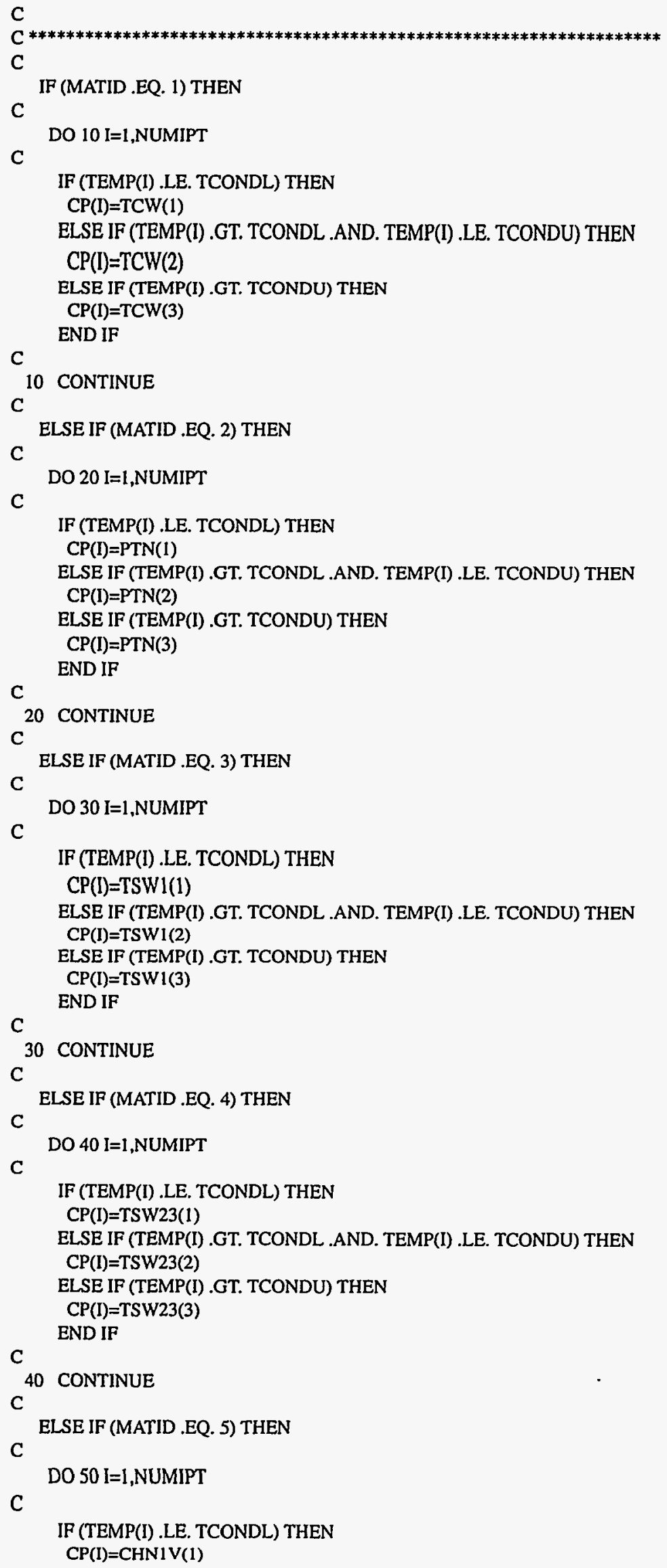




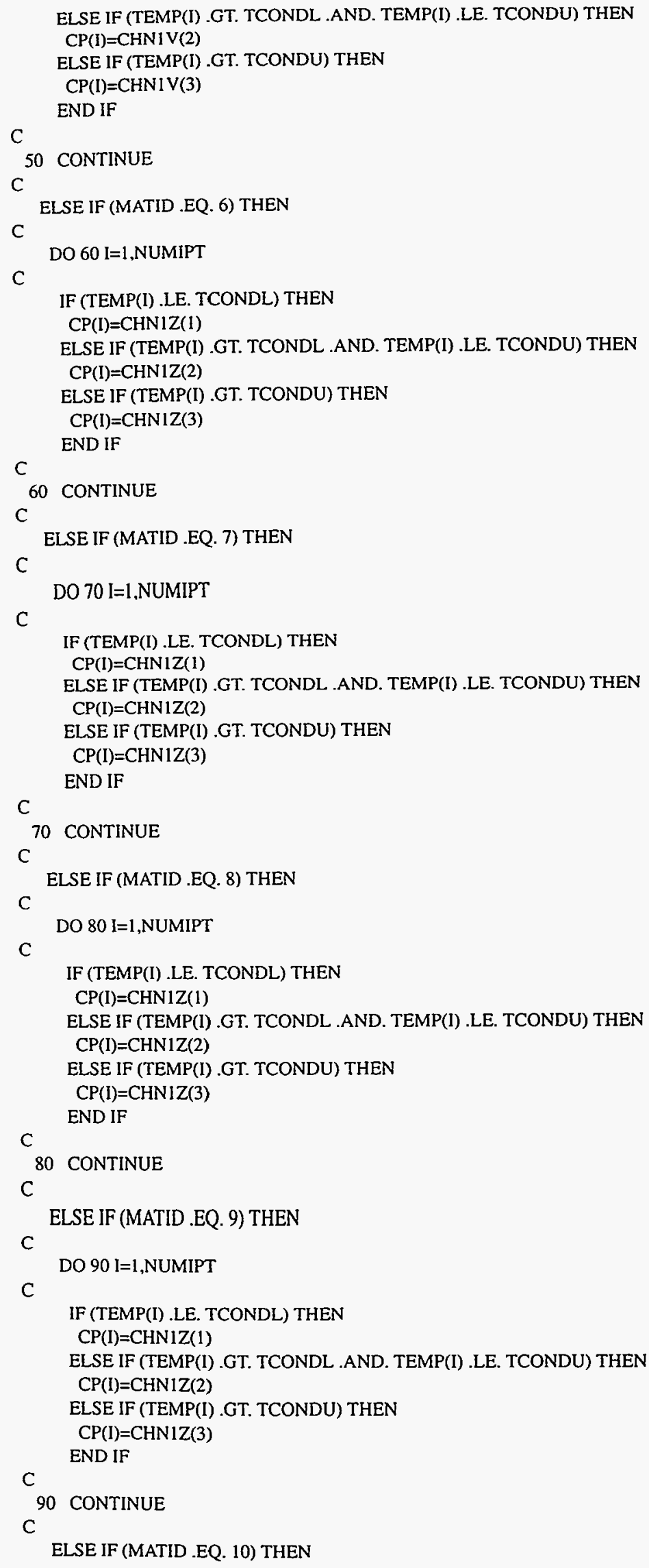


$\mathrm{C}$

C

DO $100 \mathrm{I}=1$,NUMIPT

IF (TEMP(I) .LE. TCONDL) THEN

$\mathrm{CP}(\mathrm{I})=\mathrm{CHN} 1 \mathrm{Z}(1)$

ELSE IF (TEMP(I) .GT. TCONDL .AND. TEMP(I) .LE. TCONDU) THEN $\mathrm{CP}(\mathrm{I})=\mathrm{CHN} 1 \mathrm{Z}(2)$

ELSE IF (TEMP(I) .GT. TCONDU) THEN

$\mathrm{CP}(\mathrm{I})=\mathrm{CHN} 1 \mathrm{Z}(3)$

C

END IF

100 CONTINUE

$\mathrm{C}$

$\mathrm{C}$

ELSE IF (MATID .EQ. 11) THEN

C

DO $110 \mathrm{I}=1$,NUMIPT

IF (TEMP(I) .LE. TCONDL) THEN

$\mathrm{CP}(\mathrm{I})=\mathrm{CHN} 1 \mathrm{Z}(\mathrm{l})$

ELSE IF (TEMP(I) .GT. TCONDL .AND. TEMP(I) .LE. TCONDU) THEN $\mathrm{CP}(\mathrm{I})=\mathrm{CHN} I \mathrm{Z}(2)$

ELSE IF (TEMP(I) .GT. TCONDU) THEN

$\mathrm{CP}(\mathrm{I})=\mathrm{CHN} \mathrm{IZ}(3)$

C

END IF

110 CONTINUE

C

ELSE IF (MATID .EQ. 12) THEN

C

DO $120 \mathrm{I}=1$,NUMIPT

C

IF (TEMP(I) .LE. TCONDL) THEN

$\mathrm{CP}(\mathrm{I})=\mathrm{CHN} 1 \mathrm{Z}(\mathrm{I})$

ELSE IF (TEMP(I) .GT. TCONDL .AND. TEMP(I) .LE. TCONDU) THEN $\mathrm{CP}(\mathrm{I})=\mathrm{CHN} 1 \mathrm{Z}(2)$

ELSE IF (TEMP(I) .GT. TCONDU) THEN

$\mathrm{CP}(\mathrm{I})=\mathrm{CHN} 1 \mathrm{Z}(3)$

C

END IF

120 CONTINUE

C

ELSE IF (MATID .EQ. 13) THEN

C

DO $130 \mathrm{I}=\mathrm{I}, \mathrm{NUMIPT}$

C

IF (TEMP(I) .LE. TCONDL) THEN

$\mathrm{CP}(\mathrm{I})=\mathrm{CHN} 1 \mathrm{Z}(1)$

ELSE IF (TEMP(I) .GT. TCONDL .AND. TEMP(I) .LE. TCONDU) THEN

$\mathrm{CP}(\mathrm{I})=\mathrm{CHN} 1 \mathrm{Z}(2)$

ELSE IF (TEMP(I) .GT. TCONDU) THEN

$\mathrm{CP}(\mathrm{I})=\mathrm{CHN} 1 \mathrm{Z}(3)$

C

END IF

130 CONTINUE

C

C

ELSE IF (MATID .EQ. 21) THEN

C

DO $210 \mathrm{I}=1$,NUMIPT

IF (TEMP(I) .LE. TCONDL) THEN

$\mathrm{CP}(\mathrm{I})=\mathrm{TSW} 23(\mathrm{I})$

ELSE IF (TEMP(I) .GT. TCONDL .AND. TEMP(I) .LE. TCONDU) THEN

$\mathrm{CP}(\mathrm{I})=\mathrm{TSW} 23(2)$

ELSE IF (TEMP(I) .GT. TCONDU) THEN

$\mathrm{CP}(\mathrm{I})=\mathrm{TSW} 23(3)$ 
END IF

210 CONTINUE

C END IF

C RETURN

END 


\section{D.3 Thermal Property Subroutines Used for LVLHL and LVLSL Calculations}

Subroutine USRCON is used to provide thermal conductivity as a function of temperature. Subroutine USRCP was used to provide heat capacitiy as a function of temperature. Both subroutine are presented below.

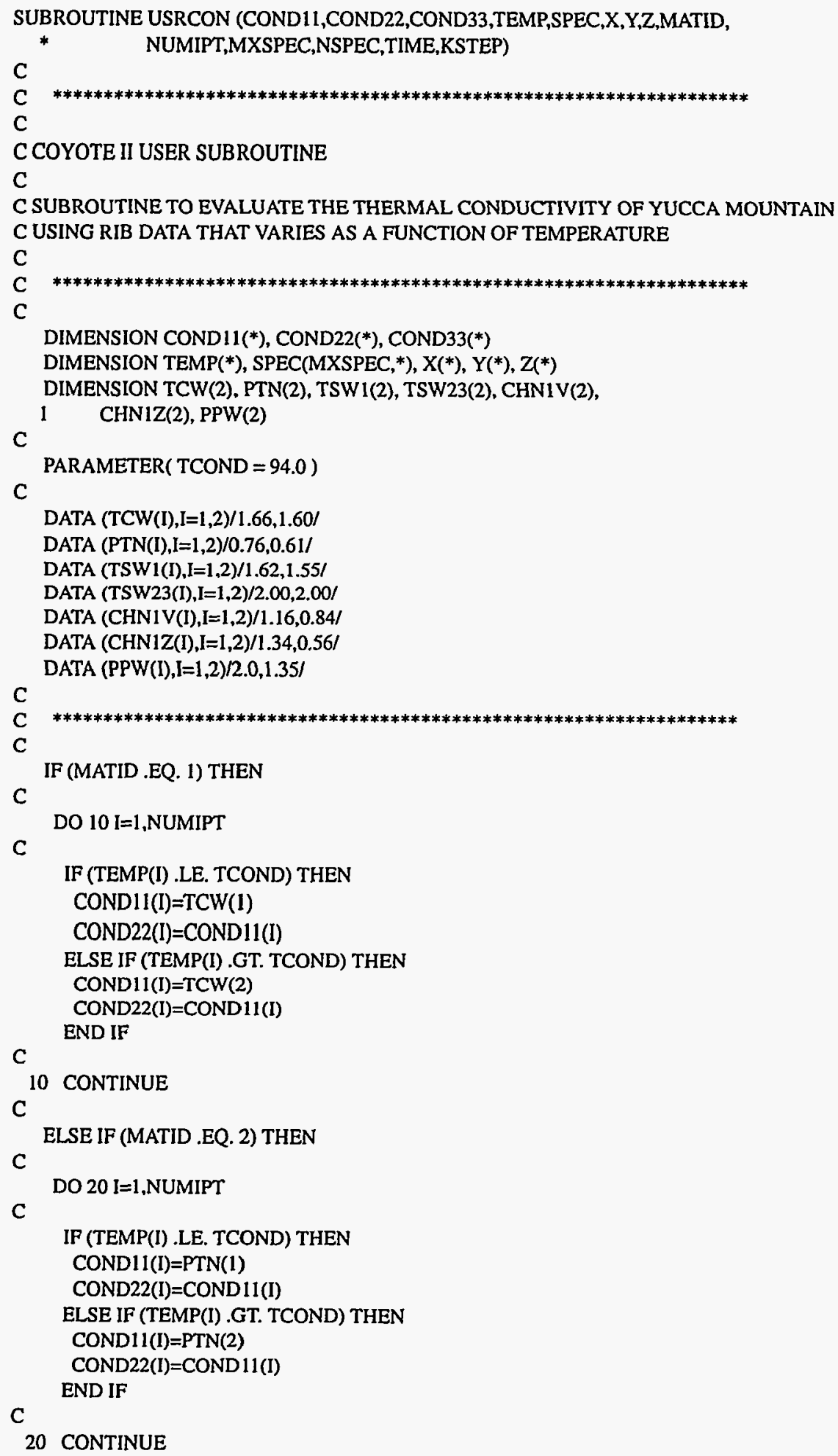


C

ELSE IF (MATID .EQ. 3) THEN

C

DO $30 \mathrm{I}=1$,NUMIPT

IF (TEMP(I) .LE. TCOND) THEN

$\operatorname{COND} 11(\mathrm{I})=\mathrm{TSW} 1(\mathrm{I})$

COND22(I)=COND11(I)

ELSE IF (TEMP(I) .GT. TCOND) THEN

COND11(I) $=$ TSW $1(2)$

COND22(I)=COND11(I)

END IF

C

30 CONTINUE

$\mathrm{C}$

C

ELSE IF (MATID .EQ. 4) THEN

C

DO $40 \mathrm{I}=1$, NUMIPT

IF (TEMP(I) .LE. TCOND) THEN

COND11 $(\mathrm{I})=\mathrm{TSW} 23(\mathrm{I})$

COND22(I) $=$ COND11 $(\mathrm{I})$

ELSE IF (TEMP(I) .GT. TCOND) THEN

COND11(I) $=$ TSW23(2)

COND22(I) $=$ COND11 (I)

END IF

C

40 CONTINUE

C

ELSE IF (MATID .EQ. 5) THEN

C

C

DO $50 \mathrm{I}=1$, NUMIPT

IF (TEMP(I) .LE. TCOND) THEN

CONDI1 $(\mathrm{i})=\mathrm{CHN} 1 \mathrm{~V}(1)$

COND22(I)=COND11(I)

ELSE IF (TEMP(I) .GT. TCOND) THEN

$\operatorname{COND} 11(\mathrm{I})=\mathrm{CHN} 1 \mathrm{~V}(2)$

COND22 $(\mathrm{I})=$ COND11 $(\mathrm{I})$

C

END IF

50 CONTINUE

C

ELSE IF (MATID .EQ. 6) THEN

DO $60 \mathrm{I}=1$, NUMIPT

IF (TEMP(I) .LE. TCOND) THEN

COND11 $(\mathrm{I})=\mathrm{CHN} 1 \mathrm{C}(1)$

COND22(I) $=$ COND11 $(I)$

ELSE IF (TEMP(I) .GT. TCOND) THEN

COND11(I) $=\mathrm{CHN} 1 \mathrm{Z}(2)$

COND22(I)=COND11(l)

C

END IF

60 CONTINUE

C

ELSE IF (MATID .EQ. 7) THEN

C

DO $70 \mathrm{l}=1$,NUMIPT

C

IF (TEMP(I) .LE. TCOND) THEN

COND11 $(\mathrm{I})=\mathrm{PPW}(1)$

COND22(I)=COND11 (I)

ELSE IF (TEMP(I) .GT. TCOND) THEN 


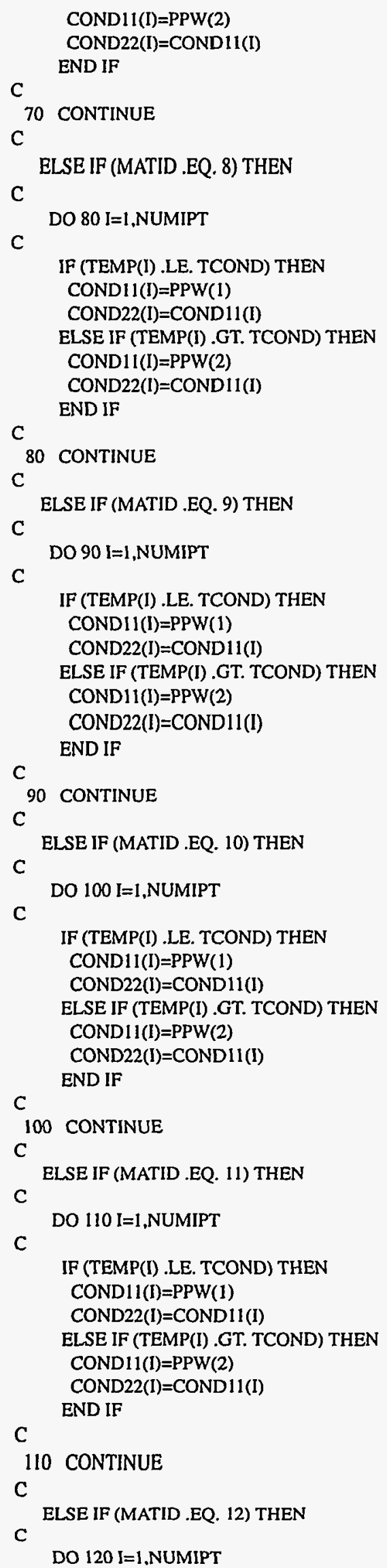


C

IF (TEMP(I) .LE. TCOND) THEN

COND11(I) $=\mathrm{PPW}(1)$

COND22(I) $=$ COND11 (I)

ELSE IF (TEMP(I) .GT. TCOND) THEN

COND11(I) $=$ PPW (2)

COND22(I) $=$ COND11 (I)

C

END IF

120 CONTINUE

C

ELSE IF (MATID .EQ. 13) THEN

C

C

DO $130 \mathrm{I}=1, \mathrm{NUMIPT}$

IF (TEMP(I) .LE. TCOND) THEN

COND11(I) $=$ PPW(1)

COND22(I) $=$ COND11 $(\mathrm{I})$

ELSE IF (TEMP(I) .GT. TCOND) THEN

COND11 (I) $=$ PPW $(2)$

$\operatorname{COND} 22(\mathrm{I})=\operatorname{COND} 11(\mathrm{I})$

END IF

C

130 CONTINUE

C

ELSE IF (MATID .EQ. 21) THEN

C

DO $210 \mathrm{I}=1$.NUMIPT

C

IF (TEMP(I) .LE. TCOND) THEN

COND11 $(\mathrm{I})=\mathrm{TSW} 23(\mathrm{I})$

COND22(I)=COND11(I)

ELSE IF (TEMP(I) .GT. TCOND) THEN

COND11(I) $=$ TSW23(2)

COND22(I)=COND11(I)

C

END IF

210 CONTINUE

C

END IF

C

RETURN

END

SUBROUTINE USRCP (CP,TEMP,SPEC,X,Y,Z,MATID,NUMIPT,MXSPEC,NSPEC,

* TIME,KSTEP)

$\mathrm{C}$

$\mathrm{C} * * * * * * * * * * * * * * * * * * * * * * * * * * * * * * * * * * * * * * * * * * * * * * * * * * * * * * * * * * * * * * * * * * *$

$\mathrm{C}$

COYOTE II USER SUBROUTINE

C SUBROUTINE TO EVALUATE THE SPECIFIC HEAT FOR YUCCA MOUNTAIN

C MATERIALS. SPECIFIC HEAT IS A FUNCTION OF TEMPERATURE.

C

$\mathrm{C}$

DIMENSION CP(*), TEMP(*), SPEC(MXSPEC,*), X(*), Y(*), Z(*)

DIMENSION TCW(3), PTN(3), TSWI(3), TSW23(3), CHN1V(3),

I CHN1Z(3), PPW(3)

C

C

PARAMETER $(\mathrm{TCONDL}=94.0 . \mathrm{TCONDU}=114.0)$

DATA (TCW(I), I=1,3)/1.951e6, 9.3748e6, $1.728 \mathrm{e} 6 /$

DATA (PTN(I).I=1.3)/1.669e6, 29.311 e6. 0.653e6/

DATA (TSWI(I),I=1,3)/2.057e6, 12.2655e6, 1.759e6/ 


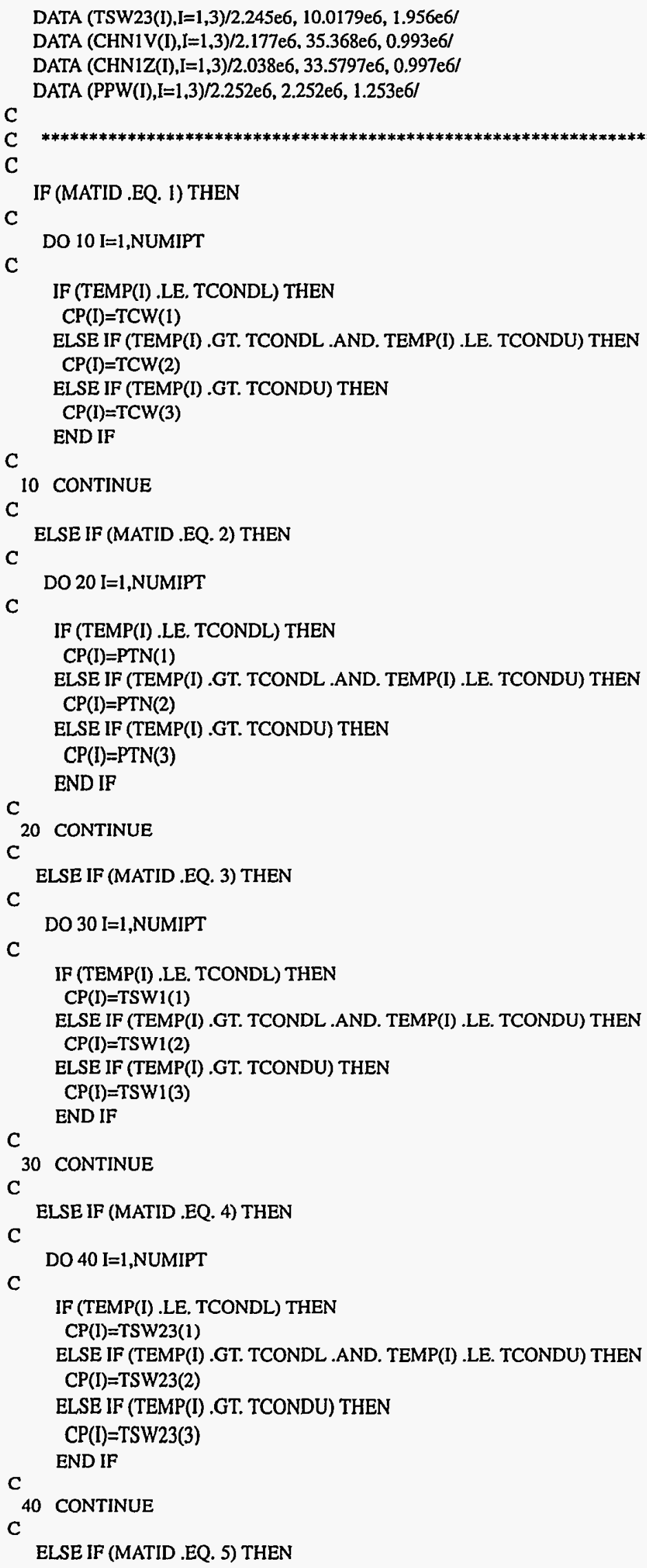


C

DO $50 \mathrm{l}=1$,NUMIPT

IF (TEMP(I) .LE. TCONDL) THEN

$\mathrm{CP}(1)=\operatorname{CHN} I V(1)$

ELSE IF (TEMP(I) .GT. TCONDL .AND. TEMP(I) .LE. TCONDU) THEN

$\mathrm{CP}(\mathrm{I})=\mathrm{CHN} I \mathrm{~V}(2)$

ELSE IF (TEMP(I) .GT. TCONDU) THEN

$\mathrm{CP}(\mathrm{I})=\mathrm{CHNIV}(3)$

C

END IF

50 CONTINUE

C

C

ELSE IF (MATID .EQ. 6) THEN

C

DO $60 \mathrm{I}=1$, NUMIPT

IF (TEMP(I) .LE. TCONDL) THEN

$\mathrm{CP}(\mathrm{l})=\mathrm{CHN} 1 \mathrm{Z}(1)$

ELSE IF (TEMP(I) .GT. TCONDL .AND. TEMP(I) .LE. TCONDU) THEN $\mathrm{CP}(\mathrm{I})=\mathrm{CHN} 1 \mathrm{Z}(2)$

ELSE IF (TEMP(I) .GT. TCONDU) THEN

$\mathrm{CP}(\mathrm{I})=\mathrm{CHN} 1 \mathrm{Z}(3)$

C

END IF

60 CONTINUE

ELSE IF (MATID .EQ. 7) THEN

C

DO $70 \mathrm{I}=1$, NUMIPT

C

IF (TEMP(I) .LE. TCONDL) THEN

$\mathrm{CP}(\mathrm{I})=\mathrm{PPW}(1)$

ELSE IF (TEMP(I) .GT. TCONDL .AND. TEMP(I) .LE. TCONDU) THEN

$\mathrm{CP}(\mathrm{I})=\mathrm{PPW}(2)$

ELSE IF (TEMP(I) .GT. TCONDU) THEN

$\mathrm{CP}(\mathrm{I})=\mathrm{PPW}(3)$

C

END IF

70 CONTINUE

C

C

ELSE IF (MATID .EQ. 8) THEN

DO $80 \mathrm{I}=1, \mathrm{NUMIPT}$

$\mathrm{C}$

IF (TEMP(I) .LE. TCONDL) THEN

$C P(I)=P P W(I)$

ELSE IF (TEMP(I) .GT. TCONDL .AND. TEMP(I) .LE. TCONDU) THEN

$\mathrm{CP}(\mathrm{I})=\mathrm{PPW}(2)$

ELSE IF (TEMP(I) .GT. TCONDU) THEN

$\mathrm{CP}(\mathrm{I})=\mathrm{PPW}(3)$

C

END IF

80 CONTINUE

C

$\mathrm{C}$

ELSE IF (MATID .EQ. 9) THEN

C

DO $90 \mathrm{I}=1$.NUMIPT

IF (TEMP(I) .LE. TCONDL) THEN

$\mathrm{CP}(\mathrm{I})=\mathrm{PPW}(\mathrm{I})$

ELSE IF (TEMP(I) .GT. TCONDL .AND. TEMP(I) .LE. TCONDU) THEN

$C P(I)=P P W(2)$

ELSE IF (TEMP(I) .GT. TCONDU) THEN

$\mathrm{CP}(\mathrm{I})=\mathrm{PPW}(3)$

END IF 
C

C

C

C

DO 100 I=1,NUMIPT

IF (TEMP(I) .LE. TCONDL) THEN

$\mathrm{CP}(\mathrm{I})=\mathrm{PPW}(\mathrm{I})$

ELSE IF (TEMP(I) .GT. TCONDL .AND. TEMP(I) .LE. TCONDU) THEN

$\mathrm{CP}(\mathrm{I})=\mathrm{PPW}(2)$

ELSE IF (TEMP(I) .GT. TCONDU) THEN

$\mathrm{CP}(\mathrm{I})=\mathrm{PPW}(3)$

END IF

C

100 CONTINUE

$\mathrm{C}$

C

C

ELSE IF (MATID .EQ. 11) THEN

DO $110 \mathrm{I}=1$,NUMIPT

IF (TEMP(I) .LE. TCONDL) THEN

$C P(I)=P P W(1)$

ELSE IF (TEMP(I) .GT. TCONDL .AND. TEMP(I) .LE. TCONDU) THEN $\mathrm{CP}(\mathrm{I})=\mathrm{PPW}(2)$

ELSE IF (TEMP(I) .GT. TCONDU) THEN

$\mathrm{CP}(\mathrm{I})=\mathrm{PPW}(3)$

C

END IF

110 CONTINUE

C

C

ELSE IF (MATID .EQ. 12) THEN

C

DO $120 \mathrm{I}=1$,NUMIPT

IF (TEMP(I) .LE. TCONDL) THEN

$\mathrm{CP}(\mathrm{I})=\mathrm{PPW}(1)$

ELSE IF (TEMP(I) .GT. TCONDL .AND. TEMP(I) .LE. TCONDU) THEN $\mathrm{CP}(\mathrm{I})=\mathrm{PPW}(2)$

ELSE IF (TEMP(I) .GT. TCONDU) THEN

$\mathrm{CP}(\mathrm{I})=\mathrm{PPW}(3)$

END IF

C

120 CONTINUE

C

C

ELSE IF (MATID .EQ. 13) THEN

DO $130 \mathrm{I}=1, \mathrm{NUMIPT}$

IF (TEMP(I) .LE. TCONDL) THEN

$\mathrm{CP}(\mathrm{I})=\mathrm{PPW}(\mathrm{I})$

ELSE IF (TEMP(I) .GT. TCONDL .AND. TEMP(I) .LE. TCONDU) THEN $C P(I)=P P W(2)$

ELSE IF (TEMP(I) .GT. TCONDU) THEN

$\mathrm{CP}(\mathrm{I})=\mathrm{PPW}(3)$

C

END IF

130 CONTINUE

C

C

ELSE IF (MATID .EQ. 2I) THEN

C

DO $210 \mathrm{I}=1$,NUMIPT

IF (TEMP(I) .LE. TCONDL) THEN

$\mathrm{CP}(\mathrm{I})=\mathrm{TSW} 23(1)$ 
ELSE IF (TEMP(I) .GT. TCONDL .AND. TEMP(I) .LE. TCONDU) THEN $\mathrm{CP}(\mathrm{I})=\mathrm{TSW} 23(2)$

ELSE IF (TEMP(I) .GT. TCONDU) THEN

$\mathrm{CP}(\mathrm{I})=\mathrm{TSW} 23(3)$

C

END IF

210 CONTINUE

C

END IF

C

RETURN

END 


\section{D.4 Thermal Property Subroutines Used for Geostatistical Calculations}

Subroutine USRCON is used to provide thermal conductivity as a function of finite element node number. Subroutine USRDEN was used to provide density as a function of finite element node number. Both subroutine are presented below.

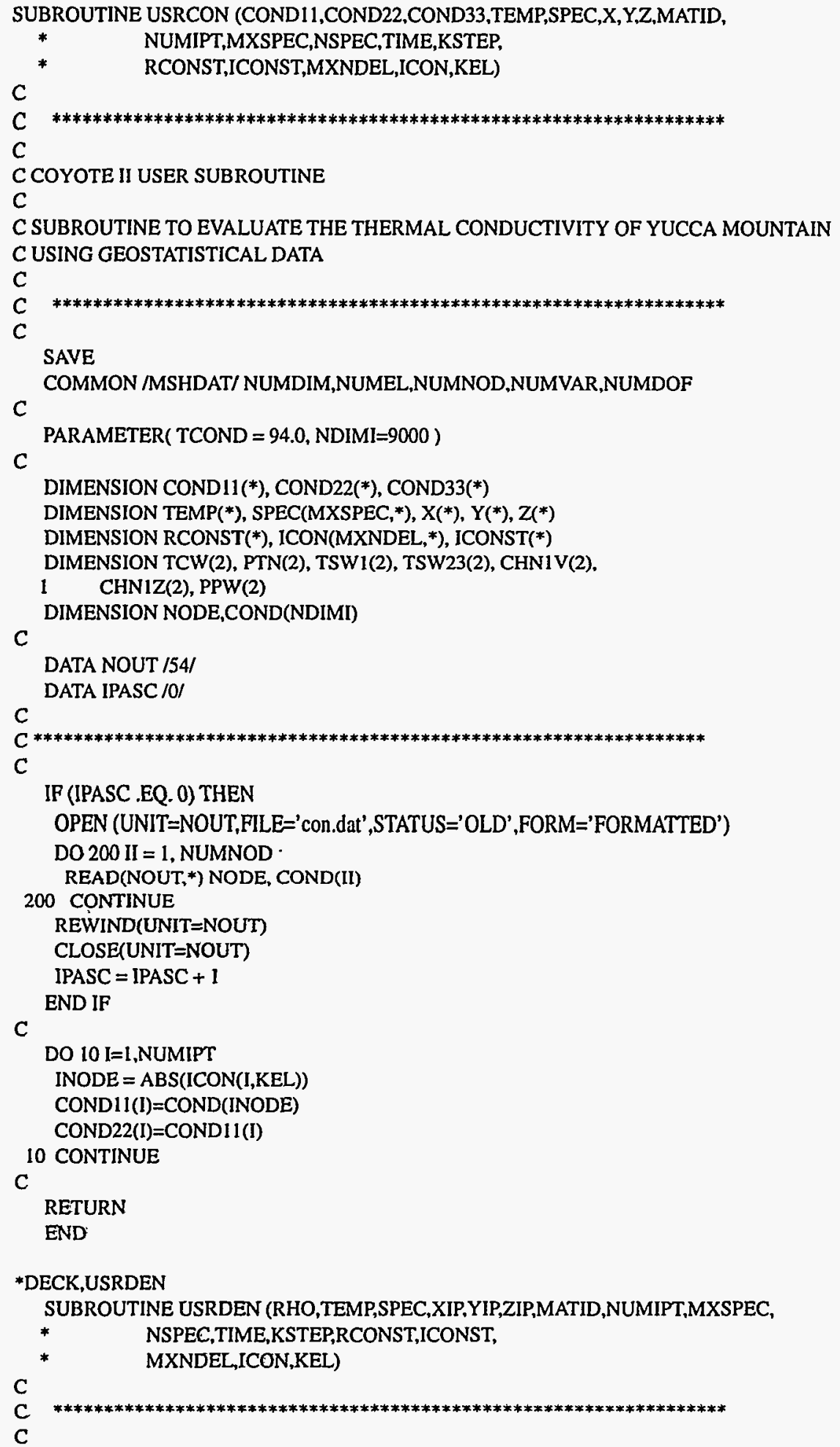




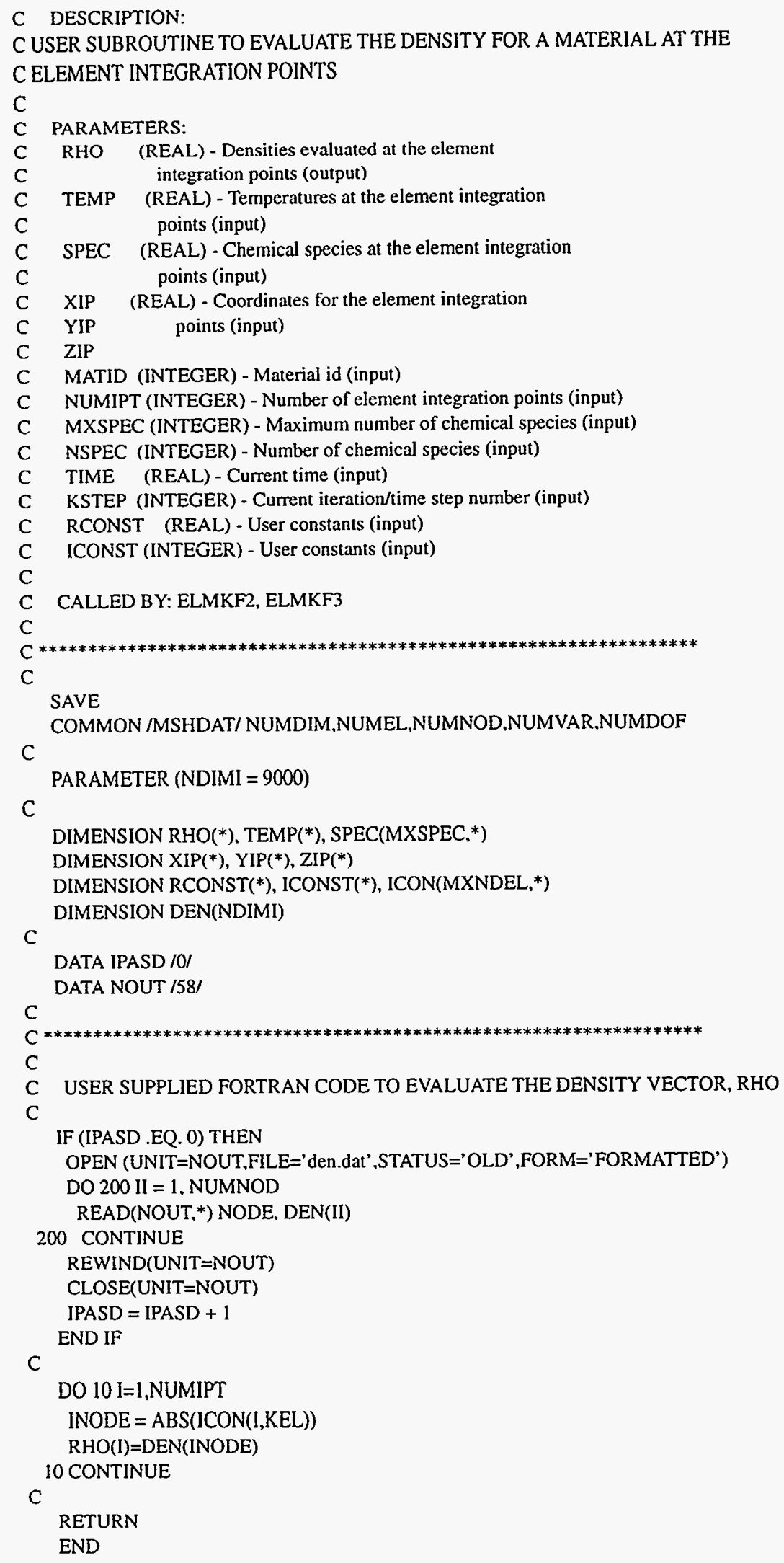




\section{APPENDIX E: RIB APPENDIX}

Information from the Reference Information Base Used in this Report:

All data obtained from the Reference Information Base are identified in the text.

Candidate Information for the Reference Information Base:

This report contains no candidate information for the Reference Information Base.

Candidate Information for the Geographic Nodal Information Study and Evaluation System:

This report contains no candidate information for the Geographic Nodal Information Study and Evaluation System. 


\section{YUCCA MOUNTAIN SITE CHARACTERIZATION PROJECT}

\section{UC814 - DISTRIBUTION LIST}

1

D. A. Dreyfus (RW-1)

Director

OCRWM

US Department of Energy

1000 Independence Avenue SW

Washington, DC 20585

$1 \quad$ L. H. Barrett (RW-2)

Acting Deputy Director

OCRWM

US Department of Energy

1000 Independence Avenue SW

Washington, DC 20585

1 S. Rousso (RW-40)

Office of Storage and Transportation OCRWM

US Department of Energy

1000 Independence Avenue SW

Washington, DC 20585

1 R. A. Milner (RW-30)

Office of Program Management

and Integration

OCRWM

US Department of Energy

1000 Independence Avenue SW

Washington, DC 20585

1 D. R. Elle, Director

Environmental Protection Division

DOE Nevada Field Office

US Department of Energy

P.O. Box 98518

Las Vegas, NV 89193-8518

1 T. Wood (RW-14)

Contract Management Division

OCRWM

US Department of Energy

1000 Independence Avenue SW

Washington, DC 20585

$4 \quad$ Victoria F. Reich, Librarian

Nuclear Waste Technical Review Board

1100 Wilson Blvd., Suite 910

Arlington, VA 22209

5 Wesley Barnes, Project Manager

Yucca Mountain Site Characterization

Office

US Department of Energy

P.O. Box 98608--MS 523

Las Vegas, NV 89193-8608
$1 \quad$ Director

Office of Public Affairs

DOE Nevada Operations Office

US Department of Energy

P.O. Box 98518

Las Vegas, NV 89193-8518

8 Technical Information Officer

DOE Nevada Operations Office

US Department of Energy

P.O. Box 98518

Las Vegas, NV 89193-8518

$1 \quad$ P. K. Fitzsimmons, Technical Advisor

Office of Assistant Manager for

Environmental Safety and Health

DOE Nevada Operations Office

US Department of Energy

P.O. Box 98518

Las Vegas, NV 89193-8518

1 J. A. Blink

Deputy Project Leader

Lawrence Livermore National Laboratory

101 Convention Center Drive

Suite 820, MS 527

Las Vegas, NV 89109

2

J. A. Canepa

Technical Project Officer - YMP

N-5, Mail Stop J521

Los Alamos National Laboratory

P.O. Box 1663

Los Alamos, NM 87545

1 Repository Licensing \& Quality

Assurance

Project Directorate

Division of Waste Management

US NRC

Washington, DC 20555

1

Senior Project Manager for Yucca

Mountain

Repository Project Branch

Division of Waste Management

US NRC

Washington, DC 20555

$1 \quad$ NRC Document Control Desk

Division of Waste Management

US NRC

Washington, DC 20555 
1 Chad Glenn

NRC Site Representative

301 E Stewart Avenue, Room 203

Las Vegas, NV 89101

$1 \quad$ E. P. Binnall

Field Systems Group Leader

Building 50B/4235

Lawrence Berkeley Laboratory

Berkeley, CA 94720

1 Center for Nuclear Waste

Regulatory Analyses

6220 Culebra Road

Drawer 28510

San Antonio, TX 78284

2

W. L. Clarke

Technical Project Officer - YMP

Attn: YMP/LRC

Lawrence Livermore National Laboratory

P.O. Box 5514

Livermore, CA 94551

$1 \quad$ V. R. Schneider

Asst. Chief Hydrologist - MS 414

Office of Program Coordination

and Technical Support

US Geological Survey

12201 Sunrise Valley Drive

Reston, VA 22092

1 J. S. Stuckless, Chief

Geologic Studies Program

MS 425

Yucca Mountain Project Branch

US Geological Survey

P.O. Box 25046

Denver, CO 80225

$1 \quad$ N. Z. Elkins

Deputy Technical Project Officer

Los Alamos National Laboratory

Mail Stop 527

101 Convention Center Drive, \#820

Las Vegas, NV 89109

$2 \quad$ Michaele C. Brady

Technical Project Officer - YMP

Sandia National Laboratories

Organization 6302, MS 1399

101 Convention Center Drive, Suite 880

Las Vegas, NV 89109

1 Ray Wallace

US Geological Survey

106 National Center

12201 Sunrise Valley Drive

Reston, VA 22092
L. R. Hayes

Technical Project Officer

Yucca Mountain Project Branch

MS 425

US Geological Survey

P.O. Box 25046

Denver, CO 80225

$1 \quad$ A. L. Flint

US Geological Survey

MS 721

P.O. Box 327

Mercury, NV 89023

$1 \quad$ R. E. Lewis

Yucca Mountain Project Branch

MS 425

US Geological Survey

P.O. Box 25046

Denver, CO 80225

1 D. Zesiger

US Geological Survey

101 Convention Center Drive

Suite 860, MS 509

Las Vegas, NV 89109

2 L. D. Foust

Nevada Site Manager

TRW Environmental Safety Systems

101 Convention Center Drive

Suite P-1 10, MS 423

Las Vegas, NV 89109

$1 \quad$ C. E. Ezra

YMP Support Office Manager

EG\&G Energy Measurements Inc.

MS V-02

P.O. Box 1912

Las Vegas, NV 89125

1 E. L. Snow, Program Manager

Roy F. Weston, Inc.

955 L'Enfant Plaza SW

Washington, DC 20024

1 Technical Information Center

Roy F. Weston, Inc.

955 L'Enfant Plaza SW

Washington, DC 20024

1 Technical Project Officer - YMP

US Bureau of Reclamation

Code D-3790

P.O. Box 25007

Denver, CO 80225 
Records Specialist

US Geological Survey

MS 421

P.O. Box 25046

Denver, CO 80225

$1 \quad$ M. D. Voegele

Technical Project Officer - YMP

M\&O/SAIC

101 Convention Center Drive

Suite 407

Las Vegas, NV 89109

1 Paul Eslinger, Manager

PASS Program

Pacific Northwest Laboratories

P.O. Box 999

Richland, WA 99352

1 A. T. Tamura

Science and Technology Division

OSTI

US Department of Energy

P.O. Box 62

Oak Ridge, TN 37831

1 P. J. Weeden, Acting Director

Nuclear Radiation Assessment Div.

US EPA

Environmental Monitoring Sys. Lab

P.O. Box 93478

Las Vegas, NV 89193-3478

1 ONWI Library

Battelle Columbus Laboratory Office of Nuclear Waste Isolation 505 King Avenue

Columbus, OH 43201

1 C. H. Johnson

Technical Program Manager

Agency for Nuclear Projects

State of Nevada

Evergreen Center, Suite 252

1802 N. Carson Street

Carson City, NV 89710

1 John Fordham, Deputy Director

Water Resources Center

Desert Research Institute

P.O. Box 60220

Reno, NV 89506

1 The Honorable Cyril Schank

Chairman

Churchill County Board of

Commissioners

190 W. First Street

Fallon, NV 89406
1 T. Hay, Executive Assistant

Office of the Governor

State of Nevada

Capitol Complex

Carson City, NV 89710

3 R. R. Loux

Executive Director

Agency for Nuclear Projects

State of Nevada

Evergreen Center, Suite 252

1802 N. Carson Street

Carson City, NV 89710

1 Brad R. Mettam

Inyo County Yucca Mountain

Repository Assessment Office

P. O. Drawer L

Independence, CA 93526

1 Lander County Board of Commissioners

315 South Humbolt Street

Battle Mountain, NV 89820

1 Vernon E. Poe

Office of Nuclear Projects

Mineral County

P.O. Box 1600

Hawthorne, NV 89415

$1 \quad$ Les W. Bradshaw

Program Manager

Nye County Nuclear Waste Repository

Project Office

P.O. Box 1767

Tonopah, NV 89049

$1 \quad$ Florindo Mariani

White Pine County Coordinator

P. O. Box 135

Ely, NV 89301

1 Judy Foremaster

City of Caliente Nuclear Waste

Project Office

P.O. Box 158

Caliente, NV 89008

1

Philip A. Niedzielski-Eichner

Nye County Nuclear Waste

Repository Project Office

P.O. Box 221274

Chantilly, VA 22022-1274 
1 Dennis Bechtel, Coordinator

Nuclear Waste Division

Clark County Department of

Comprehensive Planning

301 E. Clark Avenue, Suite 570

Las Vegas, NV 89101

1 Juanita D. Hoffman

Nuclear Waste Repository

Oversight Program

Esmeralda County

P.O. Box 490

Goldfield, NV 89013

1 Eureka County Board of Commissioners

Yucca Mountain Information Office

P.O. Box 714

Eureka, NV 89316

1 Economic Development Dept.

City of Las Vegas

400 E. Stewart Avenue

Las Vegas, NV 89101

1 Community Planning \& Development

City of North Las Vegas

P.O. Box 4086

North Las Vegas, NV 89030

l Community Development \& Planning

City of Boulder City

P.O. Box 61350

Boulder City, NV 89006

1 Commission of European Communities

200 Rue de la Loi

B-1049 Brussels

BELGIUM

$2 \quad$ Librarian

YMP Research \& Study Center

MS 407

P.O. Box 98521

Las Vegas, NV 89193-8521

1 Amy Anderson

Argonne National Laboratory

Building 362

9700 S. Cass Avenue

Argonne, IL 60439
1

G. S. Bodvarsson

Head, Nuclear Waste Department

Lawrence Berkeley Laboratory

1 Cyclotron Road, MS 50E

Berkeley, CA 94720

1 Michael L. Baughman

Intertech Services Corp.

P.O. Box 93537

Las Vegas, NV 89193

MS

$2 \quad 1330$

C. B. Michaels, 6352

100/1.2.5.4.3/SAND94-2247/QA

1330

1324

0974

0974

1325

1325

0431

WMT Library, 6352

C. Rautman

$\mathrm{R}$. Longenbaugh

D. Carroll

E. Ryder

L. Costin

S. Varnado

9018

0899

0619

0100
Central Technical Fỉes, 8523-2

Technical Library, 13414

Print Media, 12615

Document Processing, 7613-2 for DOE/OSTI 